\title{
ISOTOPE HARVESTING FROM THE BEAM DUMP COOLING LOOP AT THE FACILITY FOR RARE ISOTOPE BEAMS (FRIB)
}

\author{
A Dissertation \\ presented to \\ the Faculty of the Graduate School \\ at the University of Missouri-Columbia \\ In Partial Fulfillment \\ of the Requirements for the Degree \\ Doctor of Philosophy \\ by \\ MATTHEW D. SCOTT
}

Dr. J. David Robertson, Dissertation Supervisor

December 2018 
The undersigned, appointed by the dean of the Graduate School, have examined the dissertation entitled

ISOTOPE HARVESTING FROM THE BEAM DUMP COOLING LOOP AT THE FACILITY FOR RARE ISOTOPE BEAMS (FRIB)

presented by Matthew D. Scott, a candidate for the degree of doctor of philosophy, and hereby certify that, in their opinion, it is worthy of acceptance.

Professor J. David Robertson

Professor Silvia Jurisson

Professor Mark Lee

Professor John Brockman 


\section{DEDICATION}

"As I worked on projects which fulfilled a real human need, forces were working through me which amazed me. I would go to sleep with an apparently insoluble problem. When I awoke, the answer was there. Why then, should we who believe in Christ be so surprised at what God can do with a willing man in a laboratory?"

$\sim$ George Washington Carver

This work is dedicated to my Lord and Savior, Jesus Christ - the author of eternal salvation, in whom I live, and move, and have my being

AND to my family. You make this life fun and meaningful. 


\section{ACKNOWLEDGEMENTS}

I would like to take this opportunity to recognize the many people responsible for helping me achieve a life-long goal. Thank you to my wife and kids, who never let me give up. Your love and support give me the courage and drive to be a better man and persevere. I hope you realize how much you mean to me.

I would like to thank my advisor Dr. J. David Robertson for his continued support and guidance over these past few years. While I had thought my dreams of a chemistry $\mathrm{PhD}$ had ended long ago, he reignited the flame and welcomed me into his research group as a non-traditional graduate student.

I would like to thank the rest of my committee members: Dr. Silvia Jurisson, Dr. Mark Lee, Dr. Renee Jiji, and Dr. John Brockman for their guidance while writing this dissertation. Dr. Brockman was always there to listen, whether I was seeking advice or just needed to complain.

I would also like to take the opportunity to thank my fellow students in the Robertson research group for their advice and proof reading, the University of Missouri, the Chemistry department, and my many friends at MURR. Thank you for your friendship and support.

Lastly, I would like to thank my parents and my brother who were there to watch my childhood imaginings slowly grow into a career.

Thanks be unto God for his unspeakable gift. 2 Corinthians 9:15 


\section{TABLE OF CONTENTS}

ACKNOWLEDGEMENTS .................................................................................. ii

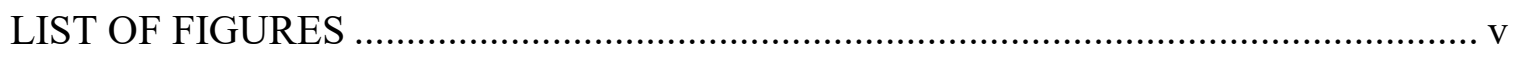

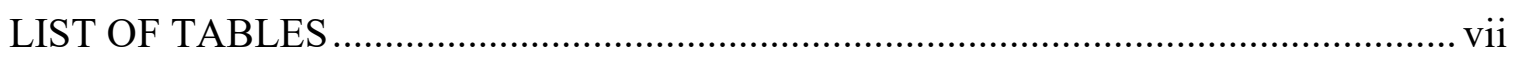

LIST OF ABBREVIATIONS ........................................................................... viii

ABSTRACT OF THE DISSERTATION ..............................................................

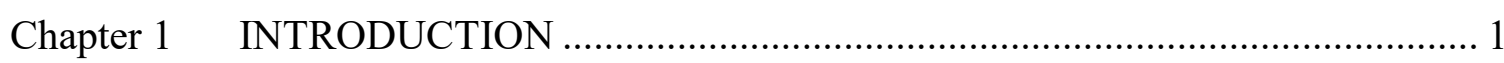

1.1 Projectile Fragmentation Facilities............................................................... 1

1.2 Isotope Harvesting at Projectile Fragmentation Facilities ................................ 2

1.3 Facility for Rare Isotope Beams (FRIB) …............................................. 3

1.4 FRIB Isotope Harvesting Locations ............................................................. 7

Chapter 2 ISOTOPE HARVESTING - BATCH EXTRACTION ........................... 14

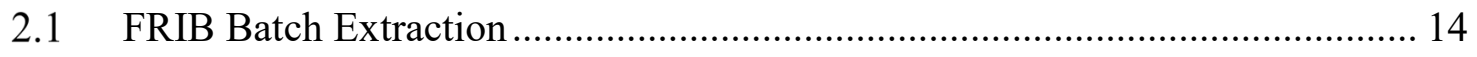

2.2 Purolite NRW3460 Mixed-Bed Resin......................................................... 15

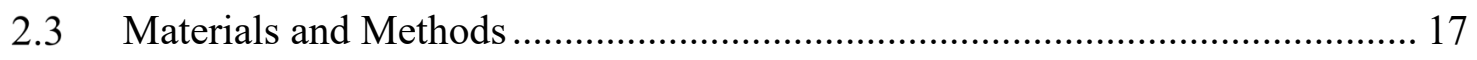

2.4 Mixed-Bed Resin Separation Experiments .................................................. 21

2.5 Cation Column - Acid Gradient Elution Experiments ..................................... 22

2.6 HIBA for Lanthanide Complexation............................................................. 28

2.7 Cation Column - HIBA Elution Experiments.............................................. 30

2.8 Cation Resin - HIBA $\mathrm{K}_{\mathrm{d}}$ experiments......................................................... 33

2.9 Cation Resin - HIBA Competition Study Experiments................................... 36

2.10 Cation Resin - Strong Acid Elution Experiments........................................... 37

2.11 Cation Resin - Strong Acid Recirculation Kinetics ....................................... 40

2.12 Cation Resin - Eichrom RE Resin, Loading and Breakthru ............................ 41

2.13 Cation Resin - Eichrom RE Resin, Experiments......................................... 45

2.14 Cation Resin - Eichrom RE Resin, Competition Study .................................. 47

2.15 Cation Resin - Eichrom DGA Resin, Competition Study .............................. 49

Chapter 3 HOLLOW FIBER SUPPORTED LIQUID MEMBRANES ..................... 55

3.1 Hollow Fiber Supported Liquid Membrane (HFSLM) ................................... 55

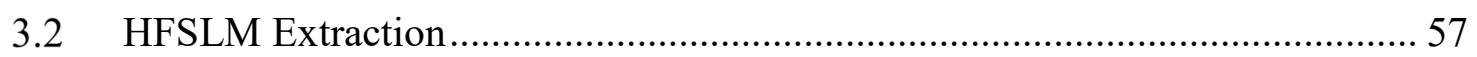

Chapter 4 ISOTOPE HARVESTING - IN SITU VANADIUM FEASIBILITY ....... 60

4.1 Vanadium Chemistry in the FRIB beam dump loop................................... 60

4.2 Calculated Vanadium Production at FRIB ................................................. 61 


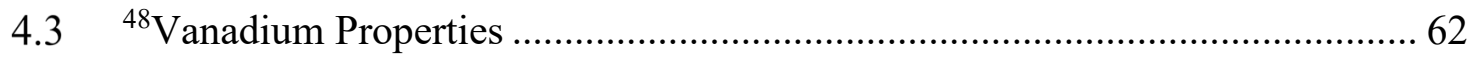

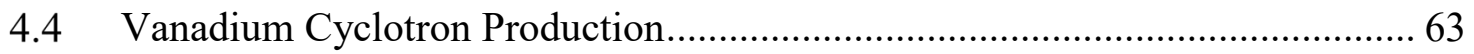

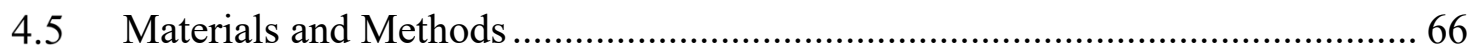

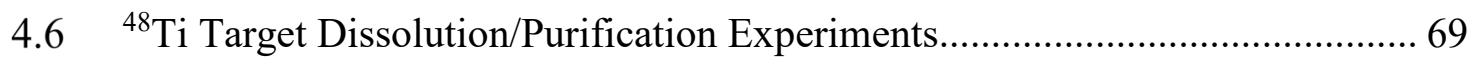

4.7 AG50 Column Separation/Recovery........................................................... 70

4.8 Vanadium Liquid-Liquid Extraction ............................................................ 71

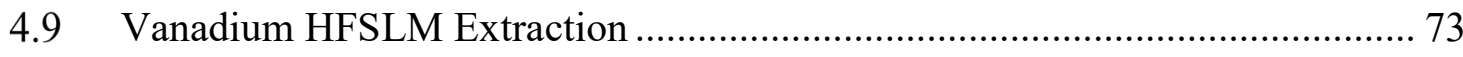

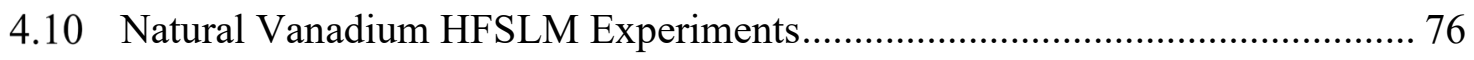

4.11 Radiotracer Vanadium HFSLM Experiments ..................................................... 77

4.12 Radiotracer Vanadium HFSLM Competition Experiments .............................. 81

Chapter 5 ISOTOPE HARVESTING - IN SITU LANTHANIDE FEASIBILITY ... 85

5.1 Lanthanide Chemistry in the FRIB beam dump loop ..................................... 85

5.2 Calculated Lutetium Production at FRIB ………........................................... 88

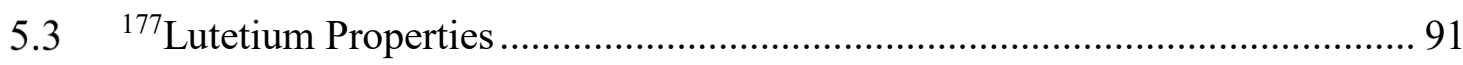

5.4 Lutetium Reactor Production ..................................................................... 92

5.5 Ionic Liquids for Liquid-Liquid Extraction ………........................................ 93

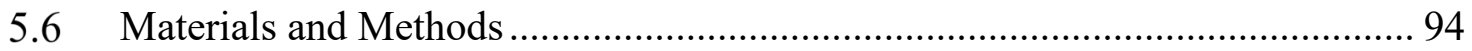

5.7 Lutetium Liquid-Liquid Extraction Optimization Experiments......................... 96

5.8 Lutetium Liquid-Liquid Extraction Kinetics Experiments .............................. 100

5.9 Lutetium HFSLM Extraction - Polycarbonate Mini-Module Experiments ..... 103

5.10 Lutetium HFSLM Extraction - PVC Mini-Module Experiments ..................... 105

5.11 RTIL Organic Dilution Experiments........................................................... 107

5.12 Carboxylic Acid for Liquid-Liquid Extraction .................................................. 108

Chapter 6 FUTURE DIRECTION AND ONGOING WORK ……........................... 111

6.1 Batch Collection Optimization, Single Element Separation ................................ 111

6.2 HFSLM Extraction Conditions Optimization ......................................................... 111

6.3 HFSLM Extraction of Other Isotopes ....................................................... 112

6.4 HFSLM for Radioisotope Separation/Purification........................................... 113

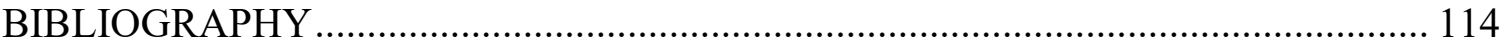

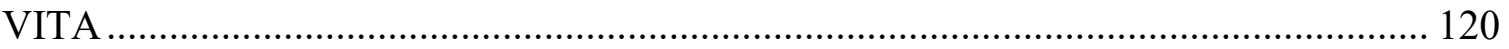




\section{LIST OF FIGURES}

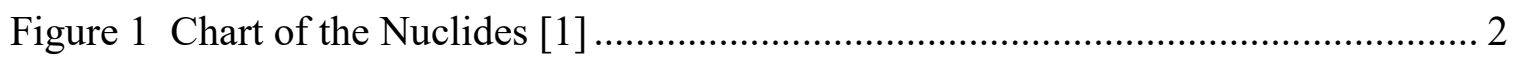

Figure 2 Newly Available Isotopes at Projectile Fragmentation Facilities [2].................. 2

Figure 3 Facility for Rare Isotope Beam Schematic [14] ............................................... 6

Figure 4 Illustration of A1900 Fragment Separator at the Current NSCL [16] ................ 7

Figure 5 Schematic of FRIB Beam Harvest Points [17]................................................ 8

Figure 6 Primary Beam Dump Barrels [19] ............................................................. 10

Figure 7 Expanded View of Primary Beam Dump Barrel [20] ...................................... 10

Figure 8 3D-Printed Beam Dump (1/4 scale prototype) [18] ....................................... 11

Figure 9 FRIB Beam Dump Loop Schematic [10] [18] ............................................. 12

Figure 10 Anion Resin Functional Groups [31] ...................................................... 15

Figure 11 Cation Resin Functional Groups [32]......................................................... 15

Figure 12 Distribution Coefficients on Anion Resin vs. Nitric Acid Molarity. .............. 16

Figure 13 Distribution Coefficients on Cation Resin with Nitric Acid .......................... 17

Figure 14 Mixed-bed Resin Separation with $\mathrm{NaCl}$ Solution .......................................... 22

Figure 15 Elution Profile Comparison AG50 vs NRW100x10 $(n=1) \ldots \ldots \ldots \ldots \ldots \ldots \ldots \ldots \ldots \ldots . . .24$

Figure 16 Elution of Lanthanides from Dowex 50Wx8 with Increasing $\mathrm{HNO}_{3} \ldots \ldots \ldots \ldots \ldots . . .25$

Figure 17 Elution of Lanthanides from Purolite NRW100x 10 with Increasing $\mathrm{HNO}_{3}$

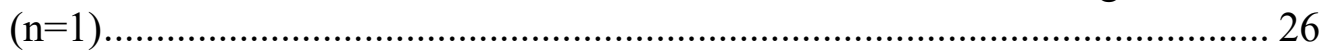

Figure 18 Column Volume Required for Elution from Dowex 50Wx4 vs. HIBA pH.... 28

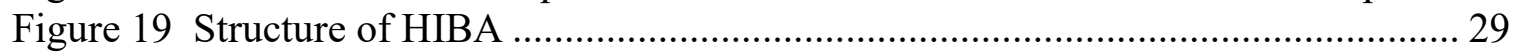

Figure 20 Oxygen Coordination Sites of HIBA [34] ................................................. 29

Figure 21 8-Coordinate Structure of Lanthanide:HIBA:Water Complex [34] ................ 30

Figure 22 Lanthanide Elution from Purolite NRW100x10 with 0.5M HIBA pH $4.9(\mathrm{n}=1)$

Figure 23 Lanthanide Elution from Purolite NRW100x10 with 0.7M HIBA pH $6(n=1)$

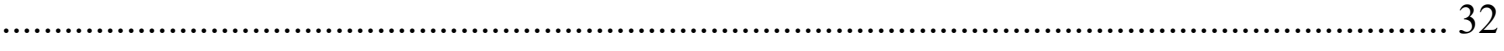

Figure 24 Percent Lanthanide Extracted with Increasing HIBA pH $(\mathrm{n}=2)$.................... 34

Figure 25 Percent Lanthanide Extracted with Increasing HIBA Molarity $(\mathrm{n}=2)$............ 35

Figure 26 HIBA Elution of a Mixture of Lanthanides and Transition Metals $(n=1) \ldots . . .36$

Figure 27 Percent ${ }^{177 \mathrm{~m}} \mathrm{Lu}$ Elution vs. $10 \mathrm{M} \mathrm{HNO}_{3}$ Acid Volume $(\mathrm{n}=1)$......................... 38

Figure 28 Percent ${ }^{177 \mathrm{~m}}$ Lu Elution vs. $6.5 \mathrm{M} \mathrm{HCl}$ Acid Volume $(\mathrm{n}=1)$........................... 39

Figure $292 \mathrm{~mL}$ Eichrom RE Resin Cartridge ............................................................ 42

Figure 30 Octyl(phenyl)-N,N-diisobutyl-carbamoylmethylphosphine oxide (CMPO) [35]

Figure 31 Tributyl Phosphate (TBP) [36] ............................................................... 42

Figure 32 Eichrom RE Cartridge $K_{d}$ Values vs. Nitric Acid Molarity [37] .................... 43

Figure 33 Loading and Breakthru Profile of ${ }^{177 \mathrm{~m}} \mathrm{Lu}$ on Eichrom RE Cartridge $(\mathrm{n}=1)$.... 44

Figure $34{ }^{177 \mathrm{~m}} \mathrm{Lu}$ Recovery from Eichrom RE Cartridge (4 Elution Cycles, $\mathrm{n}=1$ ) ......... 46

Figure 35 RE Cartridge Discoloration Due to Iron Adsorption...................................... 49

Figure 36 Distribution Coefficients on TODGA Resin vs. $\mathrm{HNO}_{3}$ molarity [38] ............ 50

Figure 37 Proposed System for Batch Harvesting of Rare Earth Elements from FRIB Beam Dump Resin ........................................................................... 54

Figure 38 Commercial Liqui-Cel 10x28 Membrane Contactor System [42] .................. 56

Figure 39 Membrane Contactor for Gas Removal....................................................... 56 


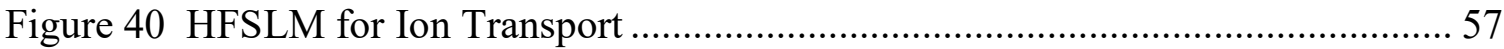

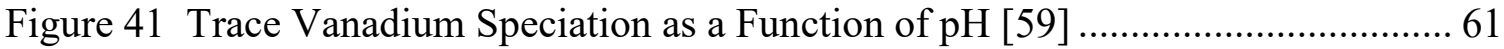

Figure 42 16.5 MeV GE PETtrace Cyclotron at MURR ............................................. 65

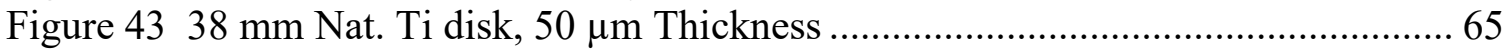

Figure 44 Excitation Function for ${ }^{48} \mathrm{Ti}(\mathrm{p}, \mathrm{n})^{48} \mathrm{~V}$ Reaction from EXFOR Database.......... 66

Figure 45 Cyclotron Target Assembly with Irradiated Ti Foil .................................... 70

Figure 46 Test Tube Liquid-Liquid Extraction of Vanadium with Aliquot 336 ............ 71

Figure 47 Vanadium Concentration in Water vs Mixing Time with Various Aliquat 336

Concentrations $(n=1)$.......................................................................... 72

Figure 48 Vanadium Stripping from Aliquat 336:Dodecane vs Strip Solution $\mathrm{pH}(\mathrm{n}=1) 73$

Figure 49 Counter-Current Flow Diagram for HFSLM Recycle Mode Operation ........ 75

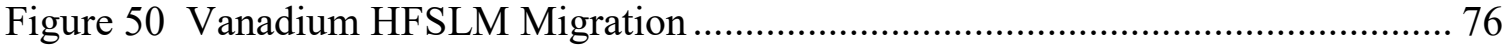

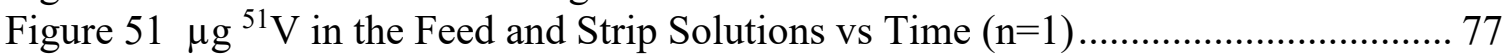

Figure 52 Concentration (ppm) of ${ }^{51} \mathrm{~V}$ in the Feed and Strip Solutions vs Time $(\mathrm{n}=1)$.. 77

Figure 53 Concentration (ppt) of ${ }^{48} \mathrm{~V}$ in Feed and Strip Solution vs Time (with Titanium,

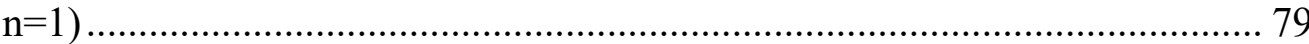

Figure 54 Percent ${ }^{48}$ V Extracted into Strip Solution vs Time (with Titanium, $n=1$ )...... 79

Figure 55 Concentration (ppt) of ${ }^{48} \mathrm{~V}$ in Feed and Strip Solution vs Time (Titanium

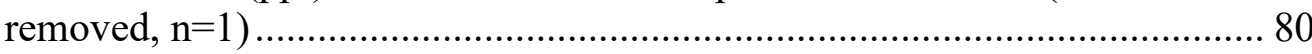

Figure 56 Percent ${ }^{48}$ V Extracted into Strip Solution vs Time (Titanium removed, $n=1$ ) 80

Figure 57 Concentration (ppt) of ${ }^{48} \mathrm{~V}$ in Feed and Strip Solutions vs Time, Competition

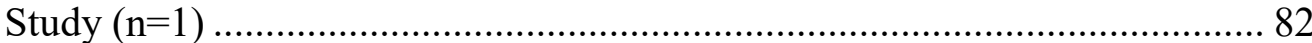

Figure 58 Percent ${ }^{48}$ V Extracted into Strip Solution vs Time, Competition Study $(n=1) 83$

Figure 59 Coordination Number $(\mathrm{CN})$ of Rare Earth Aqua Ions [65] .......................... 86

Figure $60 \mathrm{Yb}$ and Lu Speciation as a Function of $\mathrm{pH}$. (REE $10^{-6}$, Carbonate $\left.10^{-3} \mathrm{M}\right) \ldots 87$

Figure 61 Lanthanide Beam Dump Particles, 1 Week ${ }^{238} \mathrm{U}$ Beam - no decay time....... 89

Figure $62{ }^{177} \mathrm{Lu}$ Beam Dump Particles, 1 Week ${ }^{186} \mathrm{~W}$ Beam - no decay time ................. 90

Figure 63 Mole Fraction Solubility of Water in RTIL - Lengthening Cation Alkyl ....... 97

Figure 64 Mole Fraction Solubility of Water in RTIL - Changing Anion...................... 98

Figure 65 Percent ${ }^{177}$ Lu Extracted from Neutral pH Feed vs. CMPO Concentration $(n=1)$

Figure 66 Percent ${ }^{177} \mathrm{Lu}$ Stripped from CMPO:RTIL vs. EDTA Concentration $(n=1) .100$

Figure 67 Feed Extraction with 5 mM CMPO:RTIL................................................. 101

Figure 68 Feed Activity of ${ }^{177}$ Lu vs. mixing time with 5 mM CMPO: RTIL $(n=1) \ldots . .101$

Figure 69 CMPO:RTIL Stripping with 0.05 mM EDTA: 1 M Guanidine Carbonate... 102

Figure $70{ }^{177}$ Lu Activity in EDTA:Guanidine Carbonate Strip Solution vs. Mixing Time

with CMPO:RTIL $(n=1)$...................................................................... 103

Figure 71 Damaged Polycarbonate HFSLM.......................................................... 105

Figure $72{ }^{177}$ Lu Activity in Feed and Strip Solutions vs Time $(n=1)$.......................... 106

Figure 73 RTIL/Ethyl Acetate Colloid Formation with Water.................................... 108

Figure 74 Versatic 10, Neodecanoic Acid ............................................................... 109

Figure 75 Structure of Sym-Dibenzo-16-Crown-5-Oxyacetic Acid............................ 113 


\section{LIST OF TABLES}

Table 1 Production Rate of Important Isotopes in the FRIB Beam Dump, Grouped by

Primary Beam [11]

Table 2 Estimated Beam Dump Yield for 6-Month ${ }^{238} \mathrm{U}$ Primary Beam ......................... 9

Table $3 \mathrm{~K}_{\mathrm{d}}$ Values for Lanthanides with Increasing HIBA $\mathrm{pH}(\mathrm{n}=1)$............................... 34

Table $4 \mathrm{~K}_{\mathrm{d}}$ Values for Lanthanides with Increasing HIBA Molarity $(\mathrm{n}=2) \ldots \ldots \ldots \ldots \ldots \ldots \ldots . . . .35$

Table 5 Milligrams of Element Recovered with 6 Elution Cycles of Eichrom RE Column

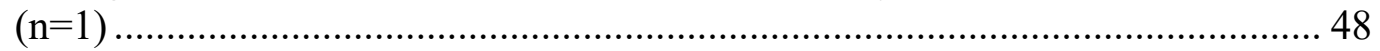

Table 6 Estimated Beam Dump Concentrations and Experimental Concentrations ....... 51

Table 7 Micrograms of Element Recovered with 3 Elution Cycles from Eichrom DGA

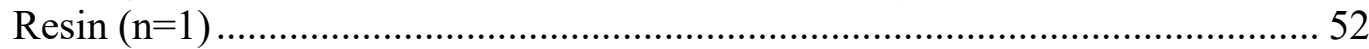

Table 8 Estimated Beam Dump Concentrations in $7000 \mathrm{~L}$ and Experimental

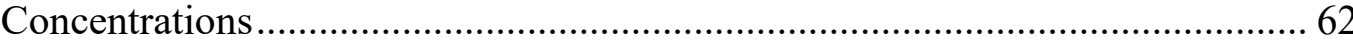

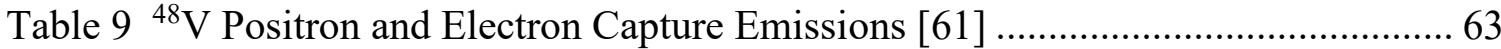

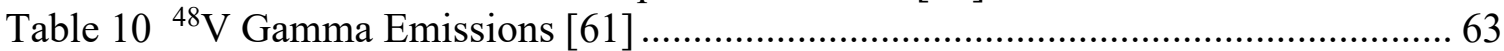

Table 11 Approximate ${ }^{48} \mathrm{~V}$ Activity/ $\mu \mathrm{Ahr}$ using 10 Equal Slices ..................................66 66

Table 12 HFSLM Liqui-Cel Specifications ............................................................... 74

Table 13 Beam Dump Yields of Lanthanides with Different Primary Beams ................ 91

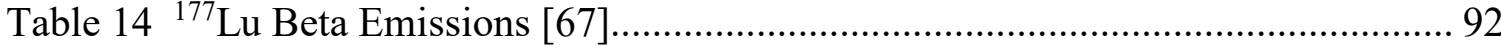

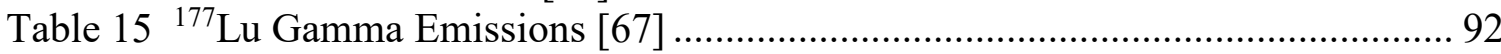

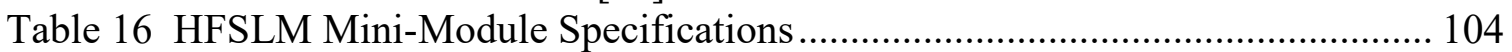

Table 17 RTIL ${ }^{177} \mathrm{Lu}$ Extraction Efficiency Upon Dilution with Organic Solvent ....... 107

Table 18 Lutetium-177 Extraction with Varying Versatic 10 Concentration and Mixing

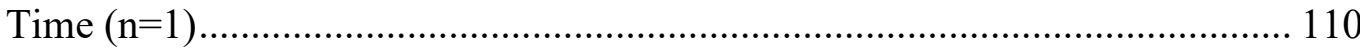




\section{LIST OF ABBREVIATIONS}

1. $\left[\mathrm{C}_{4} \mathrm{mim}\right][\mathrm{PF} 6]-1$-Butyl-3-methyl-imidazolium hexafluorophosphate

2. $\left[\mathrm{C}_{6} \operatorname{mim}\right]\left[\mathrm{Tf}_{2} \mathrm{~N}\right]-1$-Hexyl-3-methyl-imidazolium bis(trifluoromethylsulfonyl) imide

3. ATLAS - Argonne Tandem Linac Accelerator System

4. CMPO - Octyl(phenyl)-N,N-diisobutyl-carbamoylmethylphosphine oxide

5. $\mathrm{CN}$ - Coordination Number

6. DGA normal - N, N, N',N'-tetra-n-octyldiglycolamide

7. DGA branched - N, N, N', N'-tetrakis-2-ethylhexyl-diglycolamide

8. DOE - Department of Energy

9. EDM - Electric Dipole Moment

10. EDTA - Ethylenediaminetetraacetic acid (acid form)

11. FRIB - Facility for Rare Isotope Beams

12. HDEHP - di-(2-ethylhexyl)phosphoric acid

13. HFSLM - Hollow Fiber Supported Liquid Membrane

14. HIBA - $\alpha$-Hydroxy-Isobutyric Acid

15. HPGe - High Purity Germanium

16. ICP-MS - Inductively Coupled Plasma Mass Spectroscopy

17. ICP-OES - Inductively Coupled Plasma Optical Emission Spectroscopy

18. IL - Ionic Liquid

19. ITEP - Institute for Theoretical and Experimental Physics

20. LINAC - Linear Accelerator 
21. MEQ - milliequivalent

22. MSU - Michigan State University

23. MURR - University of Missouri Research Reactor

24. NSCL - National Superconducting Cyclotron Laboratory

25. PET - Positron Emission Tomography

26. $\mathrm{ppb}-$ Part per Billion $(\mu \mathrm{g} / \mathrm{L})$

27. ppm - Part per Million (mg/L)

28. ppt - Part per Trillion (ng/L)

29. PSI - Paul Scherrer Institute

30. REE - Rare Earth Element

31. RFQ - Radio Frequency Quadrupole

32. RHIC - Relativistic Heavy Ion Collider

33. RTG - Radioisotope Thermoelectric Generator

34. RTIL - Room Temperature Ionic Liquid

35. SC-ECR- Super-Conducting Electron Cyclotron Resonance

36. TBP - Tri-butyl Phosphate

37. TRUEX - Transuranium Extraction 


\section{ABSTRACT OF THE DISSERTATION}

Isotope harvesting from the beam dump cooling loop of the Facility for Rare Isotope Beams (FRIB) offers usable quantities of many isotopes unavailable anywhere else in the world. Many of these co-produced isotopes are of significant interest for research in biomedicine, energy, environmental studies, and materials science, and yet they are destined for disposal. One option for retrieval of these rare isotopes is harvesting from the spent mixed-bed resin in a batch collection mode. Alternatively, Hollow Fiber Supported Liquid Membrane (HFSLM) extraction poses a method of quickly retrieving these rare isotopes while overcoming the challenges associated with the beam dump environment: ultra-trace concentrations (ppt), high flow rates (4-6 L/s), neutral $\mathrm{pH}$ environment (6-7), vast mixture of elements, and a high radiation environment $(1.3 \mathrm{kGy} / \mathrm{hr})$.

After one to two years of operation, the two 50-gallon resin tanks of Purolite NRW3460 mixed-bed resin will be hydraulically removed for transfer to storage tanks for waste shipment, at which point the isotopes will be accessible for harvesting. The lanthanides contained within this waste are of particular interest because their long halflives and high energy density make them excellent candidates for use in nuclear batteries.

${ }^{177} \mathrm{Lu}$ was chosen as a radiotracer to determine the feasibility of harvesting long-lived lanthanides from the mixed-bed resin. This work describes a method for high recovery of the lanthanides utilizing strong acid recirculation coupled with removal of the extracted lanthanides with an Eichrom DGA cartridge. Ninety-seven percent of dosed lanthanides were recovered from a surrogate system into only thirty milliliters of dilute acid, while utilizing approximately three column volumes of strong acid for elution. 
${ }^{48} \mathrm{~V}$ was chosen as a radiotracer to determine the feasibility of using HFSLM extraction to remove short-lived transition metals from the beam dump loop. Part per trillion levels of ${ }^{48} \mathrm{~V}$ were successfully recovered from the aqueous feed solution spiked with chemically similar species at flow rates of 6 gallons/hour $(450 \mathrm{~mL} / \mathrm{min}$.) utilizing 0.15 M Aliquat 336 in 3\% dodecanol/dodecane in the HFSLM pores and $0.5 \mathrm{M}$ ammonia in 0.1 $\mathrm{M}$ ammonium nitrate as the stripping solution. The chemical extraction efficiency from this matrix was found to be $71 \%$ in 60 minutes. This is the first ever demonstration of part per trillion level recovery with HFSLM extraction.

${ }^{177} \mathrm{Lu}$ was chosen as a radiotracer to determine the feasibility of using HFSLM extraction to remove lanthanides from the beam dump loop. Preliminary benchtop liquidliquid extraction tests showed successful extraction of ${ }^{177} \mathrm{Lu}$ from a neutral $\mathrm{pH}$ feed solution with $5 \mathrm{mM}$ Octyl(phenyl)-N,N-diisobutyl-carbamoylmethylphosphine oxide (CMPO) in a room temperature ionic liquid, 1-Hexyl-3methylimidazolium bis(trifluoromethylsulfonyl) imide $\left[\mathrm{C}_{6} \mathrm{mim}\right]\left[\mathrm{Tf}_{2} \mathrm{~N}\right]$; however, upon testing with a Liqui-Cel $1.7 \times 10$ mini module membrane contactor, it was discovered that the RTIL degraded the polycarbonate minimodule causing cracking and leaking, and no lutetium migrated to the strip solution. It is hypothesized that the high viscosity of the RTIL prevents permeation into the HFSLM pores. 


\section{Chapter 1 INTRODUCTION}

\subsection{Projectile Fragmentation Facilities}

Nuclear physics research facilities such as the RHIC (Relativistic Heavy Ion Collider), ATLAS (Argonne Tandem Linac Accelerator System), ITEP (Institute for Theoretical and Experimental Physics), and FRIB (Facility for Rare Isotope Beams) produce secondary ion beams by bombarding light target materials with heavy ion beams. These secondary ion beams are typically radioactive nuclei and the beams are used for nuclear structure and nuclear reaction studies far from stability (Figure 1). Individual experiments typically focus upon only one nuclide of interest, while the remainder of the rare, radioactive isotopes (Figure 2) end up as waste. Developing a method of recycling or "harvesting" these rare co-produced isotopes is necessary to advance research in medicine, materials science, stockpile stewardship, astrophysics, plant biology, and other important areas. 


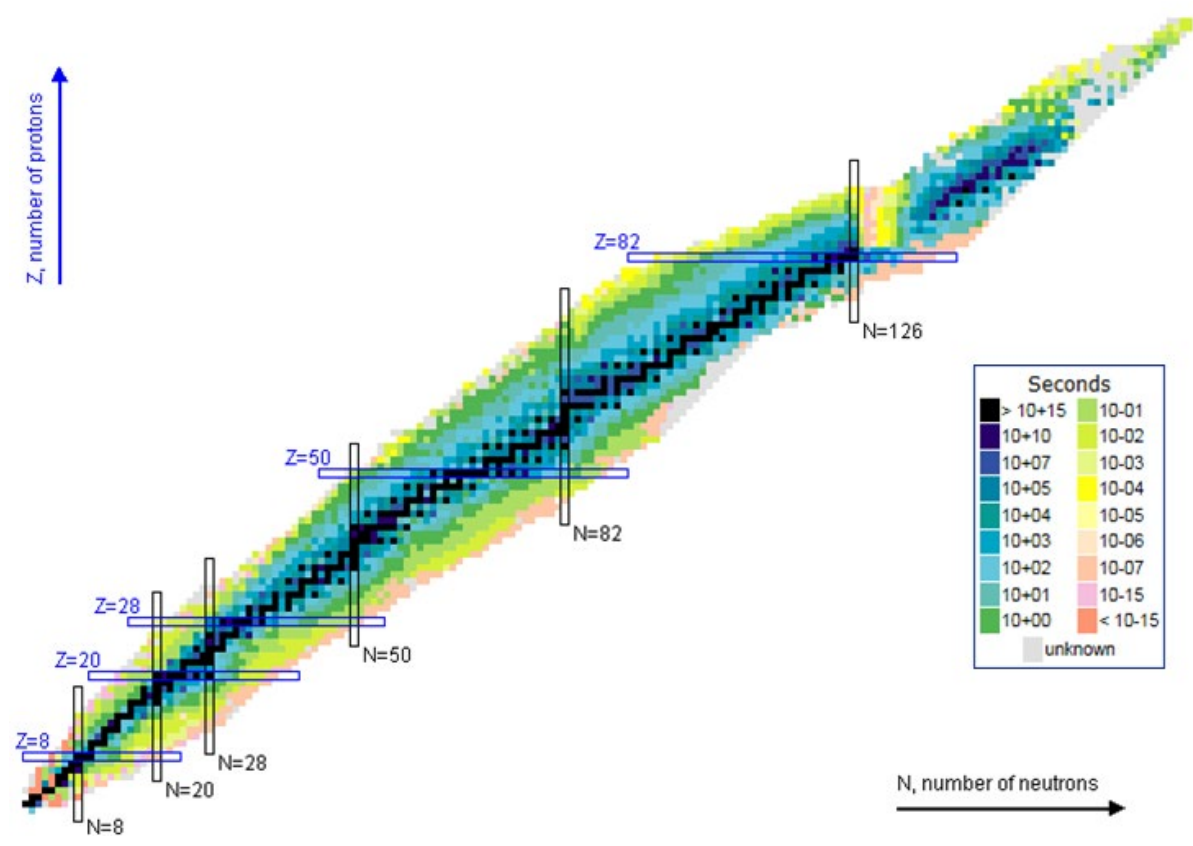

Figure 1 Chart of the Nuclides [1]

Attributed to National Nuclear Data Center, Brookhaven National Laboratory, www.nndc.bnl.gov/

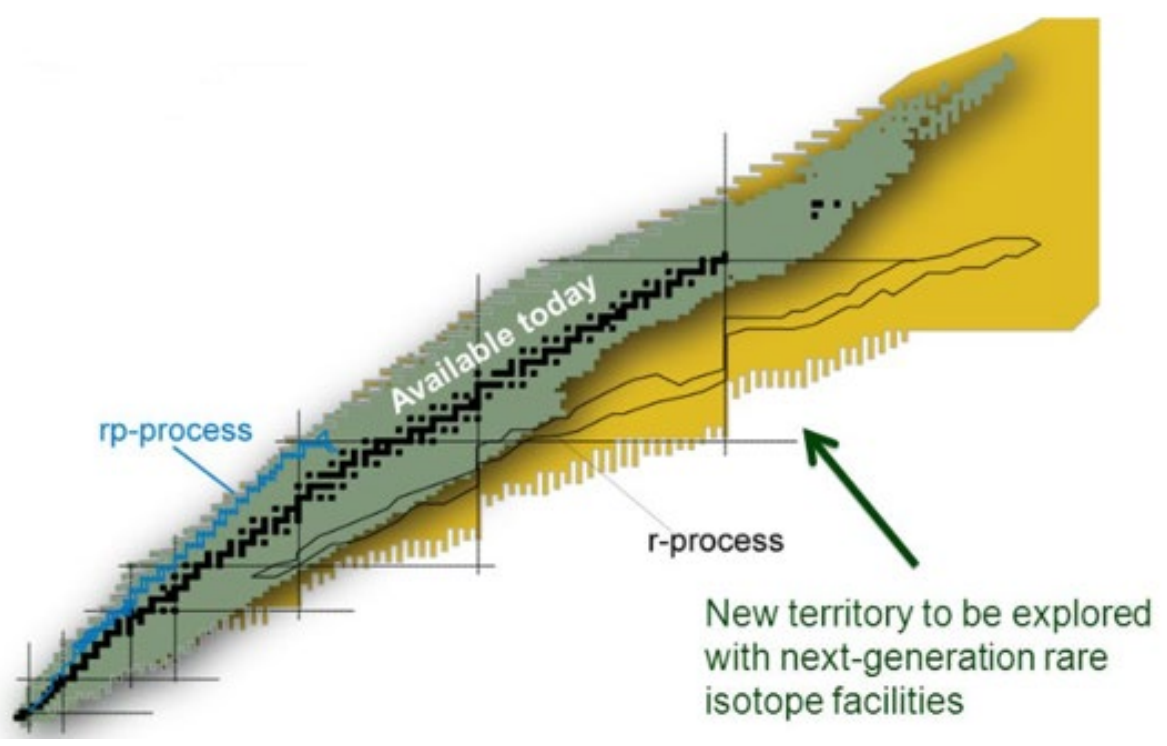

Figure 2 Newly Available Isotopes at Projectile Fragmentation Facilities [2] Attributed to MSU/FRIB

\subsection{Isotope Harvesting at Projectile Fragmentation Facilities}

The feasibility of recycling or "harvesting" rare co-produced isotopes from projectile fragmentation facilities has recently been under investigation. For example, 
Mastren et al. [3] [4] researched harvesting ${ }^{67} \mathrm{Cu}$ using an aqueous beam stop built by Pen et al. [5] at the National Superconducting Cyclotron Laboratory (NSCL) on the campus of Michigan State University, demonstrating the recovery of the radiochemically pure isotope. Loveless [6] performed successful harvesting experiments utilizing the same aqueous beam stop for ${ }^{48} \mathrm{~V}$. Schumann et. al. have demonstrated the successful recovery of isotopes of importance to astrophysics $\left({ }^{44} \mathrm{Ti},{ }^{26} \mathrm{Al},{ }^{53} \mathrm{Mn}\right.$, and $\left.{ }^{7} \mathrm{Be}\right)$ from accelerator waste generated at the Paul Scherrer Institute (PSI) in Switzerland [7] [8] [9]. Lastly, the recovery of FRIB gaseous isotopes such as radon has been investigated by Visser and Scielzo [10].

\subsection{Facility for Rare Isotope Beams (FRIB)}

The Facility for Rare Isotope Beams (FRIB) is a new national user facility for nuclear science, funded by the Department of Energy, Office of Science (DOE-SC), Office of Nuclear Physics, Michigan State University (MSU), and the State of Michigan, and operated by MSU. Currently under construction, the estimated completion date of the facility is June 2022, and is a major upgrade to the current National Superconducting Cyclotron Laboratory (NSCL). This $\$ 730$ million facility will produce beams of radionuclides that have previously only existed in supernovae explosions and the crusts of neutron stars.

As it creates and delivers beams of some of the most exotic nuclei in the universe, FRIB will simultaneously generate thousands of other radionuclides that could be synergistically harvested without impact to the primary experiment. Many of these coproduced isotopes are of significant interest for research in biomedicine, energy, environmental studies, and materials science. For example, an experiment utilizing ${ }^{58} \mathrm{Ni}$ 
as the primary beam will create significant quantities of ${ }^{44} \mathrm{Ti},{ }^{48} \mathrm{~V},{ }^{48} \mathrm{Cr}$ and ${ }^{52} \mathrm{Fe}$ over the course of a week (Table 1) [11]. Vanadium-48 would be useful as a radiotracer for nitrogen fixation studies in plants, ${ }^{48} \mathrm{Cr}$ is needed as a precursor for generating isotopically pure ${ }^{48} \mathrm{~V}$ for stockpile stewardship studies, and ${ }^{52} \mathrm{Fe}$ would be useful as a positron-emission tomography (PET) radiotracer for both medicine and plant sciences.

\begin{tabular}{|c|c|c|c|c|c|c|}
\hline \multicolumn{7}{|c|}{ Radionuclides for harvest at FRIB } \\
\hline Element & $\begin{array}{c}\text { Mass } \\
\#\end{array}$ & t 1/2 & Research Field & & $\begin{array}{c}\text { Beam } \\
\text { Rate }\end{array}$ & units \\
\hline $\mathrm{Mg}$ & 28 & $21 \mathrm{~h}$ & plants & ${ }^{36} \mathrm{~S}$ & $2.10 \mathrm{E}+03$ & $\mathrm{mCi} / \mathrm{d}$ \\
$\mathrm{Si}$ & 32 & $153 \mathrm{y}$ & environmental tracer & & $1.10 \mathrm{E}+00$ & $\mathrm{mCi} / \mathrm{wk}$ \\
\hline $\mathrm{Ca}$ & 47 & $4.5 \mathrm{~d}$ & medicine & ${ }^{48} \mathrm{Ca}$ & $1.00 \mathrm{E}+04$ & $\mathrm{mCi} / \mathrm{d}$ \\
\hline $\mathrm{Ti}$ & 44 & $60 \mathrm{y}$ & astrophysics, medicine & ${ }^{58} \mathrm{Ni}$ & $2.50 \mathrm{E}-01$ & $\mathrm{mCi} / \mathrm{wk}$ \\
$\mathrm{V}$ & 48 & $16 \mathrm{~d}$ & stewardship, plants & & $2.60 \mathrm{E}+03$ & $\mathrm{mCi} / \mathrm{wk}$ \\
$\mathrm{Cr}$ & 48 & $22 \mathrm{~h}$ & stewardship & & $6.10 \mathrm{E}+02$ & $\mathrm{mCi} / \mathrm{d}$ \\
$\mathrm{Fe}$ & 52 & $8.3 \mathrm{~h}$ & plants, medicine & & $9.80 \mathrm{E}+02$ & $\mathrm{mCi} / \mathrm{d}$ \\
\hline $\mathrm{Fe}$ & 60 & $1.5 \mathrm{My}$ & astrophysics & ${ }^{64} \mathrm{Ni}$ & $2.80 \mathrm{E}-05$ & $\mathrm{mCi} / \mathrm{wk}$ \\
$\mathrm{Ni}$ & 63 & $101 \mathrm{y}$ & RTG & & $5.60 \mathrm{E}+00$ & $\mathrm{mCi} / \mathrm{wk}$ \\
\hline $\mathrm{Zn}$ & 62 & $9.2 \mathrm{~h}$ & materials, biochemistry & ${ }^{64} \mathrm{Zn}$ & $3.20 \mathrm{E}+03$ & $\mathrm{mCi} / \mathrm{d}$ \\
\hline $\mathrm{Se}$ & 72 & $8.5 \mathrm{~d}$ & medicine & ${ }^{74} \mathrm{Se}$ & $2.20 \mathrm{E}+03$ & $\mathrm{mCi} / \mathrm{wk}$ \\
$\mathrm{Se}$ & 73 & $7.2 \mathrm{~h}$ & materials, biochemistry & & $1.60 \mathrm{E}+04$ & $\mathrm{mCi} / \mathrm{d}$ \\
\hline $\mathrm{Cu}$ & 67 & $2.6 \mathrm{~d}$ & medicine & ${ }^{76} \mathrm{Ge}$ & $6.90 \mathrm{E}+02$ & $\mathrm{mCi} / \mathrm{d}$ \\
$\mathrm{As}$ & 77 & $35 \mathrm{~h}$ & astrophysics & & $9.60 \mathrm{E}+03$ & $\mathrm{mCi} / \mathrm{d}$ \\
\hline $\mathrm{Ge}$ & 68 & $271 \mathrm{~d}$ & medicine & ${ }^{78} \mathrm{Kr}$ & $1.60 \mathrm{E}+01$ & $\mathrm{mci} / \mathrm{wk}$ \\
$\mathrm{Kr}$ & 76 & $14.8 \mathrm{~h}$ & medicine & & $2.50 \mathrm{E}+03$ & $\mathrm{mCi} / \mathrm{d}$ \\
$\mathrm{Kr}$ & 77 & $74 \mathrm{~m}$ & materials, biochemistry & & $6.70 \mathrm{E}+03$ & $\mathrm{mCi} / \mathrm{hr}$ \\
\hline $\mathrm{Sr}$ & 82 & $25 \mathrm{~d}$ & medicine & ${ }^{92} \mathrm{Mo}$ & $7.90 \mathrm{E}+02$ & $\mathrm{mci} / \mathrm{wk}$ \\
$\mathrm{Zr}$ & 86 & $16.5 \mathrm{~h}$ & materials, biochemistry & & $2.90 \mathrm{E}+03$ & $\mathrm{mCi} / \mathrm{d}$ \\
$\mathrm{Zr}$ & 88 & $83 \mathrm{~d}$ & stewardship & & $6.30 \mathrm{E}+02$ & $\mathrm{mCi} / \mathrm{wk}$ \\
$\mathrm{Mo}$ & 90 & $5.7 \mathrm{~h}$ & plants & & $2.80 \mathrm{E}+03$ & $\mathrm{mCi} / \mathrm{d}$ \\
\hline $\mathrm{Pd}$ & 100 & $3.7 \mathrm{~d}$ & medicine & ${ }^{106} \mathrm{Cd}$ & $6.50 \mathrm{E}+02$ & $\mathrm{mCi} / \mathrm{d}$ \\
$\mathrm{Pd}$ & 103 & $17 \mathrm{~d}$ & medicine & & $2.70 \mathrm{E}+03$ & $\mathrm{mCi} / \mathrm{wk}$ \\
\hline $\mathrm{In}$ & 111 & $2.8 \mathrm{~d}$ & materials, biochemistry & ${ }^{112} \mathrm{Sn}$ & $2.90 \mathrm{E}+03$ & $\mathrm{mCi} / \mathrm{d}$ \\
\hline
\end{tabular}




\begin{tabular}{|c|c|c|c|c|c|c|}
\hline \multicolumn{7}{|c|}{ Radionuclides for harvest at FRIB (cont.) } \\
\hline Element & $\begin{array}{c}\text { Mass } \\
\#\end{array}$ & $\mathrm{t} 1 / 2$ & Research Field & Beam & $\begin{array}{l}\text { Production } \\
\text { Rate }\end{array}$ & units \\
\hline $\mathrm{Te}$ & 119 & 4.7 & medicine & ${ }^{124} \mathrm{Xe}$ & $3.00 E+03$ & $\mathrm{mCi} / \mathrm{wk}$ \\
\hline $\mathrm{Xe}$ & 122 & $20 \mathrm{~h}$ & medicine & & $2.80 \mathrm{E}+03$ & $\mathrm{mCi} / \mathrm{d}$ \\
\hline $\mathrm{Ba}$ & 128 & $2.4 \mathrm{~d}$ & medicine & ${ }^{136} \mathrm{Ce}$ & $6.80 E+02$ & $\mathrm{mCi} / \mathrm{d}$ \\
\hline $\mathrm{Ce}$ & 134 & $3.2 \mathrm{~d}$ & medicine & & $4.20 E+03$ & $\mathrm{mCi} / \mathrm{wk}$ \\
\hline $\mathrm{Nd}$ & 140 & $3.4 \mathrm{~d}$ & medicine & ${ }^{144} \mathrm{Sm}$ & $4.10 E+03$ & $\mathrm{mCi} / \mathrm{wk}$ \\
\hline $\mathrm{Nd}$ & $139 m$ & $4.4 \mathrm{~h}$ & materials, biochemistry & & $8.60 \mathrm{E}+02$ & $\mathrm{mCi} / \mathrm{d}$ \\
\hline $\mathrm{Ce}$ & 143 & $33 \mathrm{~h}$ & materials, biochemistry & ${ }^{150} \mathrm{Nd}$ & $1.80 E+02$ & $\mathrm{mCi} / \mathrm{d}$ \\
\hline $\mathrm{Pm}$ & 147 & $2.6 \mathrm{y}$ & chemistry, RTG & & $2.60 E+01$ & $\mathrm{mCi} / \mathrm{wk}$ \\
\hline $\mathrm{Gd}$ & 146 & $48 d$ & medicine & $156 \mathrm{Dy}$ & $1.20 \mathrm{E}+02$ & $\mathrm{mCi} / \mathrm{wk}$ \\
\hline $\mathrm{Gd}$ & 147 & $38 \mathrm{~h}$ & materials, biochemistry & & $4.60 \mathrm{E}+02$ & $\mathrm{mCi} / \mathrm{d}$ \\
\hline $\mathrm{Gd}$ & 148 & 71 y & batteries & & 4.70E-01 & $\mathrm{mCi} / \mathrm{wk}$ \\
\hline $\mathrm{Gd}$ & 149 & $9.3 d$ & stewardship & & $1.20 \mathrm{E}+03$ & $\mathrm{mCi} / \mathrm{wk}$ \\
\hline $\mathrm{Eu}$ & 150 & $36 y$ & stewardship & & $6.00 \mathrm{E}-02$ & $\mathrm{mCi} / \mathrm{wk}$ \\
\hline $\mathrm{Hf}$ & 172 & $1.9 \mathrm{y}$ & chemistry & ${ }^{174} \mathrm{Hf}$ & $2.10 E+01$ & $\mathrm{mCi} / \mathrm{wk}$ \\
\hline $\mathrm{Hf}$ & 173 & $24 \mathrm{~h}$ & stewardship & & $1.80 \mathrm{E}+03$ & $\mathrm{mCi} / \mathrm{d}$ \\
\hline $\mathrm{Tm}$ & 168 & $93 d$ & stewardship & ${ }^{176} \mathrm{Yb}$ & $5.80 E+01$ & $\mathrm{mCi} / \mathrm{wk}$ \\
\hline Lu & 174 & $3.3 \mathrm{y}$ & stewardship & ${ }^{186} \mathrm{~W}$ & $6.50 \mathrm{E}-01$ & $\mathrm{mCi} / \mathrm{wk}$ \\
\hline $\mathrm{TI}$ & 204 & $3.8 \mathrm{y}$ & RTG & ${ }^{208} \mathrm{~Pb}$ & $1.40 \mathrm{E}+00$ & $\mathrm{mCi} / \mathrm{wk}$ \\
\hline $\mathrm{Sr}$ & 91 & $9.7 \mathrm{~h}$ & $\begin{array}{l}\text { astrophysics } \\
\text { stewardship, }\end{array}$ & ${ }^{238} \mathrm{U}$ & $9.10 E+02$ & $\mathrm{mCi} / \mathrm{d}$ \\
\hline $\mathrm{Zr}$ & 95 & $64 d$ & astrophysics & & $1.10 \mathrm{E}+02$ & $\mathrm{mCi} / \mathrm{wk}$ \\
\hline Mo & 99 & $66 \mathrm{~h}$ & materials, biochemistry & & $3.00 E+02$ & $\mathrm{mCi} / \mathrm{d}$ \\
\hline $\mathrm{Ru}$ & 103 & $39 d$ & medicine & & $1.90 \mathrm{E}+02$ & $\mathrm{mCi} / \mathrm{wk}$ \\
\hline $\mathrm{Ru}$ & 105 & $4.4 \mathrm{~h}$ & astrophysics & & $1.60 \mathrm{E}+03$ & $\mathrm{mCi} / \mathrm{d}$ \\
\hline $\mathrm{Ru}$ & 106 & $372 \mathrm{~d}$ & astrophysics & & $2.10 E+01$ & $\mathrm{mCi} / \mathrm{wk}$ \\
\hline $\mathrm{Ba}$ & 140 & $12.7 \mathrm{~d}$ & astrophysics & & $1.50 E+02$ & $\mathrm{mCi} / \mathrm{wk}$ \\
\hline $\mathrm{Rn}$ & 211 & $14.6 \mathrm{~h}$ & medicine & & $4.30 E+02$ & $\mathrm{mCi} / \mathrm{d}$ \\
\hline $\mathrm{Rn}$ & 221 & $25 \mathrm{~m}$ & EDM & & $2.10 E+11$ & steady state \\
\hline $\mathrm{Rn}$ & 223 & $23 \mathrm{~m}$ & EDM & & $5.70 E+10$ & steady state \\
\hline $\mathrm{Ra}$ & 225 & $15 d$ & EDM & & $4.90 E+00$ & $\mathrm{mCi} / \mathrm{wk}$ \\
\hline Ac & 225 & $10 d$ & medicine & & $4.40 \mathrm{E}+01$ & $\mathrm{mCi} / \mathrm{wk}$ \\
\hline$A c$ & 227 & $21.7 \mathrm{y}$ & medicine & & $3.40 \mathrm{E}-02$ & $\mathrm{mCi} / \mathrm{wk}$ \\
\hline Th & 227 & $18.7 \mathrm{~d}$ & medicine & & $6.40 E+01$ & $\mathrm{mCi} / \mathrm{wk}$ \\
\hline Th & 228 & $1.9 \mathrm{y}$ & medicine & & $8.10 E+00$ & $\mathrm{mCi} / \mathrm{wk}$ \\
\hline $\mathrm{Pa}$ & 229 & $1.5 \mathrm{~d}$ & EDM & & $3.90 E+02$ & $\mathrm{mCi} / \mathrm{d}$ \\
\hline Th & 229 & $7.9 \mathrm{ky}$ & medicine, EDM & & $2.00 \mathrm{E}-03$ & $\mathrm{mCi} / \mathrm{ky}$ \\
\hline
\end{tabular}

Table 1 Production Rate of Important Isotopes in the FRIB Beam Dump, Grouped by Primary Beam [11] 
The FRIB heavy-ion beam begins at the front end (Figure 3) with a Super Conducting Electron Cyclotron Resonance (SC-ECR) ion source operating at $28 \mathrm{GHz}$ [12]. Ions of the appropriate energy are extracted with an $80.5 \mathrm{MHz}$ four vanes Radio Frequency Quadrupole (RFQ) and accelerated through the $400 \mathrm{~kW}, 200 \mathrm{MeV} /$ nucleon superconducting-RF driver linear accelerator (LINAC) [13], which is folded into three segments.

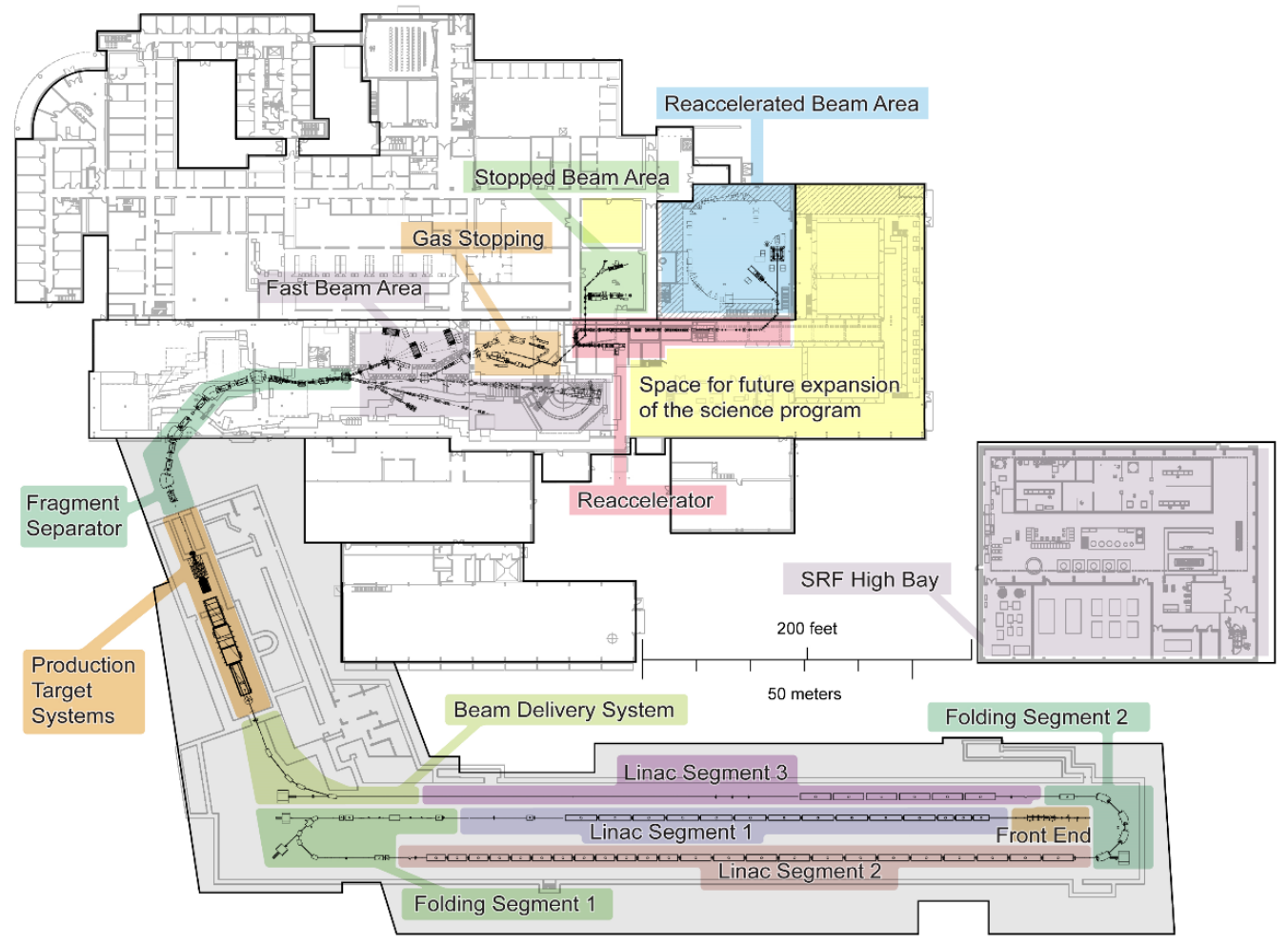

Figure 3 Facility for Rare Isotope Beam Schematic [14] Attributed to MSU/FRIB

In-flight fission and nuclear fragmentation (spallation) interactions with a light production target generate the primary beam, which is directed through the A1900 fragment separator [15] to electromagnetically select the rare isotope ions of interest to the 
primary user for experimentation (Figure 4). Co-produced isotopes will be available for harvesting at various points throughout the beam line.
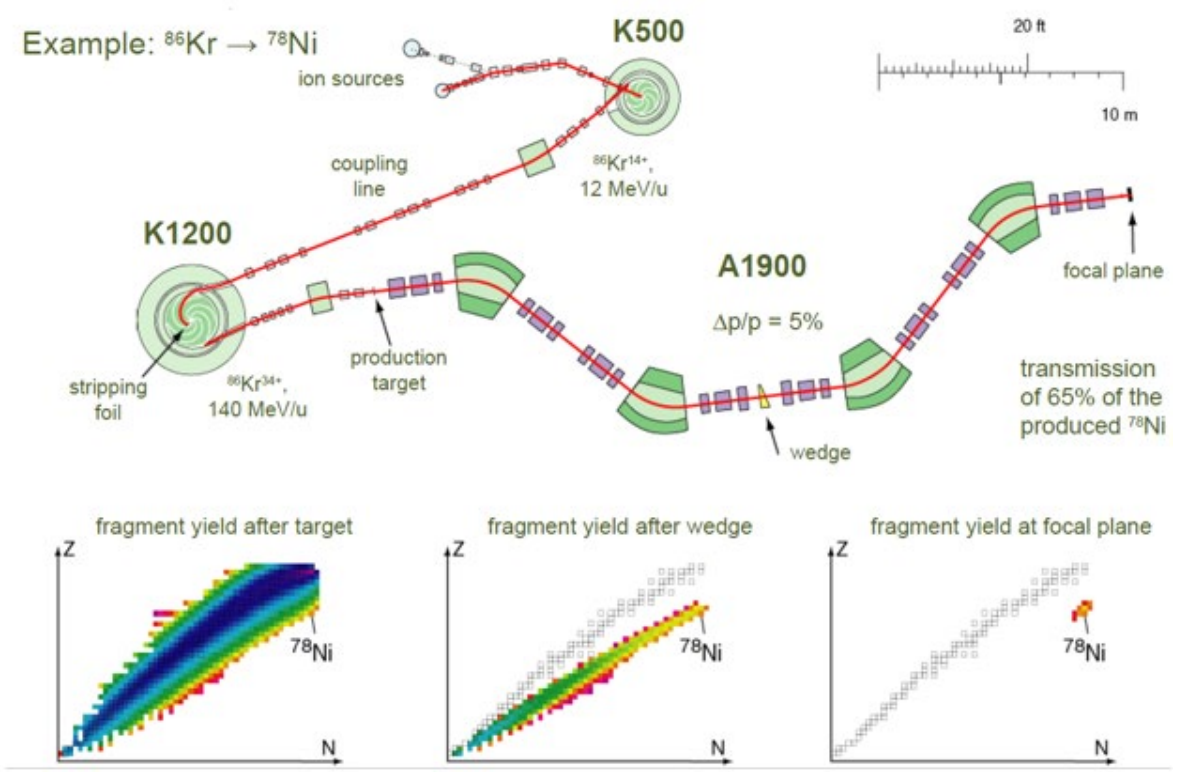

Figure 4 Illustration of A1900 Fragment Separator at the Current NSCL [16] Attributed to MSU/FRIB

\subsection{FRIB Isotope Harvesting Locations}

Co-produced isotopes will be available as both gaseous and dissolved species in various locations throughout FRIB, including the primary beam dump, fragment catcher, and mass slit areas (Figure 5). 


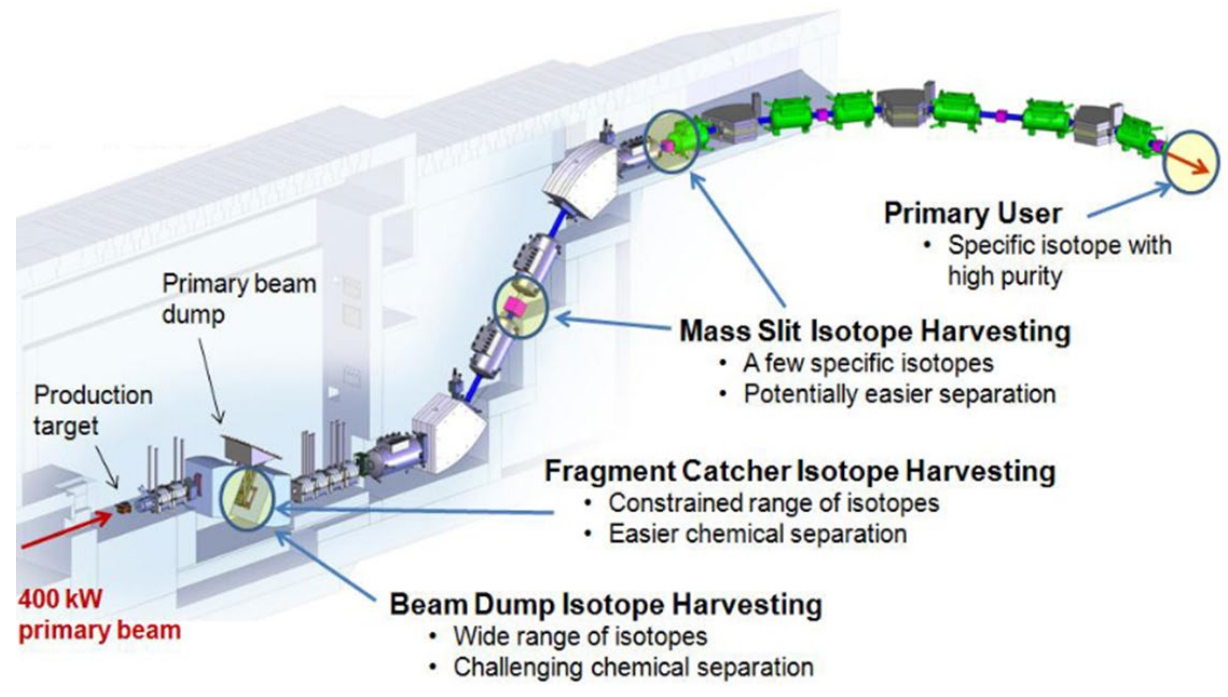

Figure 5 Schematic of FRIB Beam Harvest Points [17]

Attributed to MSU/FRIB

The primary beam dump was chosen for harvesting because approximately $75 \%$ of the unreacted primary beam and the majority of the co-produced isotopes are deposited there. This spinning titanium container filled with cooling water captures and concentrates the co-produced isotopes on the mixed-bed resin. An example of the expected beam dump masses for all isotopes of a few representative elements following six months of operation with ${ }^{238} \mathrm{U}$ as the primary beam are given in Table 2 . 


\begin{tabular}{|c|r|}
\hline Element & $\begin{array}{c}\mu \text { in } \\
\text { beam } \\
\text { dump }\end{array}$ \\
\hline $\mathrm{Be}$ & 0.3 \\
\hline $\mathrm{Na}$ & 2.0 \\
\hline $\mathrm{Ti}$ & 19.9 \\
\hline $\mathrm{Sc}$ & 5.0 \\
\hline $\mathrm{Fe}$ & 42.3 \\
\hline $\mathrm{Co}$ & 21.4 \\
\hline $\mathrm{Cu}$ & 29.6 \\
\hline $\mathrm{Y}$ & 211.0 \\
\hline $\mathrm{Zr}$ & 860.0 \\
\hline $\mathrm{Ba}$ & 495.0 \\
\hline $\mathrm{La}$ & 181.0 \\
\hline $\mathrm{Gd}$ & 251.0 \\
\hline $\mathrm{Lu}$ & 99.3 \\
\hline $\mathrm{U}$ & 386000.0 \\
\hline
\end{tabular}

Table 2 Estimated Beam Dump Yield for 6-Month ${ }^{238} \mathrm{U}$ Primary Beam

The primary beam dump loop consists of approximately 7000 liters of high purity (3-4 Mohm-cm) deionized and filtered cooling water circulating at a rate of $4.6 \mathrm{~L} / \mathrm{s}$. Here the unreacted beam is intercepted by a water-filled Ti-6Al-4V alloy drum (Figure 6, Figure 7, Figure 8) approximately $8 \mathrm{~cm}$ tall, $70 \mathrm{~cm}$ in diameter, and rotating at $400 \mathrm{rpm}$ [18]. 


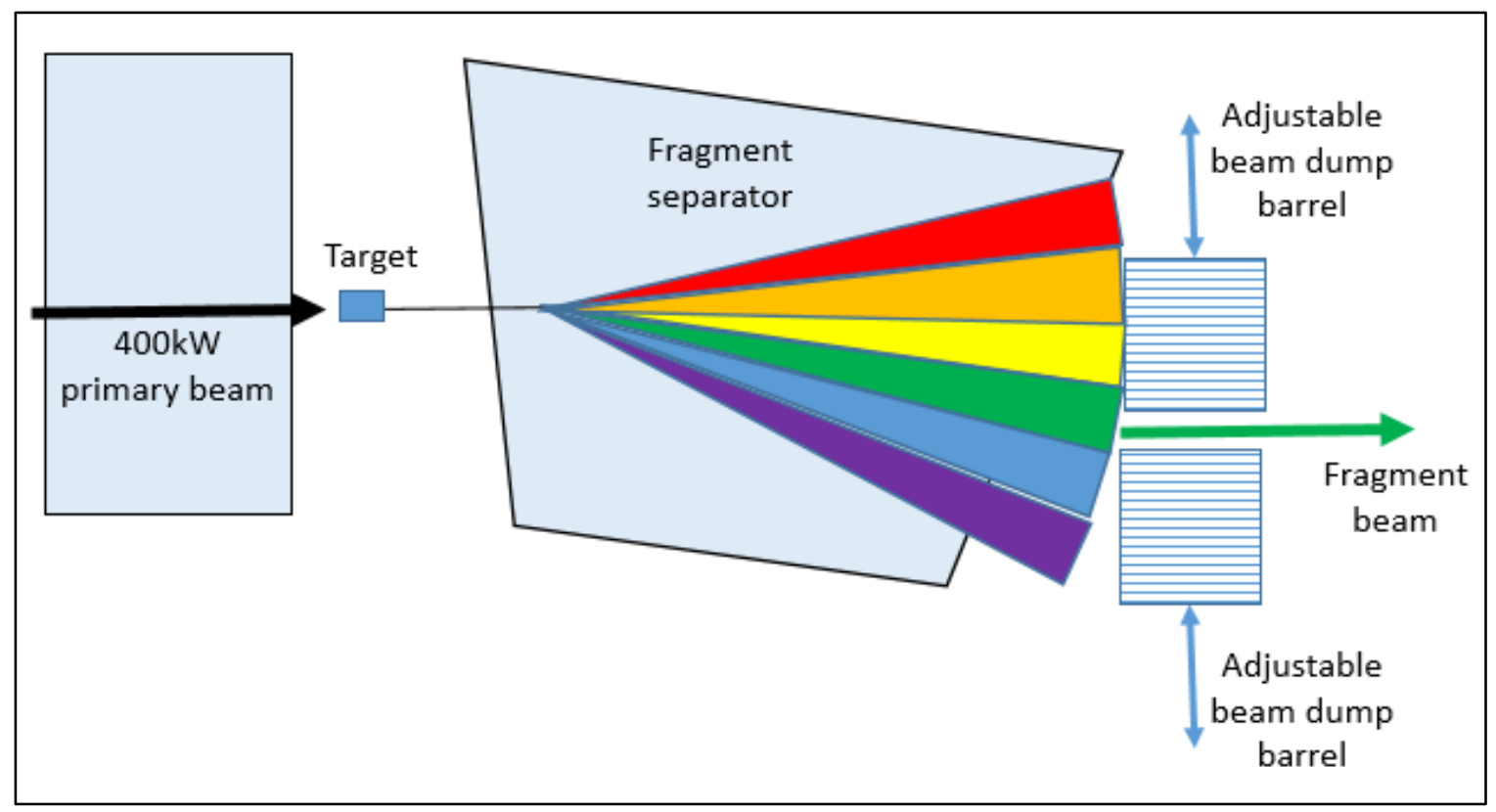

Figure 6 Primary Beam Dump Barrels [19]

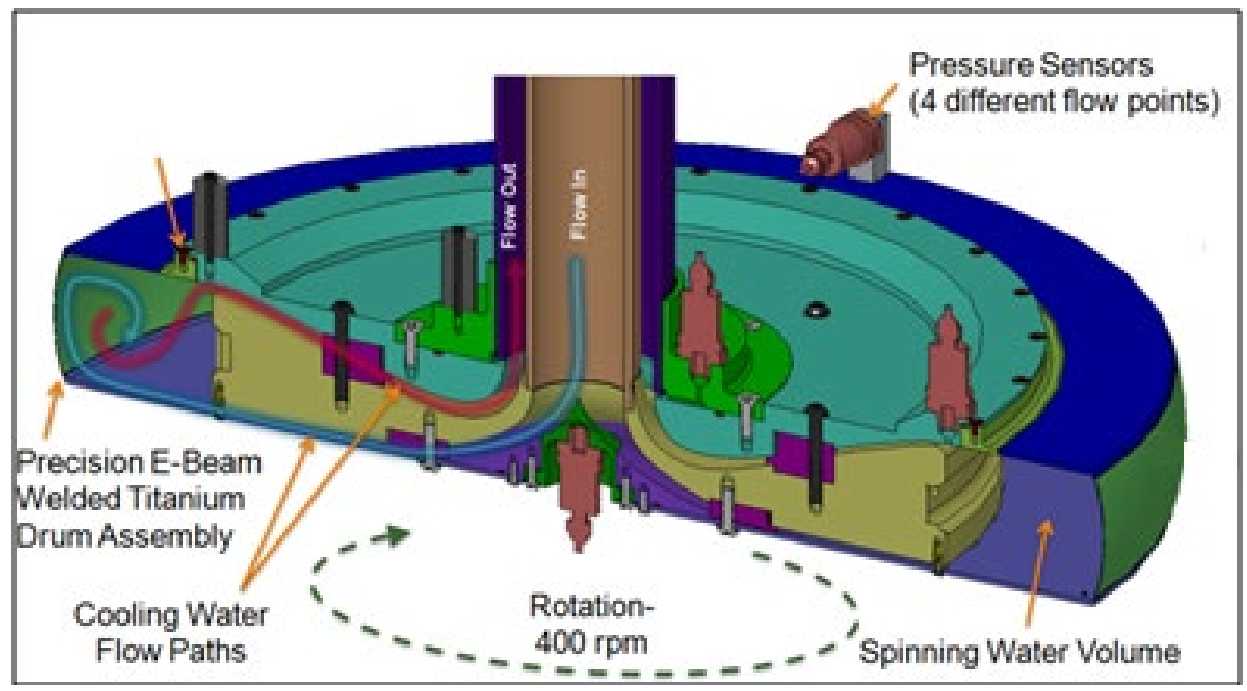

Figure 7 Expanded View of Primary Beam Dump Barrel [20]

Reprinted from Nuclear Instruments and Methods in Physics Research B, vol. 317, M. Hausmann et. al., Design of the Advanced Rare Isotope Separator ARIS at FRIB, pp. 349-353, Copyright 2013, with permission from Elsevier. 


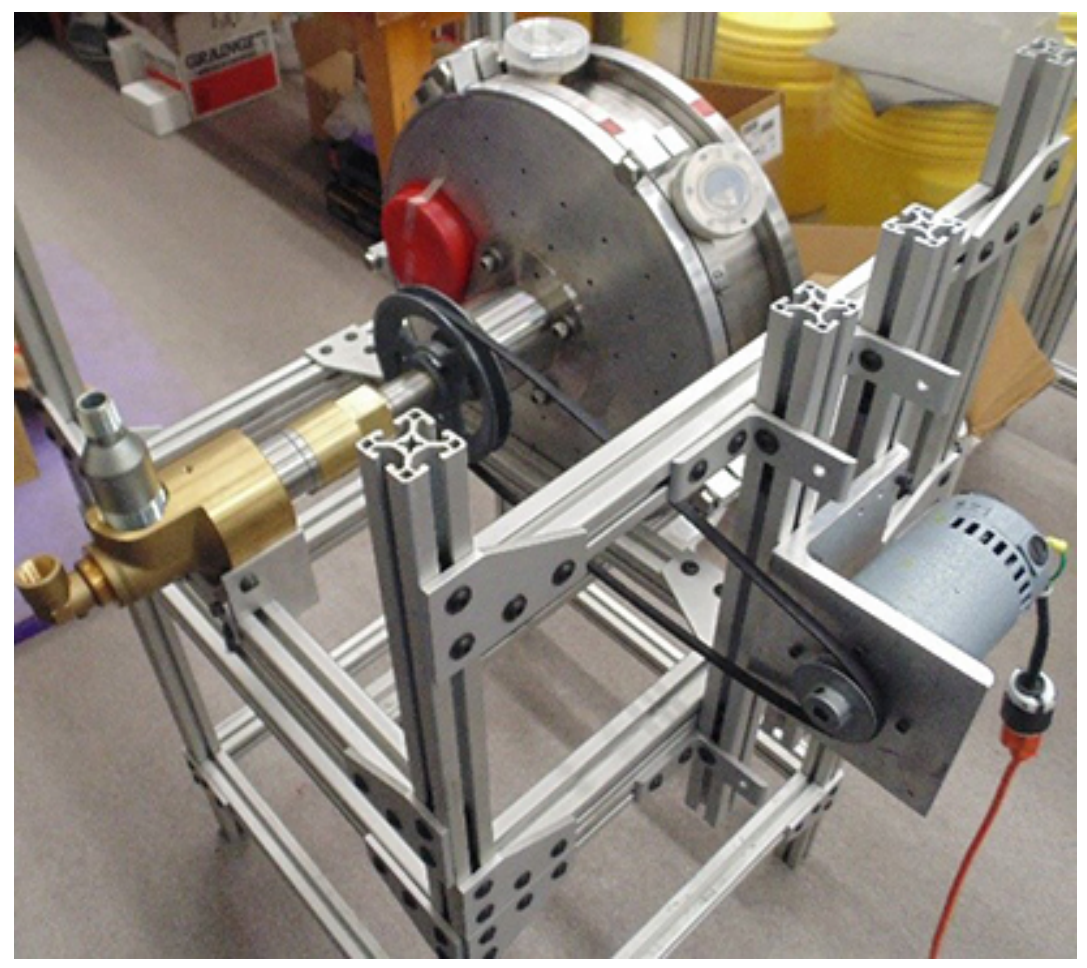

Figure 8 3D-Printed Beam Dump (1/4 scale prototype) [18]

\section{Attributed to MSU/FRIB}

The beam dump water passes through a delay tank, a gas-liquid separator, pumps, and a heat exchanger before returning to the beam dump [10]. After the heat exchanger, one-quarter of the beam dump water is diverted through a cleaning loop (Figure 9) containing a prefilter for particulate removal, two 50-gallon mixed-bed resin tanks of Purolite NRW3460 for ion removal, and a post filter for resin fines removal. The resin bed tanks may be temporarily bypassed to aid in isotope harvesting. 


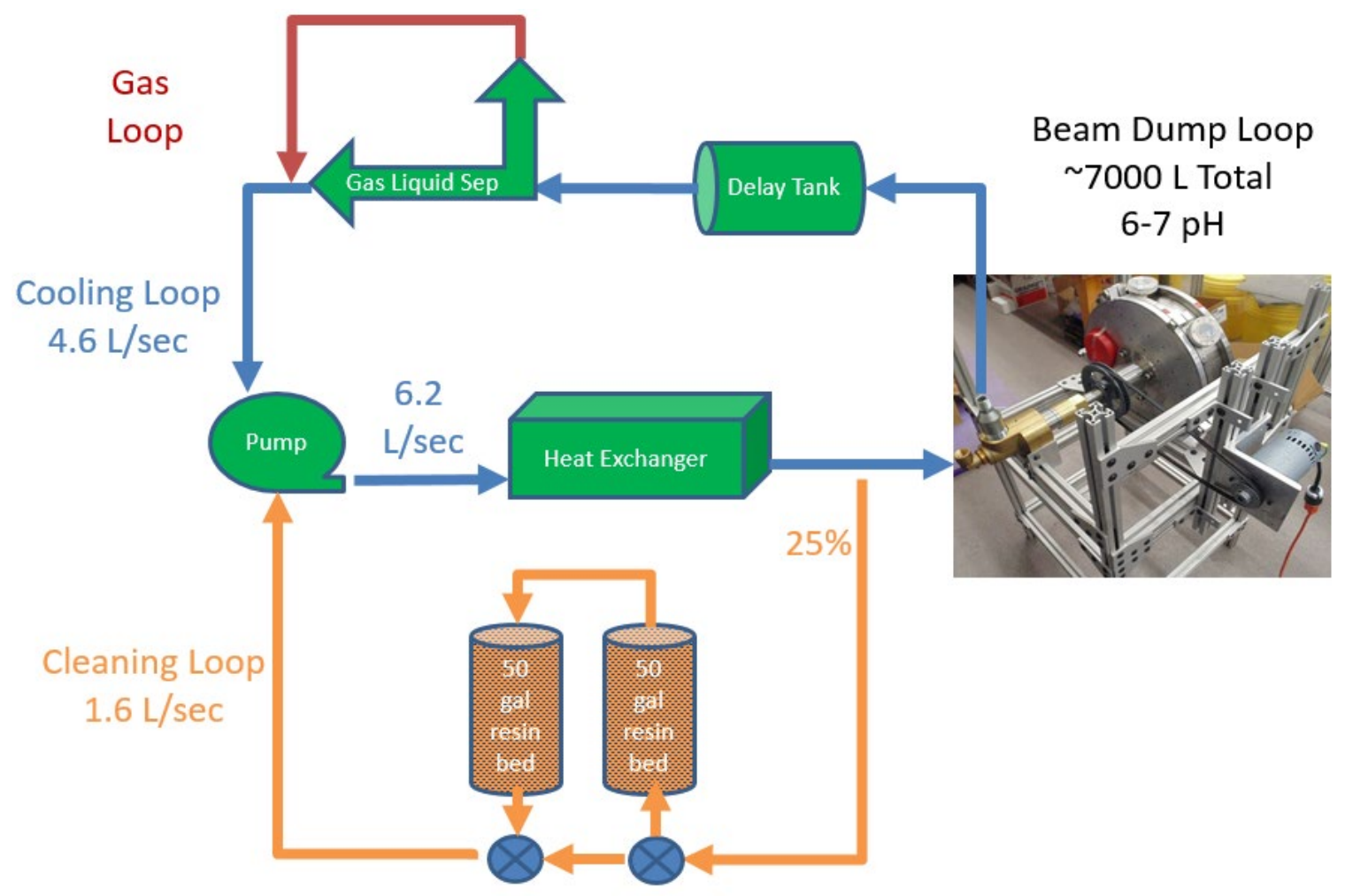

Figure 9 FRIB Beam Dump Loop Schematic [10] [18]

There are several challenges associated with isotope harvesting from the primary beam dump loop. The large volume of the beam dump loop and high flow rates limit the technologies available for isotope harvesting. The two 50-gallon resin beds will only be accessible during major shutdown operations, effectively limiting harvesting operations to long-lived isotopes. The neutral $\mathrm{pH}$ environment and restrictions on chemical additions to the beam dump loop also severely limit the options available for isotope harvesting. Moreover, chemical separation schemes will have to be developed in order to harvest a specific element from the wide variety of species that will be present at ultra-trace concentrations in the circulating water system. Two methods stand out as the most likely to succeed in this environment: batch collection from the spent mixed-bed resin, and insitu extraction from the primary beam dump loop using Hollow Fiber Supported Liquid 
Membrane (HFSLM) extraction. HFSLM extraction is feasible for both liquid and gaseous extraction of isotopes, but only the liquid extraction is evaluated in this work. 


\section{Chapter 2 ISOTOPE HARVESTING - BATCH EXTRACTION}

The objective of this research is to investigate the feasibility of batch harvesting long-lived co-produced isotopes captured in the spent mixed-bed resin at FRIB.

\subsection{FRIB Batch Extraction}

The standard mode of operation at FRIB will be to produce a rare isotope beam for a primary user, but at the same time this beam will produce many other isotopes for which there is currently no comparable source. After approximately six to twelve months of operation, the two 50-gallon resin tanks of Purolite NRW3460 mixed-bed resin will be spent, and hydraulically removed for transfer to storage tanks for waste shipment, at which point the isotopes will be accessible for harvesting. There are two steps involved in this isotope separation: initial physical separation of the mixed-bed resin into cation and anion components, then subsequent separation of isotope classes from the resin components. For the initial separation, the mixed-bed resin components can be separated by fluidization and sedimentation utilizing the differences in density of the resins, which may require the addition of an electrolyte [21] [22] [23]. For removing the isotopes from the component resins, several options are available including: Hollow Fiber Supported Liquid Membrane (HFSLM), acid gradients [24] [25] [26], and complexing agents [27] [28] [29] [30]. 


\subsection{Purolite NRW3460 Mixed-Bed Resin}

The Purolite NRW3460 mixed-bed resin used at FRIB is an intimate 1:1 mixture of Purolite NRW600 anion resin, and Purolite NRW100x10 cation resin. Both resins are composed of functional groups attached to styrene divinylbenzene copolymer lattices, with the anion resin using quaternary ammonium functional groups and the cation using sulfonic acid functional groups (Figure 10, Figure 11). The beam dump of the FRIB facility will contain two 50 gal. columns of the Purolite NRW3460 resin, which will be ion exchanging with 7000 liters of water circulating at $4.6 \mathrm{~L} / \mathrm{s}$.

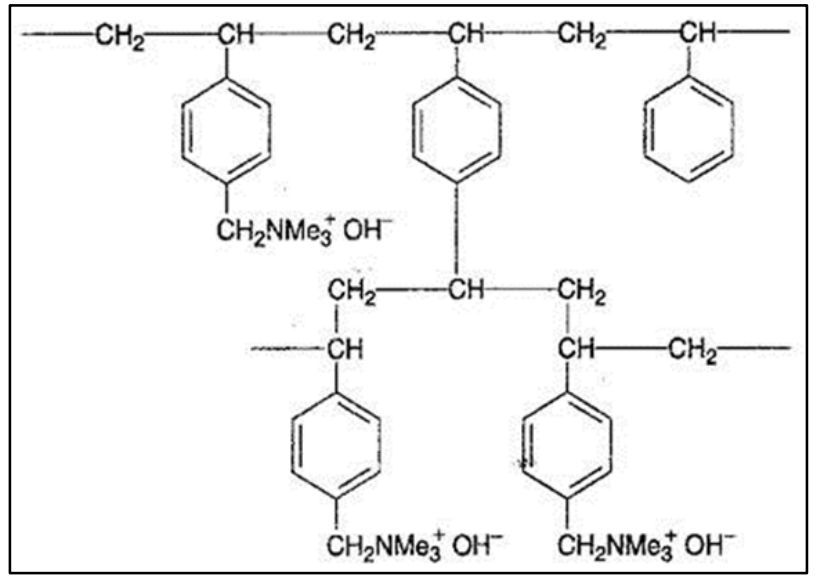

Figure 10 Anion Resin Functional Groups [31]

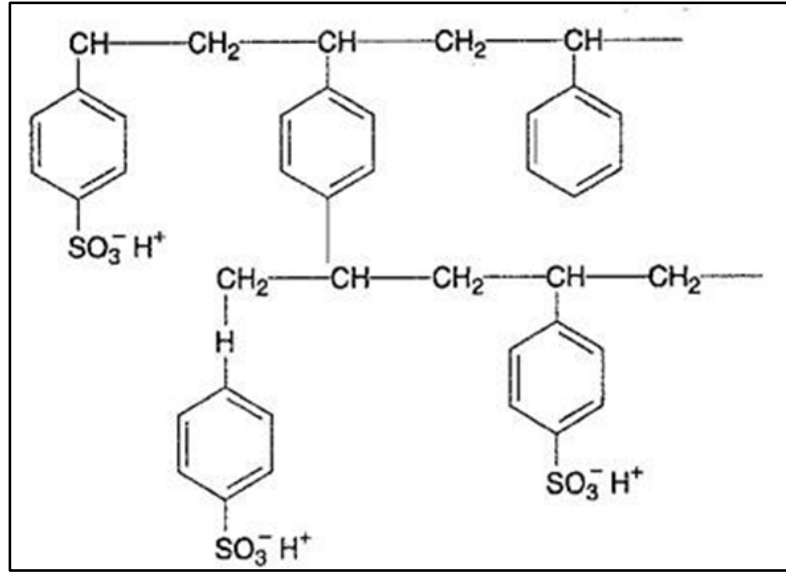

Figure 11 Cation Resin Functional Groups [32] 
The anion resin NRW600 is anticipated to undergo similar interactions as the strong base anion exchanger Dowex $1 \times 10$ resin (Figure 12). In the neutral $\mathrm{pH}$ of the beam dump, the majority of elements expected to bind to the resin are those which form anions or oxoanions, such as the halogens and pertechnetate $\left(\mathrm{TcO}_{4}^{-}\right)$.

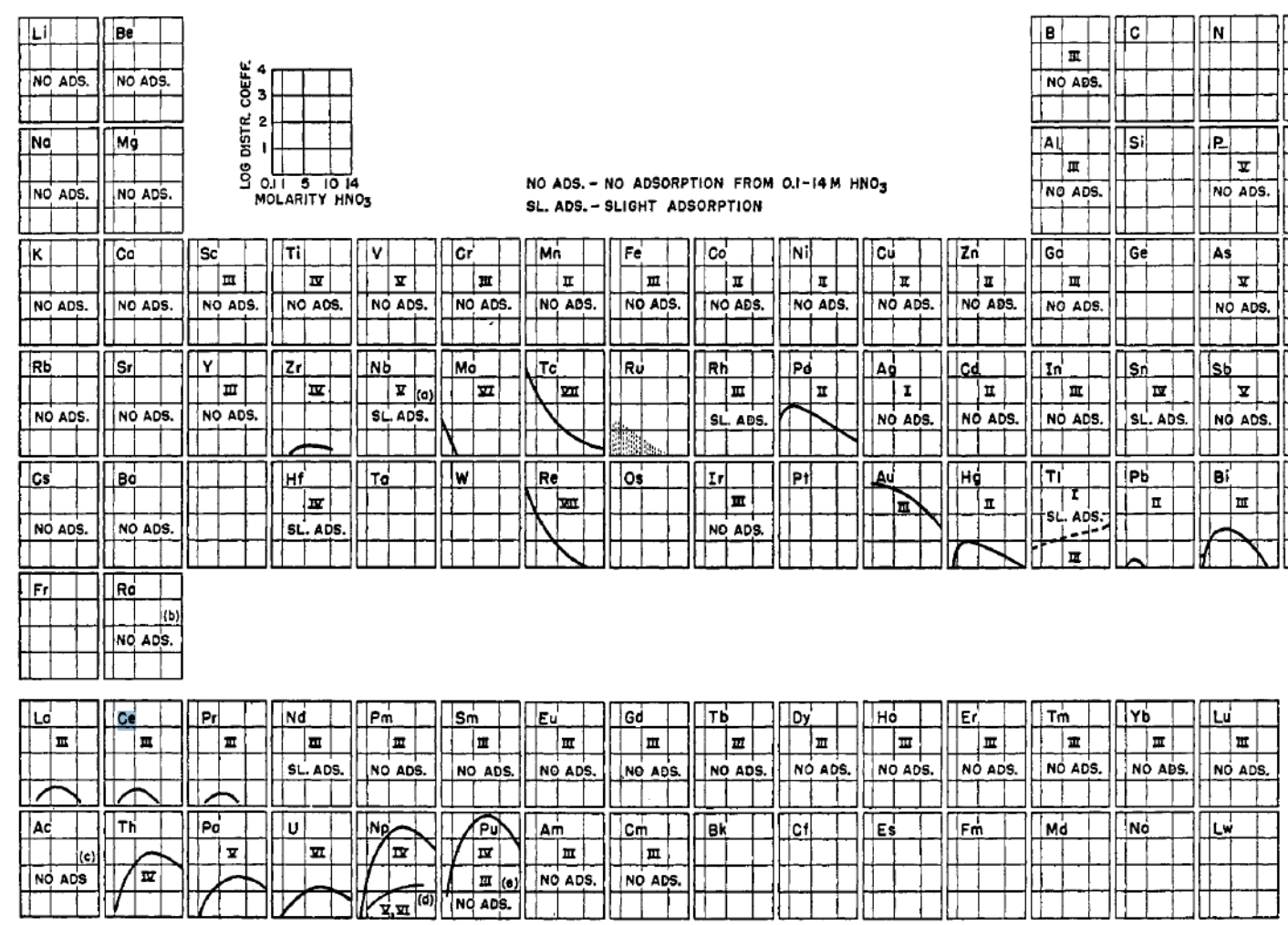

Figure 12 Distribution Coefficients on Anion Resin vs. Nitric Acid Molarity. Reprinted with permission from J.P. Faris, R.F. Buchanan, Analytical Chemistry, vol. 36, no. 6, pp. 1157-1158. Copyright 1964 American Chemical Society [33]

The cation resin NRW100x10 is expected to behave like the strong acid cation exchanger AG50Wx8 resin (Figure 13). In the neutral $\mathrm{pH}$ of the beam dump, the majority of elements are expected to bind to the cation resin due to their tendency to form cations in solution, with the most positively charged ions binding first. This work focused upon the elements captured in the Purolite cation resin. 


\begin{tabular}{|c|c|c|c|c|c|c|c|}
\hline Cation & $0.1 N$ & $0.2 \mathrm{~N}$ & $0.5 N$ & $1.0 \mathrm{~N}$ & $2.0 \mathrm{~N}$ & $3.0 \mathrm{~N}$ & $4.0 \mathrm{~N}$ \\
\hline $\operatorname{Zr}(I V)^{a}$ & $>10^{4}$ & $>10^{4}$ & $>10^{4}$ & 6500 & 652 & 112 & 30.7 \\
\hline $\mathrm{Hf}(\mathrm{IV})$ & $>10^{4}$ & $>10^{4}$ & $>10^{4}$ & 2400 & 166 & 61 & 20.8 \\
\hline Th(IV) & $>10^{4}$ & $>10^{4}$ & $>10^{4}$ & 1180 & 123 & 43.0 & 24.8 \\
\hline $\mathrm{La}(\text { III })^{a}$ & $>10^{4}$ & $>10^{4}$ & 1870 & 267 & 47.3 & 17.1 & 9.1 \\
\hline $\mathrm{Ce}(\mathrm{III})^{a}$ & $>10^{4}$ & $>10^{4}$ & 1840 & 246 & 44.2 & 15.4 & 8.2 \\
\hline $\mathrm{Yb}(\mathrm{III})$ & $>10^{4}$ & $>10^{4}$ & 1150 & 193 & 41.3 & 16.0 & 9.0 \\
\hline $\operatorname{Er}(\mathrm{III})$ & $>10^{4}$ & $>10^{4}$ & 1100 & 182 & 38.2 & 14.9 & 8.0 \\
\hline $\mathrm{Y}(\mathrm{III})^{a}$ & $>10^{4}$ & $>10^{4}$ & 1020 & 174 & $3 \tilde{5} .8$ & 13.9 & 10.0 \\
\hline $\mathrm{Sm}$ (III) & $>10^{4}$ & $>10^{4}$ & 1000 & 168 & 29.8 & 10.9 & 7.2 \\
\hline Gd(III) & $>10^{4}$ & $>10^{4}$ & 1000 & 167 & 29.2 & 10.8 & 6.9 \\
\hline $\operatorname{In}(\mathrm{III})$ & $>10^{4}$ & $>10^{4}$ & 680 & 118 & 23.0 & 10.1 & 5.8 \\
\hline $\mathrm{Sc}(\mathrm{III})$ & $>10^{4}$ & 3300 & 500 & 116 & 23.3 & 11.6 & 7.6 \\
\hline $\mathrm{Cr}$ (III) & 5100 & 1620 & 418 & 1.12 & 27.8 & 19.2 & 10.9 \\
\hline $\mathrm{Hg}(\mathbf{I})^{a}$ & $>10^{4}$ & 7600 & 640 & 94 & 33.5 & 19.2 & 13.6 \\
\hline $\mathrm{Ga}(\mathrm{III})$ & $>10^{4}$ & 4200 & 445 & 94 & 20.0 & 9.0 & 5.8 \\
\hline $\mathrm{Al}(\mathrm{III})^{a}$ & $>10^{4}$ & 3900 & 392 & 79 & 16.5 & 8.0 & 5.4 \\
\hline $\mathrm{Fe}(\text { III })^{\circ}$ & $>10^{4}$ & 4100 & 362 & 74 & 14.3 & 6.2 & 3.1 \\
\hline $\mathrm{Ba}(\mathrm{II})^{4}$ & 5000 & 1560 & 271 & 68 & 13.0 & 6.0 & 3.6 \\
\hline $\operatorname{Sr}(\mathrm{II})^{a}$ & 3100 & 775 & 146 & 39.2 & 8.8 & 6.1 & 4.7 \\
\hline $\mathrm{Pb}$ (II $)^{a}$ & $>10^{4}$ & 1420 & 183 & 35.7 & 8.5 & 5.5 & 4.5 \\
\hline $\mathrm{Ca}(\mathrm{II})^{a}$ & 1450 & 480 & 113 & 35.3 & 9.7 & 4.3 & 1.8 \\
\hline $\mathrm{Cd}(\mathrm{II})^{a}$ & 1500 & 392 & 91 & 32.8 & 10.8 & 6.8 & 3.4 \\
\hline $\mathrm{Co}(\mathrm{II})^{a}$ & 1260 & 392 & 91 & 28.8 & 10.1 & 6.1 & 4.7 \\
\hline $\operatorname{Mn}(I I)^{a}$ & 1240 & 389 & 89 & 28.4 & 11.4 & 7.1 & 3.0 \\
\hline $\mathrm{Ni}(\mathrm{II})^{a}$ & 1140 & 384 & 91 & 28.1 & 10.3 & 8.6 & 7.3 \\
\hline $\mathrm{Cu}(\mathrm{II})^{4}$ & 1080 & 356 & 84 & 26.8 & 8.6 & 4.8 & 3.1 \\
\hline $\mathrm{Zn}(\mathrm{II})^{a}$ & 1020 & 352 & 83 & 25.2 & 7.5 & 4.6 & 3.6 \\
\hline $\mathrm{Bi}(\mathrm{III})$ & 893 & 305 & 79 & 25.0 & 7.9 & 3.7 & 3.0 \\
\hline $\mathrm{U}(\mathrm{VI})$ & 659 & 262 & 69 & 24.4 & 10.7 & 7.4 & 6.6 \\
\hline $\operatorname{Mg}(\mathrm{II})^{a}$ & 794 & 295 & 71 & 22.9 & 9.1 & 5.8 & 4.1 \\
\hline $\mathrm{Tl}(\mathrm{I})^{a}$ & 173 & 91 & 41.0 & 22.3 & 9.9 & 5.8 & 3.3 \\
\hline $\mathrm{Ag}(\mathrm{I})^{a}$ & 156 & 86 & 36.0 & 18.1 & 7.9 & 5.4 & 4.0 \\
\hline $\mathrm{Hg}(\mathrm{II})^{a}$ & 4700 & 1090 & 121 & 16.9 & 5.9 & 3.9 & 2.8 \\
\hline $\mathrm{Cs}(\mathrm{I})$ & 148 & 81 & 34.8 & 16.8 & 7.6 & 4.7 & 3.4 \\
\hline $\mathrm{Be}(\mathrm{II})^{a}$ & 553 & 183 & 52 & 14.8 & 6.6 & 4.5 & 3.1 \\
\hline $\mathrm{Ti}(\mathrm{IV})^{a}$ & 1410 & 461 & 71 & 14.6 & 6.5 & 4.5 & 3.4 \\
\hline $\mathrm{V}(\mathrm{IV})$ & 495 & 157 & 35.6 & 14.0 & 4.7 & 3.0 & 2.5 \\
\hline $\mathrm{Rb}(\mathrm{I})$ & 118 & 68 & 29.1 & 13.4 & 6.6 & 4.1 & 2.9 \\
\hline $\mathrm{K}(\mathbf{I})$ & 99 & 59 & 26.2 & 11.4 & 5.7 & 3.5 & 2.6 \\
\hline $\mathrm{Te}\left(\mathrm{IV}^{-}\right)^{b}$ & 40.3 & 19.7 & 8.5 & 5.0 & 2.4 & 0.6 & 0.2 \\
\hline $\mathrm{Pd}(\mathrm{II})$ & 97 & 62 & 23.5 & 9.1 & 3.4 & 2.7 & 2.5 \\
\hline $\mathrm{Rh}$ (III) & 78 & 44.7 & 19.5 & 7.8 & 4.1 & 2.1 & 1.0 \\
\hline $\mathrm{Na}(\mathrm{I})$ & 54 & 29.4 & 12.7 & 6.3 & 3.4 & 2.0 & 1.3 \\
\hline $\mathrm{Li}(\mathrm{I})$ & 33.1 & 18.6 & 8.0 & 3.9 & 2.6 & 1.7 & 1.1 \\
\hline$V(V)$ & 20.0 & 10.9 & 4.9 & 2.0 & 1.2 & 0.8 & 0.5 \\
\hline $\mathrm{Mo}(\mathrm{VI})$ & Ppt. & 5.2 & 2.9 & 1.6 & 1.0 & 0.8 & 0.6 \\
\hline $\mathrm{Nb}(\mathrm{V})$ & 11.6 & 6.3 & 0.9 & 0.2 & 0.1 & 0.1 & 0.1 \\
\hline Se(IV) & $<0.5$ & $<0.5$ & $<0.5$ & $<0.5$ & $<0.5$ & $<0.5$ & $<0.5$ \\
\hline $\mathrm{As}$ (III) & $<0.1$ & $<0.1$ & $<0.1$ & $<0.1$ & $<0.1$ & $<0.1$ & $<0.1$ \\
\hline
\end{tabular}

Figure 13 Distribution Coefficients on Cation Resin with Nitric Acid

Reprinted with permission from F. Strelow et al., Analytical Chemistry, vol. 37, pp. 106-111. Copyright 1965 American Chemical Society [25]

\subsection{Materials and Methods}

All materials and reagents were used as received unless otherwise stated. All water used was $18 \mathrm{M} \Omega$ grade water. Purolite NRW3460 mixed-bed resin, Purolite NRW600 anion resin, and Purolite NRW100x10 cation resin were obtained from Purolite, Bala Cynwyd, PA. Metal free centrifuge tubes were obtained from Labcon. Glass Econo- 
Column chromatography columns $(2.5 \times 50 \mathrm{~cm})$ and Chelex 100 resin $(100-200$ mesh, sodium form) were obtained from Bio-Rad. Single element ICP standards were obtained from High Purity Standards. Nitric acid (69\%, Trace Metal Grade), hydrochloric acid (34\%, Trace Metal Grade), sodium chloride (A.C.S. Grade), 0.45 micron GE Healthcare Whatman nylon membrane filters, and ammonium hydroxide (21\%, Optima grade) were obtained from ThermoFisher Scientific. 2-Hydroxyisobutyric acid (HIBA, 99\%) was obtained from Alfa Aesar. Eichrom $2 \mathrm{~mL}$ RE and DGA cartridges were obtained from Eichrom Technologies. ${ }^{177} \mathrm{LuCl}_{3}$ was obtained from the University of Missouri Research Reactor.

Elemental analysis was performed at the University of Missouri Research Reactor on a PerkinElmer NexION 300X ICP-MS operated in KED (Kinetic Energy Discrimination) mode with a helium flow of $3.5 \mathrm{~mL} / \mathrm{min}$. Each isotope was acquired as 5 replicates of 10 sweeps, with $50 \mathrm{~ms}$ dwell time per sweep. Internal standards In and $\mathrm{Tl}$ were used to normalize data and account for instrument drift. Standards were prepared from dilutions of commercial High Purity Standards multi-element stock solutions.

Radiotracers were evaluated at the University of Missouri Research Reactor on a $23 \%$ relative efficiency high purity germanium detector (Canberra Model GC2018S, coaxial p-type crystal), geometry calibrated with a NIST-traceable mixed-gamma standard. Samples were counted for 10 min. with dead times below 10\%, and the software for data acquisition and analysis was Canberra Genie PROcount 2000 V3.3.

For the cation exchange experiments, glass Econo-Column Chromatography Columns with $25 \mathrm{~mm}$ internal diameter were filled with approximately $20 \mathrm{~g}$ of wet cation-exchange resin Purolite NRW100x10 and conditioned by flowing $500 \mathrm{~mL}$ of $6 \mathrm{M}$ 
$\mathrm{HNO}_{3}$ followed by $500 \mathrm{~mL}$ of pure water through the column. The column was stored in 0.05 $\mathrm{M} \mathrm{HNO}_{3}$ when not in use. After each column elution experiment, the column was washed with $500 \mathrm{~mL}$ of $6 \mathrm{M} \mathrm{HNO}_{3}$ and $500 \mathrm{~mL}$ of deionized water, and stored in $0.05 \mathrm{M}$ $\mathrm{HNO}_{3}$. Column flow rates were maintained with a Masterflex peristaltic pump 7-200 rpm, equipped with an easy load II pumphead.

For the HIBA $K_{d}$ experiments, 0.25 grams of Purolite NRW100x10 resin was weighed into a scintillation vial and dosed with 0.01 meq of $\mathrm{La}, \mathrm{Gd}$, and $\mathrm{Yb}$. $2.5 \mathrm{~mL}$ of HIBA solution (various concentrations and $\mathrm{pH}$ values) was added to the scintillation vial and shaken at room temperature for three hours. After settling, the HIBA solution was analyzed by ICP-MS to determine percent sorbed onto the resin and $\mathrm{K}_{\mathrm{d}}$.

For the strong acid recirculation experiments, $8 \mathrm{M} \mathrm{HNO}_{3}$ acid solution was recirculated through a $20 \mathrm{~g}$ column of Purolite NRW100x10 cation resin in a $2.5 \times 50 \mathrm{~cm}$ glass Econo-column column. The recirculation rate was regulated with a peristaltic pump, using tubing connected to the top and bottom of the column at a flowrate of 10 $\mathrm{mL} / \mathrm{min}$. The activity of $10 \mathrm{~mL}$ fractions was measured by HPGe gamma-ray spectrometer over various time points to determine the time required to establish equilibrium.

For the strong acid recirculation with Eichrom RE resin experiments, 1 meq of lu and 1 meq each of Be, Na, Ti, Sc, Fe, Co, Cu, Y, Zr, Ba, La, and Gd were added to a $20 \mathrm{~g}$ column of Purolite NRW100x10 cation resin (in a 2.5x50 cm glass Econo-column) in 59 $\mathrm{mL}$ of $0.32 \mathrm{M} \mathrm{HNO}_{3}$ and rinsed with $15 \mathrm{~mL}$ of $0.05 \mathrm{M} \mathrm{HNO}_{3}$. Forty milliliters of $12 \mathrm{M}$ $\mathrm{HNO}_{3}$ was added to the top of the column (creating a total of $60 \mathrm{~mL}$ of $8 \mathrm{M} \mathrm{HNO}_{3}$ ) and recirculated through the column using a peristaltic pump with tubing connected to the top 
and bottom of the column at a flowrate of $10 \mathrm{~mL} / \mathrm{min}$. Every $60 \mathrm{~min}$., two samples were taken for testing. First, $30 \mathrm{~mL}$ of column solution were passed through Eichrom RE column 1, and then returned to the recirculating column. Second, another $30 \mathrm{~mL}$ of column solution were passed through Eichrom RE column 2, and then returned to the recirculating column. Each Eichrom RE column was then eluted with $10 \mathrm{~mL}$ of $0.05 \mathrm{M}$ $\mathrm{HCl}$ and the resin cartridge reused for the following sample point. The amount extracted by each column was measured by ICP-MS and added together, and this process was continued for a total of 6 iterations.

For the strong acid recirculation with Eichrom DGA resin experiments, the expected concentration of select competing ions were determined to prepare a beam dump surrogate solution. The surrogate solution was prepared by mixing $20 \mu \mathrm{g} \mathrm{Be}, 20$ $\mu \mathrm{g} \mathrm{Na}, 20 \mu \mathrm{g}$ Ti, $20 \mu \mathrm{g} \mathrm{Sc}, 40 \mu \mathrm{g}$ Fe, $20 \mu \mathrm{g}$ Co, $30 \mu \mathrm{g} \mathrm{Cu}, 200 \mu \mathrm{g} \mathrm{Y}, 900 \mu \mathrm{g}$ Zr, $500 \mu \mathrm{g}$ $\mathrm{Ba}, 200 \mu \mathrm{g} \mathrm{La}, 300 \mu \mathrm{g} \mathrm{Gd}$, and $100 \mu \mathrm{g} \mathrm{Lu}$ in $10 \mathrm{~mL}$ of $0.05 \mathrm{M} \mathrm{HNO}_{3}$. The surrogate solution was added to a $20 \mathrm{~g}$ column of Purolite NRW 100x 10 cation resin (in a $2.5 \times 50$ cm glass Econo-column) and rinsed with $10 \mathrm{~mL}$ of $0.05 \mathrm{M} \mathrm{HNO}_{3}$. Forty milliliters of 9 $\mathrm{M} \mathrm{HNO}_{3}$ was added to the top of the column (creating a total of $60 \mathrm{~mL}$ of $6 \mathrm{M} \mathrm{HNO}_{3}$ ) and recirculated through the column using a peristaltic pump with tubing connected to the top and bottom of the column at a flowrate of $10 \mathrm{~mL} / \mathrm{min}$. After $60 \mathrm{~min}$., the flowrate was slowed to $2 \mathrm{~mL} / \mathrm{min}$ and the Eichrom DGA column was installed inline. The $6 \mathrm{M}$ $\mathrm{HNO}_{3}$ was allowed to circulate through both the cation column and the Eichrom DGA cartridge for one hour. The DGA cartridge was disconnected and rinsed with $8 \mathrm{~mL}$ of clean $6 \mathrm{M} \mathrm{HNO}_{3}$, which was retained for ICP-MS analysis. The DGA column was then eluted with $10 \mathrm{~mL}$ of $0.05 \mathrm{M} \mathrm{HCl}$, which was also retained for ICP-MS analysis, and then 
the cartridge was reinstalled in the circulating loop for two additional rinses and elutions. This process was repeated for a total of 3 iterations, each sample point consisting of a one-hour circulation through the Purolite resin and DGA cartridge. The elemental compositions of the 8 and $10 \mathrm{~mL}$ fractions were analyzed by ICP-MS.

\subsection{Mixed-Bed Resin Separation Experiments}

The initial experiments of the batch collection testing focused upon separating the anion and cation component resins of Purolite NRW3460 using a NaCl salt solution. An experimental column was prepared with approximately 25 grams of mixed-bed resin (Purolite NRW3460, as received) in a $2.5 \times 50 \mathrm{~cm}$ glass Econo-column. In order to separate the mixed-bed resin into the component cation and anion resins, the column was backflushed with $5 \% \mathrm{NaCl}$ at a rate of $500 \mathrm{~mL} / \mathrm{min}$ with a peristaltic pump. The addition of the sodium chloride solution caused an almost immediate density separation of the two resin layers (Figure 14). After approximately twelve minutes, the anion resin had been expelled from the top of the column and captured in a resin trap. 

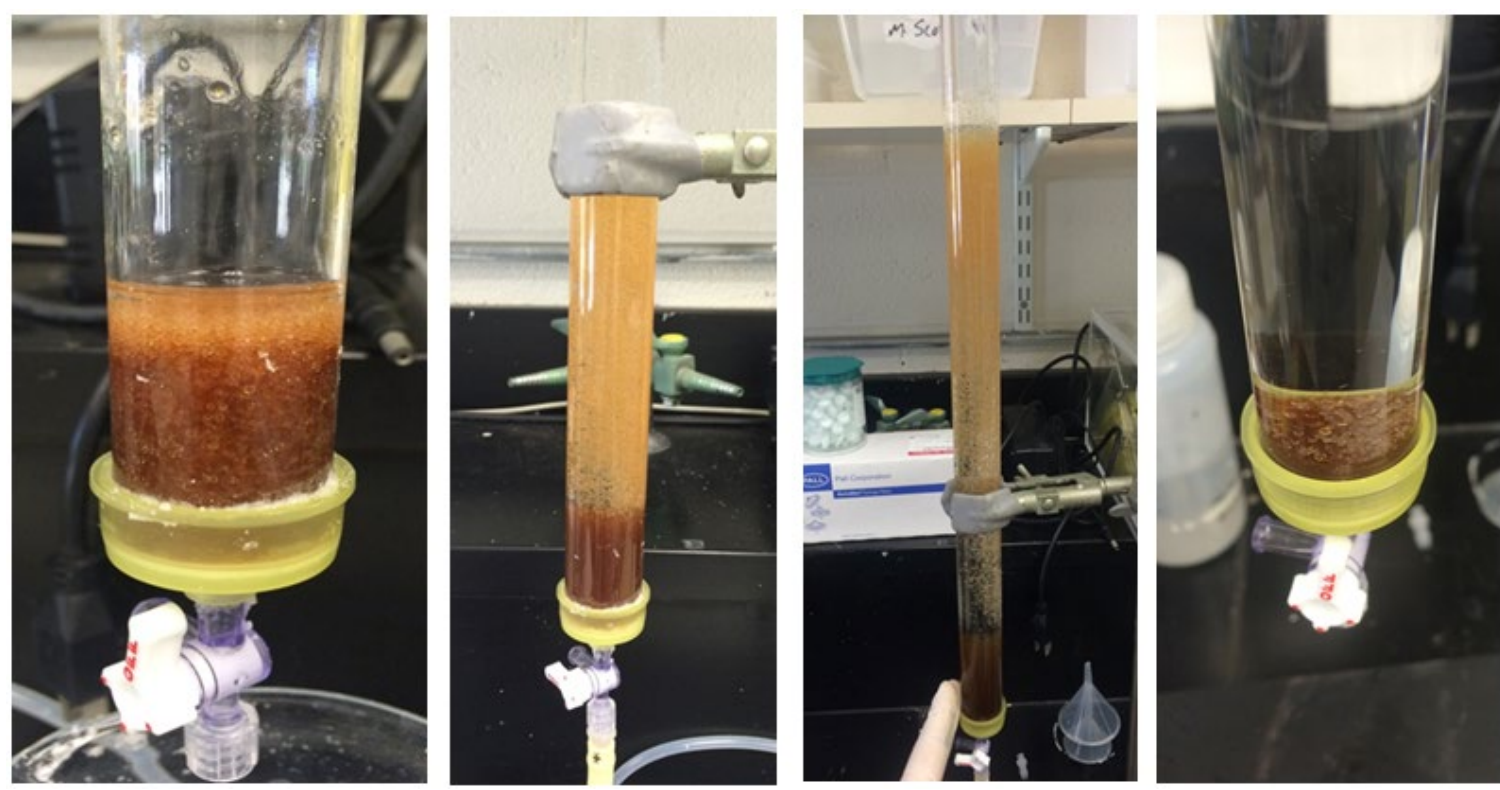

Figure 14 Mixed-bed Resin Separation with NaCI Solution

\subsection{Cation Column - Acid Gradient Elution Experiments}

Upon successful demonstration of the separation of the two Purolite NRW3460 component resins, our work focused upon characterizing the cation portion of the resin. Both the cation resin (Purolite NRW100x10) and the anion resin (Purolite NRW600) are readily available from the manufacturer, but the cation resin is the binding site of many nuclides of interest at MURR, so this work focused upon characterizing the cation resin only. Because extensive research already exists for AG-50W sulfonate polystyrene cation resin, experimental elution profiles from Purolite NRW100x10 were obtained for comparison with the literature [25].

One hundred grams of Purolite NRW100x10 cation resin was washed with deionized water and dried overnight. 21 grams of dried resin was wetted with deionized water and transferred to a $2.5 \times 50 \mathrm{~cm}$ glass Econo-column. The column was washed with $500 \mathrm{~mL}$ of $6 \mathrm{M} \mathrm{HNO}_{3}$, and rinsed with deionized water until the eluant was $\mathrm{pH}$ neutral. According to the specification sheet, this resin has an exchange capacity of 2 equivalents 
per liter, and a density of 1.22 grams per milliliter, which gives this 21 grams of resin the exchange capacity of approximately 34 meqs. After each column elution experiment, the column was washed with $500 \mathrm{~mL}$ of $6 \mathrm{M} \mathrm{HNO}_{3}$ and $500 \mathrm{~mL}$ of deionized water, and stored in $0.05 \mathrm{M} \mathrm{HNO}_{3}$.

The elution behavior of Purolite NRW100x10 was compared to AG50Wx8 from the work of Strelow [25] who used 1 milliequivalent of $\mathrm{Na}(\mathrm{I}), \mathrm{Be}(\mathrm{II}), \mathrm{Ba}(\mathrm{II}), \mathrm{Y}(\mathrm{III})$ and $\mathrm{Zr}(\mathrm{IV})$ in $0.2 \mathrm{M} \mathrm{HNO}_{3}$ loaded onto a $2.5 \times 50 \mathrm{~cm}$ glass Econo-column filled with 20 grams of AG50Wx8 cation resin. A flowrate of $3 \mathrm{~mL} / \mathrm{min}$ was used in all of their elutions except for $\mathrm{Y}$, which used a flowrate of $1.3 \mathrm{~mL} / \mathrm{min}$. Their elution profile consisted of $350 \mathrm{~mL}$ of $0.6 \mathrm{M} \mathrm{HNO}_{3}, 350 \mathrm{~mL}$ of $1.2 \mathrm{M} \mathrm{HNO}_{3}, 350 \mathrm{~mL}$ of $2.0 \mathrm{M} \mathrm{HNO}_{3}, 300 \mathrm{~mL} 3.0 \mathrm{M} \mathrm{HNO}_{3}$, and $350 \mathrm{~mL}$ of $5.0 \mathrm{M} \mathrm{HCl}$. Our experiment omitted the $\mathrm{Zr}(\mathrm{IV})$ and the $5.0 \mathrm{M} \mathrm{HCl}$ elution, but otherwise used the same flowrates and acid gradients. A solution containing 1 milliequivalent of $\mathrm{Na}(\mathrm{I}), \mathrm{Be}(\mathrm{II}), \mathrm{Ba}(\mathrm{II})$, and $\mathrm{Y}$ (III) in approximately $125 \mathrm{~mL}$ of $2 \% \mathrm{HNO}_{3}$ was loaded onto a 21-gram ( $20 \mathrm{~mL})$ Purolite NRW100x10 cation resin column and washed with approximately $10 \mathrm{~mL}$ of deionized water. Fifty-milliliter fractions were collected and analyzed for metals content by ICP-MS. The elution profile obtained from Purolite NRW100x10 is compared to that of AG50x8 in Figure 15. 


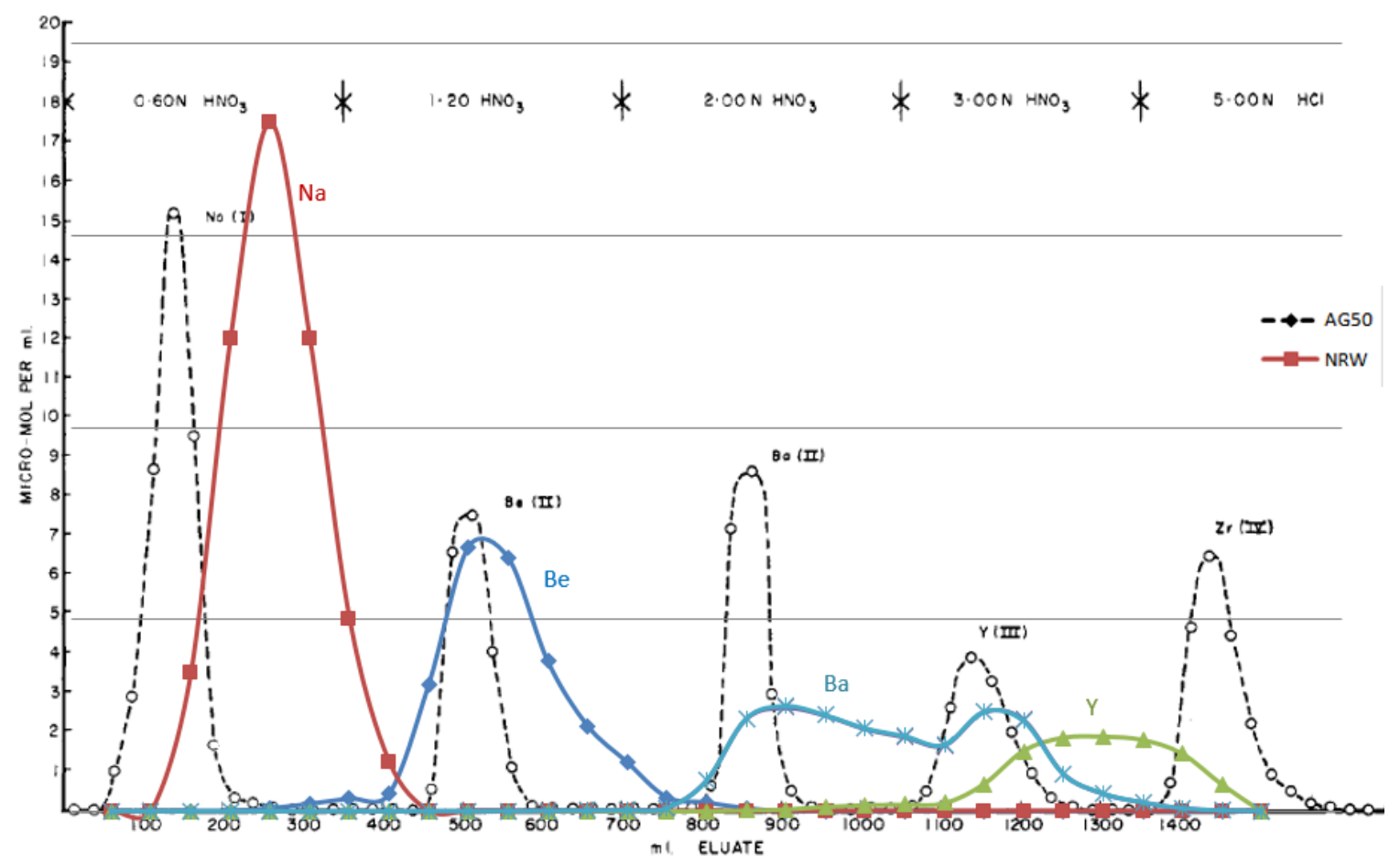

Figure 15 Elution Profile Comparison AG50 vs NRW100x10 (n=1).

Adapted with permission from F. Strelow et al., Analytical Chemistry, vol. 37, pp. 106-111. Copyright 1965 American Chemical Society

A second experiment was performed to compare the elution of lanthanides from Purolite NRW100x10 to Dowex 50Wx8. Rucandio [26] published the elution profile of geological silicate materials showing the elution of lanthanides beginning at $3 \mathrm{M} \mathrm{HNO}_{3}$ acid concentration. The original study used 25 grams of Dowex 50Wx 8 resin loaded with $100 \mathrm{mg} / \mathrm{L} \mathrm{Ba}$ and $1 \mathrm{mg} / \mathrm{L} \mathrm{REEs}$ and a flowrate of $1.5 \mathrm{~mL} / \mathrm{min}$. Two elution profiles are shown below (Figure 16): the first used $200 \mathrm{~mL}$ of $2 \mathrm{M} \mathrm{HNO}_{3}, 100 \mathrm{~mL}$ of $6 \mathrm{M} \mathrm{HNO}_{3}$, and $100 \mathrm{~mL}$ of $8 \mathrm{M} \mathrm{HNO}_{3}$ and the second used $200 \mathrm{~mL}$ of $3 \mathrm{M} \mathrm{HNO}_{3}, 100 \mathrm{~mL}$ of $6 \mathrm{M} \mathrm{HNO}_{3}$, and $100 \mathrm{~mL}$ of $8 \mathrm{M} \mathrm{HNO}_{3}$. 

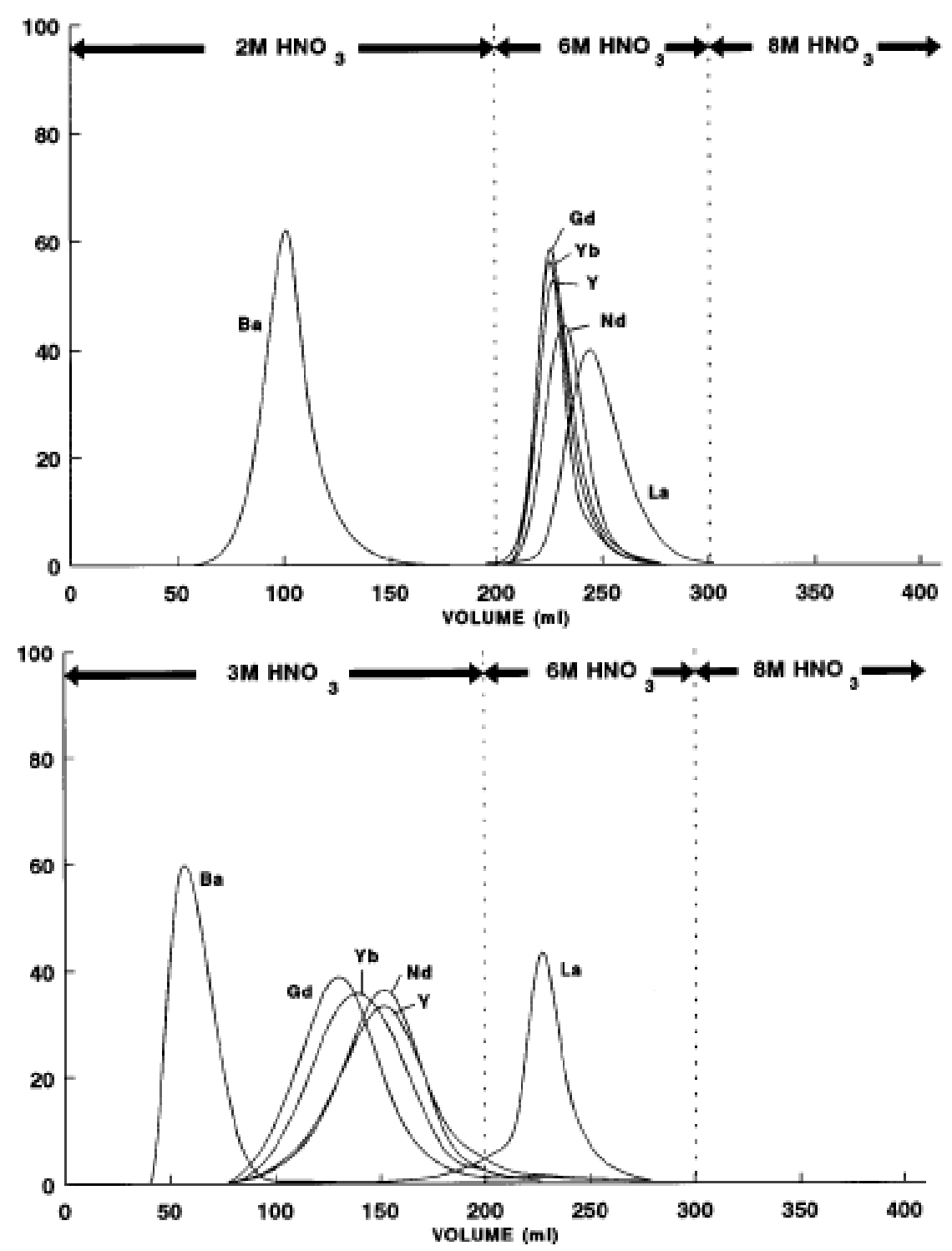

Figure 16 Elution of Lanthanides from Dowex $50 \mathrm{Wx8}$ with Increasing $\mathrm{HNO}_{3}$. Reprinted by permission from Springer Nature Customer Service Centre GmbH: Springer, J. Anal. Chem., M. Rucandio, 1997.

In our experiment, for comparison with Rucandio, we prepared a $1 \mathrm{meq}$ solution of $\mathrm{Be}, \mathrm{Ba}, \mathrm{Na}, \mathrm{Y}, \mathrm{La}, \mathrm{Gd}$, and $\mathrm{Yb}$ diluted in approximately $40 \mathrm{~mL}$ of $0.32 \mathrm{M} \mathrm{HNO}_{3}$. This solution was loaded onto 21 grams of Purolite NRW100x10 cation resin in a $2.5 \times 50 \mathrm{~cm}$ glass Econo-column by pouring it through the resin and washing with approximately 10 $\mathrm{mL}$ of deionized water. The column was eluted at the same flowrate as the literature (1.5 $\mathrm{mL} / \mathrm{min}$ ), and $50 \mathrm{~mL}$ fractions were collected for metals analysis by ICP-MS. The first 
elution was performed with $400 \mathrm{~mL}$ of $2 \mathrm{M} \mathrm{HNO}_{3}, 200 \mathrm{~mL}$ of $3 \mathrm{M} \mathrm{HNO}_{3}$, and $200 \mathrm{~mL}$ of $7 \mathrm{M} \mathrm{HNO}_{3}$ (Figure 17 top). A second experiment was performed with the same loading conditions and flowrate, and the following elution scheme: $350 \mathrm{~mL}$ of $2 \mathrm{M} \mathrm{HNO}_{3}$ and 200 $\mathrm{mL}$ of $6 \mathrm{M} \mathrm{HNO}_{3}$ (Figure 17 bottom). The relative error for both experiments $(\mathrm{n}=1)$ averaged $\pm 0.04 \mathrm{mg}$ and is not visible on the plots below.
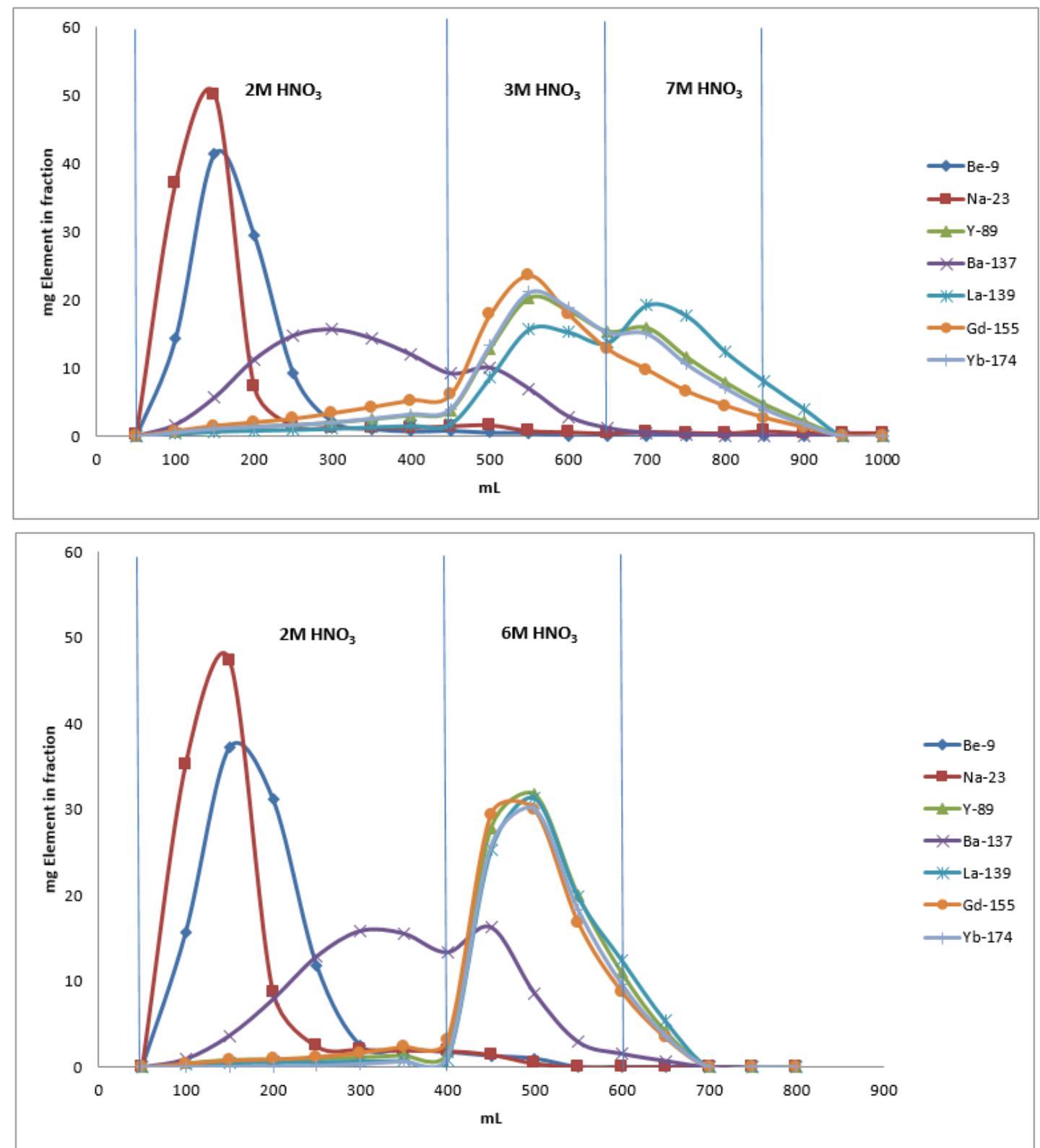

Figure 17 Elution of Lanthanides from Purolite NRW100x10 with Increasing $\mathrm{HNO}_{3}$ $(\mathbf{n}=1)$ 
Comparison of the elution profiles for Bio-Rad AG50Wx8 and Purolite NRW100x10 illustrate the similarity of the two resins. The acid gradient achieved separation of the component elements in both resin systems, with the exception of the peak doublet shown for $\mathrm{Ba}$ (Figure 15) in the Purolite resin, which is likely due to stopping and restarting the acid gradient flow at that timepoint. This data suggests that historical $\mathrm{K}_{\mathrm{d}}$ and elution profile values for Bio-Rad AG50Wx8 would also be applicable to Purolite NRW100x10. It is noteworthy that the peaks appear to be broader in the Purolite resin and may require that a slower flow rate be employed with NRW100x10 to achieve similar resolution.

Comparison of the elution profiles for Dowex 50Wx8 and Purolite NRW100x10 demonstrates a similarity in elution trends for the two resins. In both resin systems, the lanthanides began to elute in $3 \mathrm{M} \mathrm{HNO}_{3}$ acid but could be eluted as a separate group in 6 $\mathrm{M} \mathrm{HNO}_{3}$. These results demonstrate that the Dowex 50Wx8 and the Purolite NRW100x10 resins are also similar. The Ba elution appeared to be better in the Dowex resin, but in both cases the lanthanides did not elute until the nitric acid reached a concentration of $3 \mathrm{~N}$. This data suggests that historical $\mathrm{K}_{\mathrm{d}}$ and elution profile values for Dowex 50Wx8 would also be applicable to Purolite NRW100x10.

A noteworthy conclusion that can be drawn from both experiments is the large volume of acid required for elution from the resin ( $\sim 10$ column volumes), rendering this method of recycling isotopes from FRIB ineffectual. Ten column volumes of elution volume would require the generation of 1000 gallons of radioactive acidic waste to elute the resin material from the FRIB beam dump. In addition, the concentration of most nuclides in this acidic waste would be in the part per trillion range, with the maximum 
concentration belonging to the stable ${ }^{238} \mathrm{U}$ beam at approximately $97 \mathrm{ppb}$ (after 6 months of operation).

\subsection{HIBA for Lanthanide Complexation}

In an effort to reduce the number of column volumes required for lanthanide elution from the cation resin, we investigated the work of Smith and Hoffman [27] suggesting that the lanthanides could be removed in approximately 2 column volumes from Dowex 50Wx4 through complexation with $0.5 \mathrm{M}$ alpha-hydroxyisobutyric acid (HIBA) at $\mathrm{pH}$ values of 4 or greater (Figure 18).

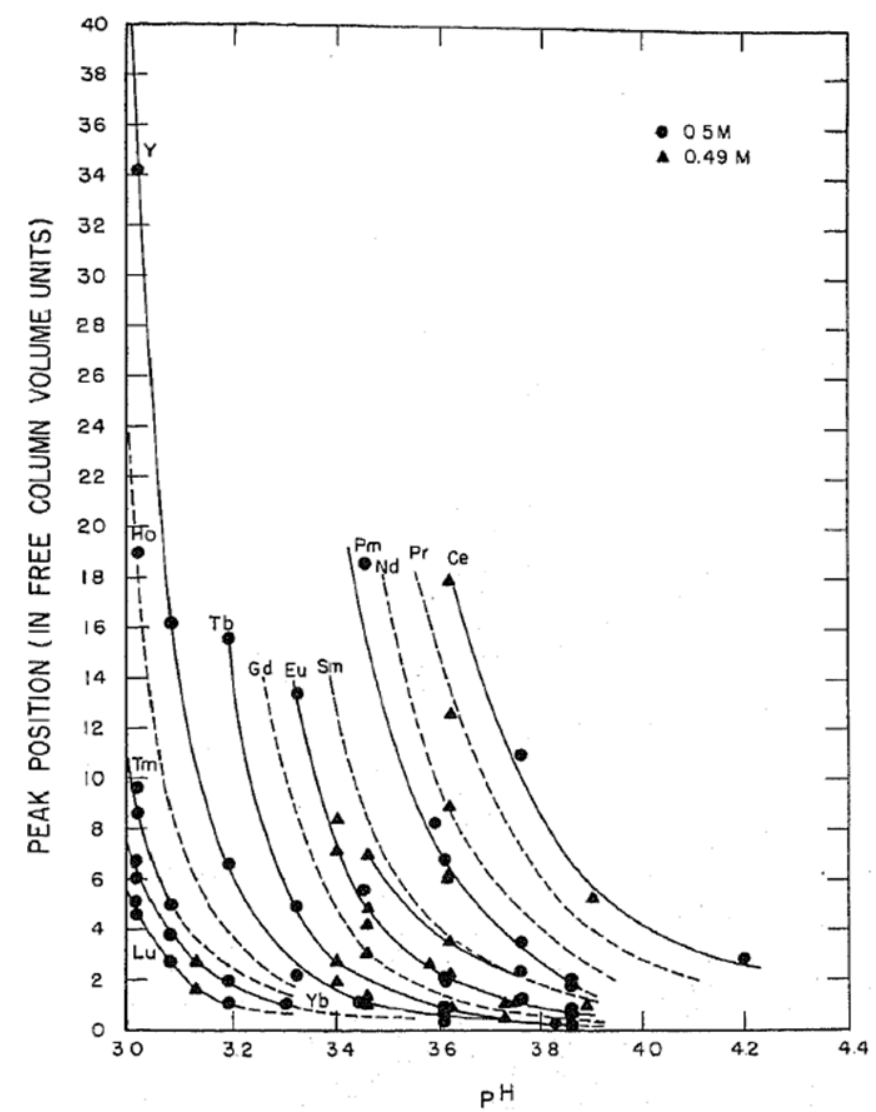

Figure 18 Column Volume Required for Elution from Dowex 50Wx4 vs. HIBA pH. Reprinted from J. Inorg. Nucl. Chem., vol. 357, H. Smith and D. Hoffman, Ion-Exchange Separations of Lanthanides and Actinides by Elution with Ammonium Alpha-Hydroxy-Isobutyrate, pp. 243-247, 1956, with permission from Elsevier. 
HIBA (Figure 19) can binds to lanthanide metals as a monodentate or bidentate ligand with an eight-coordinate geometry [34]. The eight coordination sites are taken up by oxygens: two from coordinated water molecules, two from bridging ligands, and four from chelating ligands (Figure 20).

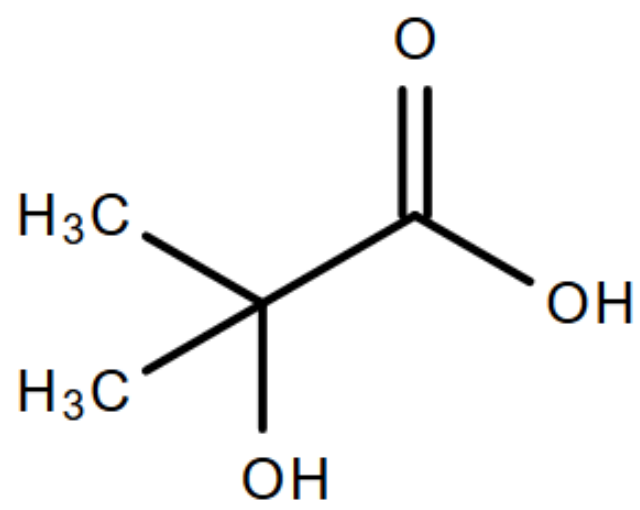

Figure 19 Structure of HIBA

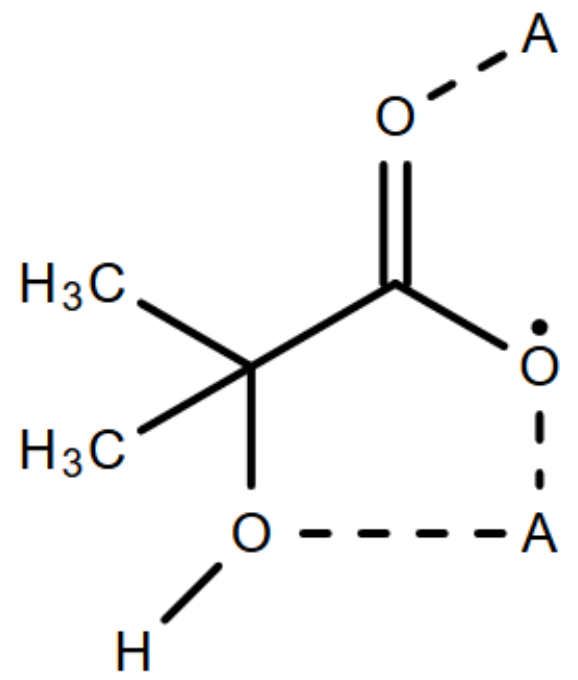

Figure 20 Oxygen Coordination Sites of HIBA [34] 
The overall structure of the Lanthanide:HIBA:Water complex is illustrated in Figure 21, where the carbon atoms are displayed as black, the oxygen atoms are red, and the hydrogen atoms are removed for clarity.

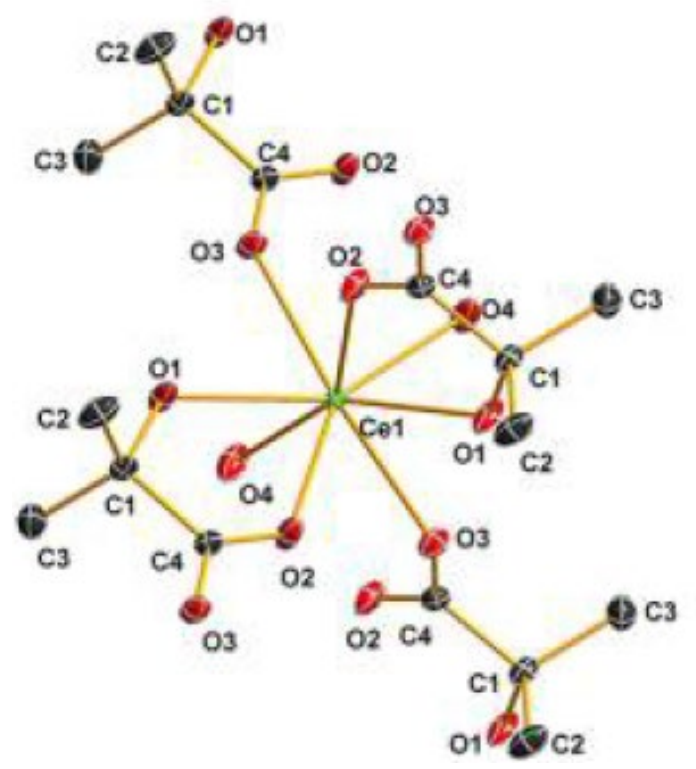

Figure 21 8-Coordinate Structure of Lanthanide:HIBA:Water Complex [34]

Reprinted with permission from X-Y.Chen et. al., Inorganic Chemistry, vol. 51, pp. 13254-13262. Copyright 2012 American Chemical Society.

\subsection{Cation Column - HIBA Elution Experiments}

To investigate the HIBA complexation approach for eluting lanthanides from Purolite resin, one meq each of $\mathrm{Ba}, \mathrm{Be}, \mathrm{Y}, \mathrm{Na}, \mathrm{La}, \mathrm{Gd}$, and $\mathrm{Yb}$ (the same metals used for previous resin characterization experiments) in $46 \mathrm{~mL}$ of $0.3 \mathrm{M} \mathrm{HNO}_{3}$ was loaded onto 21 grams of Purolite NRW100x10 cation resin in a $2.5 \times 50 \mathrm{~cm}$ glass Econo-column and the column was eluted at a flowrate of $1.5 \mathrm{~mL} / \mathrm{min}$. The $0.5 \mathrm{M}$ HIBA solution was prepared and $10 \mathrm{~mL}$ of $50 \%$ Chelex resin in water was added to remove free metals from the HIBA. The solution was mixed and the Chelex resin removed by vacuum filtration through a 0.45 micron Whatman nylon membrane filter. The elution scheme used was $200 \mathrm{~mL}$ of $0.5 \mathrm{M}$ 
HIBA at $\mathrm{pH} 4.9,300 \mathrm{~mL}$ of $2 \mathrm{M} \mathrm{HNO}_{3}$, and $200 \mathrm{~mL}$ of $7 \mathrm{M} \mathrm{HNO}_{3}$ collected in $50 \mathrm{~mL}$ fractions for metals analysis by ICP-MS. The resulting elution profile is shown in Figure 22. The relative error on this experiment $(\mathrm{n}=1)$ averaged $\pm 0.04 \mathrm{mg}$ and is not visible on the plot below. The conclusion from this experiment is that $0.5 \mathrm{M}$ HIBA elution of lanthanides requires too many $(\sim 10)$ column volumes for use in recycling from the FRIB beam dump.

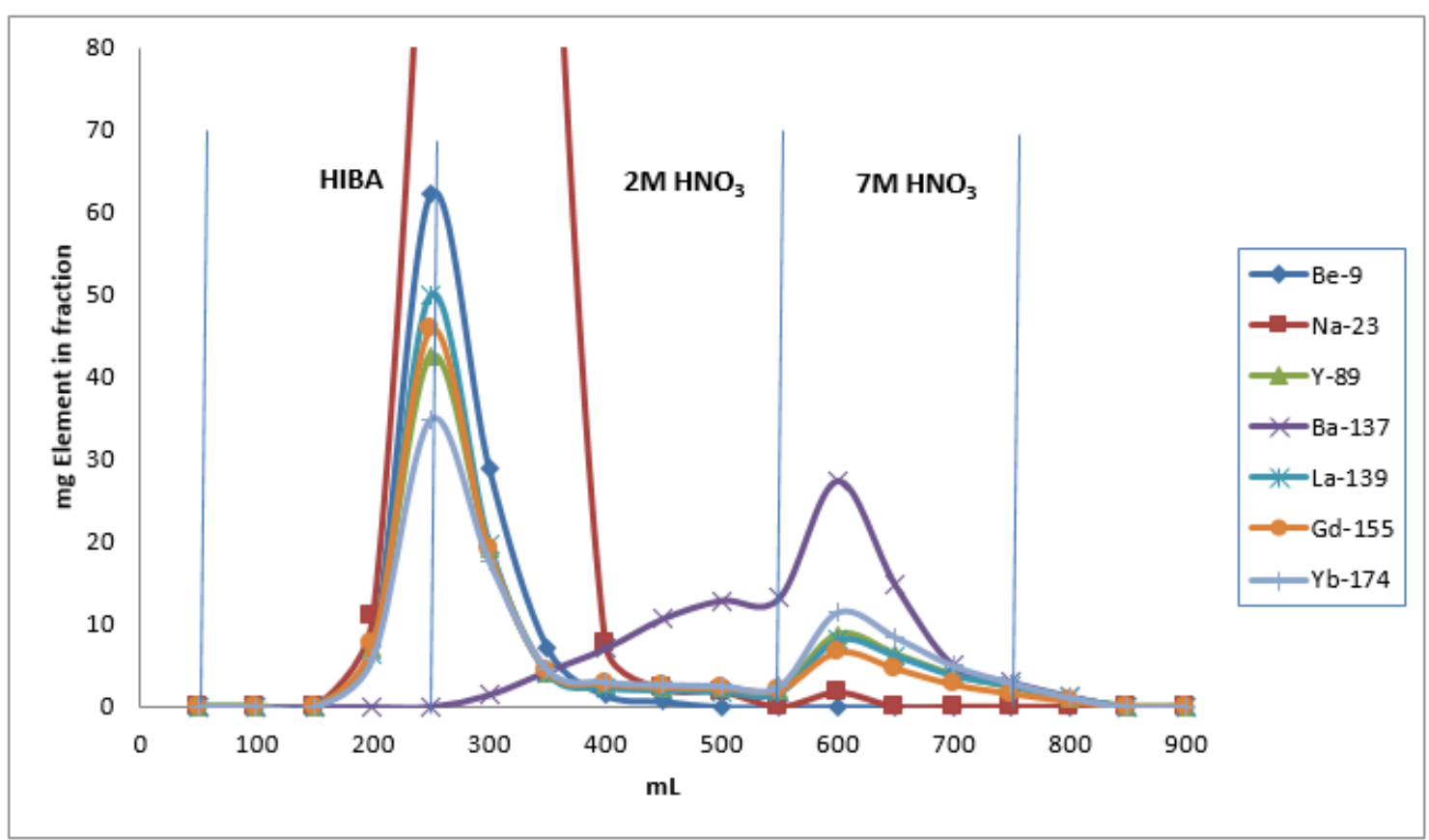

Figure 22 Lanthanide Elution from Purolite NRW100x10 with 0.5M HIBA pH 4.9 $(\mathbf{n}=1)$

In attempt to elute the lanthanide cations with a smaller volume, the HIBA concentration and $\mathrm{pH}$ of the HIBA solution were increased. One meq of $\mathrm{Ba}, \mathrm{Be}, \mathrm{Y}, \mathrm{Na}$, $\mathrm{La}, \mathrm{Gd}$, and $\mathrm{Yb}$ in $46 \mathrm{~mL}$ of $0.3 \mathrm{M} \mathrm{HNO}_{3}$ were loaded onto 21 grams of Purolite NRW100x10 cation resin in a $2.5 \times 50 \mathrm{~cm}$ glass Econo-column and the column was eluted at $1.5 \mathrm{~mL} / \mathrm{min}$. In this case, the $0.7 \mathrm{M}$ HIBA solution was not treated with Chelex resin to reduce the large amount of sodium introduced in the previous experiment. The elution 
scheme used was $200 \mathrm{~mL}$ of $0.7 \mathrm{M} \mathrm{HIBA}$ at $\mathrm{pH}$, and $200 \mathrm{~mL}$ of $7 \mathrm{M} \mathrm{HNO}_{3}$ and $50 \mathrm{~mL}$ fractions were again collected for metals analysis by ICP-MS. The resulting elution profile is shown in Figure 23. The relative error on this experiment $(\mathrm{n}=1)$ averaged $\pm 0.04 \mathrm{mg}$ and is not visible on the plot below.

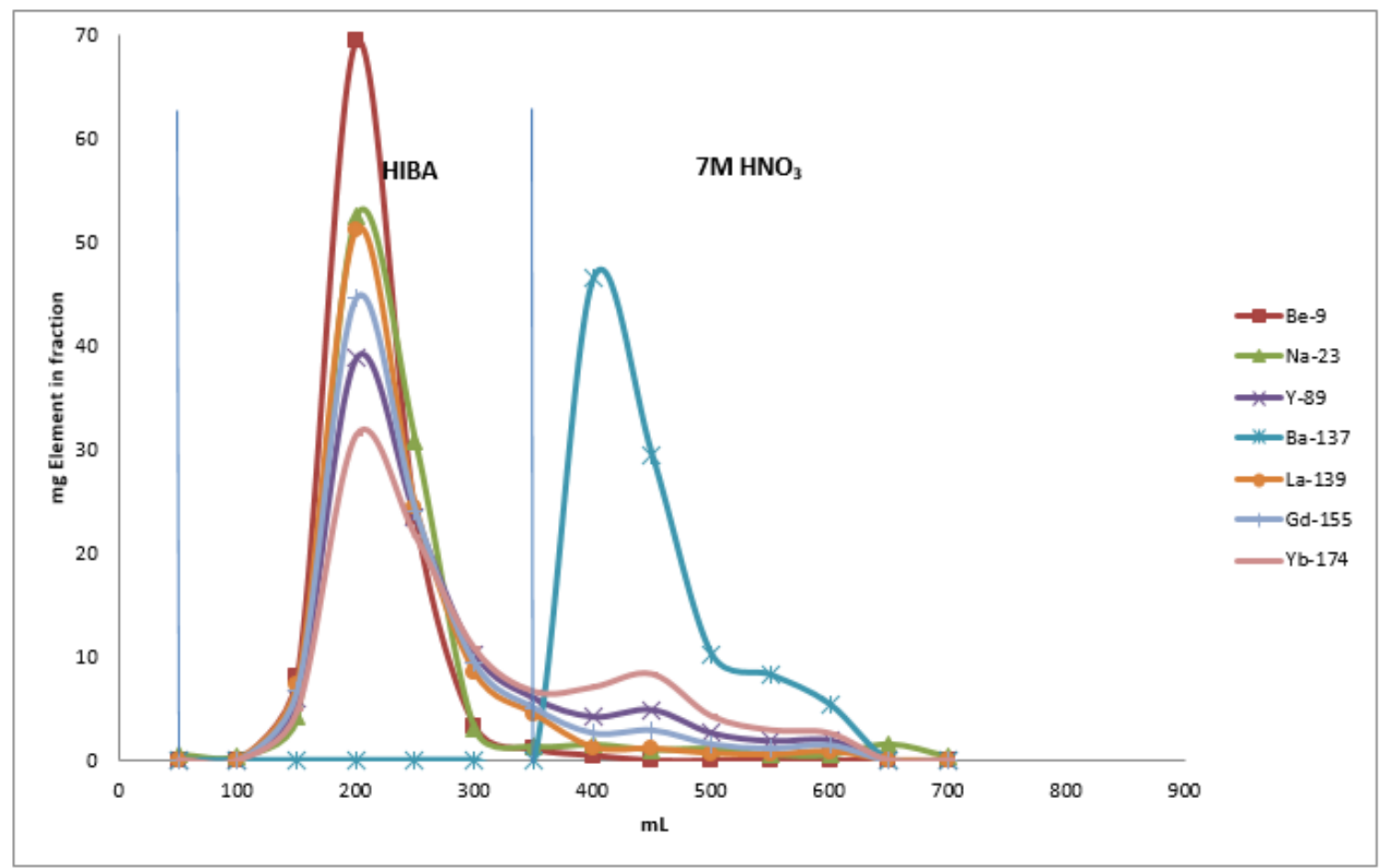

Figure 23 Lanthanide Elution from Purolite NRW100x10 with 0.7M HIBA pH 6 $(\mathbf{n}=\mathbf{1})$

The results of these two experiments show that the majority of the lanthanides can be eluted from the cation column with HIBA solution. It should be noted that the large peak of sodium in the $0.5 \mathrm{M}$ HIBA elution experiment was due to contamination from Chelex resin used in an attempt to remove possible metal contamination from the HIBA. It is also noted that increasing the molar concentration of HIBA and raising the $\mathrm{pH}$ resulted in the elution of the lanthanides with fewer column volumes. The HIBA molarity and 
solution $\mathrm{pH}$ warranted further investigation to determine the ideal HIBA solution for lanthanide elution with minimum waste volume.

\subsection{Cation Resin - HIBA $\mathbf{K}_{\mathbf{d}}$ experiments}

In order to minimize the amount of volume required to elute lanthanides with HIBA, the $\mathrm{K}_{d}$ values for various HIBA concentrations and $\mathrm{pH}$ values were investigated. $\mathrm{K}_{\mathrm{d}}$ values increase as the binding affinity of the element of interest increases, so the HIBA solution with the lowest lanthanide $\mathrm{K}_{\mathrm{d}}$ values should have the minimum required column volume for elution. $K_{d}$ values for elution of lanthanides from Purolite NRW100x10 resin with HIBA were determined according to Marsch et. al. [24] using 0.25 grams of resin and $2.5 \mathrm{~mL}$ of solution. Since this amount of resin is about 100 times less than the 21 grams used during column elution studies, the 0.25 grams of Purolite NRW100x10 resin was dosed with $0.01 \mathrm{meq}$ of $\mathrm{La}, \mathrm{Gd}$, and $\mathrm{Yb}$. In all cases, the resin was weighed into a scintillation vial and shaken with extractant at room temperature for three hours. After settling, the liquid was analyzed by ICP-MS. In initial experiments, the HIBA molarity was held constant at $0.5 \mathrm{M}$ while the $\mathrm{pH}$ of the solution was increased (Table 3, Figure 24). The error on the percent element extracted for this experiment $(\mathrm{n}=2)$ averaged $\pm 1.1 \%$, which is not visible on the graph below.

The $\mathrm{K}_{\mathrm{d}}$ and percent sorbed onto the resin $(\% \mathrm{~S})$ were determined with the following equations, where R equals 10 (the liquid to resin ratio), $\mathrm{S}_{\mathrm{pre}}$ is the element concentration in solution before resin contact and $\mathrm{S}_{\mathrm{post}}$ is the element concentration in solution after resin contact: 


$$
\% \boldsymbol{S}=100 * \frac{\boldsymbol{S}_{\text {pre resin }}-\boldsymbol{S}_{\text {post resin }}}{\boldsymbol{S}_{\text {pre resin }}} \quad \boldsymbol{K}_{\boldsymbol{d}}=\frac{\% \boldsymbol{S} * \boldsymbol{R}}{\mathbf{1 0 0 - \% S}}
$$

\begin{tabular}{|c|c|c|c|c|c|c|c|c|c|c|c|c|}
\hline \multirow[b]{2}{*}{ Extractant } & \multirow[t]{2}{*}{\begin{tabular}{|c|}
$\begin{array}{c}\text { Total La (ppb) } \\
\text { as measured } \\
\text { using } \\
\text { isotope: }\end{array}$ \\
La-139 \\
\end{tabular}} & \multirow[t]{2}{*}{$\begin{array}{c}\text { Total Gd } \\
\text { (ppb) as } \\
\text { measured } \\
\text { using } \\
\text { isotope: } \\
\text { Gd-155 }\end{array}$} & \multirow[t]{2}{*}{$\begin{array}{c}\text { Total Yb } \\
\text { (ppb) as } \\
\text { measured } \\
\text { using } \\
\text { isotope: } \\
\text { Yb-174 } \\
\end{array}$} & \multirow[t]{2}{*}{\begin{tabular}{|c|}
$\begin{array}{c}\text { Avg. La (ppb) } \\
\text { as measured } \\
\text { using } \\
\text { isotope: }\end{array}$ \\
La-139 \\
\end{tabular}} & \multirow[t]{2}{*}{\begin{tabular}{|c|}
$\begin{array}{c}\text { Avg. Gd (ppb) } \\
\text { as measured } \\
\text { using } \\
\text { isotope: }\end{array}$ \\
Gd-155 \\
\end{tabular}} & \multirow[t]{2}{*}{\begin{tabular}{|c|}
$\begin{array}{c}\text { Avg. Yb (ppb) } \\
\text { as measured } \\
\text { using } \\
\text { isotope: }\end{array}$ \\
Yb-174 \\
\end{tabular}} & \multicolumn{2}{|c|}{ La-139 } & \multicolumn{2}{|c|}{ Gd-155 } & \multicolumn{2}{|c|}{ Yb-174 } \\
\hline & & & & & & & $\% \mathrm{~s}$ & Kd & $\% \mathrm{~S}$ & Kd & $\% \mathrm{~s}$ & Kd \\
\hline $.5 \mathrm{M}$ HIBA pH 2.91 & $2.7 \pm 0.2$ & $4.4 \pm 0.6$ & $5.7 \pm 0.5$ & $19 \pm 1.3$ & $6.3 \pm 0.8$ & $5.9 \pm 0.9$ & 99.99 & $>10^{5}$ & 99.99 & $>10^{5}$ & 99.99 & $>10^{5}$ \\
\hline $.5 \mathrm{M} \mathrm{HIBA} \mathrm{pH} 2.91$ & $35.3 \pm 1.3$ & $8.2 \pm 0.5$ & $6.0 \pm 0.8$ & & & & & & & & & \\
\hline $.5 \mathrm{M}$ HIBA pH 3.8 & $15.7 \pm 0.5$ & $19.8 \pm 0.6$ & $88.0 \pm 1.4$ & $11.9 \pm 0.7$ & $12.9 \pm 1.3$ & $75.8 \pm 1.5$ & 99.99 & $>10^{5}$ & 99.99 & $>10^{5}$ & 99.97 & $>10^{5}$ \\
\hline $.5 \mathrm{M} \mathrm{HIBA} \mathrm{pH} 3.8$ & $8.1 \pm 0.5$ & $5.9 \pm 1.1$ & $63.5 \pm 0.7$ & & & & & & & & & \\
\hline $.5 \mathrm{M} \mathrm{HIBA}$ pH 4.9 & $3080 \pm 30$ & $131000 \pm 1090$ & $247000 \pm 1510$ & $3080 \pm 38$ & $132000 \pm 1379$ & $248000 \pm 1676$ & 98.53 & 670 & 45.68 & 8 & 5.24 & 1 \\
\hline $.5 \mathrm{M} \mathrm{HIBA} \mathrm{pH} 4.9$ & $3080 \pm 24$ & $133000 \pm 845$ & $249000 \pm 728$ & & & & & & & & & \\
\hline $.5 \mathrm{M} \mathrm{HIBA} \mathrm{pH} 4.9$ & $2820 \pm 20$ & $127000 \pm 714$ & $246000 \pm 1270$ & & & & & & & & & \\
\hline $.5 \mathrm{M}$ HIBA pH 6.1 & $29600 \pm 115$ & $216000 \pm 1340$ & $252000 \pm 1510$ & $27000 \pm 214$ & $213000 \pm 2284$ & $250500 \pm 2236$ & 87.14 & 68 & 12.35 & 1 & 4.02 & 0 \\
\hline $.5 \mathrm{M} \mathrm{HIBA} \mathrm{pH} 6.1$ & $24400 \pm 181$ & $210000 \pm 1850$ & $249000 \pm 1650$ & & & & & & & & & \\
\hline $.5 \mathrm{M} \mathrm{HIBA} \mathrm{pH} 6.97$ & $30000 \pm 301$ & $217000 \pm 2850$ & $254000 \pm 2150$ & $26600 \pm 348$ & $214000 \pm 3202$ & $252500 \pm 2856$ & 87.33 & 69 & 11.93 & 1 & 3.26 & 0 \\
\hline $.5 \mathrm{M} \mathrm{HIBA} \mathrm{pH} 6.97$ & $23200 \pm 175$ & $211000 \pm 1460$ & $251000 \pm 1880$ & & & & & & & & & \\
\hline Std. No Resin & $210000 \pm 1090$ & $243000 \pm 1250$ & $261000 \pm 2050$ & $210000 \pm 1090$ & $243000 \pm 1250$ & $261000 \pm 2050$ & & & & & & \\
\hline
\end{tabular}

Table $3 K_{d}$ Values for Lanthanides with Increasing HIBA pH (n=1)

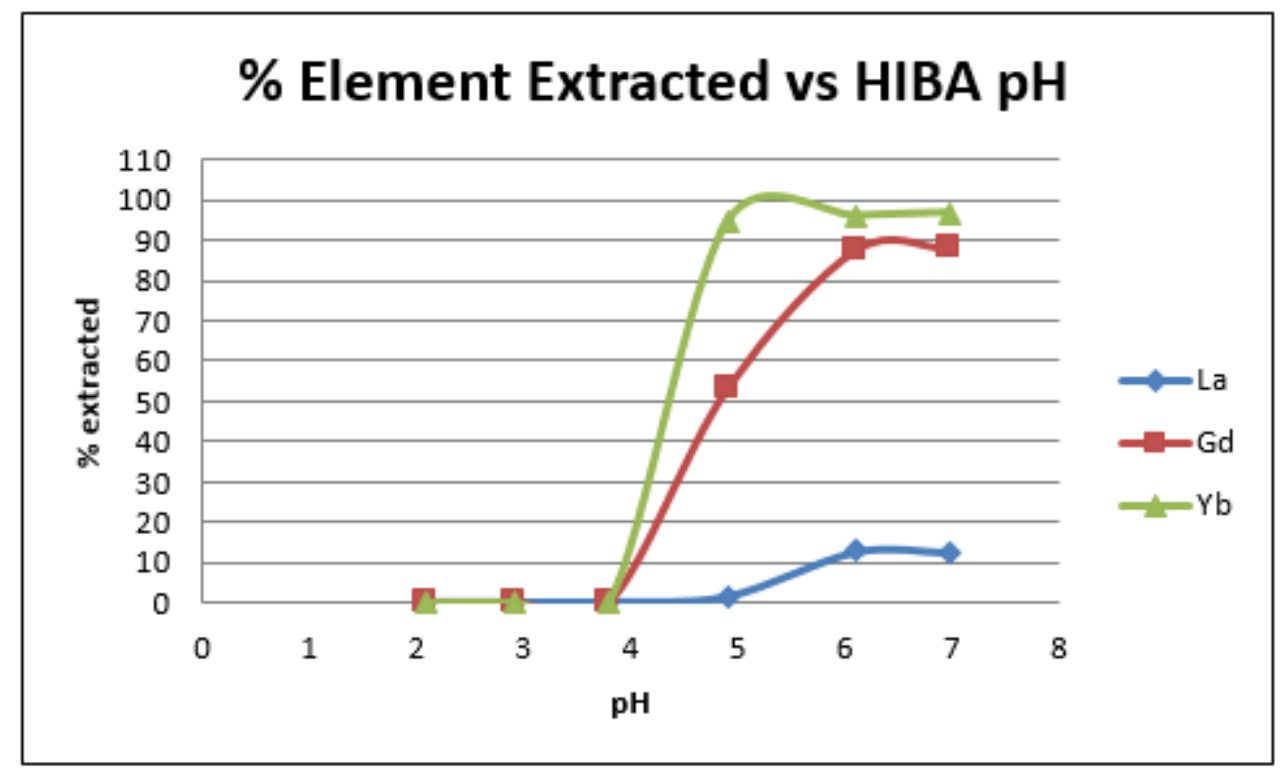

Figure 24 Percent Lanthanide Extracted with Increasing HIBA pH (n=2)

Additional experiments were also performed with HIBA at a constant $\mathrm{pH}$ of 6 and various HIBA molarities (Table 4, Figure 25). The error on the percent element extracted for this experiment $(\mathrm{n}=2)$ averaged $\pm 1.1 \%$, which is not visible on the graph below. 


\begin{tabular}{|c|c|c|c|c|c|c|c|c|c|c|c|c|}
\hline \multirow[b]{2}{*}{ Extractant } & \multirow{2}{*}{\begin{tabular}{|c|}
$\begin{array}{c}\text { Total La (ppb) } \\
\text { as measured } \\
\text { using } \\
\text { isotope: }\end{array}$ \\
La-139 \\
\end{tabular}} & \multirow[t]{2}{*}{$\begin{array}{c}\text { Total Gd } \\
\text { (ppb) as } \\
\text { measured } \\
\text { using } \\
\text { isotope: } \\
\text { Gd-155 } \\
\end{array}$} & \multirow[t]{2}{*}{$\begin{array}{c}\text { Total Yb } \\
\text { (ppb) as } \\
\text { measured } \\
\text { using } \\
\text { isotope: } \\
\text { Yb-174 } \\
\end{array}$} & \multirow{2}{*}{\begin{tabular}{|c|}
$\begin{array}{c}\text { Avg. La (ppb) } \\
\text { as measured } \\
\text { using } \\
\text { isotope: }\end{array}$ \\
La-139 \\
\end{tabular}} & \multirow{2}{*}{\begin{tabular}{|c|}
$\begin{array}{c}\text { Avg. Gd (ppb) } \\
\text { as measured } \\
\text { using } \\
\text { isotope: }\end{array}$ \\
Gd-155 \\
\end{tabular}} & \multirow{2}{*}{\begin{tabular}{|c|}
$\begin{array}{c}\text { Avg. Yb (ppb) } \\
\text { as measured } \\
\text { using } \\
\text { isotope: }\end{array}$ \\
Yb-174 \\
\end{tabular}} & \multicolumn{2}{|c|}{ La-139 } & \multicolumn{2}{|c|}{ Gd-155 } & \multicolumn{2}{|c|}{ Yb-174 } \\
\hline & & & & & & & $\% \mathrm{~S}$ & Kd & $\% \mathrm{~s}$ & Kd & $\% \mathrm{~S}$ & Kd \\
\hline $.2 \mathrm{M}$ HIBA pH 6.15 & $6.3 \pm 3.5$ & $21.0 \pm 0.8$ & $20.3 \pm 6.0$ & $3.2 \pm 4.6$ & $10.5 \pm 1.1$ & $10.2 \pm 6.8$ & 99.99 & $>10^{5}$ & 99.99 & $>10^{5}$ & 99.99 & $>10^{5}$ \\
\hline $.2 \mathrm{M} \mathrm{HIBA}$ pH 6.15 & $0.0 \pm 3.0$ & $0.0 \pm 0.8$ & $0.0 \pm 3.1$ & & & & & & & & & \\
\hline $.3 \mathrm{M}$ HIBA pH 6.22 & $12.1 \pm 1.5$ & $20.0 \pm 1.5$ & $376.0 \pm 7.9$ & $8.3 \pm 1.6$ & $10.0 \pm 2.4$ & $242.5 \pm 9.4$ & 99.99 & $>10^{5}$ & \begin{tabular}{|l|}
99.99 \\
\end{tabular} & $>10^{5}$ & 99.09 & $>10^{5}$ \\
\hline $.3 \mathrm{M}$ HIBA pH 6.22 & $4.4 \pm 0.4$ & $0.0 \pm 1.9$ & $109.0 \pm 5.1$ & & & & & & & & & \\
\hline $.5 \mathrm{M}$ HIBA pH 6.21 & $16800 \pm 50$ & $202000 \pm 224$ & $254000 \pm 1393$ & $14050 \pm 64$ & $196000 \pm 313$ & $257000 \pm 2679$ & 93.31 & 139 & 19.01 & 2 & 3.75 & 0 \\
\hline $.5 \mathrm{M}$ HIBA pH 6.21 & $11300 \pm 40$ & $190000 \pm 219$ & $260000 \pm 2288$ & & & & & & & & & \\
\hline $.7 \mathrm{M} \mathrm{HIBA}$ pH 6.22 & $77000 \pm 110$ & $233000 \pm 1079$ & $255000 \pm 4334$ & $81500 \pm 211$ & $233000 \pm 1298$ & $252000 \pm 5171$ & 61.19 & 16 & 3.72 & 0 & 5.62 & 1 \\
\hline $.7 \mathrm{M}$ HIBA pH 6.22 & $86000 \pm 180$ & $233000 \pm 722$ & $249000 \pm 2821$ & & & & & & & & & \\
\hline 1.0M HIBA pH 6.16 & $189000 \pm 2183$ & $226000 \pm 3050$ & $233000 \pm 3039$ & $187500 \pm 2533$ & $222500 \pm 4152$ & $227000 \pm 3736$ & 10.71 & 1 & 8.06 & 1 & 14.98 & 2 \\
\hline 1.0M HIBA pH 6.16 & $186000 \pm 1284$ & $219000 \pm 2817$ & $221000 \pm 2173$ & & & & & & & & & \\
\hline water $\mathrm{pH} 6.06$ & $15.4 \pm 1.5$ & $0.0 \pm 0.9$ & $0.0 \pm 3.0$ & $14.8 \pm 3.2$ & $6.0 \pm 2.3$ & $0.0 \pm 7.3$ & 99.99 & $>10^{5}$ & 99.99 & $>10^{5}$ & 100.00 & $>10^{5}$ \\
\hline water $\mathrm{pH} 6.06$ & $14.2 \pm 2.8$ & $12 \pm 2.1$ & $0.0 \pm 6.7$ & & & & & & & & & \\
\hline Std. No Resin & $210000 \pm 2050$ & $242000 \pm 1385$ & $267000 \pm 1622$ & & & & & & & & & \\
\hline
\end{tabular}

Table $4 K_{d}$ Values for Lanthanides with Increasing HIBA Molarity (n=2)

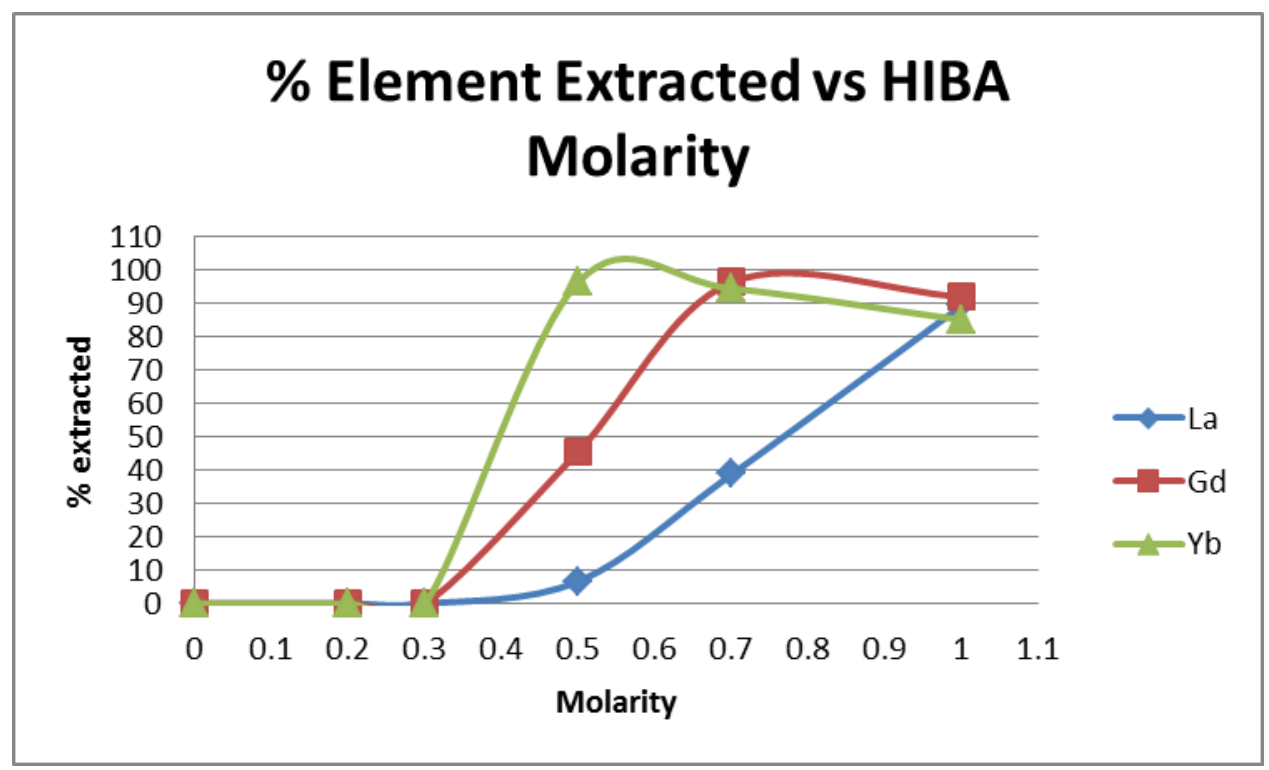

Figure 25 Percent Lanthanide Extracted with Increasing HIBA Molarity (n=2)

The $\mathrm{K}_{\mathrm{d}}$ values found with changing the $\mathrm{pH}$ of the HIBA solution show that extraction of lanthanides should be at a maximum when HIBA $\mathrm{pH}$ is greater than 6 . It is also noteworthy in Table 4 (water $\mathrm{pH}$ 6.06) that there was no extraction of lanthanides observed at the $\mathrm{pH} 6$ level without the addition of HIBA.

$\mathrm{K}_{\mathrm{d}}$ values from the experiments with changing HIBA molarity predict the best extraction across the range of lanthanides occurs with HIBA solutions of approximately 1 
Molar. Therefore, the best lanthanide extraction should occur with HIBA solution at $\mathrm{pH} 6$ and $1 \mathrm{M}$ concentration.

\subsection{Cation Resin - HIBA Competition Study Experiments}

The elution of lanthanides from Purolite NRW100x10 resin with 1 M HIBA solution at $\mathrm{pH} 6$ was investigated to determine the elution behavior with the addition of various competing species. One meq of $\mathrm{Sc}, \mathrm{Fe}, \mathrm{Co}, \mathrm{Cu}, \mathrm{Ti}, \mathrm{Zr}, \mathrm{Ba}, \mathrm{Be}, \mathrm{Y}, \mathrm{Na}, \mathrm{La}, \mathrm{Gd}$, and $\mathrm{Yb}$ in $59 \mathrm{~mL}$ of $0.3 \mathrm{M} \mathrm{HNO}_{3}$ was loaded onto 21 grams of Purolite NRW100x10 cation resin in a $2.5 \times 50 \mathrm{~cm}$ glass Econo-column and the column was eluted at $1.5 \mathrm{~mL} / \mathrm{min}$. The elution profile used was $300 \mathrm{~mL}$ of $1 \mathrm{M} \mathrm{HIBA}$ at $\mathrm{pH} 6$, and $200 \mathrm{~mL}$ of $7 \mathrm{M} \mathrm{HNO}_{3}$. Twentymilliliter fractions were collected for metals analysis by ICP-MS as shown below (Figure 26). The error on the percent element extracted for this experiment $(\mathrm{n}=1)$ averaged \pm 1.2 $\%$.

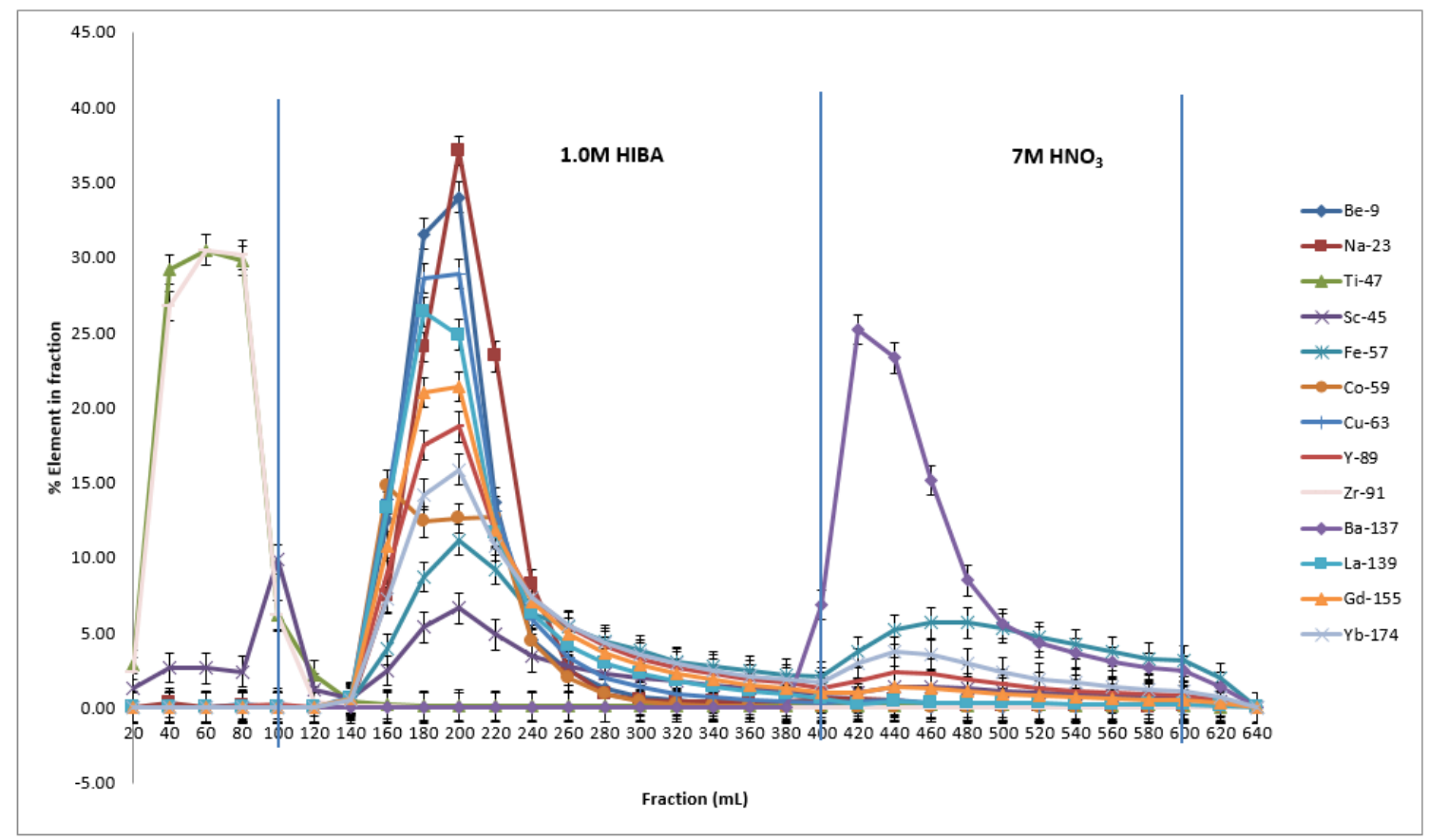

Figure 26 HIBA Elution of a Mixture of Lanthanides and Transition Metals (n=1) 
The elution profile shows that the elution with HIBA was not exclusive to lanthanides as was originally suggested in the literature [27]. It should be noted that the previous work used the ammonium form of Dowex $50 \mathrm{Wx} 4$, whereas the hydrogen form is the only available resin in the FRIB beam dump. In this work, HIBA was not found to selectively elute the lanthanides from the Purolite resin. More importantly, in contrast to the previous work in which the lanthanides were eluted with 2 column volumes from Dowex $50 \mathrm{Wx} 4,8$ column volumes were required to fully elute the entire lanthanide series from Purolite resin.

\subsection{Cation Resin - Strong Acid Elution Experiments}

Due to the fact that HIBA was unable to selectively extract the lanthanides in a few column volumes, experiments were performed to investigate complete cation elution from the Purolite cation resin with a strong acid. According to Marsch et al., maximum lanthanide elution from $\mathrm{AG} 50 \mathrm{x} 8$ cation resin occurs with around 6-8 $\mathrm{M} \mathrm{HNO}_{3}$ [24]. Using previously described Purolite column conditions, the cation resin was dosed with 1 meq of $\mathrm{Lu}$ and $36.3 \mu \mathrm{Ci}$ of ${ }^{177 \mathrm{~m}} \mathrm{Lu}$ in $20 \mathrm{~mL}$ of $0.3 \mathrm{M} \mathrm{HNO}_{3}$. The flowrate of the peristaltic pump was set to a slower $0.5 \mathrm{~mL} / \mathrm{min}$ in an effort to increase contact time and reduce tailing. Lutetium was eluted with $10 \mathrm{M} \mathrm{HNO}_{3}$ and the activity in $20 \mathrm{~mL}$ fractions was measured by HPGe gamma-ray spectrometer as shown below (Figure 27). The error on the percent extracted calculation for this experiment $(n=1)$ averaged $\pm 1.8 \%$ as calculated by peak area. 


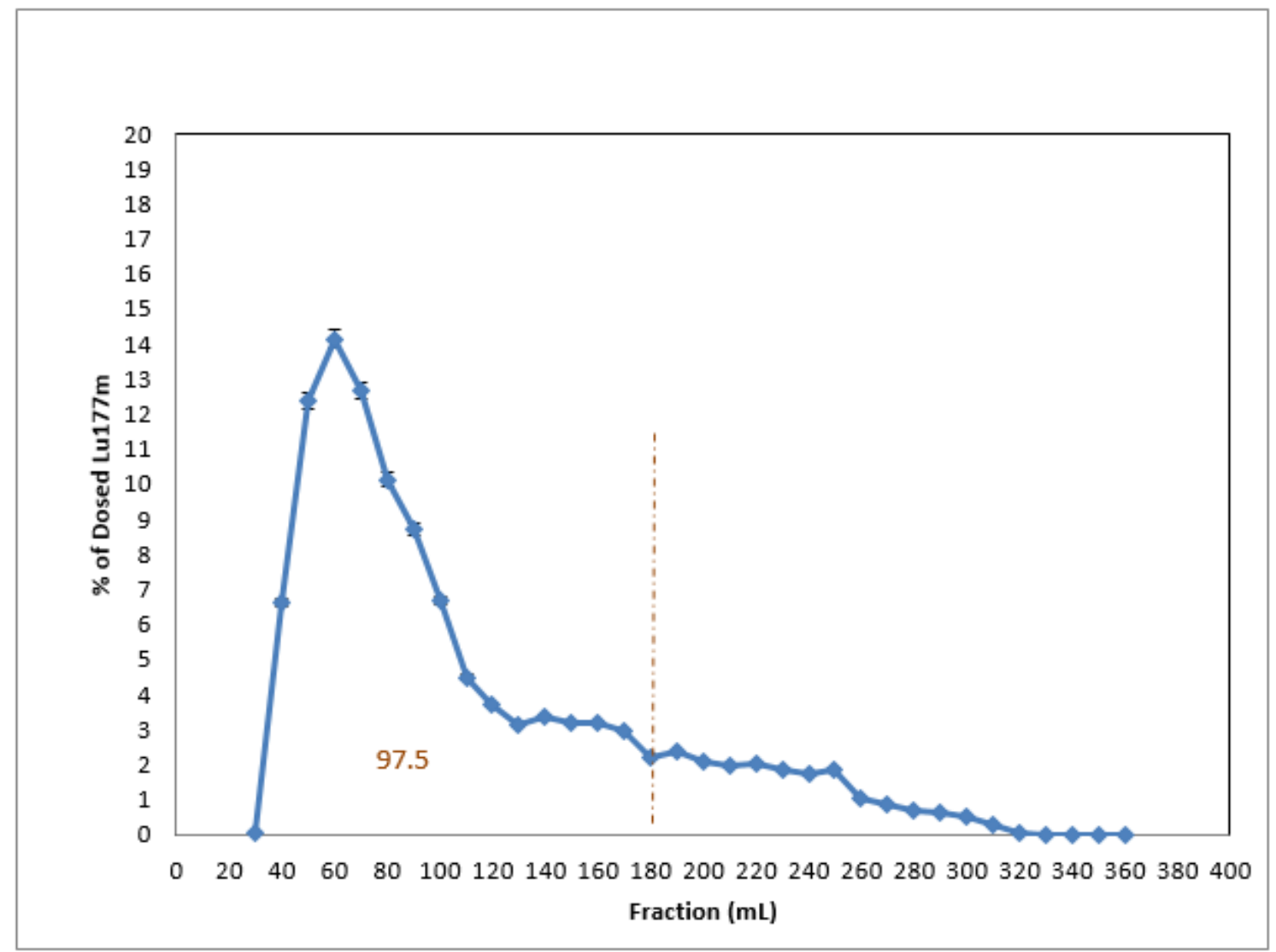

Figure 27 Percent ${ }^{177}$ Lu Elution vs. 10 M HNO3 Acid Volume (n=1) 
A second lanthanide elution experiment was performed with strong hydrochloric acid to determine the number of column volumes required for complete elution as compared to nitric acid. A new $2.5 \times 50 \mathrm{~cm}$ glass Econo-column was filled with 22 grams of Purolite NRW100x10 cation resin. The cation resin was dosed with 1 meq of natural Lu and $41.5 \mu \mathrm{Ci}$ of ${ }^{177 \mathrm{~m}} \mathrm{Lu}$ in $20 \mathrm{~mL}$ of $0.3 \mathrm{M} \mathrm{HNO}_{3}$. The flowrate of the peristaltic pump was set to $0.5 \mathrm{~mL} / \mathrm{min}$. Lutetium was eluted with $6.5 \mathrm{M} \mathrm{HCl}$ and activity in $20 \mathrm{~mL}$ fractions was measured by HPGe gamma-ray spectrometer as shown below (Figure 28). The error on the percent extracted calculation for this experiment $(n=1)$ averaged $\pm 2.2 \%$ as calculated by peak area.

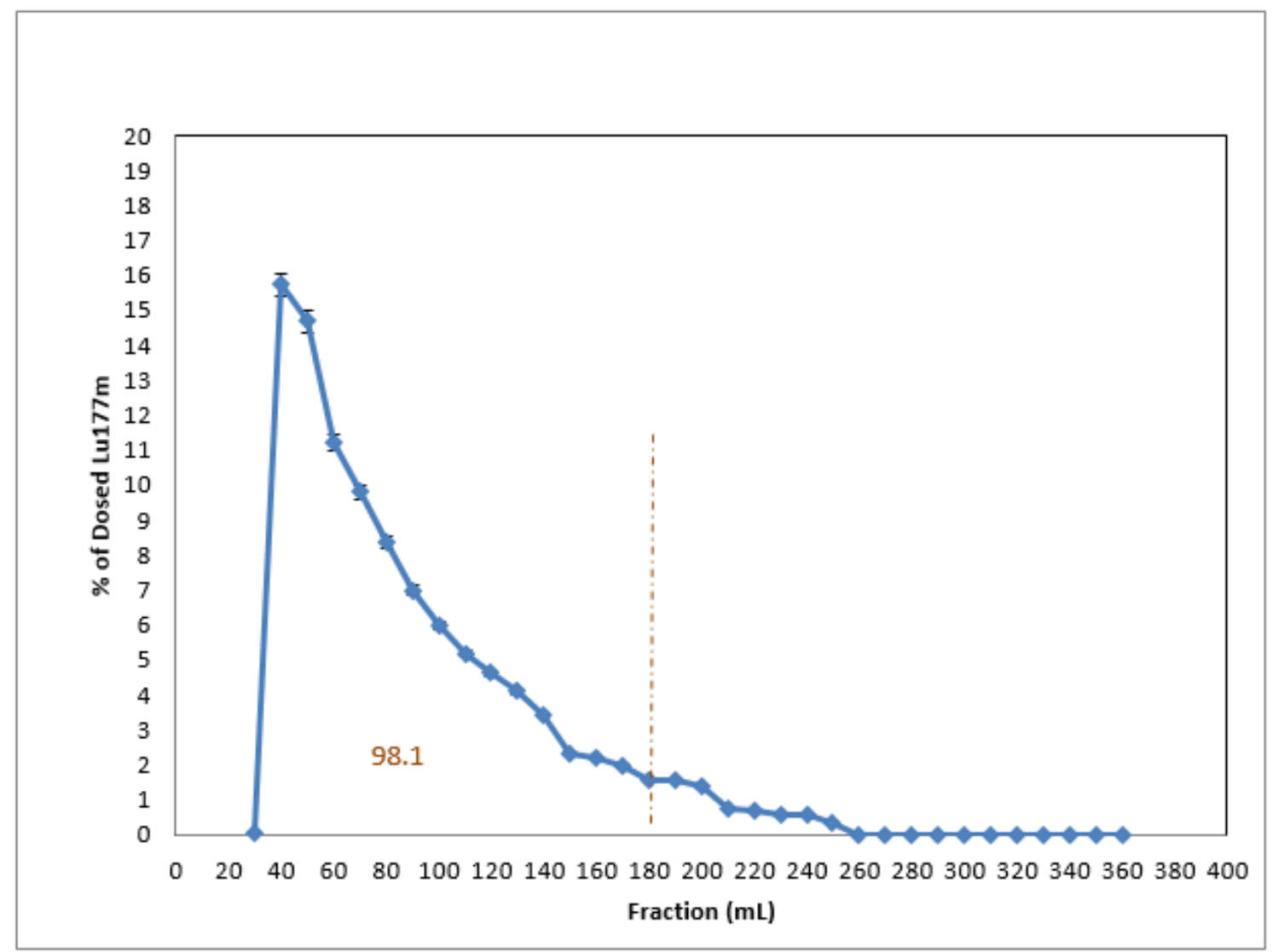

Figure 28 Percent ${ }^{177 m}$ Lu Elution vs. 6.5 M HCl Acid Volume (n=1) 
In the first experiment, 98 percent elution of the Lu was achieved with $10 \mathrm{M}$ $\mathrm{HNO}_{3}$ in approximately 8 column volumes $(150 / 20 \mathrm{~mL})$. In the second experiment, 98 percent Lu elution was achieved with $6.5 \mathrm{M} \mathrm{HCl}$ in approximately 8 column volumes $(150 / 20 \mathrm{~mL})$. Both of these elution schemes would generate too much acid waste for use in harvesting from the beam dump resin. These eight column volumes represent 800 gallons of radioactive acidic waste generation to elute the FRIB beam dump resin.

\subsection{Cation Resin - Strong Acid Recirculation Kinetics}

As we continued to work toward the goal of extracting the lanthanide series in a minimal number of column volumes of acid, we decided to test the recirculation of strong acid through the Purolite resin. Recirculation of the strong acid through the resin allows for adsorption of the maximum capacity of the lanthanides per volume of acid. Removal of the lanthanides from the recirculating acid solution would then shift the equilibrium and allow additional extraction of the lanthanides into the "cleaned" recirculating solution. Before implementing this strategy, experiments were performed in order to understand the kinetics and equilibrium shift caused by removal of the lanthanides from the recirculating solution.

An experiment was performed to determine the amount of time required to reach steady state with recirculating $8 \mathrm{M} \mathrm{HNO}_{3}$ acid solution through the column. The recirculation rate was regulated with a peristaltic pump, using tubing connected to the top and bottom of the column. A $20 \mathrm{~g}$ column of Purolite NRW 100x 10 cation resin in a $2.5 \times 50$

cm glass Econo-column was dosed with 1 meq of cold $\mathrm{Lu}$ and $29 \mu \mathrm{Ci}{ }^{177 \mathrm{~m}} \mathrm{Lu}$ in $20 \mathrm{~mL}$ of $0.05 \mathrm{M} \mathrm{HNO}_{3}$. The $8 \mathrm{M} \mathrm{HNO}_{3}$ was prepared by adding $22 \mathrm{~mL}$ of concentrated $\mathrm{HNO}_{3}$ to 
the $20 \mathrm{~mL}$ present in the column (equivalent to two column volumes). The $8 \mathrm{M} \mathrm{HNO}_{3}$ was recirculated through the column at a flow of approx. $10 \mathrm{~mL} / \mathrm{min}$. After about four hours, the volume of $8 \mathrm{M} \mathrm{HNO}_{3}$ was doubled to $84 \mathrm{~mL}$ total (equivalent to four column volumes) and recirculated at the same flow rate.

A constant reading of $1.8 \mu \mathrm{Ci}$ (in $10 \mathrm{~mL}$ of column solution) was measured by HPGe gamma-ray spectrometer after the first $1.5 \mathrm{hr}$, for a total of $7.56 \mu \mathrm{Ci}$ in the recirculating solution. Upon doubling the volume of the recirculating solution, a constant reading of $2.7 \mu \mathrm{Ci}$ (in $10 \mathrm{~mL}$ of column solution) was measured by HPGe gamma-ray spectrometer after about 1.5 hours, for a total of $22.7 \mu \mathrm{Ci}$ in solution. This study suggests that a steady state concentration is achieved in the recirculating acid after about 1.5 hours and that, as expected, the amount extracted is increased by increasing the volume of the circulating acid solution.

\subsection{Cation Resin - Eichrom RE Resin, Loading and Breakthru}

The second step in using recirculating acid for removing the lanthanides from Purolite resin is "cleaning" or removing the lanthanides from the recirculating acid solution. We hypothesized that Eichrom RE resin could be used to remove lanthanides from the Purolite NRW100x10 cation resin column solution as it contains a ligand for the binding of rare earth elements. Eichrom RE resin cartridges (Figure 29) consist of $1 \mathrm{M}$ Octyl(phenyl)-N,N-diisobutyl-carbamoylmethylphosphine oxide (CMPO)(Figure 30) in tributyl phosphate (TBP)(Figure 31) coated onto an inert polymeric support. The cartridge is designed for group separation of rare earth elements and can be loaded at 
high nitric acid molarity (Figure 32). The CMPO on the resin extracts via a coordination mechanism, which is relatively independent of the metal ion charge.

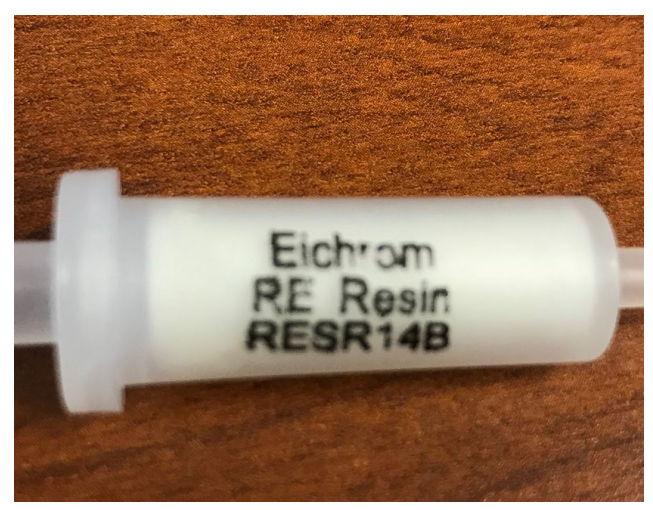

Figure $292 \mathrm{~mL}$ Eichrom RE Resin Cartridge

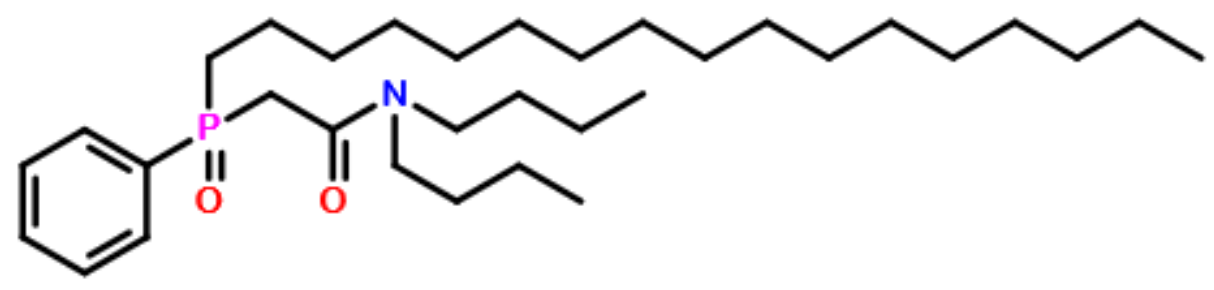

Figure 30 Octyl(phenyl)-N,N-diisobutyl-carbamoylmethylphosphine oxide (CMPO) [35]

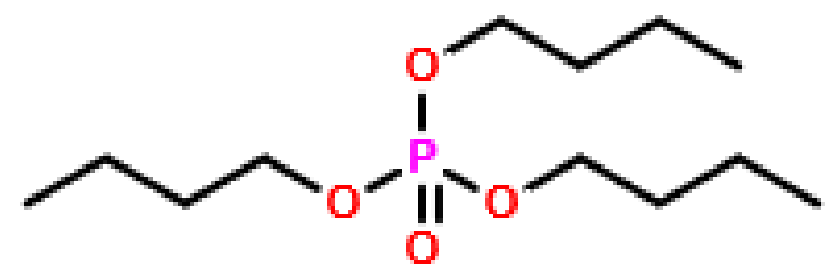

Figure 31 Tributyl Phosphate (TBP) [36] 


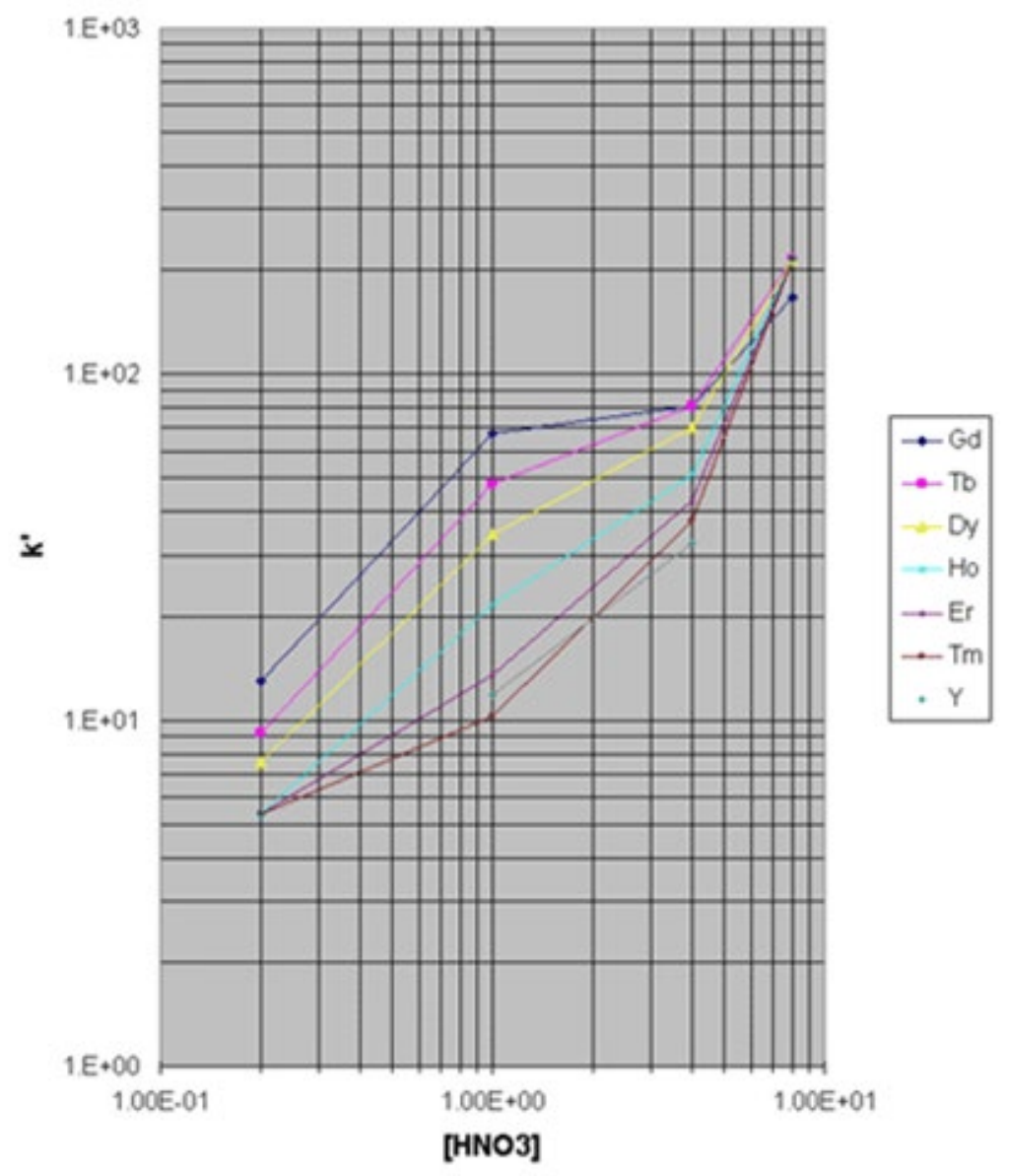

Figure 32 Eichrom RE Cartridge $K_{d}$ Values vs. Nitric Acid Molarity [37] Attributed to Eichrom, 2014 Product Catalog

A study was conducted to determine the loading and breakthrough conditions of an Eichrom RE cartridge with radioactive $\mathrm{Lu}$. One meq of cold $\mathrm{Lu}$ and $30 \mu \mathrm{Ci}{ }^{177 \mathrm{~m}} \mathrm{Lu}$ were placed into $82 \mathrm{~mL}$ of $8 \mathrm{M} \mathrm{HNO}_{3}$ and mixed. The Lu solution was then passed through two Eichrom RE cartridges (connected in series) with a syringe, and $10 \mathrm{~mL}$ fractions were collected as the solution passed through the cartridges. The eight $10 \mathrm{~mL}$ fractions were measured for ${ }^{177 \mathrm{~m}} \mathrm{Lu}$ activity on a HPGe gamma-ray spectrometer. The double Eichrom RE cartridge was then eluted with three $10 \mathrm{~mL}$ fractions of $0.05 \mathrm{M} \mathrm{HCl}$, which were also collected and measured for ${ }^{177 m}$ Lu activity (Figure 33 ). The error on the 
percent ${ }^{177 \mathrm{~m}} \mathrm{Lu}$ extracted calculation for this experiment $(\mathrm{n}=1)$ averaged $\pm 2.0 \%$ as calculated by peak area.

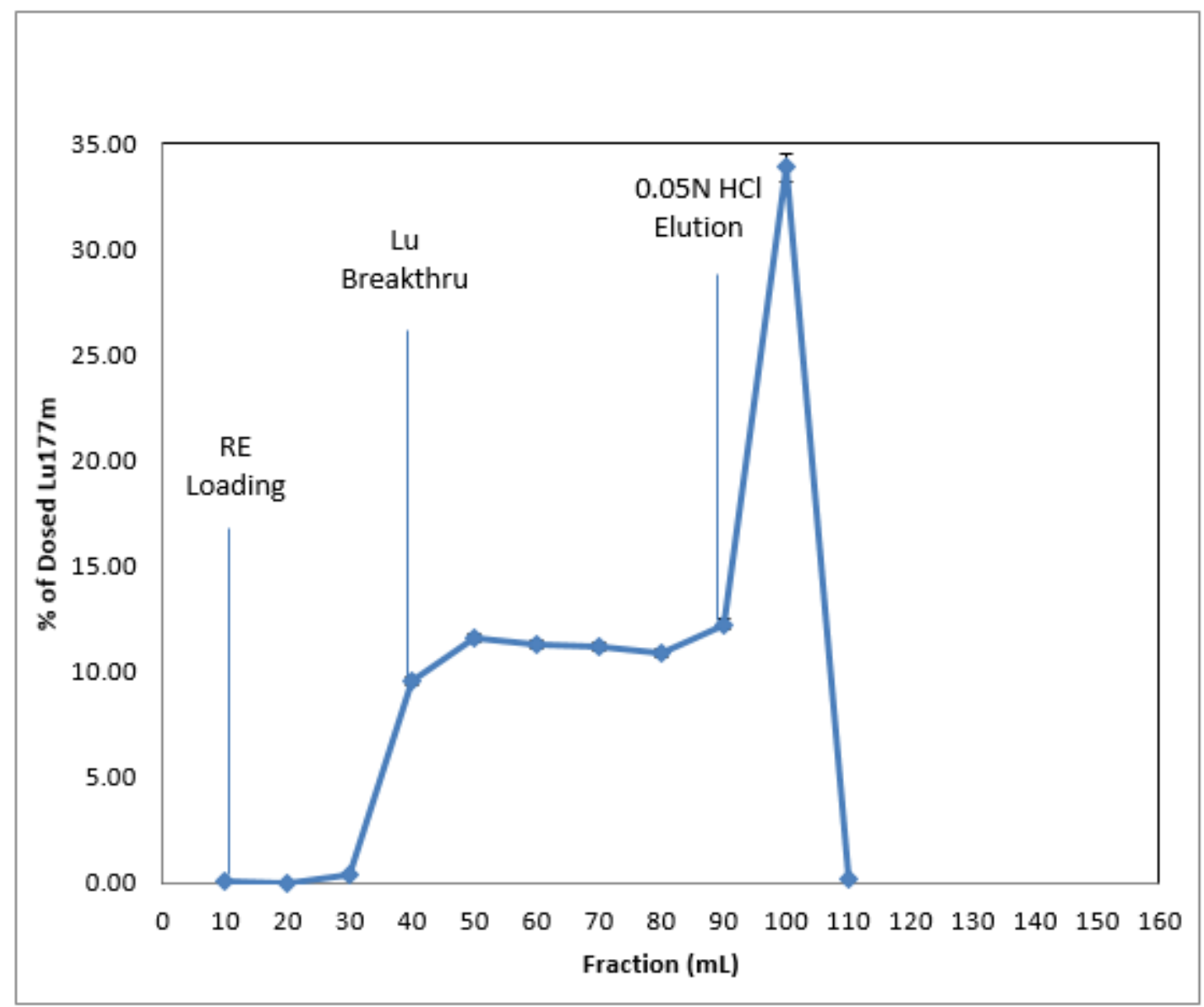

Figure 33 Loading and Breakthru Profile of ${ }^{177 \mathrm{~m}} \mathrm{Lu}$ on Eichrom RE Cartridge (n=1)

The breakthrough experiment shows that ${ }^{177 \mathrm{~m}} \mathrm{Lu}$ is loaded onto a double $2 \mathrm{~mL}$ Eichrom RE cartridge in $8 \mathrm{M} \mathrm{HNO}_{3}$, with breakthrough of ${ }^{177 \mathrm{~m}} \mathrm{Lu}$ occurring after approximately $30 \mathrm{mLs}$. Elution from the double cartridge is achieved with three $10 \mathrm{~mL}$ fractions of $0.05 \mathrm{M} \mathrm{HCl}$, although this elution volume has not been optimized. Twenty milliliters of $0.05 \mathrm{M} \mathrm{HCl}$ appears to be sufficient to remove all activity from the two cartridges. 


\subsection{Cation Resin - Eichrom RE Resin, Experiments}

Investigations were performed with the combination of strong acid recirculation and lanthanide removal with Eichrom RE resin in order to remove lanthanides from the Purolite NRW100x10 resin in minimal acid volume. Eichrom RE experiments were performed by loading $20 \mathrm{~g}$ of the Purolite NRW $100 \times 10$ cation resin into a $2.5 \times 50 \mathrm{~cm}$ glass Econo-column with 1 meq of $\mathrm{Lu}$ and $35 \mu \mathrm{Ci}$ of ${ }^{177 \mathrm{~m}} \mathrm{Lu}$ in $20 \mathrm{~mL}$ of $0.05 \mathrm{M} \mathrm{HNO}_{3}$. Forty milliliters of $12 \mathrm{M} \mathrm{HNO}_{3}$ was added to the top of column and mixed by recirculation at a flowrate of $10 \mathrm{~mL} / \mathrm{min}$ through the peristaltic pump to create a final solution concentration of 8 Molar, and total solution volume of $60 \mathrm{~mL}$. Every thirty minutes, $10 \mathrm{~mL}$ aliquots were taken from the column solution and counted by a HPGe detector, and then the solution was returned to the column. After one hour, $30 \mathrm{~mL}$ of column solution were eluted through a $2 \mathrm{~mL}$ Eichrom RE cartridge (RE1) and the solution was returned to the system. After a second hour of recirculation, $30 \mathrm{~mL}$ of column solution were eluted through a second $2 \mathrm{~mL}$ Eichrom RE cartridge (RE2) and returned to the system. The two Eichrom RE cartridges were each eluted with $10 \mathrm{~mL}$ of $0.05 \mathrm{M} \mathrm{HCl}$ and counted by HPGe gamma spectroscopy. After another hour of recirculation, $30 \mathrm{~mL}$ of column solution were again eluted through the first Eichrom RE cartridge (RE1a), and the final $30 \mathrm{~mL}$ of column solution were again eluted through the second Eichrom RE cartridge (RE2a). Both Eichrom RE cartridges were again eluted with $10 \mathrm{~mL}$ each of $0.05 \mathrm{M} \mathrm{HCl}$ and counted by HPGe gamma spectroscopy. The $60 \mathrm{~mL}$ of column solution post Eichrom RE cartridge elution were also counted by HPGe Gamma Spectroscopy (Figure 34). The error on the percent ${ }^{177 \mathrm{~m}} \mathrm{Lu}$ extracted calculation for this experiment $(\mathrm{n}=1)$ averaged $\pm 1.0 \%$ as calculated by peak area. 


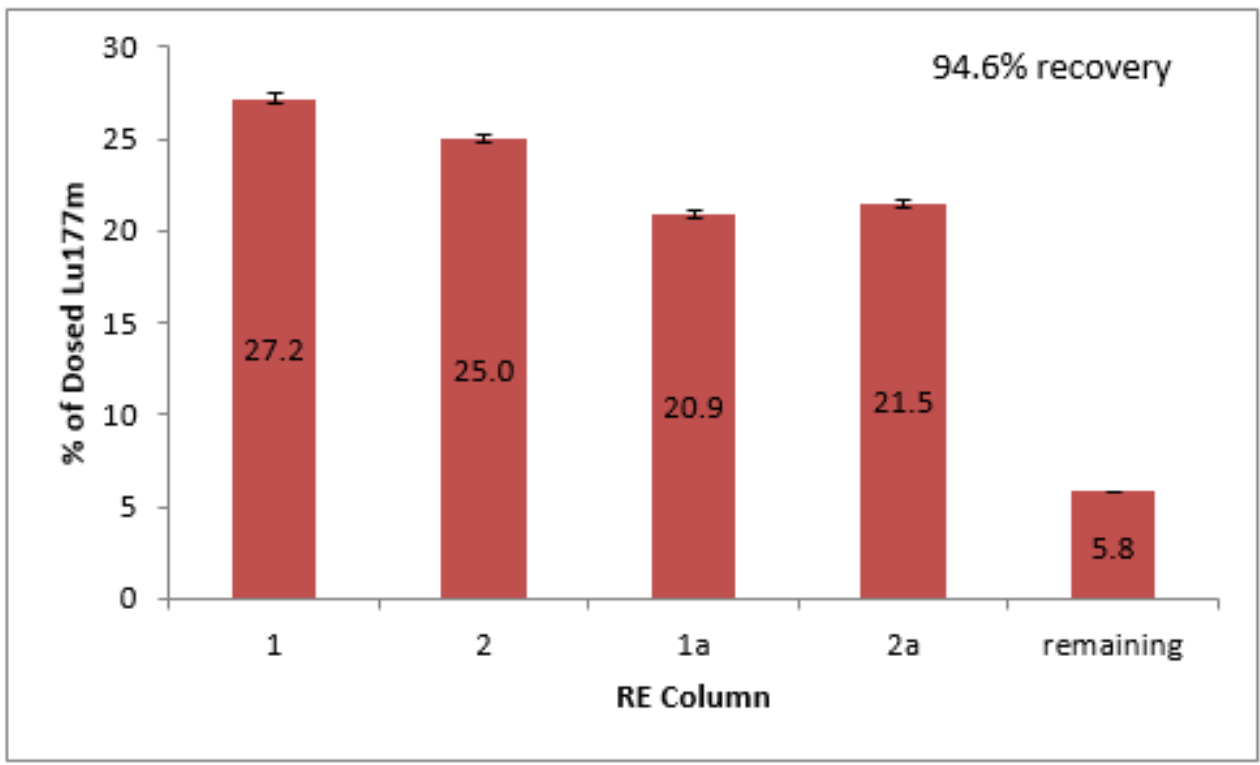

Figure $34{ }^{177}$ Lu Recovery from Eichrom RE Cartridge (4 Elution Cycles, n=1)

The use of $8 \mathrm{M} \mathrm{HNO}_{3}$ recirculation and Eichrom RE resin for the recovery of lanthanides had promising results, with $94.6 \%$ of the ${ }^{177 m} \mathrm{Lu}$ recovered. After the first hour of recirculation, a constant reading of approximately $4 \mu \mathrm{Ci}$ per aliquot was observed. After the second hour of recirculation, a constant reading of approximately 3.4 $\mu \mathrm{Ci}$ per aliquot was observed. And after the third hour, a constant $2.3 \mu \mathrm{Ci}$ per aliquot was observed.

The $60 \mathrm{~mL}$ of acid used for recirculation represents a much more reasonable 3 column volumes, which makes this a viable method for recovery of lanthanides from the beam dump resin (300 gallon required for FRIB resin as compared to 800 gallon previously). With the acid being cleaned by the Eichrom RE resin, it could also be reused for subsequent lanthanide harvesting at the next resin changeout. Experiments demonstrate that Eichrom RE cartridges can be loaded and eluted with lanthanides at least two times without losing functionality. In addition, the $10 \mathrm{~mL}$ of $0.05 \mathrm{M} \mathrm{HCl}$ 
required for the elution of the Eichrom RE cartridge is a marked improvement over previous lanthanide recovery experiments. The amount of material generated from a 6 month ${ }^{238} \mathrm{U}$ beam is approximately $100 \mu \mathrm{g}$ per lanthanide (calculated for $\mathrm{Lu}$ ). With the maximum $12 \mathrm{mg}$ Eu loading capacity of the Eichrom RE cartridge, the entire 100 gallons of FRIB resin could theoretically be harvested with one cartridge and eluted with this method in as little as $30 \mathrm{~mL}$ of $0.05 \mathrm{M} \mathrm{HCl}$.

\subsection{Cation Resin - Eichrom RE Resin, Competition Study}

The recovery of lutetium from the Purolite NRW 100x 10 cation resin with recirculating $8 \mathrm{M} \mathrm{HNO}_{3}$ and Eichrom $\mathrm{RE}$ resin was investigated as before but with the addition of competing ions: $\mathrm{Be}, \mathrm{Na}, \mathrm{Ti}, \mathrm{Sc}, \mathrm{Fe}, \mathrm{Co}, \mathrm{Cu}, \mathrm{Y}, \mathrm{Zr}, \mathrm{Ba}, \mathrm{La}$, and $\mathrm{Gd}$. Eichrom $\mathrm{RE}$ competition experiments were performed by loading the cation column with 1 meq of $\mathrm{Lu}$ and $1 \mathrm{meq}$ each of the above listed competing ions in a total of $59 \mathrm{~mL}$ of $0.32 \mathrm{M}$ $\mathrm{HNO}_{3}$. One milliliter of this starting solution was reserved for ICP-MS analysis. The solution was loaded onto $20 \mathrm{~g}$ of Purolite NRW100x 10 resin in a $2.5 \times 50 \mathrm{~cm}$ glass Econocolumn and the column washed with $15 \mathrm{~mL}$ of $0.05 \mathrm{M} \mathrm{HNO}_{3}$. Forty milliliters of $12 \mathrm{M}$ $\mathrm{HNO}_{3}$ was added to the top of column and mixed by recirculation through the peristaltic pump at a rate of $10 \mathrm{~mL} / \mathrm{min}$. to create a final solution concentration of $8 \mathrm{M} \mathrm{HNO}_{3}$, and total solution volume of $60 \mathrm{~mL}$. Every $60 \mathrm{~min}$., two samples were taken for testing. First, $30 \mathrm{~mL}$ of column solution were passed through Eichrom RE column 1, and then returned to the recirculating column. Second, another $30 \mathrm{~mL}$ of column solution were passed through Eichrom RE column 2, and then returned to the recirculating column. Each Eichrom RE column was then eluted with $10 \mathrm{~mL}$ of $0.05 \mathrm{M} \mathrm{HCl}$ and the resin cartridge reused for the following sample point. The amount extracted by each column 
was measured by ICP-MS and added together, and this process was continued for a total of 6 iterations. The data for each iteration is combined in the table below (Table 5). Start represents the amount of each element initially loaded onto the Purlolite column. Each following row contains the amount of element extracted for that iteration, the percentage of the original element removed for that iteration, and the percentage of the total milligrams extracted in that iteration for that particular element.

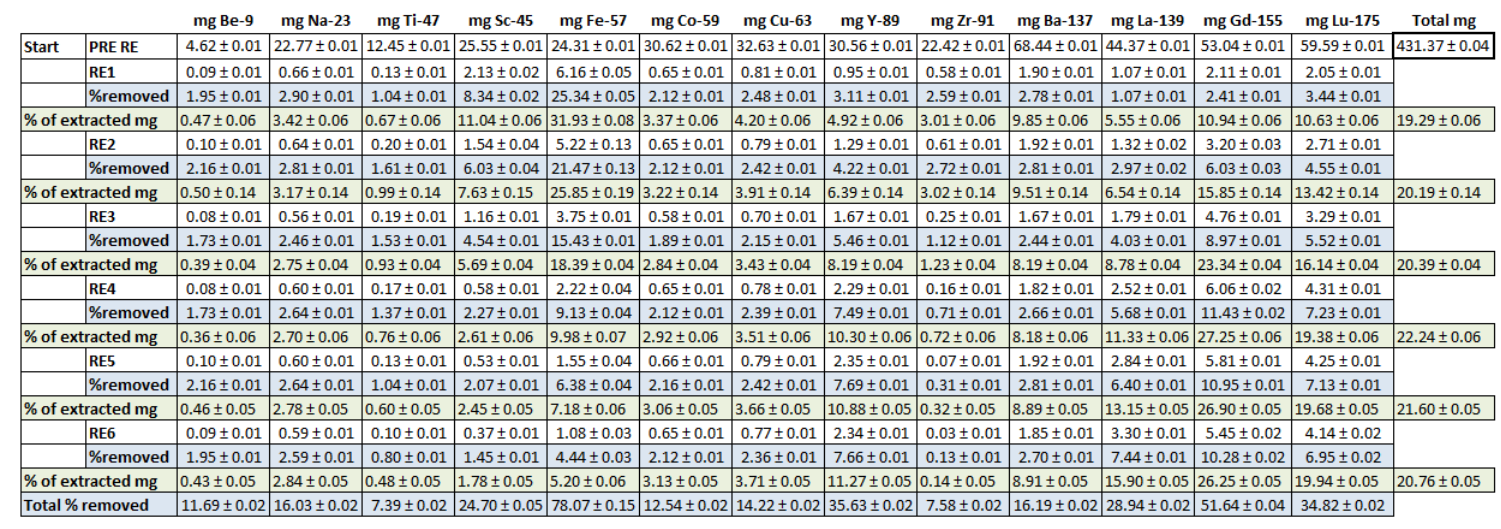

Table 5 Milligrams of Element Recovered with 6 Elution Cycles of Eichrom RE Column $(\mathbf{n}=\mathbf{1})$

Upon discussion with the manufacturer, it was discovered that the functional capacity of a $2 \mathrm{~mL}$ Eichrom $\mathrm{RE}$ cartridge is $\sim 6 \mathrm{mg} \mathrm{Eu}$, with a theoretical maximum loading of $12 \mathrm{mg} \mathrm{Eu} \mathrm{(0.08} \mathrm{mmol),} \mathrm{thus} \mathrm{for} \mathrm{two} \mathrm{columns} \mathrm{the} \mathrm{RE} \mathrm{resin} \mathrm{was} \mathrm{overloaded} \mathrm{by}$ approximately 18 times its capacity. It is interesting to note that under these conditions, iron was the element most preferentially extracted as shown by the color change of the cartridge (Figure 35), followed by the lanthanides. Also, the percentage of lanthanide extraction increased with each iteration as competing elements were removed from solution. 


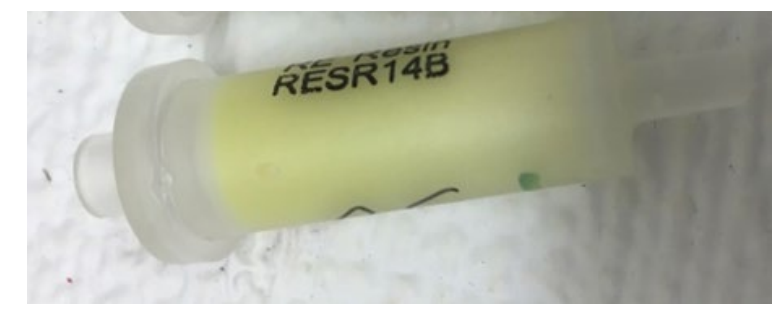

Figure 35 RE Cartridge Discoloration Due to Iron Adsorption

\subsection{Cation Resin - Eichrom DGA Resin, Competition Study}

Due to the large amount of iron adsorbed by the Eichrom RE resin, Eichrom DGA resin was chosen as a replacement. Eichrom manufactures two types of DGA resin columns, DGA normal and DGA branched. DGA normal (N,N,N',N'-tetra-noctyldiglycolamide) has a column capacity of $12 \mathrm{mg} \mathrm{Eu} / \mathrm{ml}$ of resin and DGA branched (N, N, N', N'-tetrakis-2-ethylhexyl-diglycolamide) has a column capacity of $15 \mathrm{mg}$ $\mathrm{Eu} / \mathrm{ml}$ of resin. Both resins have a low affinity for iron in 6-8 $\mathrm{M} \mathrm{HNO}_{3}$ with a $\log \mathrm{K}_{\mathrm{d}}$ of approximately 1 in $6 \mathrm{M} \mathrm{HNO}_{3}$ (Figure 36), making them more attractive for the recovery of Lu from the Purolite NRW100x10 cation resin than Eichrom RE resin. Another attractive attribute of DGA resin is the affinity for lanthanides with a $\log K_{d}$ of $>4$ in $6 \mathrm{M}$ $\mathrm{HNO}_{3}$ compared to a $\log \mathrm{K}_{\mathrm{d}}$ of 2 for $\mathrm{U}(\mathrm{IV})$ (the primary beam). Of the two possible resin choices, the DGA branched resin was chosen for further investigation due to its higher column capacity. 


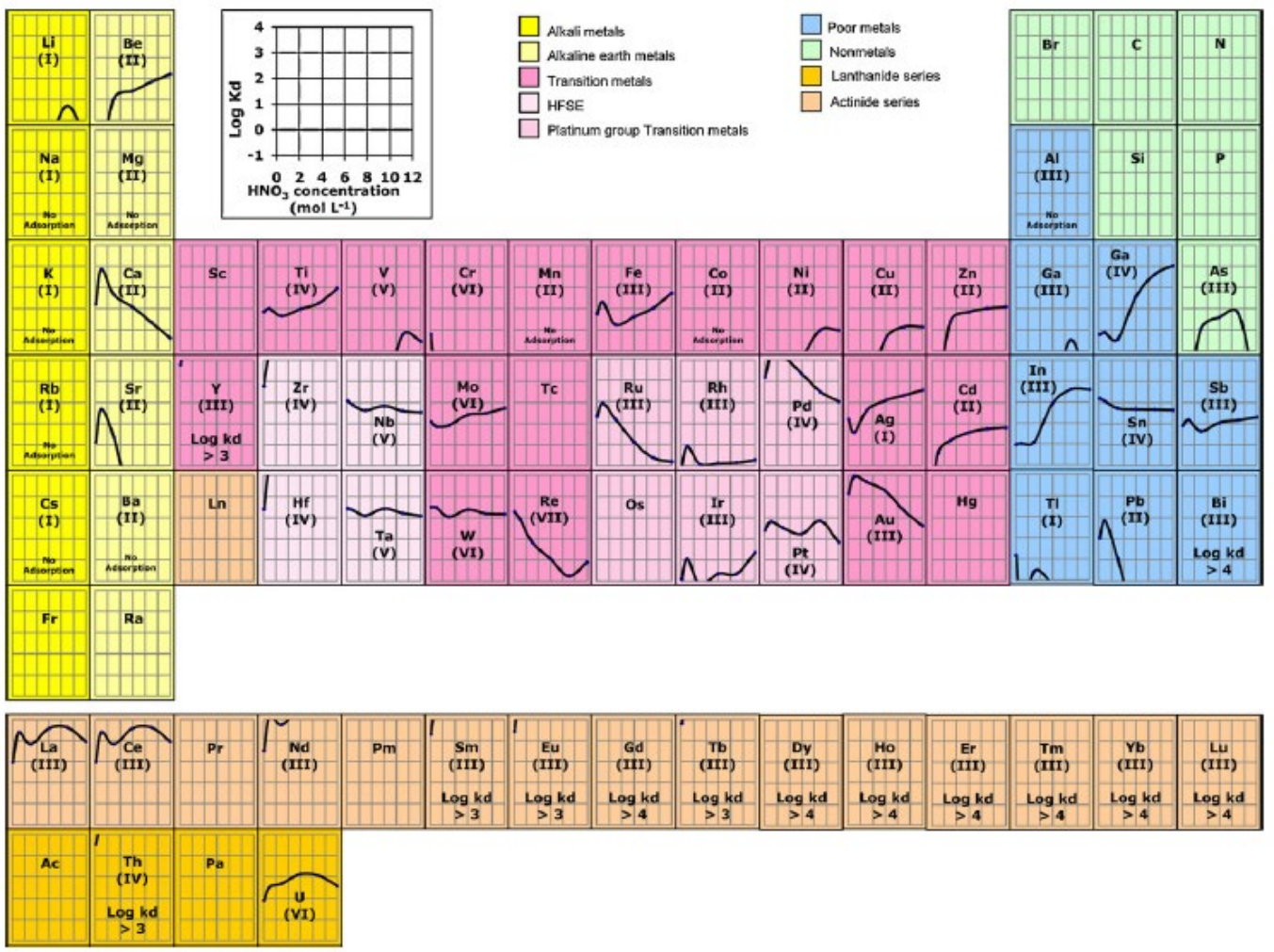

Figure 36 Distribution Coefficients on TODGA Resin vs. HNO3 molarity [38]

Reprinted from Talanta, vol. 81, A. Pourmand and N. Dauphas, Distribution coefficients of 60 elements on TODGA resin: Application to $\mathrm{Ca}, \mathrm{Lu}, \mathrm{Hf}, \mathrm{U}$ and Th isotope geochemistry, pp. 741-753, 2010, with permission from Elsevier.

The production of radioisotopes in the FRIB beam dump loop was approximated (Lu and the same selection of competing elements) using the software developed by scientists at Michigan State University called LISE++ [39]. The number of micrograms produced following a 6-month ${ }^{238} \mathrm{U}$ beam irradiation of a $1.1 \mathrm{~g} / \mathrm{cm}^{2}$ carbon target at FRIB is presented below (Table 6). 


\begin{tabular}{|c|c|r|}
\hline Element & $\begin{array}{c}\mu \mathrm{g} \text { in } \\
\text { beam } \\
\text { dump }\end{array}$ & $\mu$ g in std \\
\hline $\mathrm{Be}$ & 0.33 & 20 \\
\hline $\mathrm{Na}$ & 2.02 & 20 \\
\hline $\mathrm{Ti}$ & 19.90 & 20 \\
\hline $\mathrm{Sc}$ & 4.97 & 20 \\
\hline $\mathrm{Fe}$ & 42.30 & 40 \\
\hline $\mathrm{Co}$ & 21.40 & 20 \\
\hline $\mathrm{Cu}$ & 29.60 & 30 \\
\hline $\mathrm{Y}$ & 211.00 & 200 \\
\hline $\mathrm{Zr}$ & 860.00 & 900 \\
\hline $\mathrm{Ba}$ & 495.00 & 500 \\
\hline $\mathrm{La}$ & 181.00 & 200 \\
\hline $\mathrm{Gd}$ & 251.00 & 300 \\
\hline $\mathrm{Lu}$ & 99.30 & 100 \\
\hline $\mathrm{U}$ & 386000 & \\
\hline Total & & 2370 \\
\hline
\end{tabular}

Table 6 Estimated Beam Dump Concentrations and Experimental Concentrations

The recovery of lutetium from the Purolite NRW100x10 cation resin with Eichrom DGA branched resin was investigated as in previous experiments but with the expected concentrations of competing ions, as illustrated above (Table 6). A surrogate solution was prepared by mixing the competing ions to a total volume of $10 \mathrm{~mL}$ in 0.05 $\mathrm{M} \mathrm{HNO}_{3}$ and loaded onto the cation column. Two hundred microliters of this starting solution were reserved for ICP-MS analysis. The surrogate solution was loaded onto 20 grams of Purolite NRW100x10 resin in a $2.5 \times 50 \mathrm{~cm}$ glass Econo-column and the column washed with $10 \mathrm{~mL}$ of $0.05 \mathrm{M} \mathrm{NO}_{3}$. Forty milliliters of $9 \mathrm{M} \mathrm{HNO}_{3}$ was added to the top of column and mixed by recirculation through the peristaltic pump at a rate of 10 $\mathrm{mL} / \mathrm{min}$. to create a final solution concentration of $6 \mathrm{M} \mathrm{HNO}_{3}$, and total solution volume of $60 \mathrm{~mL}$. After $60 \mathrm{~min}$., the peristaltic pump was slowed to $2 \mathrm{~mL} / \mathrm{min}$ and the Eichrom DGA cartridge was installed inline. The $6 \mathrm{M} \mathrm{HNO}_{3}$ was allowed to circulate through 
both the cation column and the Eichrom DGA cartridge for one hour. The DGA cartridge was disconnected and rinsed (Rinse 1) with $8 \mathrm{~mL}$ of clean $6 \mathrm{M} \mathrm{HNO}_{3}$, which was retained for ICP-MS analysis. The DGA column was then eluted with $10 \mathrm{~mL}$ of $0.05 \mathrm{M}$ $\mathrm{HCl}$, which was also retained for ICP-MS analysis (Elution 1), and then the cartridge was reinstalled in the circulating loop for two additional rinses and elutions. This process was repeated for a total of 3 iterations, each sample point consisting of a one-hour circulation through the Purolite resin and DGA cartridge. The ICP-MS data for each iteration is combined in the table below (Table 7).

\begin{tabular}{|c|c|c|c|c|c|c|c|c|c|c|c|c|c|}
\hline & -9 & & & 5 & 7 & 59 & Cu-63 & $Y-89$ & Zr-91 & a-137 & a-139 & $d-155$ & -175 \\
\hline $\begin{array}{r}\mu \mathrm{g} \text { in } \\
\text { original } \\
\text { fraction }\end{array}$ & $\begin{array}{c}\text { Total Be } \\
(\mu \mathrm{g}) \text { as } \\
\text { measured } \\
\text { using } \\
\text { isotope: }\end{array}$ & $\begin{array}{c}\text { Total Na } \\
(\mu \mathrm{g}) \text { as } \\
\text { measured } \\
\text { using } \\
\text { isotope: }\end{array}$ & \begin{tabular}{|c} 
Total Ti \\
$(\mu \mathrm{g})$ as \\
measured \\
using \\
isotope:
\end{tabular} & $\begin{array}{c}\text { Total Sc } \\
(\mu \mathrm{g}) \text { as } \\
\text { measured } \\
\text { using } \\
\text { isotope: }\end{array}$ & \begin{tabular}{|c|} 
Total Fe \\
$(\mu g)$ as \\
measured \\
using \\
isotope: \\
\end{tabular} & \begin{tabular}{|c|} 
Total Co \\
$(\mu \mathrm{g})$ as \\
measured \\
using \\
isotope:
\end{tabular} & \begin{tabular}{|c} 
Total Cu \\
$(\mu \mathrm{g})$ as \\
measured \\
using \\
isotope:
\end{tabular} & \begin{tabular}{|c|} 
Total Y \\
$(\mu \mathrm{g})$ as \\
measured \\
using \\
isotope: \\
\end{tabular} & $\begin{array}{c}\text { Total Zr } \\
(\mu \mathrm{g}) \text { as } \\
\text { measured } \\
\text { using } \\
\text { isotope: }\end{array}$ & \begin{tabular}{|c|} 
Total Ba \\
$(\mu \mathrm{g})$ as \\
measured \\
using \\
isotope:
\end{tabular} & \begin{tabular}{|c|} 
Total La \\
$(\mu \mathrm{g})$ as \\
measured \\
using \\
isotope:
\end{tabular} & \begin{tabular}{|c|} 
Total Gd \\
$(\mu \mathrm{g})$ as \\
measured \\
using \\
isotope:
\end{tabular} & \begin{tabular}{|c} 
Total Lu \\
$(\mu \mathrm{g})$ as \\
measured \\
using \\
isotope:
\end{tabular} \\
\hline & & & & & & & & & & & & & \\
\hline & & & & & & & & 4 & 3.2 & 4.0 & 178 & 0.7 & \\
\hline & & & & & & & & & & & & & \\
\hline Elut & & & & & & & & 2.0 & 549. & & 125. & 191 & \\
\hline Rins & & & & & & & & & & & & & \\
\hline lut & & & & & & & & 0.5 & & & & & \\
\hline Rinse 3 & & & & & 7 & & & & & & & & \\
\hline Elution 3 & & & & 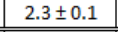 & & & & $6 \pm 0.2$ & 0.5 & 0.1 & $12.9 \pm 0.4$ & $16.9 \pm 0.2$ & $8.45 \pm 0.2$ \\
\hline Extracted & \pm 0.8 & & & & 0 & & 0.4 & $83.2 \pm 0.1$ & $696.2 \pm 0.2$ & \pm 0.1 & $172.9 \pm 0.1$ & $259.5 \pm 0.1$ & 103. \\
\hline 6 Ext & $0.0 \pm 1.5$ & $4.8 \pm 0.6$ & $39.0 \pm 1.7$ & $96.5 \pm 1.3$ & $0.0 \pm 0.8$ & $2.3 \pm 0.3$ & $1.6 \pm 1.1$ & $96.9 \pm 0.4$ & $99.2 \pm 13.2$ & $0.6 \pm 4.0$ & $97.1 \pm 0.4$ & $97.7 \pm 0.7$ & $97.4 \pm 0.6$ \\
\hline
\end{tabular}

\section{Table 7 Micrograms of Element Recovered with 3 Elution Cycles from Eichrom DGA Resin (n=1)}

The results of the $6 \mathrm{M} \mathrm{HNO}_{3}$ recirculation with Eichrom DGA cartridge capture of lanthanides prove this method to be successful. Over $97 \%$ of the lanthanides were recovered (along with $\mathrm{Sc}, \mathrm{Y}$, and $\mathrm{Zr}$ ) from a surrogate system in only $30 \mathrm{~mL}$ of $0.05 \mathrm{M}$ $\mathrm{HCl}$ (three elutions), far less volume than any other evaluated method. Assuming all of the lanthanides were captured in the 100 gallons of beam dump resin, this harvesting scheme represents a concentration factor of over 12,000. Lutetium as an example, after a 
6-month ${ }^{238} \mathrm{U}$ beam, would be present in the resin at a concentration of $0.26 \mathrm{ppb}$, but would be concentrated to over 3 ppm after elution from the Eichrom DGA resin (100 $\mu \mathrm{g}$ in 100 gallons versus $100 \mu \mathrm{g}$ in $30 \mathrm{~mL}$ ).

Although a 6-month ${ }^{238} \mathrm{U}$ beam will generate milligram amounts of uranium in the FRIB beam dump, the surrogate system omitted uranium from the competition studies. This omission was primarily due to the fact that the $\log \mathrm{K}_{\mathrm{d}}$ of the lanthanides ( $\left.>4\right)$ is more than 2 orders of magnitude greater than the $\log K_{d}$ of uranium (2) (Figure 36). In addition, carbonate incorporation upon exposure to the atmosphere during the transfer of spent resin to storage tanks could introduce as much as $1.3 \mathrm{E}-5 \mathrm{M}$ carbonate anion [40]. Under these conditions, uranium $K_{d}$ values would decrease further as uranium converts to a mixture of the singly charged $\left(\mathrm{UO}_{2}\right)_{3}(\mathrm{OH})_{5}{ }^{+}$and $\left(\mathrm{UO}_{2}\right)_{4}(\mathrm{OH})_{7}{ }^{-}$ions at neutral $\mathrm{pH}[41]$.

The batch harvesting of lanthanides from the FRIB beam dump resin can be accomplished as proposed in Figure 37. After six months of use, the mixed-bed resin is pumped from the FRIB beam dump loop into a separation tank (green loop) with 5\% $\mathrm{NaCl}$ solution. In the separation tank, the $500 \mathrm{~mL} / \mathrm{min}$ flow of $5 \% \mathrm{NaCl}$ solution will cause the lighter anion resin to be expelled from the separation tank, while the heavier cation resin remains behind. Upon removal of the anion resin, the cation resin is then pumped to the cation resin tank with water (blue loop). In the cation tank, the lanthanides are eluted by circulating $6 \mathrm{M} \mathrm{HNO}_{3}$ at a rate of $10 \mathrm{~mL} / \mathrm{min}$ (red loop). After at least one hour of circulation, the flowrate is slowed to $2 \mathrm{~mL} / \mathrm{min}$ and the valves are diverted to flow the $6 \mathrm{M} \mathrm{HNO}_{3}$ through the DGA column for capture of lanthanides. After $1 \mathrm{~h}$ of contact with the DGA column, the valves are reset to allow $6 \mathrm{M} \mathrm{HNO}_{3}$ to recirculate through the cation resin and the flowrate reset to $10 \mathrm{~mL} / \mathrm{min}$. While the cation resin loop 
is recirculating, the valves are also diverted to elute the DGA column with $10 \mathrm{~mL}$ of 0.05 $\mathrm{M} \mathrm{HCl}$ at a flowrate of $2 \mathrm{~mL} / \mathrm{min}$. This process of recirculation of $6 \mathrm{M} \mathrm{HNO}_{3}$ through the cation resin, cleaning it with the DGA column, and then eluting the DGA column with $0.05 \mathrm{M} \mathrm{HCl}$ is continued for at least three total iterations. Ninety-seven percent of the lanthanides are removed with this method with only $30 \mathrm{~mL}$ of $0.05 \mathrm{M} \mathrm{HCl}$.

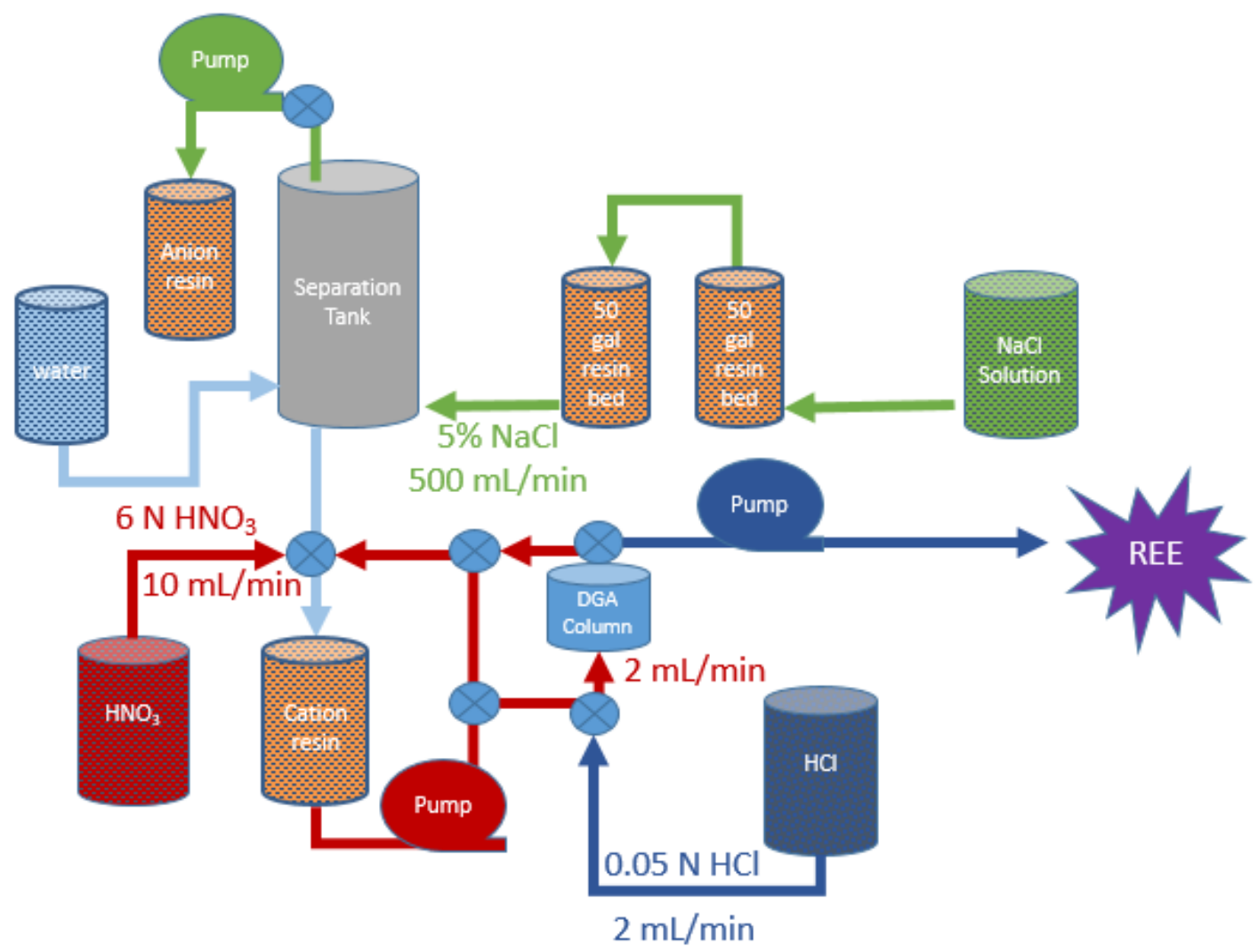

Figure 37 Proposed System for Batch Harvesting of Rare Earth Elements from FRIB Beam Dump Resin 


\section{Chapter 3 HOLLOW FIBER SUPPORTED LIQUID MEMBRANES}

\subsection{Hollow Fiber Supported Liquid Membrane (HFSLM)}

It is necessary in many manufacturing processes to separate, concentrate, and/or purify materials, by-products, and wastes. Industry has addressed this need by the introduction of various membrane technologies, including Hollow Fiber Supported Liquid Membranes, which are popular due to their large surface area to volume ratio. HFSLM contactors have been used for over 20 years in large volume systems to control dissolved gases in many applications, including power plants, pharmaceuticals, and food and beverage industries. In 2014, Disney Land Shanghai commissioned a membrane contractor system to maintain a dissolved oxygen concentration of $<10 \mathrm{ppb}$ in its cooling water system, designed to treat 960 tons/day (Figure 38) [42]. These membrane contactors consist of hydrophobic microporous polypropylene hollow fiber membranes wrapped around a central tube and contained within a contactor housing (Figure 39). During operation, applying vacuum or sweep gas creates a difference in gas concentration between the inside and outside of the membrane, which causes dissolved gas to enter or exit the liquid system. 


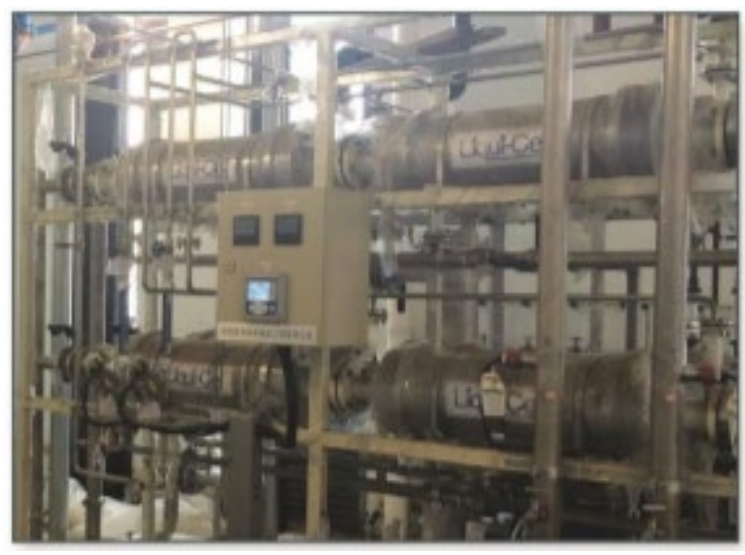

Figure 38 Commercial Liqui-Cel 10x28 Membrane Contactor System [42]

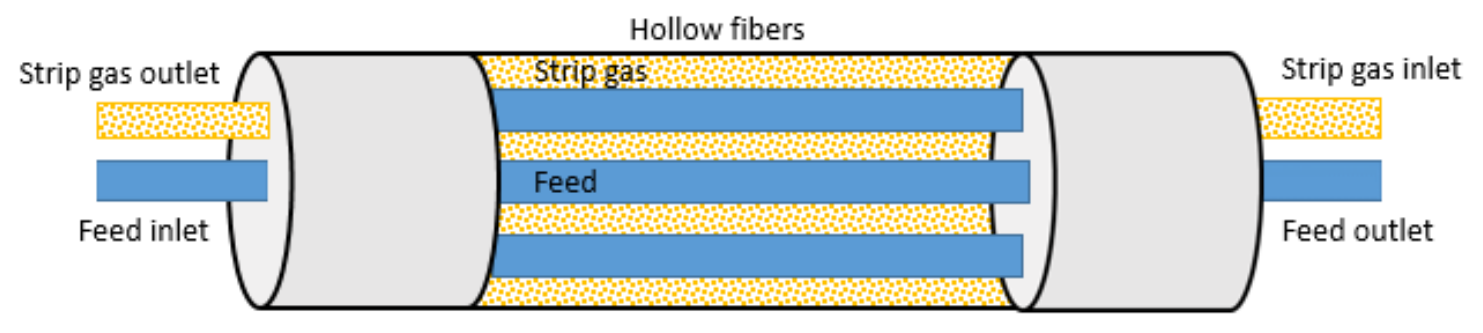

Figure 39 Membrane Contactor for Gas Removal

HFSLM modules are available for use in a wide range of flowrates, from milliliters per minute up to thousands of gallons per minute. Various housing materials are available: polycarbonate, polypropylene, PVC, or stainless steel. The hydrophobic polypropylene membrane has a high breakthrough pressure, which prevents water from passing through the membrane at pressures up to $150 \mathrm{psi}$. The module is designed such that sweep gas flows around the outside (shellside) of the hollow fibers and feed solution travels on the inside (lumenside) of the hollow fibers in the opposite direction. The pores of the hollow fiber membrane can also be loaded with an organic extractant to aid in the transport of nongaseous target species. 


\subsection{HFSLM Extraction}

In the case of HFSLM extraction, a stripping solution replaces the vacuum or sweep gas traditionally used in industrial settings. A water immiscible organic solvent is also embedded in the small pores of the polypropylene membrane and kept there by capillary forces (Figure 40, inset) [43].

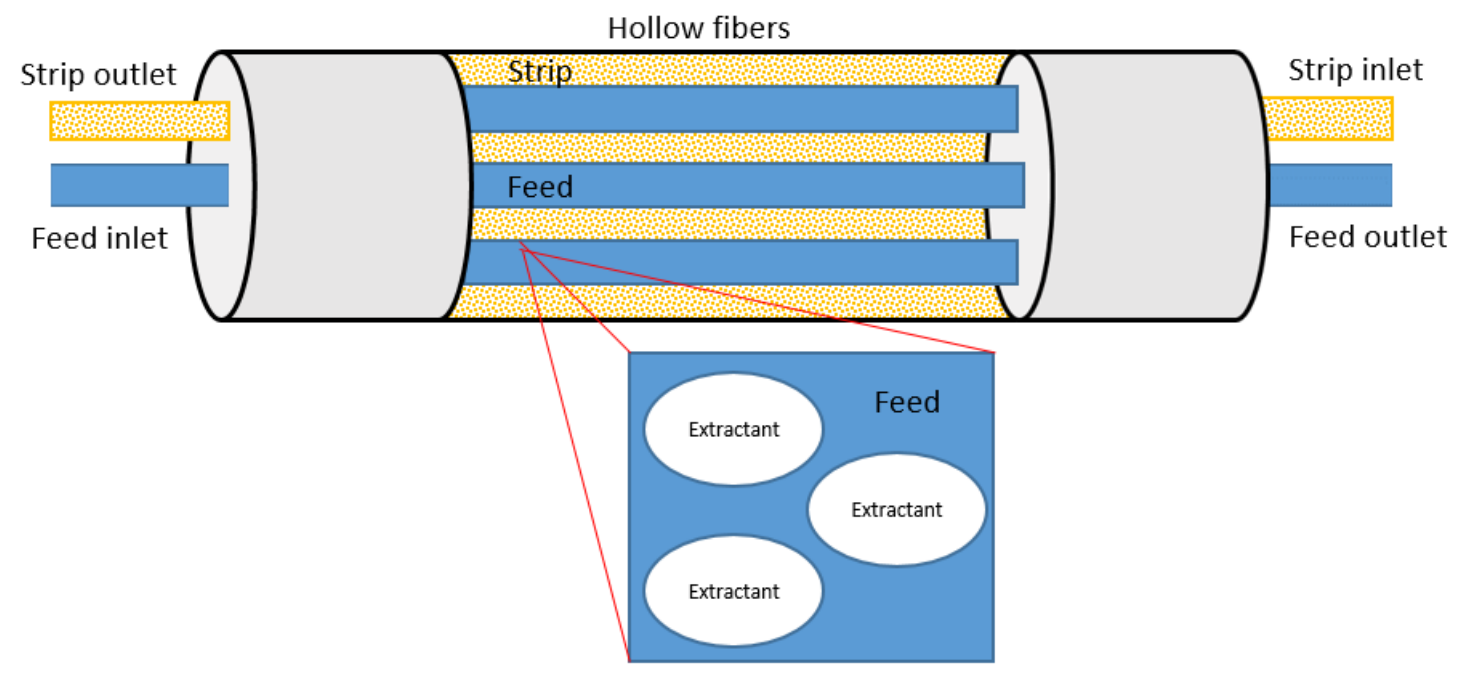

Figure 40 HFSLM for Ion Transport

By loading the organic solvent with an appropriate extractant, specific ions or groups of ions are selectively transported from aqueous feed solutions at low concentrations into the stripping solution, mimicking liquid-liquid extraction techniques with one combined step. HFSLM uses the non-equilibrium conditions of high driving forces over extended periods of time to enhance separation [44]. The feed and strip solutions circulate continuously in a counter-current direction, without mixing the phases. 
As aqueous feed solution travels through the HFSLM module, target species interact with the extractant at the membrane interface to form complex species. The complex species diffuse to the opposite side of the membrane due to a concentration or $\mathrm{pH}$ gradient where they then interact with the stripping solution at the opposite membrane interface. Metal ions are released into the stripping solution at this interface and the extractant moves back to the opposite side of the membrane to react again with target species in the feed solution. The equation [45] [46] for the permeability of target species in recirculation mode is described as follows:

$$
\ln \left(\frac{C_{t}}{C_{o}}\right)=-\frac{A P}{V} * \frac{\phi}{\phi+1} t
$$

where $\mathrm{P}$ is the overall permeability coefficient $(\mathrm{cm} / \mathrm{s}), \mathrm{C}_{\mathrm{t}}$ is the concentration of the target species in the feed at time $t, \mathrm{C}_{\mathrm{o}}$ is the initial concentration of the target species in the feed, $\mathrm{V}$ is the total volume of the feed solution $\left(\mathrm{cm}^{3}\right)$, $\mathrm{A}$ is the total effective surface area of the hollow fiber $\left(\mathrm{cm}^{2}\right)$, and $\phi$ is the module parameter. A is calculated as follows:

$$
A=2 \pi r_{i} L N \epsilon
$$

where $r_{i}$ is the internal radius of the fiber $(\mathrm{cm}), \mathrm{L}$ is the length of the fiber $(\mathrm{cm}), \mathrm{N}$ is the number of fibers, and $\epsilon$ is the membrane porosity (\%). For a module containing $\mathrm{N}$ number of fibers, the module parameter $\phi$ is:

$$
\phi=Q_{T} /\left(P r_{i} L N \pi \epsilon\right)
$$

where $\mathrm{QT}_{\mathrm{T}}$ is the total flow rate of feed solution $\left(\mathrm{cm}^{3} / \mathrm{s}\right), \mathrm{r}_{\mathrm{i}}$ is the internal radius of the fiber $(\mathrm{cm}), \mathrm{L}$ is the length of the fiber (cm), $\epsilon$ is the membrane porosity (\%) [45].

With environmental concerns and solvent costs on the rise, HFSLM modules appear to be a viable alternative to organic solvent extractions used in the nuclear industry. HFSLM modules can extract dilute amounts of target species (as little as $0.25 \mathrm{ppm}$ [45]) 
and concentrate them with minimal use of organic solvent. Some scientists have already begun investigating the application of this membrane technology for the separation of lanthanides and actinides from waste streams using acidified feed solutions, organophosphorus or malonamide based extractants dissolved in organic solvents, and a strong acid stripping agent [44] [47] [48] [49] [50] [51]. These experiments were performed at low feed/strip flow rates on average of $200 \mathrm{~mL} / \mathrm{min}$. The variables determining the extraction efficiency of the membrane include: concentration of metals in the feed solution, extractant concentration, acidity of feed and stripping solutions, membrane configuration, solution temperature, and flow rate of feed and strip solutions.

Further research needs to be performed to determine the performance of this technology at gallon per minute flow rates and durability of the membranes, but preliminary data suggests HFSLM extraction is a viable way to harvest co-produced isotopes in-situ from the primary beam dump loop, unlocking the potential to harvest both short and long-lived isotopes. 


\section{Chapter 4 ISOTOPE HARVESTING - IN SITU VANADIUM FEASIBILITY}

In this work we investigated the use of HFSLM for in-situ recovery of ultra-trace concentrations of isotopes, with the potential for seamless integration into the FRIB primary beam dump loop. If successful, this technology has the potential to allow for the recovery of rare isotopes at a rapid rate even while the beam is in operation. This capability is essential for harvesting shorter-lived isotopes such as ${ }^{48} \mathrm{~V}$, which is important for stockpile stewardship [52] and plant microbiome studies [53] [54]. The 15.98-day half-life makes ${ }^{48} \mathrm{~V}$ a good model for shorter-lived isotopes, and it already has an established HFSLM method for extraction from aqueous solution [55] [56]. In this work, we demonstrate that HFSLM can be used to separate part per trillion levels of ${ }^{48} \mathrm{~V}$ from aqueous solutions spiked with chemically similar species at predicted beam dump production ratios.

\subsection{Vanadium Chemistry in the FRIB beam dump loop}

Vanadium has a complicated aqueous chemistry, governed by both the solution $\mathrm{pH}$ and concentration of the vanadium species. The oxidation states of vanadium can range from as low as -3 to as high as +5 . There is also a rich polyanion chemistry to consider. The vanadate ion, $\mathrm{VO}_{4}{ }^{3-}$ exists in extremely basic solution $(\mathrm{pH} \mathrm{13+})$. The behavior of vanadium at the very dilute concentrations expected in the FRIB beam dump loop is shown in Figure 41. As the $\mathrm{pH}$ decreases from 13, protonation occurs to give the following species [57]:

$$
\mathrm{VO}_{4}{ }^{3-} \rightarrow \mathrm{HVO}_{4}{ }^{2-} \rightarrow \mathrm{H}_{2} \mathrm{VO}_{4}{ }^{-} \rightarrow \mathrm{V}_{2} \mathrm{O}_{5} \rightarrow \mathrm{VO}^{2+}
$$


The vanadium species anticipated to exist at trace concentrations in the neutral $\mathrm{pH}$ of the beam dump loop is the singly charged $\mathrm{H}_{2} \mathrm{VO}_{4}^{-}$. In situations where the solution was more concentrated, however, protonation and dehydration would occur to form $\mathrm{V}_{2} \mathrm{O}_{7}^{4-}$ and higher vanadates [58].

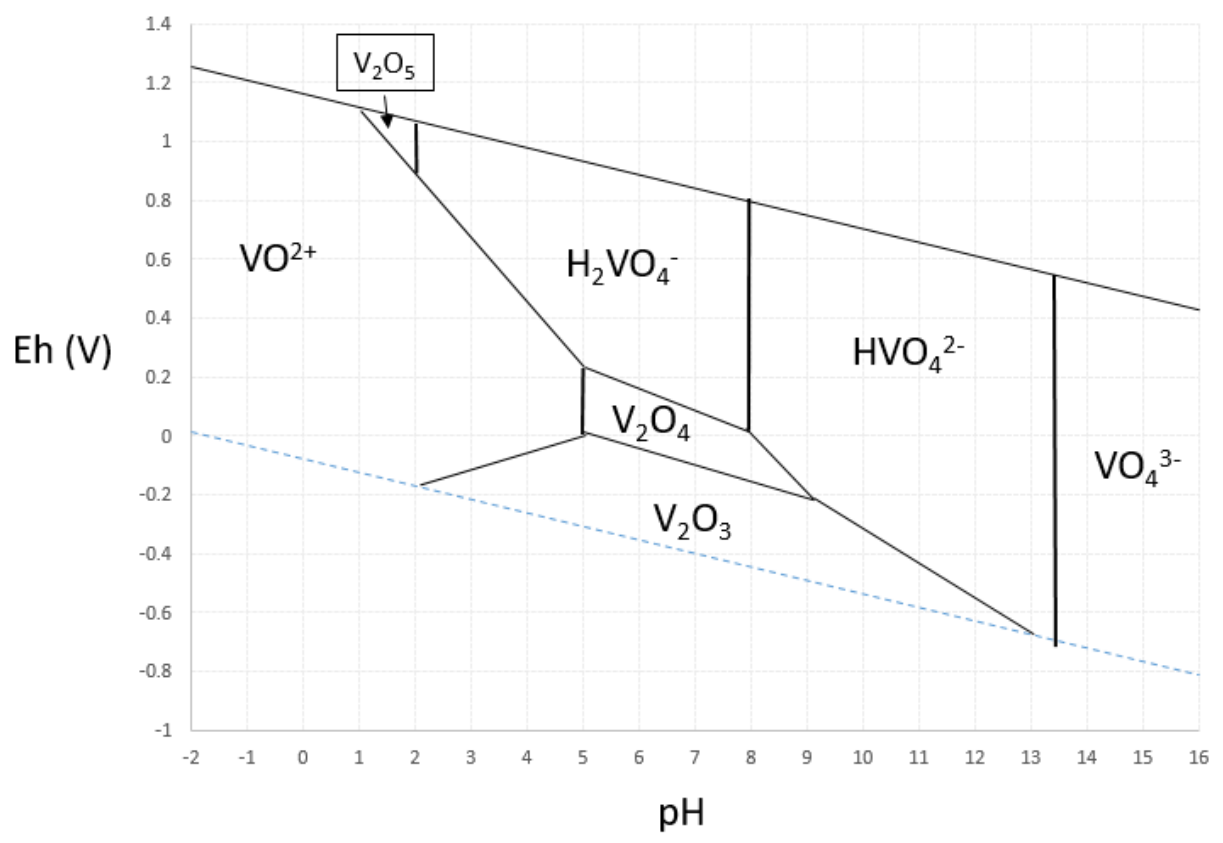

Figure 41 Trace Vanadium Speciation as a Function of pH [59]

Adapted from D. Bookins, Eh-pH Diagrams for Geochemistry, New York: Springer-Verlag, 1988.

\subsection{Calculated Vanadium Production at FRIB}

The production of radioisotopes in the beam dump loop can be approximated using the software developed by scientists at Michigan State University called LISE++ [39]. The number of ${ }^{48} \mathrm{~V}$ atoms produced following a 1 -week ${ }^{58} \mathrm{Ni}$ beam irradiation of a $1.1 \mathrm{~g} / \mathrm{cm}^{2}$ carbon target at FRIB was estimated to be 1.92E17. The number of atoms in the beam dump from the ${ }^{58} \mathrm{Ni}$ beam was estimated to be over 300 times greater. Other elements generated by irradiation, which may form similar species as ${ }^{48} \mathrm{~V}$ (oxoanions) at neutral $\mathrm{pH}$, include: Ti, $\mathrm{Cr}$, and $\mathrm{Mn}$ (formed at the same order of magnitude), and $\mathrm{B}$ and $\mathrm{P}$ (formed at 
10 times less than ${ }^{48} \mathrm{~V}$ level). The radiolysis products and the highly oxidizing conditions found in the beam dump water will introduce some unusual elemental species. These estimates were used to determine the concentration ratios of elements for use in competition studies (Table 8).

\begin{tabular}{|c|c|c|c|}
\hline \multicolumn{3}{|c|}{$\begin{array}{c}\text { Estimated beam dump yield, } \\
\text { 1-week }\end{array}$} & \\
\hline Isotope & particles & ppt & ppt \\
\hline${ }^{48} \mathrm{~V}$ & $1.92 \mathrm{E}+17$ & 2.19 & 8 \\
\hline${ }^{11} \mathrm{~B}$ & $5.00 \mathrm{E}+16$ & 0.13 & 100 \\
\hline${ }^{32} \mathrm{P}$ & $7.46 \mathrm{E}+16$ & 0.57 & 100 \\
\hline${ }^{47} \mathrm{Ti}$ & $2.71 \mathrm{E}+17$ & 3.02 & 10 \\
\hline${ }^{51} \mathrm{Cr}$ & $2.88 \mathrm{E}+17$ & 3.49 & 10 \\
\hline${ }^{53} \mathrm{Mn}$ & $3.59 \mathrm{E}+17$ & 4.52 & 10 \\
\hline${ }^{58} \mathrm{Ni}$ & $6.59 \mathrm{E}+19$ & 907.02 & 10,000 \\
\hline
\end{tabular}

Table 8 Estimated Beam Dump Concentrations in $7000 \mathrm{~L}$ and Experimental Concentrations

\section{3 $\quad{ }^{48}$ Vanadium Properties}

${ }^{48}$ Vanadium decays with a half-life ( $\left.t \frac{1}{2}\right)$ of 15.97 days by positron or electron capture decay to form the stable isotope ${ }^{48}$ Titanium [60]:

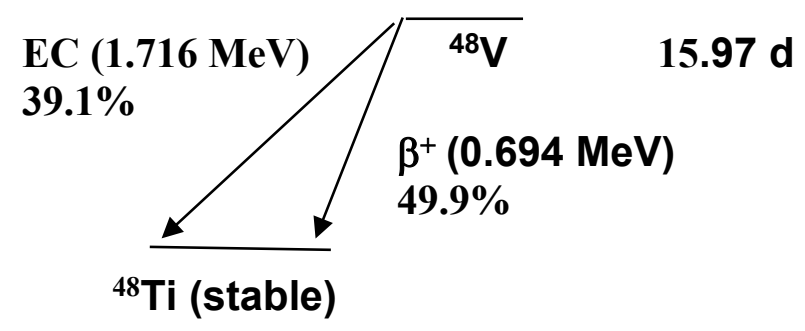

The maximum positron energy for the decay of ${ }^{48} \mathrm{~V}$ to ${ }^{48} \mathrm{Ti}$ is $0.694 \mathrm{MeV}$, and the maximum electron capture decay energy is $1.716 \mathrm{MeV}$ (Table 9). ${ }^{48} \mathrm{~V}$ also emits several 
gamma rays (Table 10), of which the most significant energies and abundancies are: 983 $\mathrm{keV}(99.98 \%)$ and $1312 \mathrm{keV}(97.5 \%)$.

\begin{tabular}{|c|c|}
\hline \multicolumn{2}{|c|}{$\begin{array}{l}{ }^{48} \text { V Positron and E.C. Decay } \\
\text { (15.9735 day half-life) }\end{array}$} \\
\hline Energy (keV) & Intensity (\%) \\
\hline 653.5 & 0.016 \\
\hline 694.68 & 49.9 \\
\hline 772.56 & 7.76 \\
\hline 788.38 & 3.33 \\
\hline 1716.68 & 39.1 \\
\hline
\end{tabular}

\section{Table $9{ }^{48}$ V Positron and Electron Capture Emissions [61]}

\begin{tabular}{|c|c|}
\hline \multicolumn{2}{|c|}{$\mathbf{4 8}^{\mathbf{V}}$ Gamma Decay (15.9735 day half-life) } \\
\hline Energy (keV) & Intensity (\%) \\
\hline 802.87 & 0.150 \\
\hline 928.290 & 0.77 \\
\hline 938 & 0.0008 \\
\hline 944.104 & 7.76 \\
\hline 983.517 & 99.98 \\
\hline 1063.19 & 0.0050 \\
\hline 1312.096 & 97.5 \\
\hline 1437.487 & 0.120 \\
\hline 2240.375 & 2.41 \\
\hline 2375.211 & 0.010 \\
\hline 2420.90 & 0.010 \\
\hline
\end{tabular}

\section{Table $10{ }^{48}$ V Gamma Emissions [61]}

\subsection{Vanadium Cyclotron Production}

The 16.5 MeV GE PETtrace (Figure 42) cyclotron at the University of Missouri Research Reactor (MURR) was employed to produce ${ }^{48} \mathrm{~V}$ by proton irradiation of natural ${ }^{\text {nat }} \mathrm{Ti}$ foils, ${ }^{48} \mathrm{Ti}(\mathrm{p}, \mathrm{n}){ }^{48} \mathrm{~V}$. The activity of ${ }^{48} \mathrm{~V}$ can be calculated based upon the following equation:

$$
A=N I x \sigma\left(1-e^{-\lambda t}\right)
$$


where $N$ is the number of target nuclei/cc, $I$ is the intensity of the beam (charged particles per second), $x$ is the target thickness in $\mathrm{cm}, \sigma$ is the cross section (barns) from the excitation function for ${ }^{48} \mathrm{Ti}$ (Figure 44$), \lambda$ is the decay constant $\left(\mathrm{sec}^{-1}\right)$, and $t$ is the beam exposure time (sec). The cyclotron was operated at $50 \mu \mathrm{A}$, and the natural titanium foil target was a $38 \mathrm{~mm}$ disk with a thickness of 50 microns (Figure 43). For the activity calculation, the $50 \mu \mathrm{m}$ disk was divided into ten theoretical $0.005 \mathrm{~mm}$ slices to account for the stopping power of the titanium foil. The $\mathrm{MeV}$ of the incoming beam decreases by the amount given in the NIST PSTAR database as it passes through each theoretical slice of the titanium target, and the activity of each slice was calculated at this reduced value of beam energy (and corresponding cross section). The summation of the individual ten slices predicts a value of $0.02 \mathrm{mCi}$ of ${ }^{48} \mathrm{~V}$ per $\mu \mathrm{A}$ of beam per hour, see Table 11 . For a $2 \mathrm{~h}$ irradiation, this equates to a theoretical value of $2.23 \mathrm{mCi}$ of ${ }^{48} \mathrm{~V}$, which compares favorably to the value of $2.55 \mathrm{mCi}^{48} \mathrm{~V}$ measured on a Capintec CRC-Ultra at setting 569 following irradiation of the foil at $50 \mathrm{uA}$ for 2 hours. 


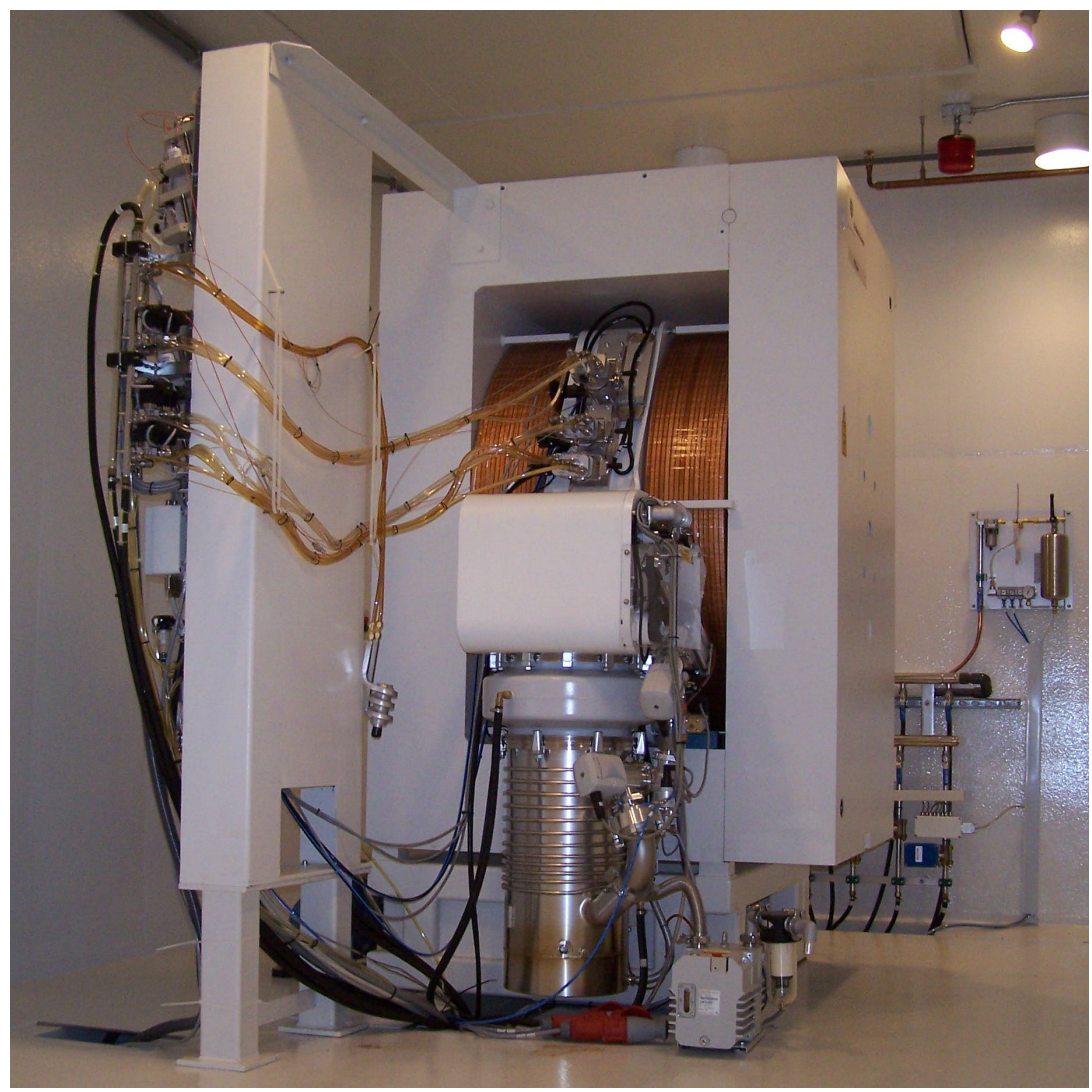

Figure 42 16.5 MeV GE PETtrace Cyclotron at MURR

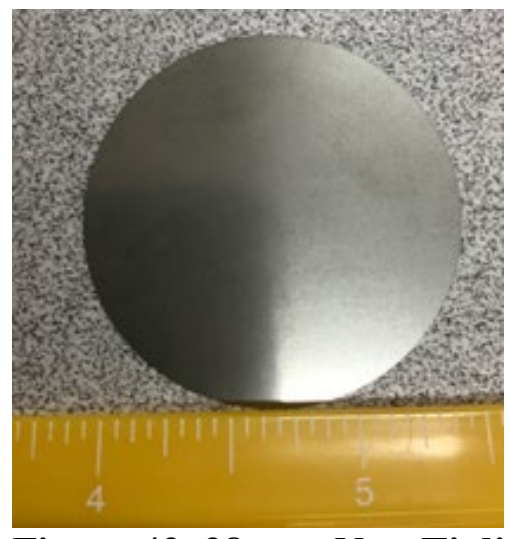

Figure 4338 mm Nat. Ti disk, $50 \mu \mathrm{m}$ Thickness 


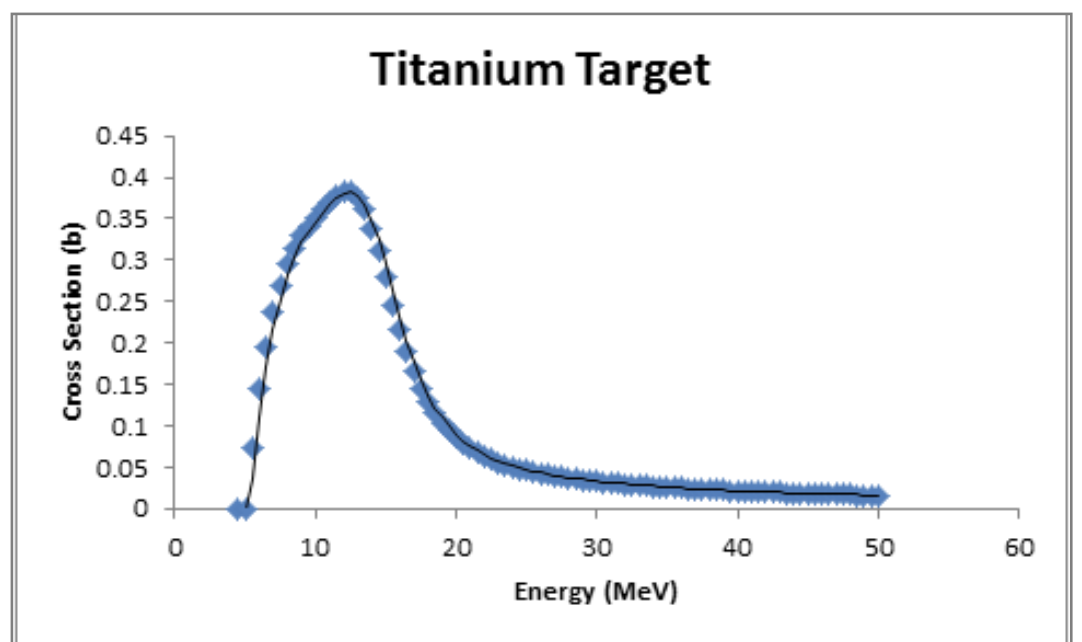

Figure 44 Excitation Function for ${ }^{48} \mathrm{Ti}(\mathrm{p}, \mathrm{n})^{48} \mathrm{~V}$ Reaction from EXFOR Database

\begin{tabular}{|c|c|c|c|c|c|c|c|c|c|c|c|c|c|c|}
\hline layer & $\begin{array}{l}\text { interp. cross } \\
\text { section } \\
\text { (b) }\end{array}$ & $\begin{array}{c}\text { EXFOR } \\
\text { cross section } \\
\text { (cm^-2) }\end{array}$ & $\begin{array}{l}\text { Beam } \\
\text { Energy } \\
\text { (MeV) }\end{array}$ & $\begin{array}{c}\text { Current } \\
\text { (uA) }\end{array}$ & \begin{tabular}{|c|} 
Irradiation \\
Time \\
(sec)
\end{tabular} & $\begin{array}{l}\text { Decay } \\
\text { Time } \\
\text { (sec) } \\
\end{array}$ & $\begin{array}{c}\text { Target } \\
\text { Thickness } \\
(\mathrm{mm})\end{array}$ & \begin{tabular}{|c} 
Target \\
Thickness \\
$\left(\mathrm{g} / \mathrm{cm}^{\wedge} 2\right)$ \\
\end{tabular} & $\begin{array}{l}\text { Stopping Power } \\
\text { (Mev } \mathrm{cm}^{\wedge} 2 / \mathrm{g} \text { ) }\end{array}$ & $\begin{array}{c}\text { Stopping } \\
\text { Power * } \\
\text { Thickness } \\
\text { (MeV) }\end{array}$ & $\mathrm{n}$ & $\begin{array}{c}1 \\
(+/ s)\end{array}$ & $\begin{array}{c}\text { Activity } \\
\text { (dps) }\end{array}$ & $\begin{array}{l}\text { Activity } \\
\text { (mci) }\end{array}$ \\
\hline 1 & 0.1894 & $1.894 \mathrm{E}-25$ & 16.5 & 1 & 3600 & 0 & 0.005 & 0.00227 & 20.29 & 0.04606 & $2.85 \mathrm{E}+19$ & $6.25 \mathrm{E}+12$ & 61023 & 0.0016 \\
\hline 2 & 0.20419818 & \begin{tabular}{|l|}
$2.04198 \mathrm{E}-25$ \\
\end{tabular} & 16.45 & 1 & 3600 & 0 & 0.005 & 0.00227 & 20.34 & 0.09234 & $2.85 \mathrm{E}+19$ & $6.25 \mathrm{E}+12$ & 65791 & \begin{tabular}{|l|}
0.0018 \\
\end{tabular} \\
\hline 3 & 0.206700691 & $2.06701 \mathrm{E}-25$ & 16.36 & 1 & 3600 & 0 & 0.005 & 0.00227 & 20.43 & 0.13913 & $2.85 \mathrm{E}+19$ & $6.25 \mathrm{E}+12$ & 66597 & \begin{tabular}{|l|}
0.0018 \\
\end{tabular} \\
\hline 4 & 0.210471068 & $2.10471 \mathrm{E}-25$ & 16.22 & 1 & 3600 & 0 & 0.005 & 0.00227 & 20.56 & 0.18668 & $2.85 E+19$ & $6.25 E+12$ & 67812 & \begin{tabular}{|l|}
0.0018 \\
\end{tabular} \\
\hline 5 & 0.215530227 & $2.1553 \mathrm{E}-25$ & 16.04 & 1 & 3600 & 0 & 0.005 & 0.00227 & 20.74 & 0.23540 & $2.85 \mathrm{E}+19$ & $6.25 E+12$ & 69442 & \begin{tabular}{|l|}
0.0019 \\
\end{tabular} \\
\hline 6 & 0.240652229 & $2.40652 \mathrm{E}-25$ & 15.80 & 1 & 3600 & 0 & 0.005 & 0.00227 & 20.98 & 0.28575 & $2.85 \mathrm{E}+19$ & $6.25 E+12$ & 77536 & \begin{tabular}{|l|}
0.0021 \\
\end{tabular} \\
\hline 7 & 0.24640528 & $2.46405 E-25$ & 15.51 & 1 & 3600 & 0 & 0.005 & 0.00227 & 21.28 & 0.33814 & $2.85 E+19$ & $6.25 \mathrm{E}+12$ & 79390 & 0.0021 \\
\hline 8 & 0.275784838 & $2.75785 \mathrm{E}-25$ & 15.18 & 1 & 3600 & 0 & 0.005 & 0.00227 & 21.63 & 0.39280 & $2.85 \mathrm{E}+19$ & $6.25 E+12$ & 88856 & \begin{tabular}{|l|}
0.0024 \\
\end{tabular} \\
\hline 9 & 0.306614052 & $3.06614 \mathrm{E}-25$ & 14.78 & 1 & 3600 & 0 & 0.005 & 0.00227 & 22.08 & 0.45109 & $2.85 E+19$ & $6.25 \mathrm{E}+12$ & 98789 & \begin{tabular}{|l|}
0.0027 \\
\end{tabular} \\
\hline 10 & 0.335273522 & $3.35274 \mathrm{E}-25$ & 14.33 & 1 & 3600 & 0 & 0.005 & 0.00227 & 22.6 & 0.51302 & $2.85 \mathrm{E}+19$ & $6.25 \mathrm{E}+12$ & 108023 & 0.0029 \\
\hline Total & & & & & & & \multicolumn{2}{|l|}{0.05} & & & & & & 0.0 \\
\hline
\end{tabular}

Table 11 Approximate ${ }^{48} \mathrm{~V}$ Activity/ $\mu$ Ahr using 10 Equal Slices

\subsection{Materials and Methods}

Titanium foil, $0.127 \mathrm{~mm}$ thick, 99.99+\% was obtained from Alfa Aesar. Metal free centrifuge tubes were obtained from Labcon. Single element ICP standards were obtained from High Purity Standards. Nitric acid (69\%, Optima Grade), $60 \mathrm{~mL}$ borosilicate glass test tubes, ammonium nitrate (A.C.S. grade), ammonium hydroxide (Optima grade), sulfuric acid (A.C.S. grade), and hydrogen peroxide (30\%, A.C.S. grade) were obtained from ThermoFisher Scientific. Aliquat 336 (MW 442) and dodecane (99\%) were obtained from Acros Organics. AG50x8 resin (100-200 mesh) was obtained from Bio-Rad, USA. 1-Dodecanol ( $\geq 98 \%$, A.C.S. grade) was obtained from Sigma. 
The Hollow Fiber Supported Liquid Membrane (Membrane Contactor) was a Liqui-Cel $2.5 \times 8$ manufactured by $3 \mathrm{M}$. Membrane contactor flow rates were maintained with a Masterflex peristaltic pump 7-200 rpm, equipped with an easy load II pumphead.

Elemental analysis was performed at the University of Missouri Research Reactor on a PerkinElmer NexION 300X ICP-MS operated in KED (Kinetic Energy Discrimination) mode with a helium flow of $3.5 \mathrm{~mL} / \mathrm{min}$. Each isotope was acquired as 5 replicates of 10 sweeps, with $50 \mathrm{~ms}$ dwell time per sweep. Internal standards In and T1 were used to normalize data and account for instrument drift. Standards were prepared from dilutions of commercial High Purity Standards multi-element stock solutions.

Elemental analysis of radioactive samples was performed at the University of Missouri Research Reactor on a Perkin Elmer ICP-OES 2100 using axial plasma view, plasma gas flow of $15 \mathrm{~L} / \mathrm{min}$, auxiliary gas flow of $0.2 \mathrm{~L} / \mathrm{min}$, nebulizer gas flow of 0.7 $\mathrm{L} / \mathrm{min}$, and peristaltic pump rate of $0.40 \mathrm{~mL} / \mathrm{min}$. Each sample was acquired as 5 replicates with 7 points per peak, and utilizing $\mathrm{Y}$ as an internal standard. Standards were prepared from dilutions of commercial High Purity Standards stock solutions.

Radiotracers were evaluated at the University of Missouri Research Reactor on a 23\% relative efficiency high purity germanium detector (Canberra Model GC2018S, coaxial p-type crystal), geometry calibrated with a NIST-traceable mixed-gamma standard. Samples were counted for $10 \mathrm{~min}$. with dead times below $10 \%$, and the software for data acquisition and analysis was Canberra Genie PROcount 2000 V3.3.

For the titanium target dissolution experiments, approximately $60 \mathrm{mg}$ of titanium foil was refluxed with $5 \mathrm{~mL}$ of $6 \mathrm{M} \mathrm{H}_{2} \mathrm{SO}_{4}$ (A.C.S. grade) for approximately $5 \mathrm{~h}$. The resulting purple solution was taken to $70 \mathrm{~mL}$ with water for testing. 
For the AG50x8 column separation experiments, an approximately 15 g AG50x8 cation resin column was prepared $(13 \mathrm{~cm} \times 1.5 \mathrm{~cm})$ and the purple titanium solution prepared above was passed through the column with a syringe for titanium removal. After loading, the vanadium was eluted from the AG50x8 column with $3 \times 10 \mathrm{~mL}$ fractions of $1 \% \mathrm{H}_{2} \mathrm{O}_{2}$ (A.C.S. grade) in $0.01 \mathrm{M}$ Optima $\mathrm{HNO}_{3}$ [62]

For the liquid-liquid extraction experiments, solutions were prepared in $60 \mathrm{~mL}$ vials and mixed with a stirbar for up to 60 minutes. Vanadium extraction was measured by HPGe gamma spectroscopy. The vanadium extraction efficiency was determined by mixing $20 \mathrm{~mL}$ of $2 \mathrm{ppm}$ vanadium solution prepared in water with $20 \mathrm{~mL}$ of varying concentrations of Aliquat 336 in 3\% dodecanol/dodecane organic solution. Samples were taken at 15 min. intervals while mixing with a stir bar and were analyzed by ICP-MS. . The vanadium stripping efficiency of $0.5 \mathrm{M}$ ammonia in $0.1 \mathrm{M}$ ammonium nitrate was also investigated by measuring the stripping of vanadiuim from the $0.05 \mathrm{M}$ Aliquat 336 in 3\% dodecanol/dodecane into varying $\mathrm{pH}$ levels of $0.5 \mathrm{M}$ ammonia in $0.1 \mathrm{M}$ ammonium nitrate. The vanadium stripping experiment was performed in $60 \mathrm{~mL}$ borosilicate glass test tubes to evaluate the effect of strip solution $\mathrm{pH}$ on the extraction of vanadium. Fifty microgram solutions of vanadium were prepared in $0.05 \mathrm{M}$ Aliquat 336 in 3\% dodecanol/dodecane and mixed with an equal volume of $0.5 \mathrm{M}$ ammonia in $0.1 \mathrm{M}$ ammonium nitrate (at varying $\mathrm{pH}$ ) to determine optimum stripping conditions. Samples were taken after 60 minutes of mixing with a stir bar and analyzed by ICP-MS.

For the HFSLM experiments, the liquid membrane was prepared by dissolving $0.15 \mathrm{M}$ Aliquat 336 in 3\% dodecanol/dodecane and this organic solution was circulated into the lumen side of the HFSLM system (under 3 p.s.i. pressure) for at least two hours 
[55] to permeate the membrane pores, while the shell side of the membrane remained open to air. After charging with the organic solution, the excess organic solution was pumped out of the system and the entire system washed with deionized water for $30 \mathrm{~min}$. The deionized water rinsing step was performed three times. Following rinsing, $500 \mathrm{~mL}$ of the feed solution was pumped into the lumen side and $500 \mathrm{~mL}$ of the stripping solution was pumped counter-currently into the shell side, operating the unit in recirculation mode. The feed solution was aqueous vanadium at neutral $\mathrm{pH}$ in a closed system (slightly pressurized at 3 p.s.i.). The strip solution was $0.5 \mathrm{M}$ ammonia in $0.1 \mathrm{M}$ ammonium nitrate at $\mathrm{pH} 9-10$, open to the atmosphere. Flow rates of both the feed and stripping solutions were maintained at 6 gph $(\sim 450 \mathrm{~mL} / \mathrm{min})$ by peristaltic pump (checked by flowmeter) throughout the experiments. Feed and strip reservoirs were stirred throughout the experiment with stirbars. For the competition study, the feed solution also contained $10 \mathrm{ppt}$ of $\mathrm{Mn}, \mathrm{Cr}$, and $\mathrm{Ti} ; 100 \mathrm{ppt}$ of $\mathrm{B}$, and $\mathrm{P}$; and $10 \mathrm{ppb}$ of $\mathrm{Ni}$. Initial and final 1-mL samples were taken from the feed solution, and periodic 1-mL samples were taken from the strip solutions throughout the run. All samples were analyzed for ${ }^{48} \mathrm{~V}$ by HPGe gamma spectroscopy.

\section{6 ${ }^{48}$ Ti Target Dissolution/Purification Experiments}

Initial experiments focused upon the method for dissolution of an irradiated

titanium foil and separation and isolation of the ${ }^{48} \mathrm{~V}$. A $38 \mathrm{~mm}$ diameter 50 -micron ${ }^{48} \mathrm{Ti}$ foil was irradiated at $50 \mu \mathrm{A}$ for two hours. The approximately $1 / 2$ " circle of beam bombardment area (Figure 45) was removed from the foil with scissors and refluxed with $5 \mathrm{~mL}$ of $6 \mathrm{M} \mathrm{H}_{2} \mathrm{SO}_{4}$ (A.C.S. grade) for approximately $5 \mathrm{~h}$. The resulting purple solution was taken to $70 \mathrm{~mL}$ with water and transferred to a syringe body. The liquid was then 
pushed through a cation-exchange column containing 15 grams of AG50-X8 resin, 100200 mesh (Bio-Rad, USA) for titanium removal. The ${ }^{48} \mathrm{~V}$ was eluted with $3 \times 10 \mathrm{~mL}$ fractions of $1 \% \mathrm{H}_{2} \mathrm{O}_{2}$ (A.C.S. grade) in $0.01 \mathrm{M}$ Optima $\mathrm{HNO}_{3}$ [62].

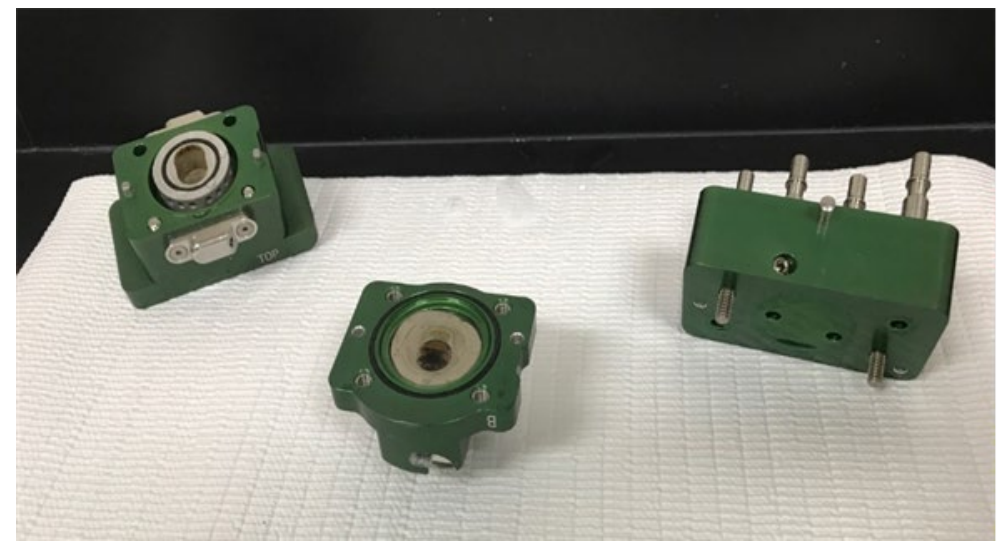

\section{Figure 45 Cyclotron Target Assembly with Irradiated Ti Foil}

\subsection{AG50 Column Separation/Recovery}

An experiment was performed in order to determine the purity and AG50x8 column recovery for ${ }^{48} \mathrm{~V}$. A $38 \mathrm{~mm}$ diameter 50 -micron ${ }^{48} \mathrm{Ti}$ foil was irradiated at $50 \mu \mathrm{A}$ for two hours. The approximately $1 / 2$ " circle of beam bombardment area was removed from the foil with scissors and refluxed with $5 \mathrm{~mL}$ of $6 \mathrm{M} \mathrm{H}_{2} \mathrm{SO}_{4}$ (A.C.S. grade) for approximately 5 hours. The resulting purple solution was taken to $70 \mathrm{~mL}$ with water and transferred to a syringe body. One third of the sample was retained and the remaining two thirds was passed through an AG50x8 cation resin column. The pre and post column solutions were measured on a HPGe gamma-ray spectrometer.

The initial $70 \mathrm{~mL}$ pre-column sample of dissolved target had decay corrected activities of $2562 \mu \mathrm{Ci}{ }^{48} \mathrm{~V}, 46 \mu \mathrm{Ci}{ }^{47} \mathrm{Sc}$, and $33 \mu \mathrm{Ci}{ }^{44 \mathrm{~m}} \mathrm{Sc}$. The one third retained sample showed activities of $734 \mu \mathrm{Ci}{ }^{48} \mathrm{~V}, 19 \mu \mathrm{Ci}{ }^{47} \mathrm{Sc}$, and $13 \mu \mathrm{Ci}{ }^{44 \mathrm{~m}} \mathrm{Sc}$, while the post-column sample showed $1626 \mu \mathrm{Ci}{ }^{48} \mathrm{~V}$ and below detection limit of Sc activity. The column 
recovery was $89 \%$ for ${ }^{48} \mathrm{~V}$ and there were no other isotopes detected in the final postcolumn sample.

\subsection{Vanadium Liquid-Liquid Extraction}

Liquid-liquid extraction experiments in $60 \mathrm{~mL}$ borosilicate glass test tubes (Figure 46) were used to evaluate the expected behavior of vanadium during HFSLM extraction [55]. Twenty milliliters of $2 \mathrm{ppm}$ vanadium solution was prepared in water, and mixed with $20 \mathrm{~mL}$ of varying concentrations of Aliquat 336 in 3\% dodecanol/dodecane organic solution to determine optimum extraction conditions. Samples were taken at $15 \mathrm{~min}$. intervals while mixing with a stir bar and were analyzed by ICP-MS (Figure 47), with an average error of $\pm 1.8 \%$.

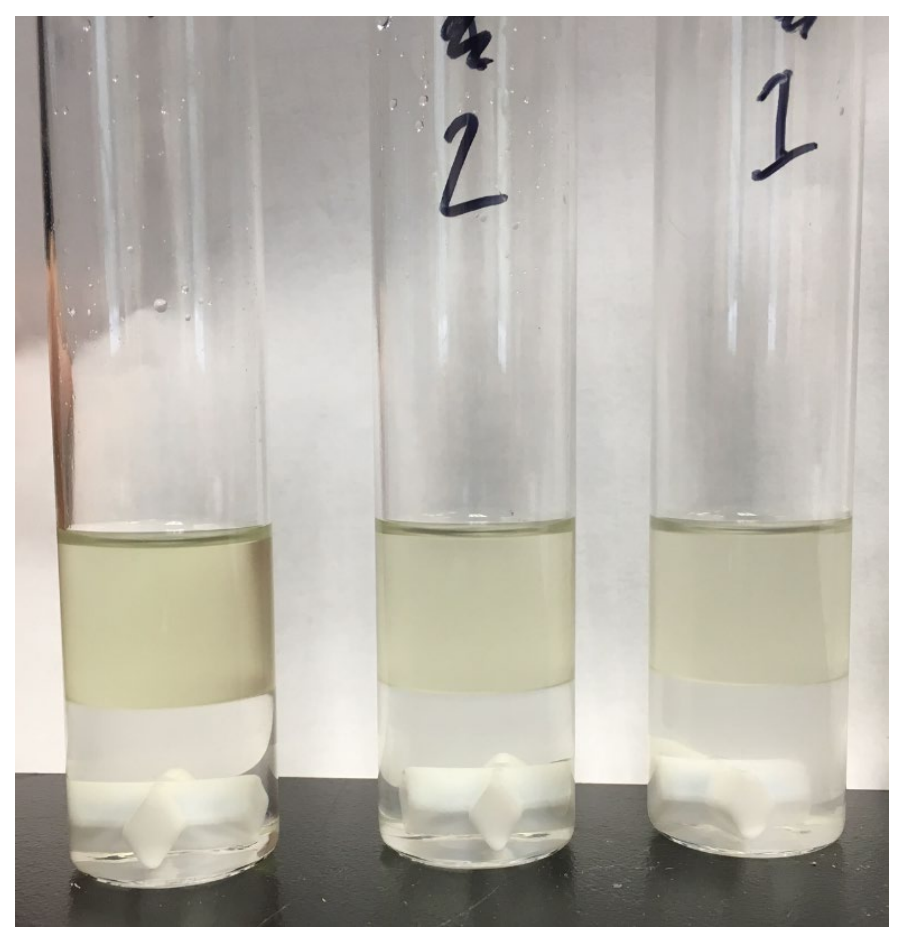

Figure 46 Test Tube Liquid-Liquid Extraction of Vanadium with Aliquot 336 


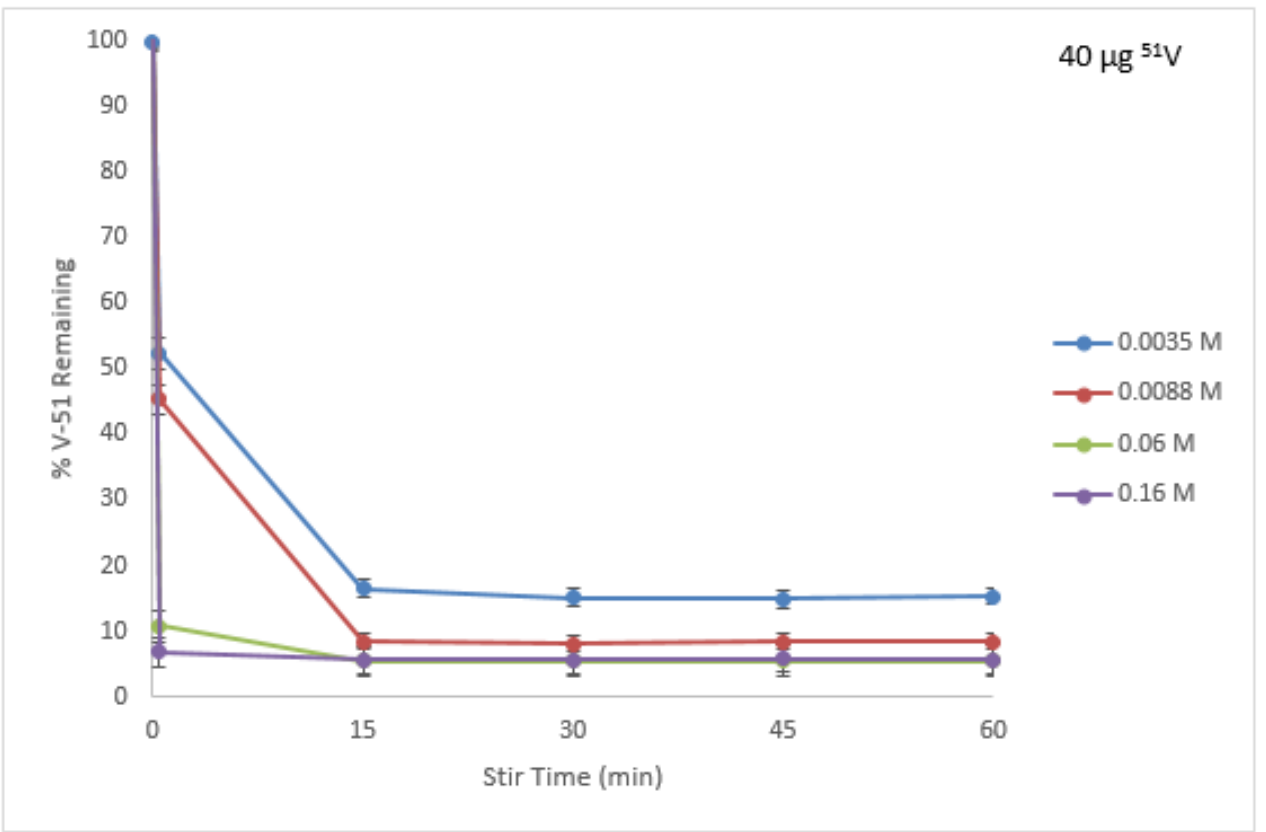

Figure 47 Vanadium Concentration in Water vs Mixing Time with Various Aliquat 336 Concentrations $(n=1)$

A second liquid-liquid extraction experiment was performed in $60 \mathrm{~mL}$ borosilicate glass test tubes to evaluate the effect of strip solution $\mathrm{pH}$ on the extraction of vanadium. Fifty microgram solutions of vanadium were prepared in $0.05 \mathrm{M}$ Aliquat 336 in 3\% dodecanol/dodecane and mixed with an equal volume of $0.5 \mathrm{M}$ ammonia in $0.1 \mathrm{M}$ ammonium nitrate (at varying $\mathrm{pH}$ ) to determine optimum stripping conditions. Samples were taken after 60 minutes of mixing with a stir bar and analyzed by ICP-MS (Figure 48), with an average error of $\pm 2.2 \%$. 


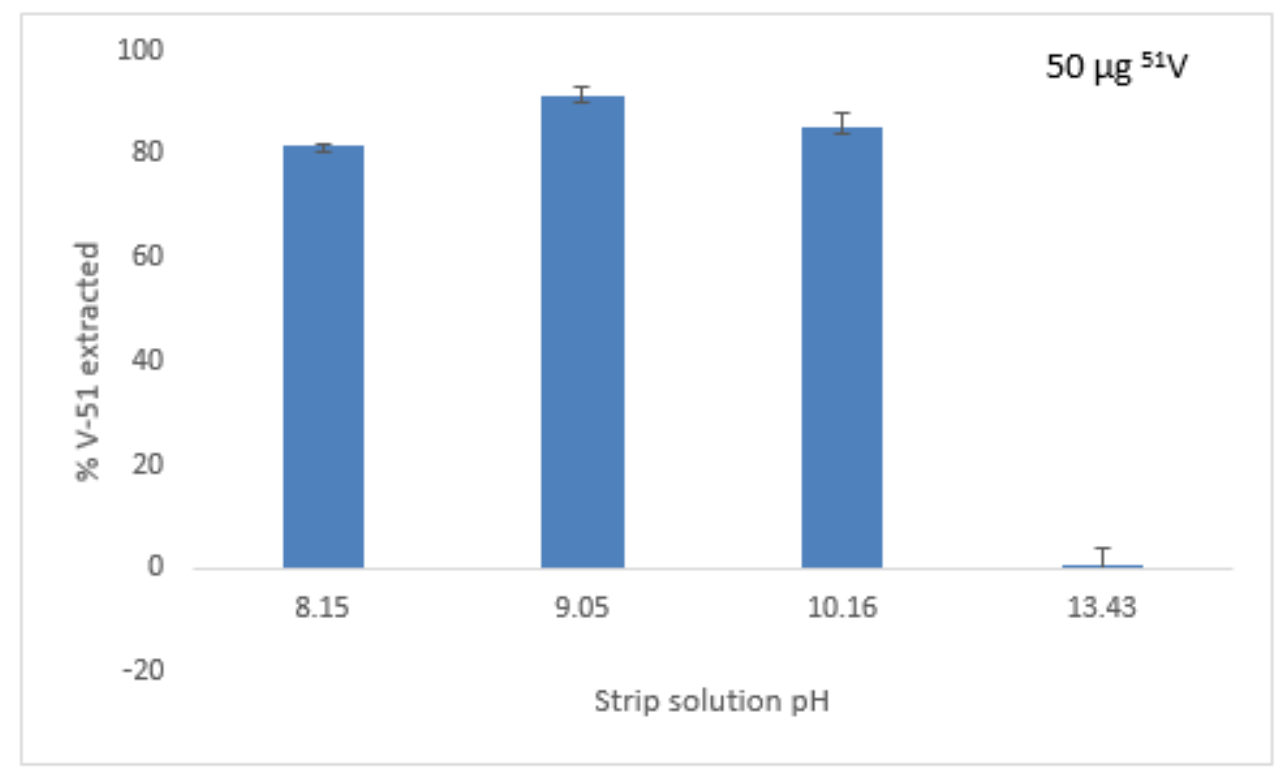

Figure 48 Vanadium Stripping from Aliquat 336:Dodecane vs Strip Solution pH $(\mathbf{n}=\mathbf{1})$

The first experiment investigating vanadium extraction from the aqueous layer into the organic layer showed that the maximum extraction of vanadium ( $>90 \%)$ occurred with concentrations of 0.06 to $0.16 \mathrm{M}$ Aliquat 336 in 3\% dodecanol/dodecane organic solution after 60 minutes. The second experiment showed maximum vanadium stripping from the organic layer occurred with strip solution $\mathrm{pH}$ values between 8 and 10. Stripping solution $\mathrm{pH}$ values below 8 were not investigated because this would cause the elimination of the $\mathrm{pH}$ gradient between the feed and stripping solutions. The $90 \%$ recovery of vanadium in both of these experiments suggest that HFSLM extraction is possible using these conditions.

\subsection{Vanadium HFSLM Extraction}

The HFSLM cartridge used for vanadium experiments is a Liqui-Cel $2.5 \times 8$ manufactured by $3 \mathrm{M}$ (Table 12). The liquid membrane was prepared by dissolving 0.15 M Aliquat 336 in 3\% dodecanol/dodecane and this organic solution was circulated into 
the lumen side of the HFSLM system (under 3 p.s.i. pressure) for at least two hours [55] to permeate the membrane pores, while the shell side of the membrane remained open to air. After charging with the organic solution, the excess organic solution was pumped out of the system and the entire system washed with deionized water for $30 \mathrm{~min}$. The deionized water rinsing step was performed three times. Following rinsing, the feed solution was pumped into the lumen side and the stripping solution was pumped countercurrently into the shell side, operating the unit in recirculation mode. The feed solution was aqueous at neutral $\mathrm{pH}$ in a closed system (slightly pressurized at 3 p.s.i.). The strip solution was $0.5 \mathrm{M}$ ammonia in $0.1 \mathrm{M}$ ammonium nitrate at $\mathrm{pH}$ 9-10, open to the atmosphere. Flow rates of both the feed and stripping solutions were maintained at $6 \mathrm{gph}$ ( $\sim 50 \mathrm{~mL} / \mathrm{min}$ ) by flowmeter throughout the experiments. Feed and strip reservoirs were stirred throughout the experiment and arranged as illustrated in Figure 49.

\begin{tabular}{||l|l||}
\hline \hline Characteristics & Descriptions \\
\hline Model & Liqui-Cel $2.5 \times 8$ Extra-Flow \\
\hline Module diameter $(\mathrm{mm})$ & 66.6 \\
\hline Module length $(\mathrm{mm})$ & 281.8 \\
\hline Inside diameter of hollow fiber $(\mu \mathrm{m})$ & 240 \\
\hline Outside diameter of hollow fiber $(\mu \mathrm{m})$ & 300 \\
\hline Effective length of hollow fiber $(\mathrm{cm})$ & 15 \\
\hline Number of hollow fibers & 35,000 \\
\hline Average pore size $(\mu \mathrm{m})$ & 0.03 \\
\hline Porosity $(\%)$ & 25 \\
\hline Effective surface area $\left(\mathrm{cm}^{2}\right)$ & $1.4 \times 10^{4}$ \\
\hline Area per unit volume $\left(\mathrm{cm}^{2} / \mathrm{cm}^{3}\right)$ & 29.3 \\
\hline Tortuosity factor & 2.6 \\
\hline Operating temperature $(\mathrm{C})$ & $5-70$ \\
\hline Recommended flow rate $(\mathrm{gpm})$ & $0.5-3(900-11350 \mathrm{~mL} / \mathrm{min})$ \\
\hline Membrane Material & $\mathrm{xp} 5$ polypropylene $\mathrm{membrane}$ \\
\hline Max. pressure $(\mathrm{psi})$ & 120 \\
\hline
\end{tabular}

Table 12 HFSLM Liqui-Cel Specifications 


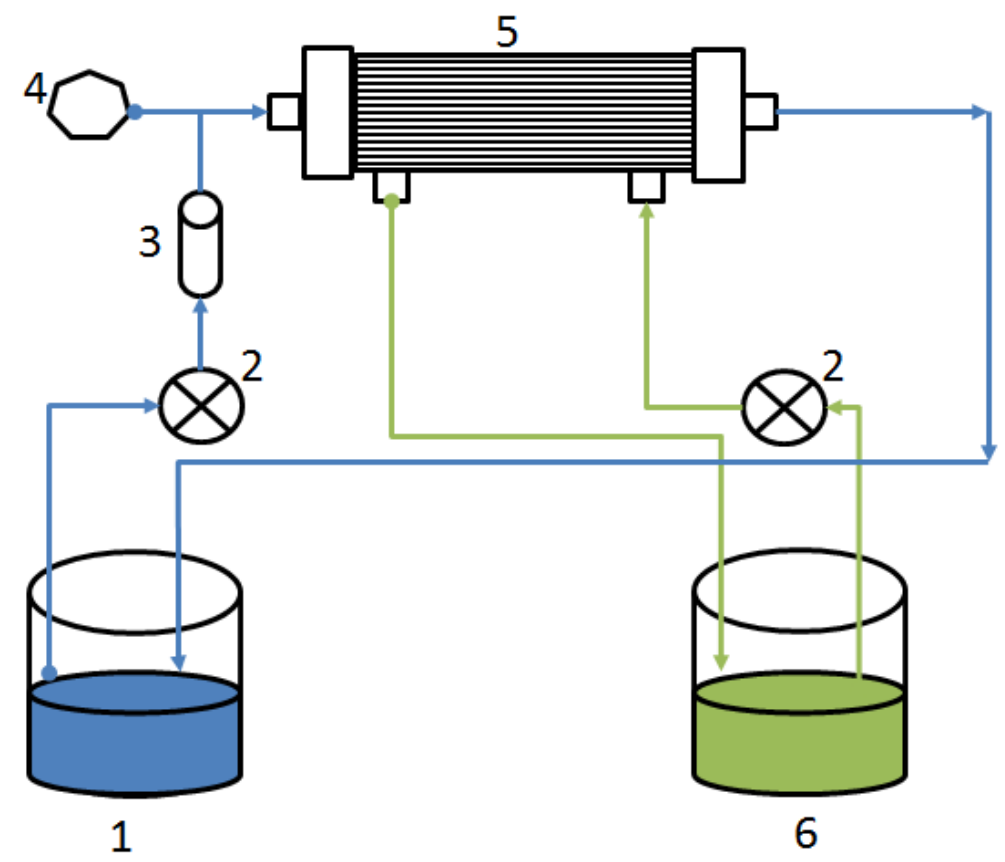

Figure 49 Counter-Current Flow Diagram for HFSLM Recycle Mode Operation

1)feed reservoir (pressurized) 2)peristaltic pumps 3)flow meter 4)pressure gauge 5)hollow fiber module 6)stripping reservoir

In the neutral $\mathrm{pH}$ feed solution, the vanadium exists as the $\mathrm{VO}_{2}(\mathrm{OH})_{2}^{-}$ion, which displaces the chloride on the Aliquat 336:

$$
\mathrm{R}_{4} \mathrm{~N}^{+} \mathrm{Cl}^{-}+\mathrm{VO}_{2}(\mathrm{OH})^{-} 2=>\mathrm{R}_{4} \mathrm{~N}^{+} \mathrm{VO}_{2}(\mathrm{OH})^{-}{ }_{2}+\mathrm{Cl}^{-}
$$

The basic $\mathrm{pH}$ of the strip solution causes the vanadium ion to form $\mathrm{VO}_{3} \mathrm{OH}^{2-}$ and cleave from the Aliquat 336:

$$
\mathrm{R}_{4} \mathrm{~N}^{+} \mathrm{VO}_{2}(\mathrm{OH})^{-}{ }_{2}+2 \mathrm{OH}^{-}=>\mathrm{R}_{4} \mathrm{~N}^{+} \mathrm{OH}^{-}+\mathrm{VO}_{3} \mathrm{OH}^{2-}+\mathrm{H}_{2} \mathrm{O}
$$

The Aliquat 336 continues to shuttle vanadium to the strip phase as illustrated by Figure 50. 


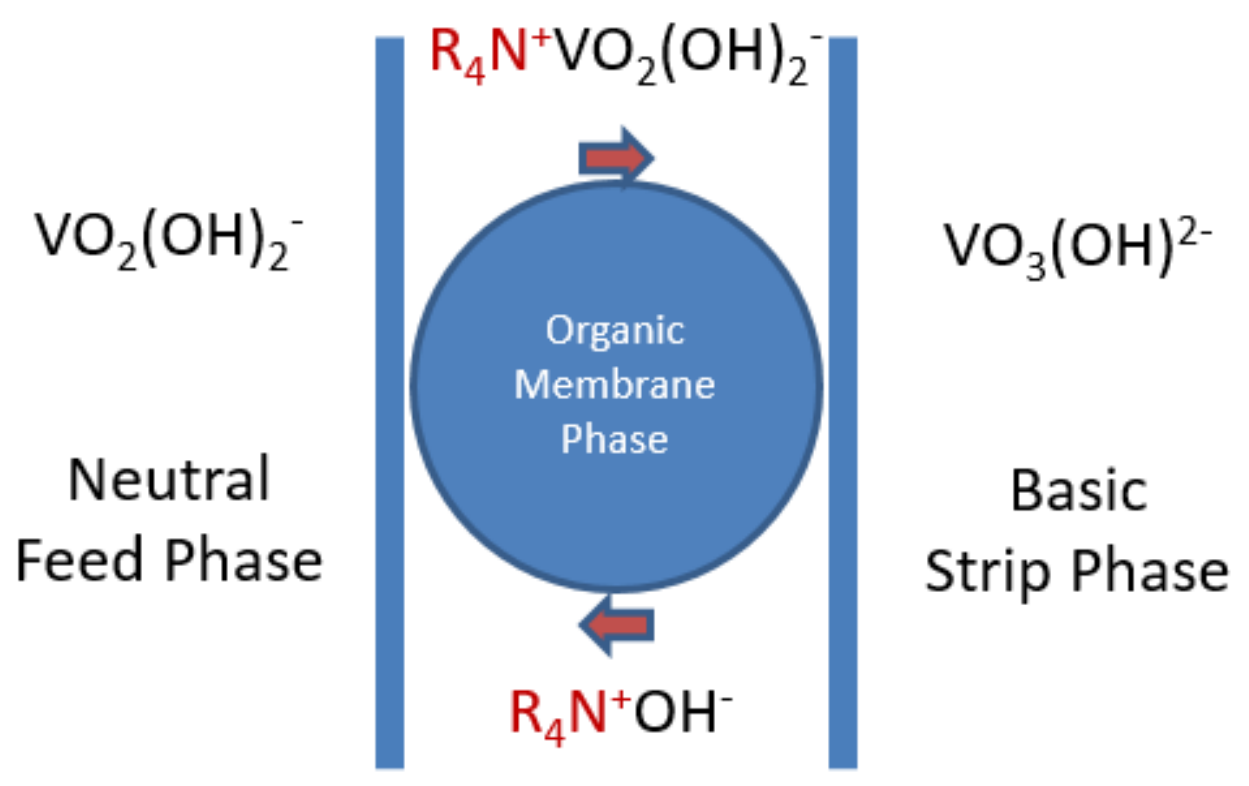

Figure 50 Vanadium HFSLM Migration

\subsection{Natural Vanadium HFSLM Experiments}

Experiments were performed to determine the feasibility of using HFSLM extraction for removal of vanadium from neutral $\mathrm{pH}$ beam dump solution. Initial HFSLM experiments were performed with natural vanadium in preparation for radioactive experiments, using the following solution concentrations: feed solution of $1000 \mathrm{~mL}$ of 0.2 ppm ${ }^{51} \mathrm{~V}$ at $\mathrm{pH} 6$, strip solution of $500 \mathrm{~mL}$ of $0.5 \mathrm{M}$ ammonia in $0.1 \mathrm{M}$ ammonium nitrate at $\mathrm{pH} 9$, and organic solution of $0.15 \mathrm{M}$ Aliquat 336 in 3\% dodecanol/dodecane [55]. The feed and strip solutions were pumped with a peristaltic pump at a constant $450 \mathrm{~mL} / \mathrm{minute}$ (6 gph). Periodic $1 \mathrm{~mL}$ samples were taken from the feed and strip solutions throughout the run and were analyzed by ICP-MS (Figure 51, Figure 52). 


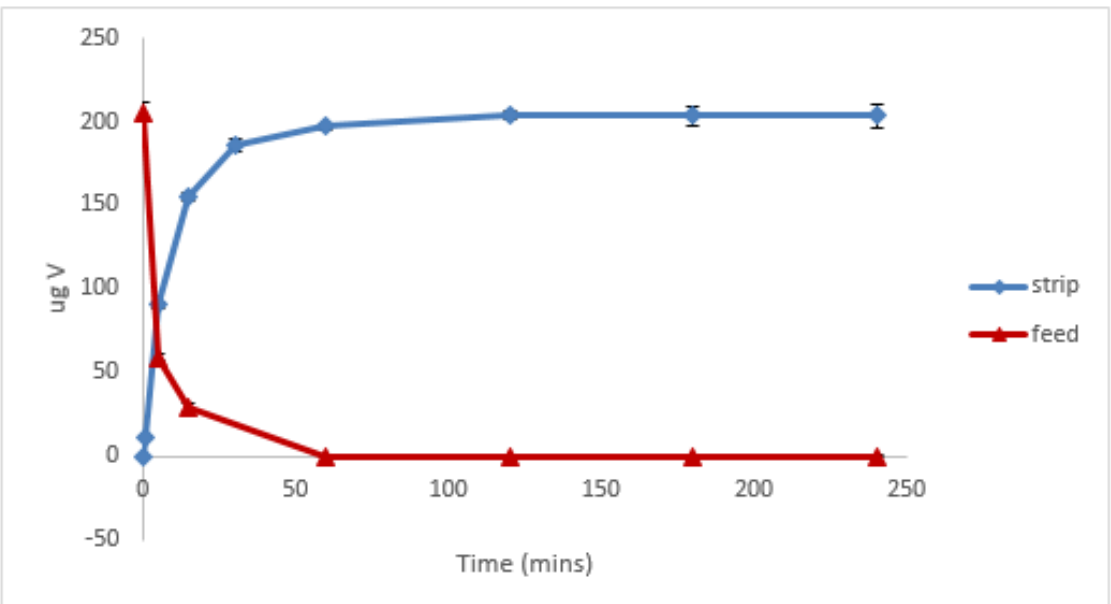

Figure $51 \mu \mathrm{g}{ }^{51} \mathrm{~V}$ in the Feed and Strip Solutions vs Time $(\mathrm{n}=1)$

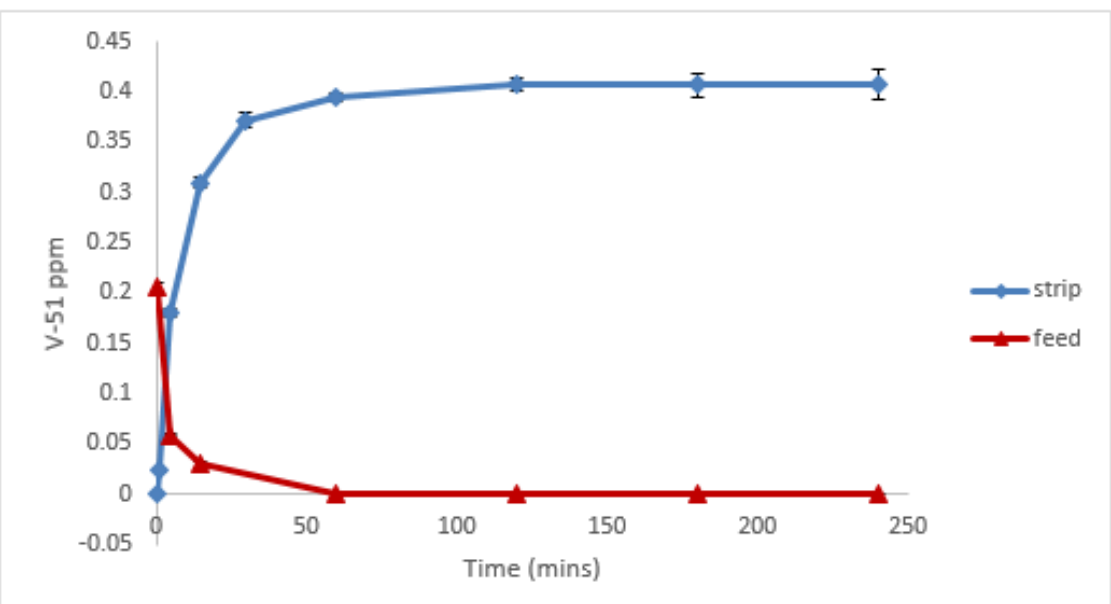

Figure 52 Concentration (ppm) of ${ }^{51} \mathrm{~V}$ in the Feed and Strip Solutions vs Time (n=1)

Results of the natural vanadium experiments show feed vanadium concentration dropping from $206 \pm 6 \mu \mathrm{g}{ }^{51} \mathrm{~V}$ to below detection limit, and strip vanadium concentration growing from zero to $197 \pm 2 \mu \mathrm{g}{ }^{51} \mathrm{~V}$ in 60 minutes. There was also a higher $(2 \mathrm{x})$ final concentration of ${ }^{51} \mathrm{~V}$ in the strip solution due to the concentrating effect of the reduced strip volume (same amount of vanadium in half the original volume).

\subsection{Radiotracer Vanadium HFSLM Experiments}


With the success of the cold vanadium experiment, a radiotracer vanadium extraction experiment was performed. Titanium foil was irradiated at $50 \mu \mathrm{mA}$ for two hours and the irradiated portion was cut out with scissors. The irradiated foil was dissolved by refluxing with $5 \mathrm{~mL}$ of $6 \mathrm{M} \mathrm{H}_{2} \mathrm{SO}_{4}$ for 5 hours. The purple solution was taken to a $70 \mathrm{~mL}$ final volume with water. Thirty-five milliliters of the target solution was taken to $500 \mathrm{~mL}$ with water and $\mathrm{pH}$ adjusted to 6.8 for the feed solution. The conditions of the radiotracer vanadium experiment were the same as the previous experiment, except the feed and strip volumes remained equal at $500 \mathrm{~mL}$. Initial and final 1-mL samples were taken from the feed solution, and periodic 1-mL samples were taken from the strip solution throughout the run. All samples were analyzed for ${ }^{48} \mathrm{~V}$ by HPGe gamma spectroscopy. The extraction results are presented below where the activities in solution have been converted to concentrations (Figure 53 and Figure 54). The activity error on this experiment $(\mathrm{n}=1)$ averaged $\pm 0.04 \mu \mathrm{Ci}$ as calculated with the Canberra Genie software, and the error on the percent extracted calculation averaged \pm 7.8 $\%$ as calculated by peak area. 


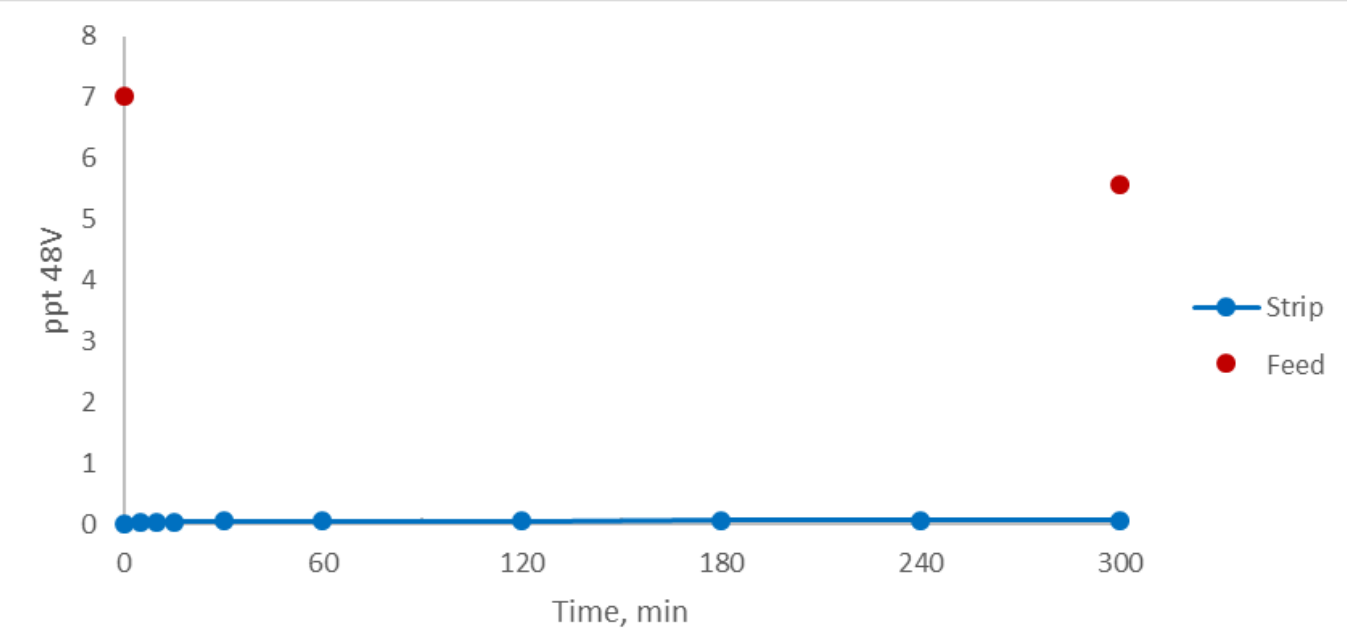

Figure 53 Concentration (ppt) of ${ }^{48} \mathrm{~V}$ in Feed and Strip Solution vs Time (with Titanium, $\mathbf{n}=1$ )

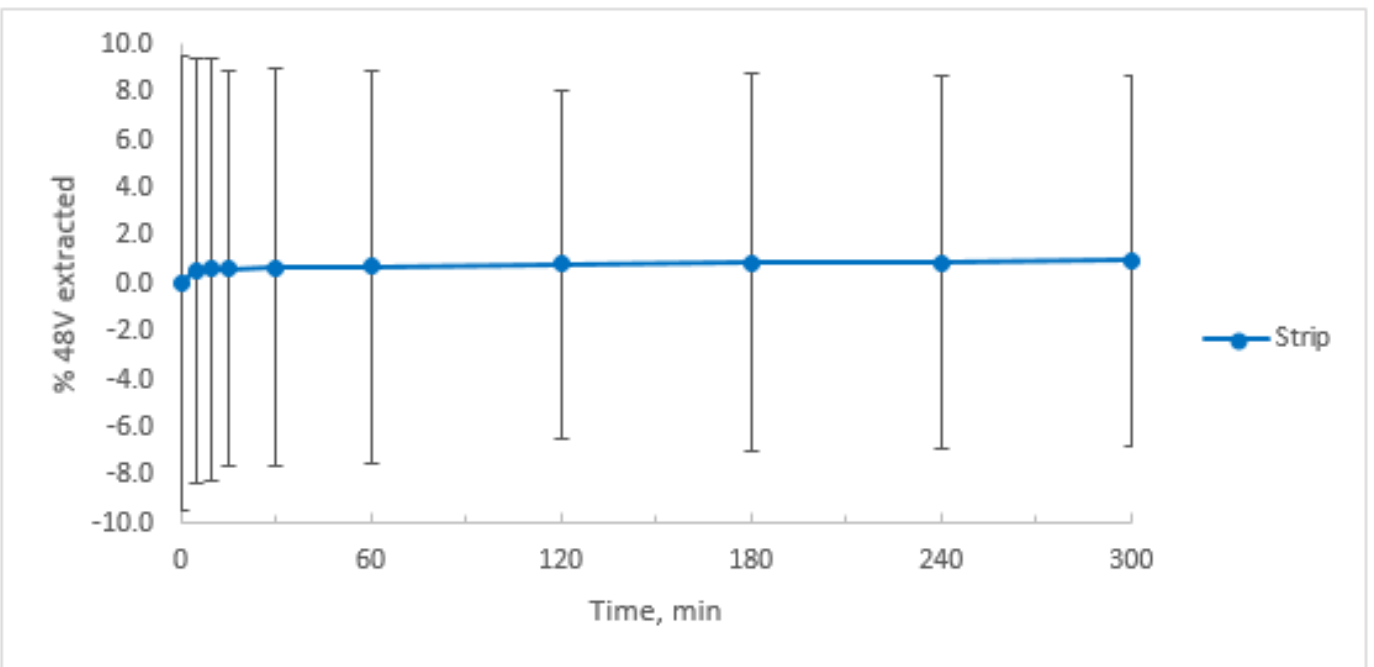

Figure 54 Percent ${ }^{48}$ V Extracted into Strip Solution vs Time (with Titanium, $n=1$ )

In a second vanadium radiotracer experiment, the same conditions were used as the initial experiment except that the target material was passed through an AG50x8 column to remove the titanium target material prior to incorporation into the feed solution. Feed and strip solution volumes remained equal at $500 \mathrm{~mL}$. Initial and final 1-mL samples were taken from the feed solution, and periodic 1- $\mathrm{mL}$ samples were taken from the strip solution throughout the run. All samples were analyzed for ${ }^{48} \mathrm{~V}$ by HPGe gamma spectroscopy. 
The extraction results are illustrated below (Figure 55 and Figure 56), with activities converted to concentration units. The activity error on this experiment $(n=1)$ averaged \pm 6.3 $\mu \mathrm{Ci}$ as calculated with the Genie software, and the error on the percent extracted calculation averaged $\pm 1.0 \%$ as calculated by peak area.

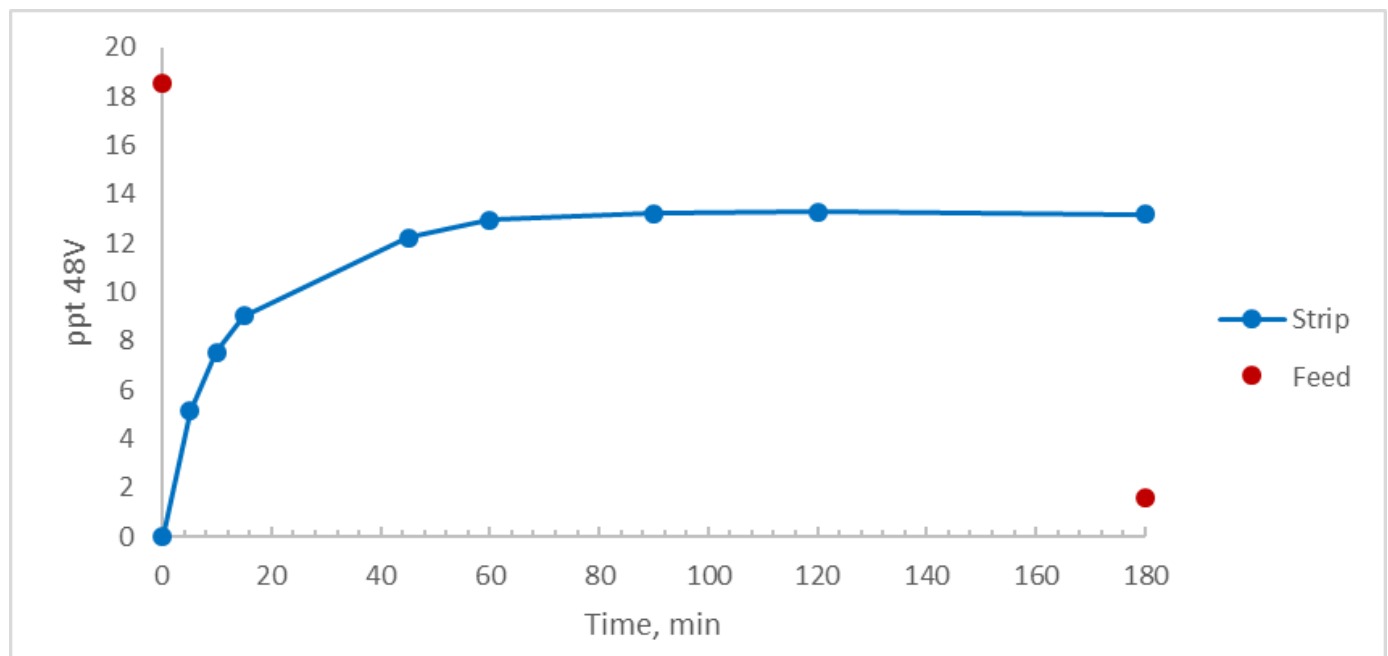

Figure 55 Concentration (ppt) of ${ }^{48} \mathrm{~V}$ in Feed and Strip Solution vs Time (Titanium removed, $n=1$ )

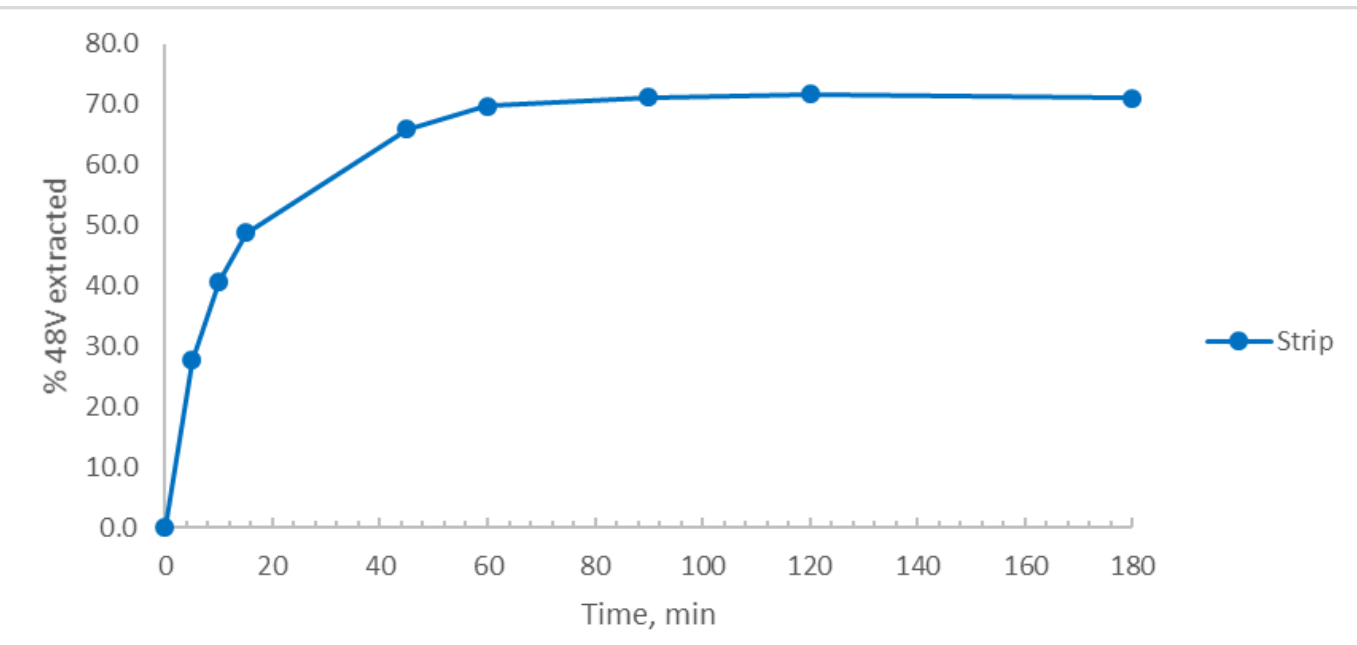

Figure 56 Percent ${ }^{48}$ V Extracted into Strip Solution vs Time (Titanium removed, n=1)

In the initial radiotracer experiment, the feed vanadium concentration dropped from $7.0 \mathrm{ppt}^{48} \mathrm{~V}$ to $5.6 \mathrm{ppt}^{48} \mathrm{~V}$ in $300 \mathrm{~min}$. The concentration of ${ }^{48} \mathrm{~V}$ in the strip solution grew 
from zero to $0.1 \mathrm{ppt}^{48} \mathrm{~V}$ in $300 \mathrm{~min}$. This result represents an extraction of only $1 \%$ of the ${ }^{48} \mathrm{~V}$ into the strip solution and was unexpected as we observed complete extraction of vanadium in the natural vanadium experiments. The best explanation for the poor extraction performance of the radiotracer is the introduction of competing titanium ions. This experiment had a high concentration of titanium in the feed solution (435 ppm) from digestion of the Ti foil target which did not exist in the natural vanadium experiments.

The second radiotracer experiment was performed after removal of excess Ti with an AG50x8 column. Feed vanadium concentration went from $18.5 \mathrm{ppt}^{48} \mathrm{~V}$ to $1.6 \mathrm{ppt}^{48} \mathrm{~V}$ and the concentration in the strip solution grew from zero to $13.2 \mathrm{ppt}^{48} \mathrm{~V}$ in 180 minutes. When the titanium was removed from the feed solution, the extraction of ${ }^{48} \mathrm{~V}$ increased to $71 \%$ in the first 60 minutes, compared to only $1 \%$ in the first experiment. It is noteworthy that the high concentrations of titanium encountered in the first radiotracer experiment will not exist in the beam dump loop at FRIB. The highest concentration of ions in the beam dump will come from the heavy ion beam, and the ${ }^{58} \mathrm{Ni}$ concentration for a 1-week irradiation is only estimated to be $900 \mathrm{ppt}$.

\subsection{Radiotracer Vanadium HFSLM Competition Experiments}

With the success of the radiotracer vanadium HFSLM extractions, further ${ }^{48} \mathrm{~V}$ extraction experiments were performed to determine the impact of competitive chemical species that would be present in the FRIB beam dump following the ${ }^{58} \mathrm{Ni}$ irradiation of a carbon target. The testing was performed with the same conditions as previous experiments with the addition of: $10 \mathrm{ppt}$ of $\mathrm{Mn}, \mathrm{Cr}$, and $\mathrm{Ti} ; 100 \mathrm{ppt}$ of $\mathrm{B}$, and $\mathrm{P}$; and 10 $\mathrm{ppb}$ of Ni to the feed solution as expected to exist in the beam dump (Table 8). These concentrations were chosen based upon the ratio of predicted particles in the FRIB beam 
dump loop with a ${ }^{58} \mathrm{Ni}$ beam (Table 8 ). Initial and final 1-mL samples were taken from the feed solution, and periodic 1-mL samples were taken from the strip solutions throughout the run. All samples were analyzed for ${ }^{48} \mathrm{~V}$ by HPGe gamma spectroscopy. The results are illustrated below (Figure 57 and Figure 58), with activities converted to concentration units. The activity error on this experiment $(n=1)$ averaged $\pm 21 \mu \mathrm{Ci}$ as calculated with the Canberra Genie software, and the error on the percent ${ }^{48} \mathrm{~V}$ extracted calculation averaged $\pm 1.0 \%$ as calculated by peak area.

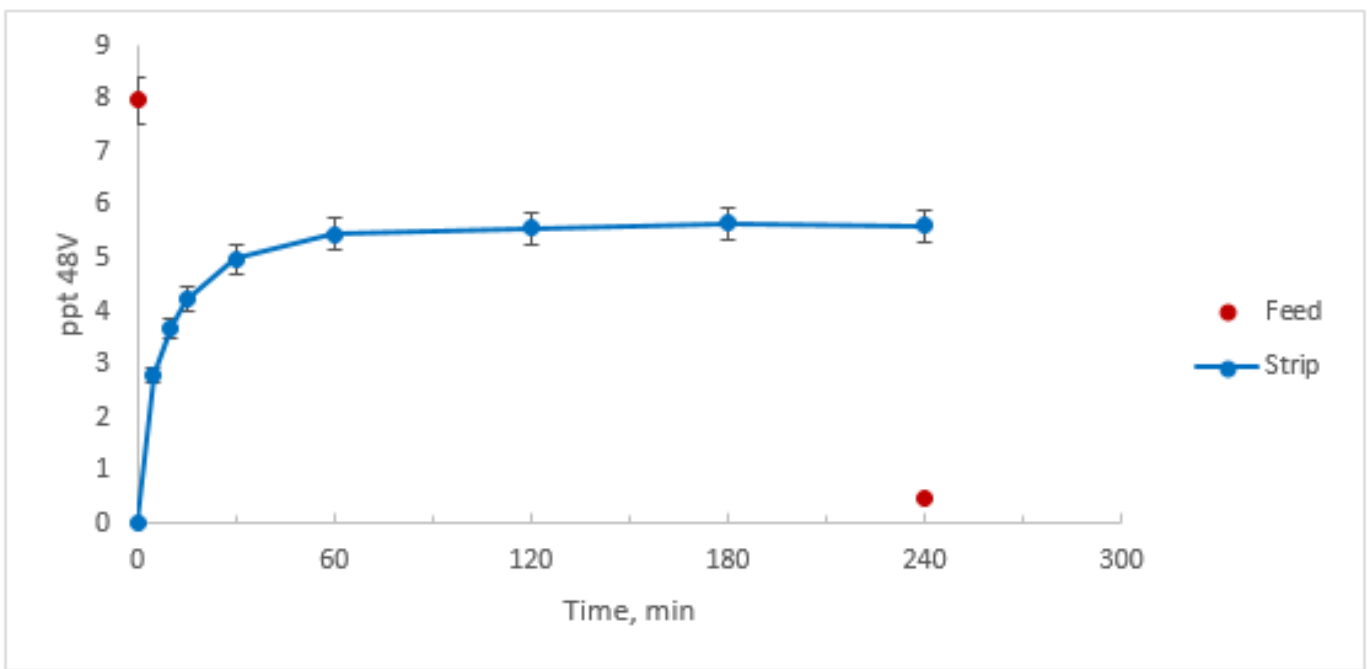

Figure 57 Concentration (ppt) of ${ }^{48} \mathrm{~V}$ in Feed and Strip Solutions vs Time, Competition Study $(n=1)$ 


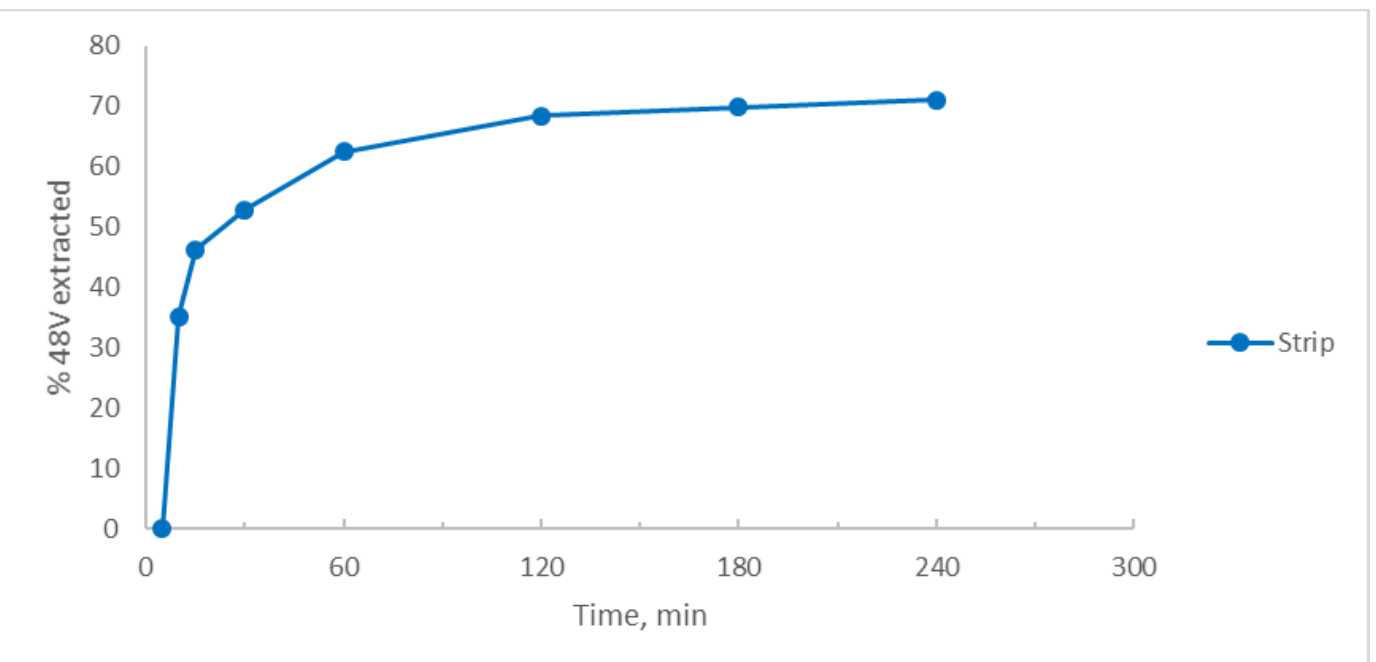

Figure 58 Percent ${ }^{48}$ V Extracted into Strip Solution vs Time, Competition Study $(n=1)$

The results of this experiment (activity measurements converted to concentration) show the vanadium concentration in the surrogate feed solution going from 8 ppt ${ }^{48} \mathrm{~V}$ to $0.5 \mathrm{ppt}^{48} \mathrm{~V}$ at the end of run. The strip vanadium concentration grew from zero to $5.7 \mathrm{ppt}$ ${ }^{48} \mathrm{~V}$ in 60 minutes. This experiment demonstrates the successful $(71 \%)$ extraction of 8 part per trillion ${ }^{48} \mathrm{~V}$ in the presence of competitive species within the first 60 minutes of operation. We understand this to be the first ever demonstrated extraction of such low concentrations of metals, which are the theoretical abundances expected in the FRIB beam dump loop. In addition, the rapid (60 min) extraction unlocks the door to harvesting many short-lived isotopes that would be decayed away before the batch harvesting method could be implemented. Lastly, these short-lived isotopes could be concentrated through the use HFSLM. For example, the HFSLM module could be plumbed to use the $7000 \mathrm{~L}$ beam dump loop as the inlet for the feed, and a $1 \mathrm{~L}$ loop inserted for the strip solution. This would introduce a concentration factor of 7000 for the isotope of interest. 
The success of HFLSM extraction gives the researcher another tool in the quest for As Low As Reasonably Achievable (ALARA) radioactive exposure. By plumbing the membrane contactor in a location away from the 50 gallon resin tanks, researchers are only exposed to the radiation field generated by the harvested isotope rather than the radiation from the entire range of beam fragments.

While this proof-of-principle experiment demonstrates the effective extraction of part per trillion level radioisotopes from an aqueous projectile-fragment beam dump, further research should focus upon radioisotopes that cannot be produced easily by other means. For example, the ${ }^{48} \mathrm{~V}$ used for this study was produced on a small medical cyclotron, which could not easily produce isotopes such as ${ }^{48} \mathrm{Cr}$, or ${ }^{56} \mathrm{Ni}$. Due to the rapid extraction, it is likely that short-lived research isotopes will be the most the most promising targets for HFSLM extraction from projectile fragmentation facilities. 


\section{Chapter 5 ISOTOPE HARVESTING - IN SITU \\ LANTHANIDE FEASIBILITY}

The potential for seamless integration of HFSLM extraction into the FRIB primary beam dump loop makes it an exciting option for the recovery of many rare radionuclides. Two examples of isotopes from FRIB that are in high demand include the lanthanides: ${ }^{147} \mathrm{Pm}$ and ${ }^{148} \mathrm{Gd}$. These isotopes are strong candidates for use in radioisotope micro power sources (RIMS) to power the next generation of micro-electromechanical systems (MEMS). The potential energy density, ability to operate in extreme environments, and long life make these nuclear batteries a top research priority [11].

\subsection{Lanthanide Chemistry in the FRIB beam dump loop}

The lanthanide metals are usually found as soft, low conductivity elements with a silver appearance [63]. An interesting characteristic of this group of elements is known as the "lanthanide contraction" in which the nuclear charge is poorly shielded by the $4 \mathrm{f}$ orbital electrons causing a greater than expected reduction in ionic radius with increasing atomic number. Lanthanide ions are classified as hard Lewis acids, belonging to a class of metal ions including alkali metals, alkaline earth metals, hydrogen ion, and lighter transition metals in higher oxidation states. Per Pearson's principle [64], hard acids prefer to bind to hard bases and soft acids prefer to bind to soft bases. Therefore, most lanthanide complexes preferentially bind with the first-row $\mathrm{F}$ and $\mathrm{O}$ donor ligands. In aqueous solution, complexation occurs with $\mathrm{H}_{2} \mathrm{O}$ and $\mathrm{OH}^{-}$, but nitrogen, sulfur, and halogen complexes (except $\mathrm{F}^{-}$) are not stable [57]. The geometry of a given lanthanide-ligand complex is

dominated by the steric limitations of its attached ligands. The ligands pack around the 
central metal ions in such a way as to minimize inter-ligand repulsion. The large size of the lanthanide ion allows an unusually high coordination number (commonly 8 or 9 , Figure $59)$.

\begin{tabular}{|c|c|c|c|c|}
\hline compound & metal soln concn & matrix & ionic radius $(\mathrm{CN}=6)^{63}$ & $\mathrm{CN}$ \\
\hline Ac-aquo & $0.264 \mathrm{mM}$ & $0.11 \mathrm{M} \mathrm{HO}_{3} \mathrm{SCF}_{3}$ & 1.12 & $10.9 \pm 0.5$ \\
\hline \multirow{2}{*}{$\mathrm{La}^{\mathrm{III}}\left(\mathrm{H}_{2} \mathrm{O}\right)_{y}^{31}$} & \multirow{2}{*}{$0.2 \mathrm{M}$} & \multirow{2}{*}{$\mathrm{pH} 1 \mathrm{HO}_{3} \mathrm{SCF}_{3}$} & \multirow[t]{2}{*}{1.032} & $6.0 \pm 0.5$ \\
\hline & & & & $3.0 \pm 0.5$ \\
\hline $\mathrm{La}^{\mathrm{III}}\left(\mathrm{H}_{2} \mathrm{O}\right)_{y}^{9}$ & $2-3 \mathrm{M}$ & $0.25 \mathrm{M} \mathrm{HCl}$ & 1.032 & $9.2 \pm 0.37$ \\
\hline \multirow[t]{2}{*}{$\mathrm{La}^{\mathrm{II}}\left(\mathrm{H}_{2} \mathrm{O}\right)_{y}^{31}$} & \multirow[t]{2}{*}{$0.2 \mathrm{M}$} & \multirow[t]{2}{*}{$\mathrm{pH} 1 \mathrm{HO}_{3} \mathrm{SCF}_{3}$} & \multirow[t]{2}{*}{1.032} & $6.0 \pm 1.0$ \\
\hline & & & & $3.0 \pm 1.2$ \\
\hline $\mathrm{U}^{\mathrm{III}}\left(\mathrm{H}_{2} \mathrm{O}\right)_{7}{ }^{6}$ & \multirow{2}{*}{$1-10 \mathrm{mM}$} & $\mathrm{pH} 0 \mathrm{HCl}$ & 1.025 & $9.1 \pm 0.6$ \\
\hline $\mathrm{U}_{\text {aq }}^{\mathrm{III}} \mathrm{7}^{7}$ & & $1 \mathrm{M} \mathrm{HCl}$ & 1.025 & $8.7 \pm 0.9$ \\
\hline $\mathrm{Np}^{1 \mathrm{III}}\left(\mathrm{H}_{2} \mathrm{O}\right)_{{ }^{6}}$ & \multirow[t]{2}{*}{$0.5-2 \mathrm{mM}$} & $\mathrm{pHOHCl}$ & 1.01 & $10.0 \pm 1.2$ \\
\hline $\mathrm{Np}_{2 \mathrm{y}}^{\text {III }}$ & & $1 \mathrm{M} \mathrm{HCl}$ & 1.01 & $9.8 \pm 0.9$ \\
\hline $\mathrm{Np}_{=4}^{\mathrm{III}}{ }^{\mathrm{II}}$ & $4.7 \mathrm{mM}$ & $1 \mathrm{M} \mathrm{HClO}_{4}$ & 1.01 & $9.0 \pm 1.0$ \\
\hline $\mathrm{Pu}^{\mathrm{III}}\left(\mathrm{H}_{2} \mathrm{O}\right)^{49}$ & $20 \mathrm{mM}$ & $0.01 \mathrm{M} \mathrm{LiCl}$ & 1 & $10.2 \pm 1.1$ \\
\hline $\mathrm{Pu}$ & $10 \mathrm{mM}$ & $0.01 \mathrm{M} \mathrm{LiCl}$ & 1 & $9.2 \pm 0.33$ \\
\hline $\mathrm{Pu}^{\mathrm{III}}\left(\mathrm{H}_{2} \mathrm{O}\right)^{6}$ & $0.8-2 \mathrm{mM}$ & $\mathrm{pH} 0 \mathrm{HCl}$ & 1 & $9.9 \pm 0.3$ \\
\hline $\mathrm{Pu}_{7 \mathrm{q}}^{\mathrm{III}}$ & $0.01 \mathrm{mM}$ & $1 \mathrm{M} \mathrm{HClO}_{4}$ & 1 & $8.6 \pm 0.2$ \\
\hline $\mathrm{Pu}_{2 \mathrm{Iq}^{-1}}^{\mathrm{II}^{-1}}$ & & $1 \mathrm{M} \mathrm{HCl}$ & 1 & $9.9 \pm 0.9$ \\
\hline $\mathrm{Pu}^{\mathrm{mil}} 50$ & & & 1 & $8-9$ \\
\hline $\mathrm{Nd}^{1 \mathrm{II}}\left(\mathrm{H}_{2} \mathrm{O}\right){ }^{9}$ & $2-3 \mathrm{M}$ & $0.25 \mathrm{M} \mathrm{HCl}$ & 0.983 & $9.5 \pm 0.37$ \\
\hline $\mathrm{Nd} d^{111}\left(\mathrm{H}_{2} \mathrm{O}\right) y^{52}$ & & $\mathrm{HClO}_{4}$ & 0.983 & 9.5 \\
\hline Am-aquo ${ }^{4}$ & $4.8 \mathrm{mM}$ & $0.11 \mathrm{M} \mathrm{HO}_{3} \mathrm{SCF}_{3}$ & 0.975 & $9.5 \pm 0.87$ \\
\hline $\mathrm{Am}^{\mathrm{III}}\left(\mathrm{H}_{2} \mathrm{O}\right)_{y}{ }^{11}$ & $1 \mathrm{mM}$ & $0.025 \mathrm{M} \mathrm{HClO}_{4}$ & 0.975 & $8.3 \pm 0.4$ \\
\hline $\mathrm{Am}^{\mathrm{III}}\left(\mathrm{H}_{2} \mathrm{O}\right)_{y}^{9}$ & $10 \mathrm{mM}$ & $0.25 \mathrm{M} \mathrm{HCl}$ & 0.975 & $10.3 \pm 0.33$ \\
\hline $\mathrm{Am}^{\mathrm{III}}\left(\mathrm{H}_{2} \mathrm{O}\right)_{y}^{12}$ & $7.9 \mathrm{mmol} \mathrm{kg}^{-1}$ & $0.03 \mathrm{M} \mathrm{NaClO}_{4}(\mathrm{pH} 3.5)$ & 0.975 & $9.0 \pm 0.0$ \\
\hline $\operatorname{Am}^{\mathrm{mI}}{ }^{\mathrm{Iq}}$ & & $1 \mathrm{M} \mathrm{HCl}$ & 0.975 & $9.5 \pm 0.9$ \\
\hline $\mathrm{Cm}^{\mathrm{II}}\left(\mathrm{H}_{2} \mathrm{O}\right)_{y}^{9}$ & $10 \mathrm{mM}$ & $0.25 \mathrm{M} \mathrm{HCl}$ & 0.97 & $10.2 \pm 0.33$ \\
\hline $\mathrm{Cm}^{\mathrm{III}}\left(\mathrm{H}_{2} \mathrm{O}\right)_{y}{ }^{13}$ & $0.523 \mathrm{M}$ & $1 \mathrm{M} \mathrm{HClO}_{4}$ & 0.97 & $7.0 \pm 0.4$ \\
\hline $\mathrm{Bk}^{\mathrm{III}}\left(\mathrm{H}_{2} \mathrm{O}\right){ }_{y}{ }^{\mathrm{i}}$ & $0.47 \mathrm{mM}$ & $1 \mathrm{M} \mathrm{HClO}_{4} 1 \mathrm{M}$ & 0.96 & $9.0 \pm 0.6$ \\
\hline $\mathrm{Sm}^{\mathrm{II}}\left(\mathrm{H}_{2} \mathrm{O}\right)_{y}^{52}$ & & $\mathrm{HClO}_{4}$ & 0.958 & 9.3 \\
\hline $\mathrm{Cf}_{2 \mathrm{II}}{ }^{\mathrm{II}}$ & & $1 \mathrm{M} \mathrm{HCl}$ & 0.95 & $9.5 \pm 0.9$ \\
\hline $\mathrm{Cf}^{\mathrm{AlI}}\left(\mathrm{H}_{2} \mathrm{O}\right)_{y}{ }^{15}$ & $2.2 \mathrm{mM}$ & $0.1 \mathrm{M} \mathrm{HClO}_{4}$ & 0.95 & $8.0 \pm 0.0$ \\
\hline $\mathrm{Cf}^{\mathrm{AlI}}\left(\mathrm{H}_{2} \mathrm{O}\right)_{7}{ }^{16}$ & $1.67 \mathrm{M}$ & $1 \mathrm{M} \mathrm{HCl}$ & 0.95 & $8.5 \pm 1.5$ \\
\hline $\mathrm{Gd}^{\mathrm{II}}\left(\mathrm{H}_{2} \mathrm{O}\right)_{y}^{52}$ & & $\mathrm{HClO}_{4}$ & 0.938 & 7.6 \\
\hline
\end{tabular}

Figure 59 Coordination Number (CN) of Rare Earth Aqua Ions [65]

\section{With permission, ACS AuthorChoice License}

Lanthanides exist in the +3 -oxidation state in aqueous solution, forming the aqua ion through attraction to the electronegative oxygen of water molecules. The $\sim 9$-coordinate complex begins to undergo hydrolysis at $\mathrm{pH}$ values above about 6 (Figure 60), and the species $\mathrm{Ln}(\mathrm{OH})^{2+}, \mathrm{Ln}_{2}(\mathrm{OH})_{2}{ }^{4+}$, and $\mathrm{Ln}_{3}(\mathrm{OH})_{5}{ }^{4+}$ have been reported. Extensive hydrolysis 
occurs at $\mathrm{pH}$ levels above 7 and the hydroxyl species begin to adsorb onto glass and form suspended particles. Hydroxy colloids form as $\mathrm{Ln}(\mathrm{OH})_{3}$ precipitates at higher $\mathrm{pH}$ levels $\left(\right.$ ca $\left.2 \times 10^{-4} \mathrm{~g} / \mathrm{dm}^{3}\right)[66]$.
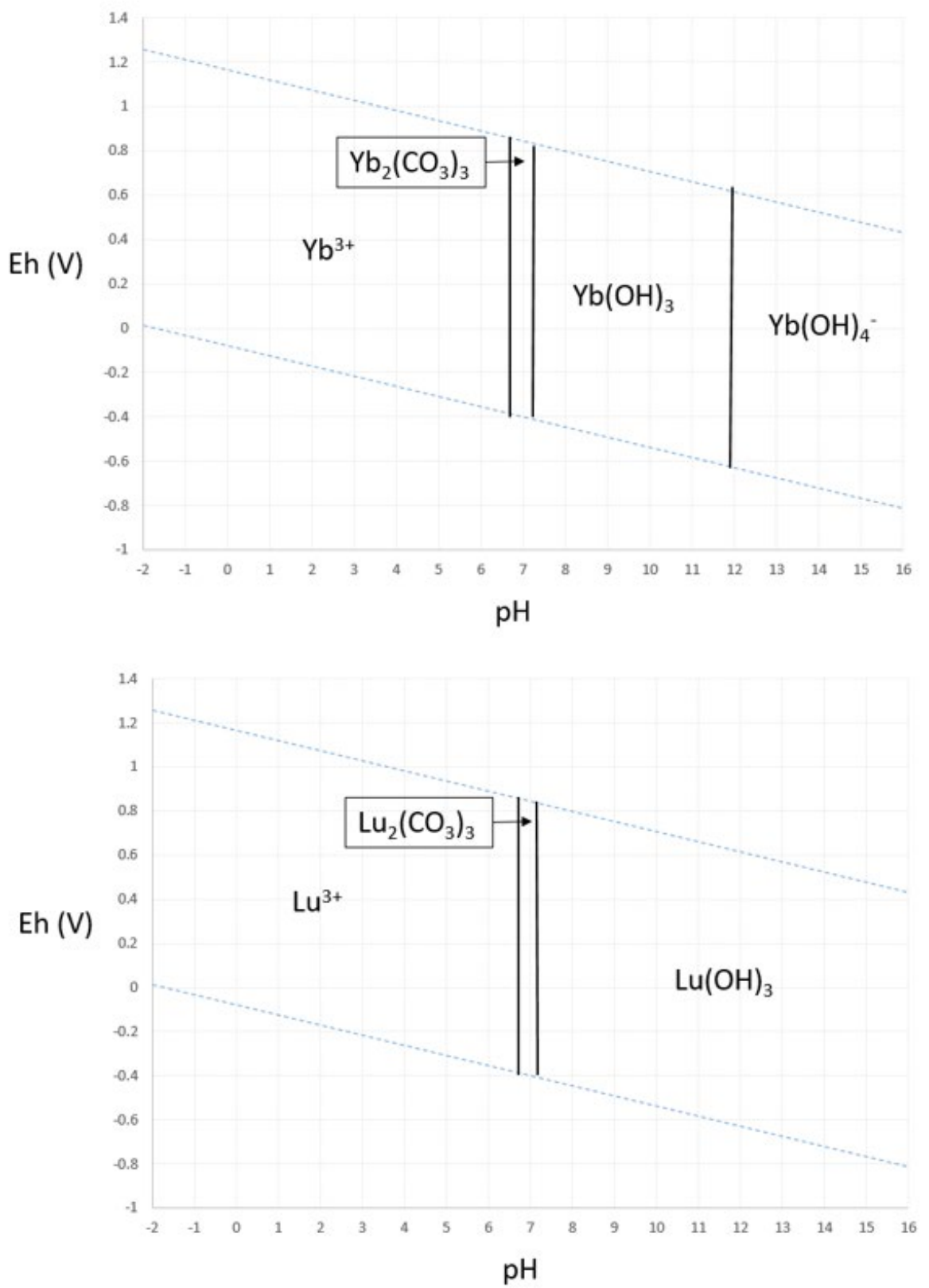

Figure $60 \mathrm{Yb}$ and Lu Speciation as a Function of pH. (REE 10 ${ }^{-6}$, Carbonate $\left.10^{-3} \mathrm{M}\right)$ Adapted from D. Bookins, Eh-pH Diagrams for Geochemistry, New York: Springer-Verlag, 1988. 


\subsection{Calculated Lutetium Production at FRIB}

The production of radioisotopes in the beam dump loop at FRIB can be approximated using the software developed by scientists at Michigan State University called LISE++ [39]. The number of lanthanide particles produced with a routine 200 $\mathrm{MeV} /$ nucleon ${ }^{238} \mathrm{U}$ beam after 1 week of operation is approximately $1 \times 10^{12}$ to $1 \times 10^{15}$ particles of each isotope (Figure 61). For the specific isotope ${ }^{177} \mathrm{Lu}$ (which is readily available at MURR), the maximum yield of particles occurs with a ${ }^{186} \mathrm{~W}$ beam, which produces $8.5 \times 10^{14}$ particles (Figure 62) per week of operation. This number of particles in the 7000-liter beam dump equates to a maximum 7-day concentration of 40 part per quadrillion ${ }^{177} \mathrm{Lu}$. Other lanthanide group isotopes of interest $\left({ }^{147} \mathrm{Pm}\right.$ and $\left.{ }^{148} \mathrm{Gd}\right)$ are more abundant with a ${ }^{156}$ Dy primary beam (Table 13$)$. 


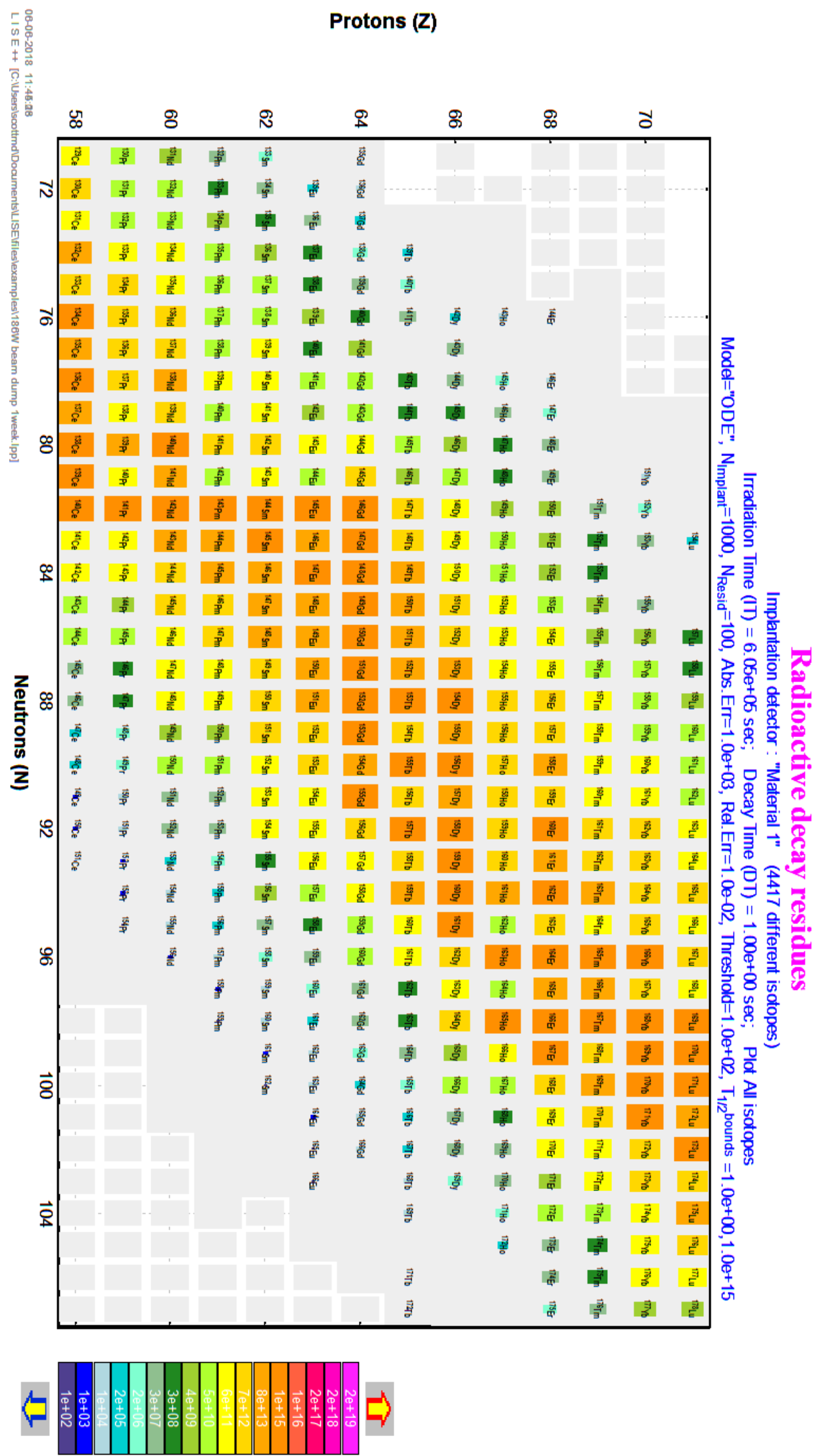

Figure 61 Lanthanide Beam Dump Particles, 1 Week ${ }^{238}$ U Beam - no decay time 


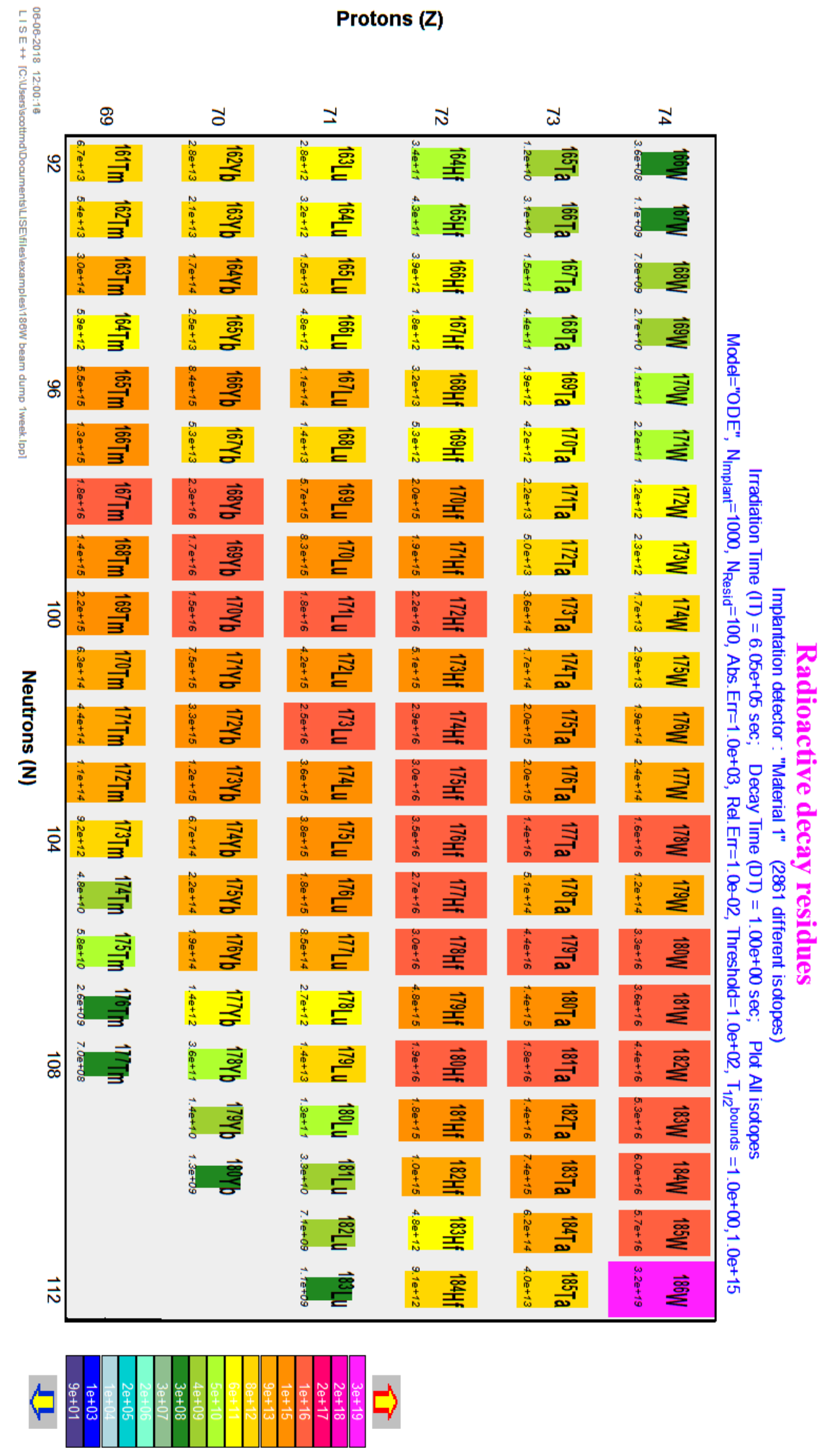

Figure $62{ }^{177}$ Lu Beam Dump Particles, 1 Week ${ }^{186} \mathrm{~W}$ Beam - no decay time 


\begin{tabular}{|c|c|c|}
\hline \multicolumn{3}{|c|}{ 1-week ${ }^{186} \mathrm{~W}$ primary beam } \\
\hline Isotope & Particles & ppt \\
\hline${ }^{177} \mathrm{Lu}$ & $8.52 \mathrm{E} 14$ & $0.04(28 \mathrm{mCi})$ \\
\hline${ }^{186} \mathrm{~W}$ & $3.21 \mathrm{E} 19$ & 1417 \\
\hline \multicolumn{3}{|c|}{ 1-week ${ }^{156}$ Dy primary beam } \\
\hline Isotope & Particles & ppt \\
\hline${ }^{147} \mathrm{Pm}$ & $1.74 \mathrm{E} 14$ & $0.01(39 \mu \mathrm{Ci})$ \\
\hline${ }^{148} \mathrm{Gd}$ & $5.28 \mathrm{E} 16$ & $1.85(418 \mu \mathrm{Ci})$ \\
\hline${ }^{156} \mathrm{Dy}$ & $3.54 \mathrm{E} 19$ & 1310 \\
\hline
\end{tabular}

\section{Table 13 Beam Dump Yields of Lanthanides with Different Primary Beams}

\section{$5.3 \quad{ }^{177}$ Lutetium Properties}

${ }^{177}$ Lutetium decays with a half-life $\left(\mathrm{t}_{1} / 2\right)$ of 6.65 days by beta decay to form the stable isotope ${ }^{177}$ Hafnium [60]:

\section{$6.65 \mathrm{~d}$}

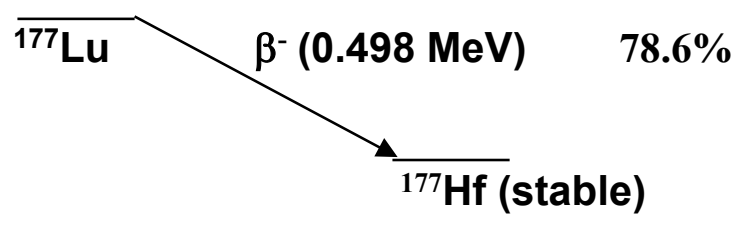

The maximum beta energy for the decay of ${ }^{177} \mathrm{Lu}$ to ${ }^{177} \mathrm{Hf}$ is $0.498 \mathrm{MeV}$ (Table 14). The average beta energy is approximately $0.13 \mathrm{MeV} .{ }^{177} \mathrm{Lu}$ also emits several gamma rays (Table 15), which are useful for imaging. The significant energies and abundance of these gamma ray emissions are $113 \mathrm{keV}(6.4 \%)$ and $208 \mathrm{keV}(11 \%)$. 


\begin{tabular}{|c|c|}
\hline \multicolumn{2}{|c|}{${ }^{\mathbf{1 7 7}}$ Lu Beta Decay (6.734 day half-life) } \\
\hline Energy (keV) & Intensity (\%) \\
\hline 176.98 & 12.2 \\
\hline 248.63 & 0.053 \\
\hline 385.35 & 9.1 \\
\hline 498.38 & 78.6 \\
\hline
\end{tabular}

Table $14{ }^{177}$ Lu Beta Emissions [67]

\begin{tabular}{|c|c|}
\hline \multicolumn{2}{|c|}{${ }^{\mathbf{1 7 7}}$ u Gamma Decay (6.734 day half-life) } \\
\hline Energy (keV) & Intensity (\%) \\
\hline 71.646 & 0.154 \\
\hline 112.9498 & 6.4 \\
\hline 136.7248 & 0.048 \\
\hline 208.3664 & 11.0 \\
\hline 249.6741 & 0.212 \\
\hline 321.3162 & 0.219 \\
\hline
\end{tabular}

\section{Table $15{ }^{177}$ Lu Gamma Emissions [67]}

\subsection{Lutetium Reactor Production}

Lutetium-177 can be produced in a research reactor by either direct or indirect production methods. Lutetium-177 used for these studies was provided by the University of Missouri Research Reactor (MURR) manufactured through the direct method, where an enriched ${ }^{176} \mathrm{Lu}$ target is irradiated with neutrons to produce ${ }^{177} \mathrm{Lu}$ through a $(\mathrm{n}, \gamma)$ reaction. The high neutron cross section of ${ }^{176} \mathrm{Lu}(\sigma=2300$ barns) [60] allows for production of ${ }^{177} \mathrm{Lu}$ with a maximum specific activity of $20-30 \mathrm{Ci} / \mathrm{mg}$. An enriched target is necessary due to the low natural abundance of ${ }^{176} \mathrm{Lu}(2.6 \%)$.

The indirect production of ${ }^{177} \mathrm{Lu}$ is achieved through the neutron bombardment $(\mathrm{n}, \gamma)$ of an enriched ${ }^{176} \mathrm{Yb}$ target, producing ${ }^{177} \mathrm{Yb}\left(\mathrm{t}_{1 / 2}=1.9\right.$ hours $)$, which then beta decays to ${ }^{177} \mathrm{Lu}$. However, ${ }^{176} \mathrm{Yb}$ has a much smaller neutron cross section ( $\sigma=3$ barns) [60] and has a low natural abundance (12.76\%) amongst seven stable isotopes, also requiring an enriched target. The indirect method requires a difficult separation of no carrier added 
${ }^{177} \mathrm{Lu}$ from macroscopic quantities of ${ }^{176} \mathrm{Yb}$, but yields specific activities in the range of $60-70 \mathrm{Ci} / \mathrm{mg}$. Recycling of the enriched ${ }^{176} \mathrm{Yb}$ target is required to make this method economically feasible.

\subsection{Ionic Liquids for Liquid-Liquid Extraction}

Room temperature ionic liquids (RTIL) are generally defined as ionic compounds that have a melting point below $110^{\circ} \mathrm{C}$. In the mid-1980s, it was proposed that these low melting point solvents could be used for organic synthesis [68] [69]. RTILs have a unique set of properties that yield some advantages over conventional organic solvents. These liquids have a negligible vapor pressure, a liquid range of up to more than $400 \mathrm{~K}$, and a density greater than that of water [70]. Ionic liquids are miscible with a wide range of substances, depending upon the polarity of the substance and the length of any alkyl groups on the ionic liquid cation.

Water immiscible RTILs can be prepared through incorporation of hydrophobic cations and anions, allowing them to replace organic solvents used in liquid-liquid extraction processes [71]. Successful extraction of metal ions from an aqueous phase has been demonstrated with traditional extractants dissolved in these ionic liquids [72]. An interesting potential application of substituting organic solvents with ionic liquids is its implementation in the TRUEX process. Traditionally the TRUEX process is used to extract transuranium metal ions from acidic nuclear waste with CMPO and TBP in a normal paraffinic hydrocarbon [73] [74]. It has been shown that replacing the normal paraffinic hydrocarbon with a RTIL allows highly efficient extraction of lanthanides with CMPO from deionized water [75], which has relevance for harvesting these rare isotopes from the aqueous beam dump of heavy-ion fragmentation facilities. Experiments were 
performed to determine the feasibility of using HFLSM loaded with CMPO in RTIL for the extraction of lanthanides from the FRIB aqueous beam dump.

\subsection{Materials and Methods}

CMPO was obtained from Marshallton Research Laboratories Incorporated, King, N.C. RTIL [ $\left.\mathrm{C}_{6} \operatorname{mim}\right]\left[\mathrm{Tf}_{2} \mathrm{~N}\right]$ (99\%) was obtained from IoLiTec, Tuscaloosa, A.L. EDTA, acid form (A.C.S. grade) was obtained from ThermoFisher Scientific. Ethyl acetate (99.8\%), toluene (99.8\%), 1-octanol (99\%), and 2-bromobenzoic acid (97\%) were obtained from Sigma-Aldrich. Guanidine carbonate (99\%) was obtained from Acros Organics.

Metal free centrifuge tubes were obtained from Labcon. ${ }^{177} \mathrm{LuCl}_{3}$ was obtained from the University of Missouri Research Reactor.

The Hollow Fiber Supported Liquid Membrane (Membrane Contactor) was a Liqui-Cel mini module manufactured by $3 \mathrm{M}$. Membrane contactor flow rates were maintained with a Masterflex peristaltic pump 7-200 rpm, equipped with an easy load II pumphead.

Radiotracers were evaluated at the University of Missouri Research Reactor on a 23\% relative efficiency high purity germanium detector (Canberra Model GC2018S, coaxial p-type crystal), geometry calibrated with a NIST-traceable mixed-gamma standard. Samples were counted for 10 min. with dead times below $10 \%$, and the software for data acquisition and analysis was Canberra Genie PROcount 2000 V3.3.

For the RTIL liquid-liquid extraction experiments, solutions were prepared in scintillation vials and mixed with a stirbar for 60 minutes. Lutetium extraction was measured by HPGe gamma spectroscopy. The lanthanide extraction efficiency of CMPO 
in RTIL $\left[\mathrm{C}_{6} \operatorname{mim}\right]\left[\mathrm{Tf}_{2} \mathrm{~N}\right]$ was investigated by measuring extraction of lutetium from a neutral $\mathrm{pH}$ aqueous stock solution. Three milliliters of a $100 \mu \mathrm{Ci}{ }^{177} \mathrm{Lu}$ neutral $\mathrm{pH}$ solution was mixed for 60 minutes in a scintillation vial with $3 \mathrm{~mL}$ of $\left[\mathrm{C}_{6} \mathrm{mim}\right]\left[\mathrm{Tf}_{2} \mathrm{~N}\right]$ consisting of varying amounts of CMPO $(5,10,15$, and $20 \mathrm{mM})$. The lanthanide stripping efficiency of EDTA in $1 \mathrm{M}$ guanidine carbonate $\mathrm{pH} 10$ was also investigated by measuring stripping of ${ }^{177} \mathrm{Lu}$ from a $\left[\mathrm{C}_{6} \mathrm{mim}\right]\left[\mathrm{Tf}_{2} \mathrm{~N}\right]$ solution. Three milliliters of a 100 $\mu \mathrm{Ci}{ }^{177} \mathrm{Lu}$ in $5 \mathrm{mM} \mathrm{CMPO}$ dissolved in $\left[\mathrm{C}_{6} \mathrm{mim}\right]\left[\mathrm{Tf}_{2} \mathrm{~N}\right]$ solution was mixed for 60 minutes in a scintillation vial with $3 \mathrm{~mL}$ of EDTA (acid form) in $1 \mathrm{M}$ guanidine carbonate strip solution consisting of varying amounts of EDTA $(0.01,0.05$, and 0.10 $\mathrm{mM})$.

For the Versatic 10 liquid-liquid extraction experiments, solutions were prepared in scintillation vials and mixed with a stirbar for 60 minutes. Lutetium extraction was measured by HPGe gamma spectroscopy. The lanthanide extraction efficiency of Versatic 10 was investigated by measuring lutetium-177 from a neutral $\mathrm{pH}$ aqueous stock solution. Seven milliliters of a $30 \mu \mathrm{Ci}{ }^{177} \mathrm{Lu}$ neutral $\mathrm{pH}$ solution was mixed in a scintillation vial with $7 \mathrm{~mL}$ of Versatic 10, which was diluted with varying amounts of dodecane. The percentage of ${ }^{177} \mathrm{Lu}$ extracted after 1 and 5 hours was measured by HPGe gamma spectroscopy. The lanthanide stripping efficiency of $\mathrm{H}_{2} \mathrm{SO}_{4}$ was also investigated by measuring the stripping of ${ }^{177} \mathrm{Lu}$ from the Versatic 10 into $0.7 \mathrm{M} \mathrm{H}_{2} \mathrm{SO}_{4}$. Seven milliliters of a $22 \mu \mathrm{Ci}{ }^{177} \mathrm{Lu}$ in Versatic 10 was mixed with 7 milliliters of $0.7 \mathrm{M} \mathrm{H}_{2} \mathrm{SO}_{4}$ in a scintillation vial. The percentage of ${ }^{177} \mathrm{Lu}$ stripped from the Versatic 10 was measured by HPGe gamma spectroscopy activity after $1 \mathrm{~h}$ of mixing. 


\subsection{Lutetium Liquid-Liquid Extraction Optimization Experiments}

Literature studies of lanthanide extraction from aqueous solutions with CMPO and RTIL show high extractability of all lanthanides with $5 \mathrm{mM} \mathrm{CMPO}$ in $\left[\mathrm{C}_{4} \mathrm{mim}\right]\left[\mathrm{PF}_{6}\right]$ [75]. $\left[\mathrm{C}_{4} \mathrm{mim}\right]\left[\mathrm{PF}_{6}\right]$ may not be the best RTIL for use in the aqueous beam dump environment due to the short alkyl chain of the cation, and because the anion is known to be moisture sensitive and undergoes hydrolysis in the presence of water to form hydrogen fluoride and other hydrolysis products [76] [77]. The hydrophobicity of the RTIL can be increased by increasing the alkyl chain length of the cation (Figure 63), and/or through changing the anion (Figure 64), which increases hydrophobicity according to the following order: $\left.\left[\mathrm{BF}_{4}\right]^{-}<\mathrm{CH}_{3}\left(\mathrm{C}_{2} \mathrm{H}_{4} \mathrm{O}\right)_{2} \mathrm{SO}_{4}\right]^{-}<\left[\mathrm{C}(\mathrm{CN})_{3}\right]^{-}<\left[\mathrm{PF}_{6}\right]^{-}<\left[\mathrm{Tf}_{2} \mathrm{~N}\right]^{-}[78]$. Therefore, the RTIL chosen for experimentation was $\left[\mathrm{C}_{6} \operatorname{mim}\right]\left[\mathrm{Tf}_{2} \mathrm{~N}\right]$. 


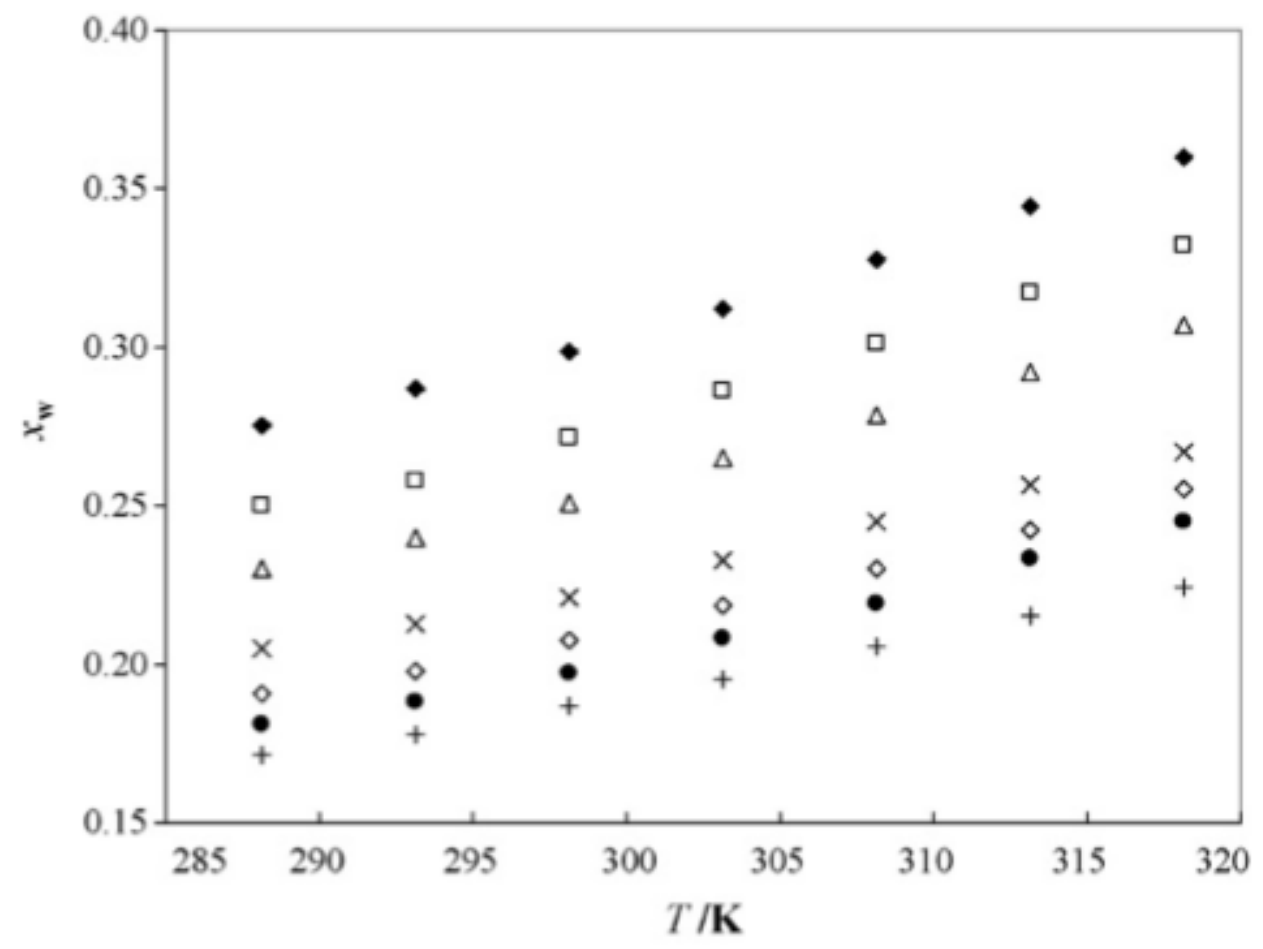

Figure 63 Mole Fraction Solubility of Water in RTIL - Lengthening Cation Alkyl

$(\diamond)\left[\mathrm{C}_{2} \mathrm{mim}\right]\left[\mathrm{Tf}_{2} \mathrm{~N}\right],(\square)\left[\mathrm{C}_{3} \mathrm{mim}\right]\left[\mathrm{Tf}_{2} \mathrm{~N}\right],(\Delta)\left[\mathrm{C}_{4} \mathrm{mim}\right]\left[\mathrm{Tf}_{2} \mathrm{~N}\right],(\mathrm{x})\left[\mathrm{C}_{5} \mathrm{mim}\right]\left[\mathrm{Tf}_{2} \mathrm{~N}\right],(\diamond)$ $\left[\mathrm{C}_{6} \mathrm{mim}\right]\left[\mathrm{Tf}_{2} \mathrm{~N}\right],(\bullet)\left[\mathrm{C}_{7} \mathrm{mim}\right]\left[\mathrm{Tf}_{2} \mathrm{~N}\right],(+)\left[\mathrm{C}_{8} \mathrm{mim}\right]\left[\mathrm{Tf}_{2} \mathrm{~N}\right]$

Reprinted from Fluid Phase Equilibria, vol. 261, M. G. Freire et. al., An Overview of the Mutual Solubilities of Water-Imidazolium-Based Ionic Liquids Systems, pp. 449-454, 2007, with permission from Elsevier. 


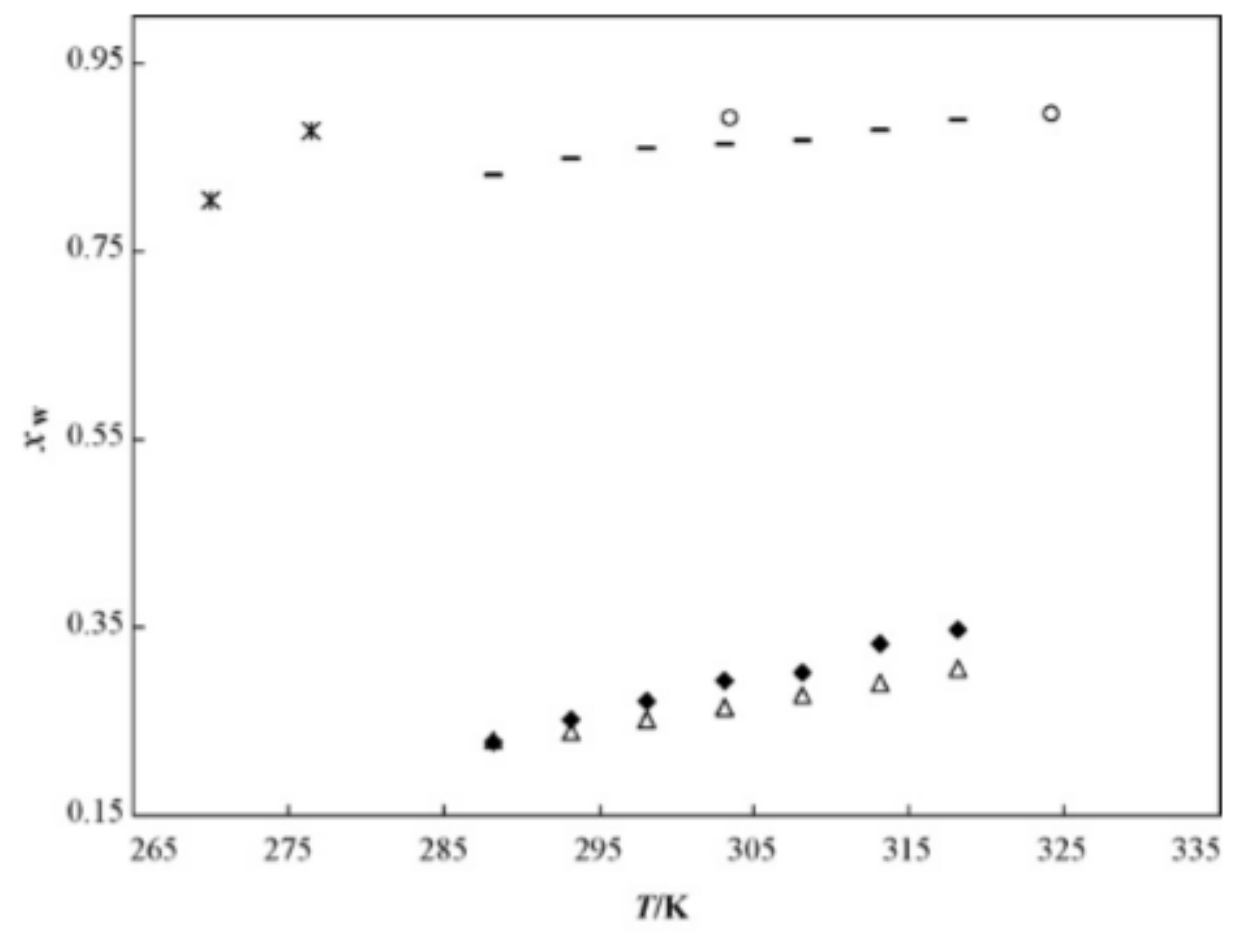

Figure 64 Mole Fraction Solubility of Water in RTIL - Changing Anion

(x) $\left[\mathrm{C}_{4} \mathrm{mim}\right]\left[\mathrm{BF}_{4}\right],(\circ)\left[\mathrm{C}_{4} \mathrm{mim}\right]\left[\mathrm{CH}_{3}\left(\mathrm{C}_{2} \mathrm{H}_{4} \mathrm{O}\right)_{2} \mathrm{SO}_{4}\right],(-)\left[\mathrm{C}_{4} \mathrm{mim}\right]\left[\mathrm{C}(\mathrm{CN})_{3}\right],(\diamond)$ $\left[\mathrm{C}_{4} \mathrm{mim}\right]\left[\mathrm{PF}_{6}\right],(\Delta)\left[\mathrm{C}_{4} \mathrm{mim}\right]\left[\mathrm{Tf}_{2} \mathrm{~N}\right]$

Reprinted from Fluid Phase Equilibria, vol. 261, M. G. Freire et. al., An Overview of the Mutual Solubilities of Water-Imidazolium-Based Ionic Liquids Systems, pp. 449-454, 2007, with permission from Elsevier.

The lanthanide extraction efficiency of CMPO in $\left[\mathrm{C}_{6} \mathrm{mim}\right]\left[\mathrm{Tf}_{2} \mathrm{~N}\right]$ was investigated by performing liquid-liquid extraction of ${ }^{177} \mathrm{Lu}$ from a neutral $\mathrm{pH}$ aqueous stock solution. Three milliliters of a $100 \mu \mathrm{Ci}{ }^{177} \mathrm{Lu}$ neutral $\mathrm{pH}$ solution was mixed for 60 minutes in a scintillation vial with $3 \mathrm{~mL}$ of $\left[\mathrm{C}_{6} \mathrm{mim}\right]\left[\mathrm{Tf}_{2} \mathrm{~N}\right]$ consisting of varying amounts of CMPO $(5,10,15$, and $20 \mathrm{mM})$. Lutetium extraction was measured by HPGe gamma spectroscopy and the results of this extraction are shown below (Figure 65). The relative error on this experiment $(n=1)$ averaged $\pm 3.8 \%$ as calculated by peak area. 


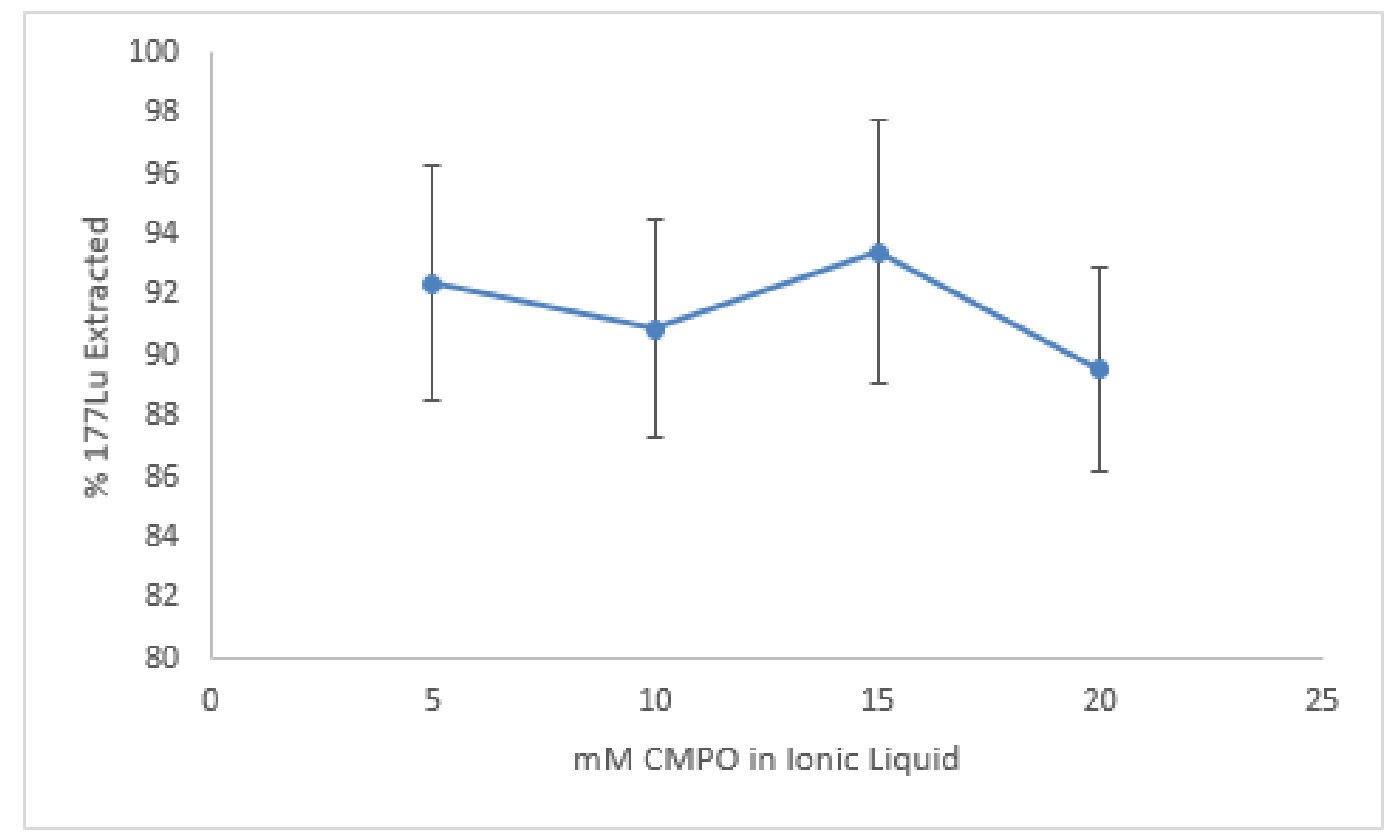

Figure 65 Percent ${ }^{177}$ Lu Extracted from Neutral pH Feed vs. CMPO Concentration $(\mathbf{n}=\mathbf{1})$

The lanthanide stripping efficiency of EDTA in $1 \mathrm{M}$ guanidine carbonate $\mathrm{pH} 10$ was also investigated by extraction of ${ }^{177} \mathrm{Lu}$ from a $\left[\mathrm{C}_{6} \mathrm{mim}\right]\left[\mathrm{Tf}_{2} \mathrm{~N}\right]$ solution. Three milliliters of a $100 \mu \mathrm{Ci}{ }^{177} \mathrm{Lu}$ in $5 \mathrm{mM} \mathrm{CMPO}$ dissolved in $\left[\mathrm{C}_{6} \mathrm{mim}\right]\left[\mathrm{Tf}_{2} \mathrm{~N}\right]$ solution was mixed for 60 minutes in a scintillation vial with $3 \mathrm{~mL}$ of EDTA (acid form) in $1 \mathrm{M}$ guanidine carbonate strip solution consisting of varying amounts of EDTA. The activity of strip solutions containing $0.01,0.05$, and $0.10 \mathrm{mM}$ EDTA were analyzed by HPGe gamma spectroscopy and plotted (Figure 66). The relative error on this experiment $(\mathrm{n}=1)$ averaged $\pm 1.3 \%$ as calculated by peak area. 


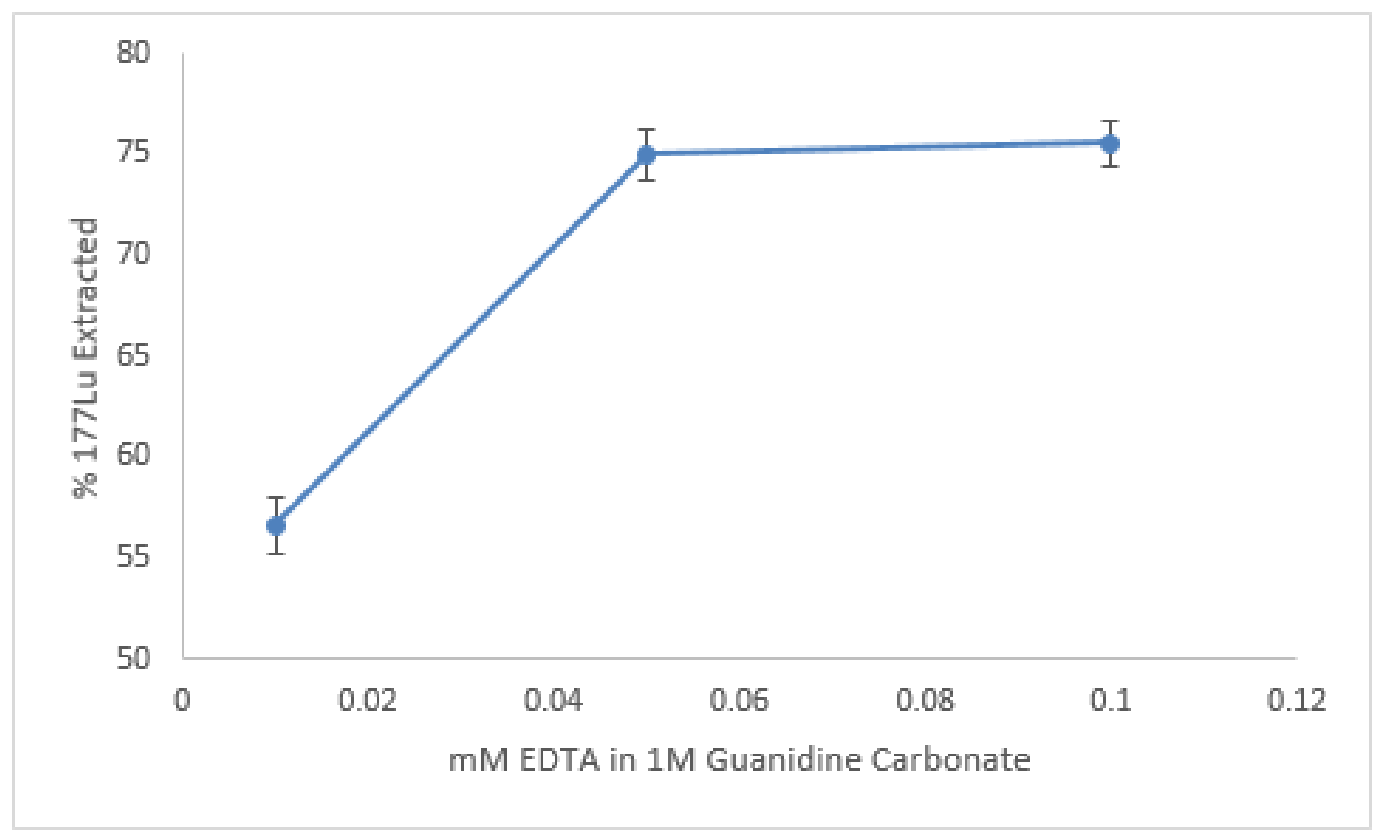

Figure 66 Percent ${ }^{177}$ Lu Stripped from CMPO:RTIL vs. EDTA Concentration (n=1)

In the first experiment, extracting ${ }^{177} \mathrm{Lu}$ from an aqueous solution with RTIL, it was shown that all concentrations of CMPO extracted greater than $90 \%$ of the ${ }^{177} \mathrm{Lu}$ activity in 60 minutes, therefore $5 \mathrm{mM} \mathrm{CMPO}$ was chosen for further extraction work. The second experiment, stripping ${ }^{177} \mathrm{Lu}$ from the RTIL, illustrated that concentrations of $0.05 \mathrm{mM}$ EDTA or greater in $1 \mathrm{M}$ guanidine carbonate extracted $75 \%$ of the ${ }^{177} \mathrm{Lu}$ activity in 60 minutes. The ideal solutions for use in HFSLM extraction would consist of $5 \mathrm{mM}$ CMPO dissolved in $\left[\mathrm{C}_{6} \mathrm{mim}\right]\left[\mathrm{Tf}_{2} \mathrm{~N}\right]$ for the aqueous extraction, and $0.05 \mathrm{mM}$ EDTA dissolved in $1 \mathrm{M}$ guanidine carbonate for the stripping solution.

\subsection{Lutetium Liquid-Liquid Extraction Kinetics Experiments}

The kinetics of extraction and stripping of ${ }^{177} \mathrm{Lu}$ with HFSLM were first investigated by liquid-liquid extraction. First, the rate of extraction of ${ }^{177} \mathrm{Lu}$ from neutral aqueous feed solution into the RTIL mixture was investigated. Ten milliliters of a 800 
$\mu \mathrm{Ci}{ }^{177} \mathrm{Lu}$ solution at $\mathrm{pH} 7$ was mixed with $10 \mathrm{~mL}$ of $5 \mathrm{mM}$ CMPO dissolved in $\left[\mathrm{C}_{6} \mathrm{mim}\right]\left[\mathrm{Tf}_{2} \mathrm{~N}\right]$ in a scintillation vial (Figure 67 ). Aliquots of the feed solution were taken at initial, 5, 10, 15, and 30-minute intervals and analyzed by HPGE for ${ }^{177} \mathrm{Lu}$ activity and plotted (Figure 68). The activity error on this experiment $(n=1)$ averaged $\pm 1.1 \mu \mathrm{Ci}$ as calculated with the Canberra Genie software.

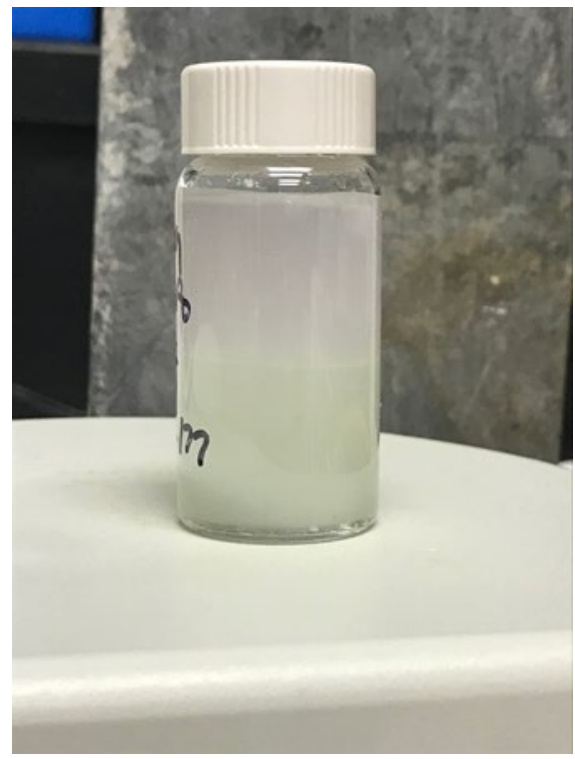

Figure 67 Feed Extraction with 5 mM CMPO:RTIL

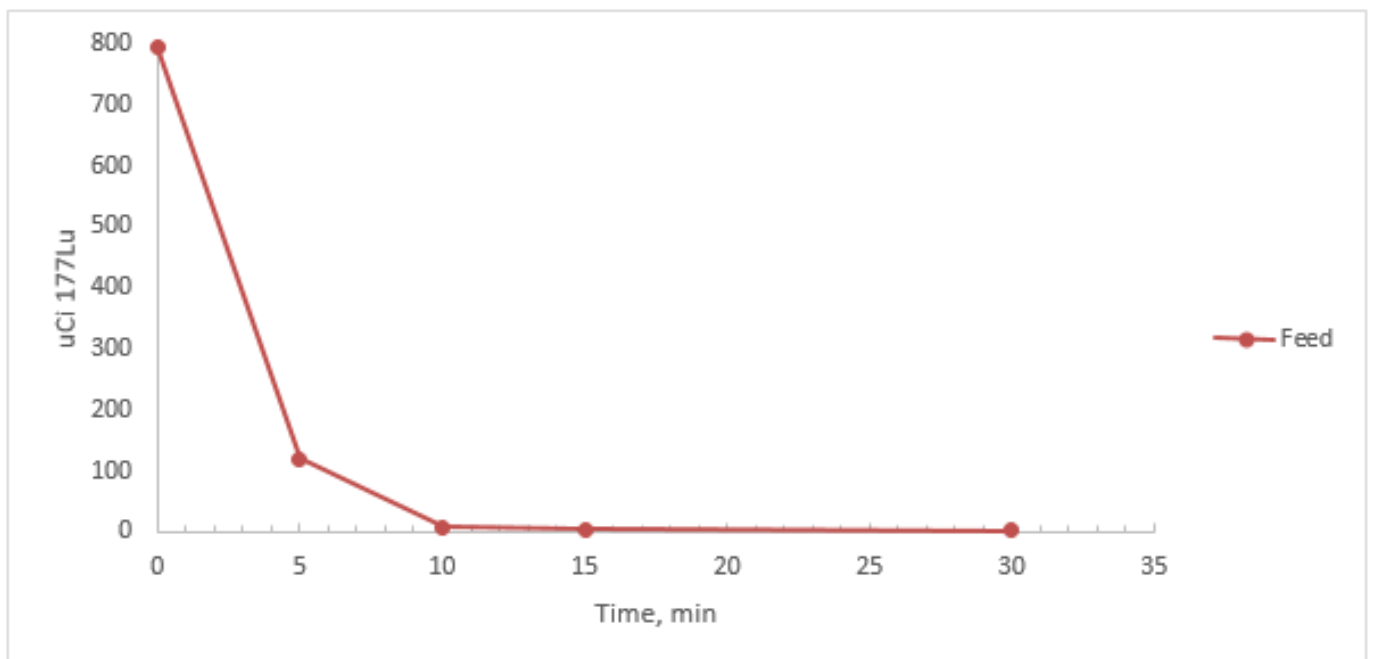

Figure 68 Feed Activity of ${ }^{177}$ Lu vs. mixing time with 5 mM CMPO: RTIL (n=1) 
In a second experiment, the rate of stripping of ${ }^{177} \mathrm{Lu}$ from the CMPO: RTIL mixture into aqueous strip solution was investigated. Ten milliliters of a $800 \mu \mathrm{Ci}{ }^{177} \mathrm{Lu}$ in $5 \mathrm{mM}$ CMPO dissolved in $\left[\mathrm{C}_{6} \mathrm{mim}\right]\left[\mathrm{Tf}_{2} \mathrm{~N}\right]$ was mixed with $10 \mathrm{~mL}$ of $0.05 \mathrm{mM}$ EDTA dissolved in $1 \mathrm{M}$ guanidine carbonate at $\mathrm{pH} 10$ in a scintillation vial (Figure 69). Aliquots of the strip solution were taken at initial, 5, 10, 15, 30, 60, and 120-minute intervals and analyzed by HPGe gamma spectroscopy for ${ }^{177} \mathrm{Lu}$ activity and plotted (Figure 70$)$. The activity error on this experiment $(\mathrm{n}=1)$ averaged $\pm 1.1 \mu \mathrm{Ci}$ as calculated with the Canberra Genie software.

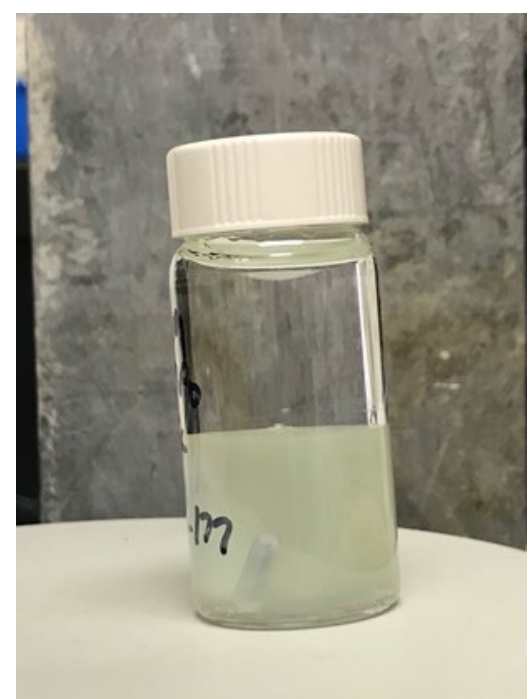

Figure 69 CMPO:RTIL Stripping with 0.05 mM EDTA: 1 M Guanidine Carbonate 


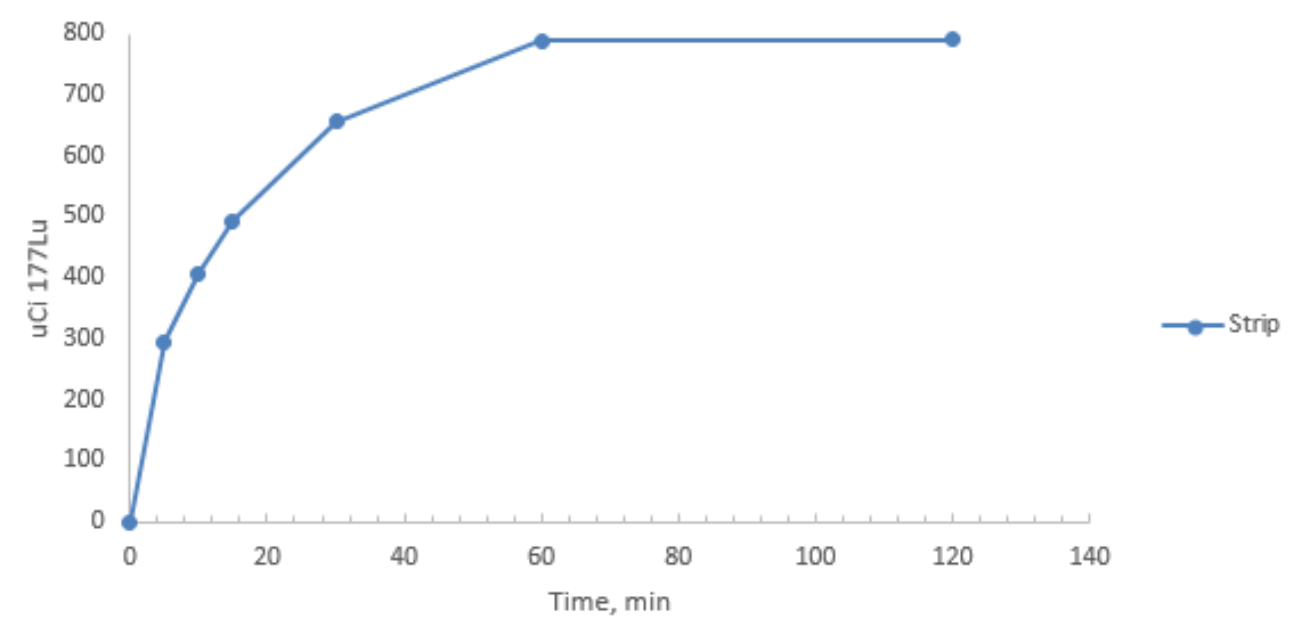

Figure $70{ }^{177}$ Lu Activity in EDTA:Guanidine Carbonate Strip Solution vs. Mixing Time with CMPO:RTIL $(n=1)$

The results of the initial liquid-liquid extraction showed $99 \%$ of the ${ }^{177}$ Lu activity removed from the aqueous feed in 30 minutes by the CMPO:RTIL mixture. The results of the stripping experiment showed the 0.05 mM EDTA: 1 M guanidine carbonate solution stripped $99 \%$ of the ${ }^{177} \mathrm{Lu}$ activity from the RTIL mixture in 60 minutes. Therefore the conditions for HFSLM extraction should use an aqueous feed solution at neutral $\mathrm{pH}, 5 \mathrm{mM}$ CMPO in $\left[\mathrm{C}_{6} \mathrm{mim}\right]\left[\mathrm{Tf}_{2} \mathrm{~N}\right]$ in the membrane pores, and $0.05 \mathrm{mM}$ EDTA:1 M guanidine carbonate stripping solution.

\subsection{Lutetium HFSLM Extraction - Polycarbonate Mini-Module Experiments}

The HFSLM cartridge used for lutetium experiments was a Mini-Module 1x5.5 manufactured by $3 \mathrm{M}$ (Table 16). Initially the liquid membrane was prepared by dissolving $5 \mathrm{mM} \mathrm{CMPO}$ in $\left[\mathrm{C}_{6} \mathrm{mim}\right]\left[\mathrm{Tf}_{2} \mathrm{~N}\right]$ and this RTIL was circulated into the lumen side of the HFSLM system (under slight pressure) for at least one hour to ensure complete permeation of the membrane pores, while the shell side of the membrane 
remained open to air. After charging with the RTIL solution, the excess RTIL was pumped out of the system and the entire system was washed with deionized water for 30 minutes. The deionized water rinsing was performed three times. Following rinsing, the feed solution was pumped into the lumen side and the stripping solution was pumped counter-currently into the shell side, operating the unit in recirculation mode. The feed solution was $100 \mathrm{~mL}$ of aqueous at neutral $\mathrm{pH}$ in a closed system (slightly pressurized at 3 p.s.i.). The strip solution was $100 \mathrm{~mL}$ of $0.5 \mathrm{M}$ EDTA in $1 \mathrm{M}$ guanidine carbonate, open to the atmosphere. Flow rates of both the feed and stripping solutions were maintained at $200 \mathrm{~mL} / \mathrm{min}(\sim 3 \mathrm{gph})$ by flowmeter throughout the experiment.

\begin{tabular}{|l|l|}
\hline \multicolumn{2}{|c|}{ Physical Characteristics of the Hollow Fiber Module } \\
\hline \hline Characteristics & Descriptions \\
\hline Model & Mini-Module $1 \times 5.5$ \\
\hline Module length $(\mathrm{mm})$ & 176 \\
\hline Inside diameter of hollow fiber $(\mu \mathrm{m})$ & 220 \\
\hline Outside diameter of hollow fiber $(\mu \mathrm{m})$ & 300 \\
\hline Effective length of hollow fiber $(\mathrm{cm})$ & 10 \\
\hline Number of hollow fibers & 2,300 \\
\hline Porosity $(\%)$ & 40 \\
\hline Effective surface area $\left(\mathrm{m}^{2}\right)$ & 0.2 \\
\hline Tortuosity factor & 3.5 \\
\hline Operating temperature $\left({ }^{\circ} \mathrm{C}\right)$ & $5-70$ \\
\hline Recommended flow rate $(\mathrm{ml} / \mathrm{min}))$ & $<500$ \\
\hline Membrane Material & $\mathrm{x} 50$ polypropylene membrane \\
\hline Max. pressure $(\mathrm{psi})$ & 30 \\
\hline \hline
\end{tabular}

\section{Table 16 HFSLM Mini-Module Specifications}

The HFSLM mini-module extraction experiments could not be successfully completed due to deterioration of the polycarbonate membrane housing. After circulation of the RTIL, the HFSLM housing began to crack and leak fluid (Figure 71). This was observed with two separate membrane modules. Evidence exists in the literature for the 
possible hydrolysis of the polycarbonate housing catalyzed by ionic liquid with water and increased temperature [79]. Also, Kubisa lists methyl methacrylate and its polymers as miscible, and butyl and t-butyl acrylate as partly soluble in $[\mathrm{Bmim}]\left[\mathrm{PF}_{6}\right][80]$. According to 3M correspondence, "Chemical resistance of G543 components, especially the polycarbonate housing and the polyurethane potting, are limited."

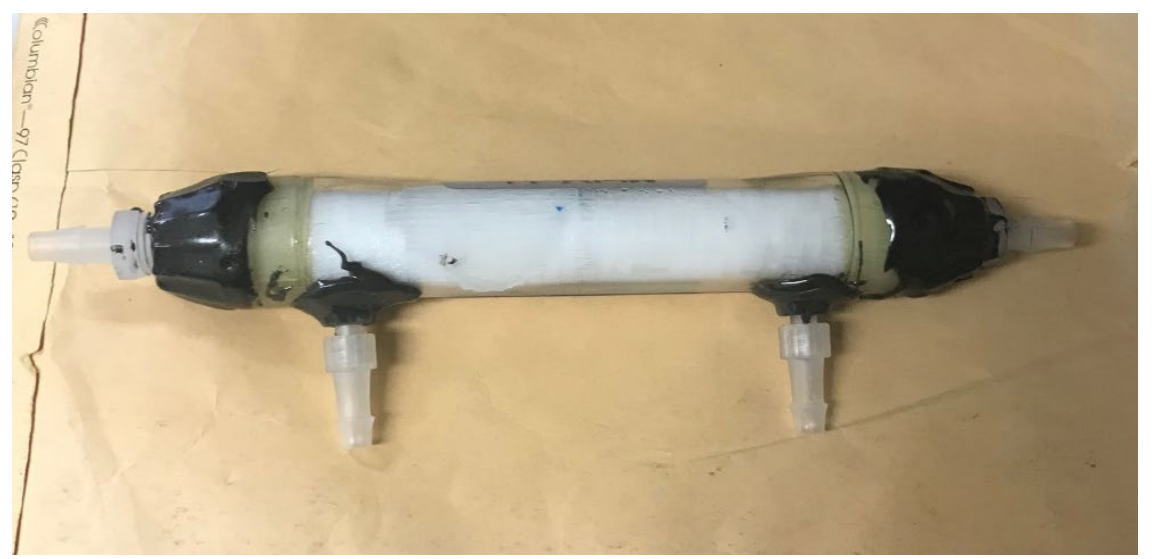

Figure 71 Damaged Polycarbonate HFSLM

\subsection{Lutetium HFSLM Extraction - PVC Mini-Module Experiments}

A replacement PVC housed HFSLM cartridge was identified for lutetium experiments, the Mini-Module 1.7x10 manufactured by 3M. Initially the liquid membrane was prepared by dissolving $5 \mathrm{mM} \mathrm{CMPO}$ in $\left[\mathrm{C}_{6} \operatorname{mim}\right]\left[\mathrm{Tf}_{2} \mathrm{~N}\right]$ and this RTIL was circulated into the lumen side of the HFSLM system (under slight pressure) for at least two hours to ensure complete permeation of the membrane pores, while the shell side of the membrane remained open to air. After charging with the RTIL solution, the excess RTIL was pumped out of the system and the entire system was washed with deionized water for 30 minutes. The deionized water rinsing was performed three times. Following rinsing, the feed solution was pumped into the lumen side and the stripping solution was pumped counter-currently into the shell side, operating the unit in 
recirculation mode. The feed solution contained $800 \mu \mathrm{Ci}$ of ${ }^{177} \mathrm{Lu}$ in $100 \mathrm{~mL}$ of aqueous at $\mathrm{pH} 7$ in a closed system (slightly pressurized at 3 p.s.i.). The strip solution was 100 $\mathrm{mL}$ of $0.5 \mathrm{M}$ EDTA in $1 \mathrm{M}$ guanidine carbonate at $\mathrm{pH} 10$, open to the atmosphere. Flow rates of both the feed and stripping solutions were maintained at $200 \mathrm{~mL} / \mathrm{min}(\sim 3 \mathrm{gph})$ by flowmeter throughout the experiment.

One initial aliquot of the initial feed solution and aliquots of the strip solution were taken at initial, 5, 10, 15, 30, and 60-minute intervals and analyzed by HPGe gamma spectroscopy for ${ }^{177} \mathrm{Lu}$ activity (Figure 72 ). The activity error on this experiment $(\mathrm{n}=1)$ averaged $\pm 1.4 \mu \mathrm{Ci}$ as calculated with the Canberra Genie software.

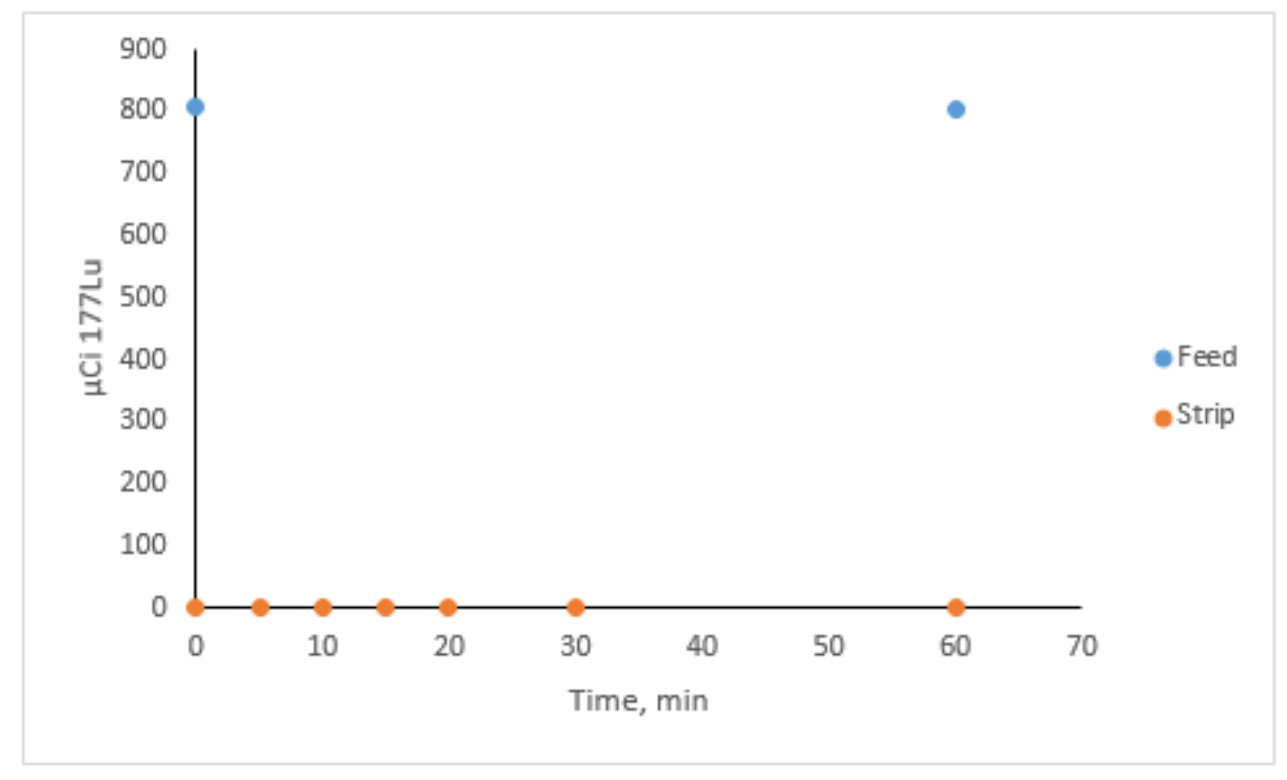

Figure $72{ }^{177}$ Lu Activity in Feed and Strip Solutions vs Time (n=1)

The PVC HFSLM mini-module extraction experiments could not be successfully completed due to the lack of migration of lutetium through the membrane. There was no lutetium detected in the strip solution aliquots. The $800 \mu \mathrm{Ci}( \pm 1.4 \mu \mathrm{Ci})$ of lutetium in the feed solution did not migrate into the membrane or the strip solution. Poor efficiency of 
metal ion transport was likely due to the high viscosity of the ionic liquid [81], which would prevent migration into the membrane pores.

\subsection{RTIL Organic Dilution Experiments}

The high viscosity of the RTIL may have prevented its migration into the pores of the HFSLM. In an attempt to reduce the RTIL viscosity, experiments were performed using RTIL diluted with an organic solvent. The lanthanide extraction efficiency of diluted RTIL was investigated by performing liquid-liquid extraction of lutetium-177 from a neutral $\mathrm{pH}$ aqueous stock solution. Ten milliliters of a $1 \mathrm{mCi}^{177} \mathrm{Lu}$ neutral $\mathrm{pH}$ solution were mixed for $60 \mathrm{~min}$. in a scintillation vial with $10 \mathrm{~mL}$ of $5 \mathrm{mM} \mathrm{CMPO} \mathrm{in}$ $\left[\mathrm{C}_{6} \mathrm{mim}\right]\left[\mathrm{Tf}_{2} \mathrm{~N}\right]$, which was diluted with varying amounts of organic solvent. HPGe gamma spectroscopy results for ${ }^{177} \mathrm{Lu}$ activity are presented in Table 17.

\begin{tabular}{|c|c|c|}
\hline \multicolumn{4}{|c|}{} \\
\multirow{2}{*}{ RTIL: 5mM CMPO in [C6mim][Tf2N] } \\
\hline $\begin{array}{c}\text { Organic } \\
\text { Solvent }\end{array}$ & $\begin{array}{c}\text { \% } \\
\text { RTIL }\end{array}$ & $\begin{array}{c}\text { \% } \\
\text { Extracted }\end{array}$ \\
\hline Dodecane & 70 & Immicible \\
\hline \multirow{3}{*}{ Ethyl Acetate } & 20 & Immicible \\
\cline { 2 - 3 } & 50 & 0 \\
\cline { 2 - 3 } & 70 & 0 \\
\hline \multirow{2}{*}{ Hexyl Acetate } & 50 & 25 \\
\cline { 2 - 3 } & 70 & 29 \\
\hline
\end{tabular}

Table 17 RTIL ${ }^{177}$ Lu Extraction Efficiency Upon Dilution with Organic Solvent

The RTIL was insoluble in dodecane but dissolved in ethyl acetate. Liquid-liquid extraction testing with the RTIL diluted with ethyl acetate showed colloid formation at high ethyl acetate concentrations (Figure 73), and no migration of radiotracer lutetium 
into the RTIL/ethyl acetate layer after mixing for 60 minutes. Hexyl acetate improved extraction results, with the best extraction consisting of 70\% RTIL: 30\% Hexyl Acetate, which removed $29 \%$ of the radioactive lutetium in 60 minutes.

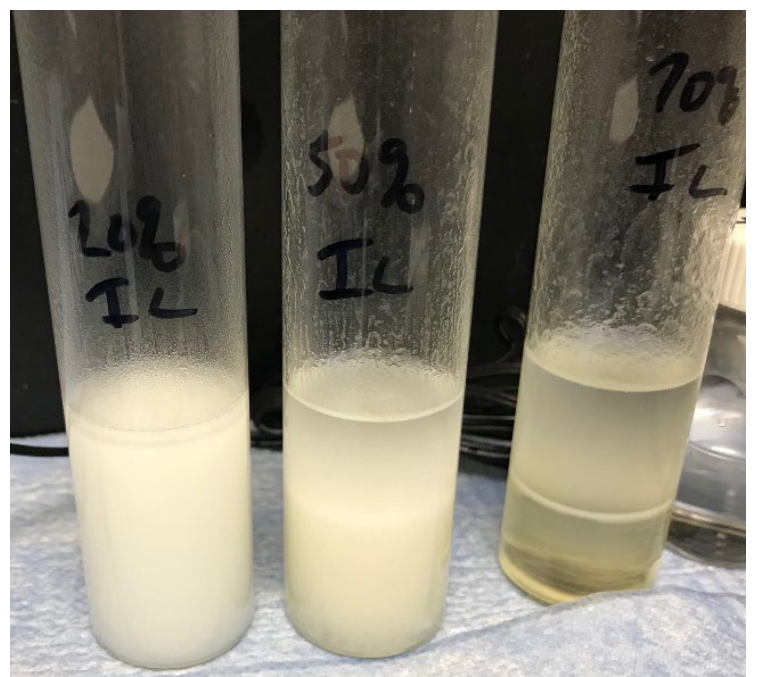

Figure 73 RTIL/Ethyl Acetate Colloid Formation with Water

\subsection{Carboxylic Acid for Liquid-Liquid Extraction}

Committee members suggested investigation of carboxylic acids for use as a ligand in HFSLM extraction as carboxylic acids are employed in the liquid-liquid extraction of rare earth elements due to their ease of incorporation, low cost, and commercial availability. Naphthenic acid and versatic acid are commonly used in mineral processing for the extraction of rare-earth ores from acidic solution [82] [83] [84]. Versatic 10 (neodecanoic acid, CAS number 26896-20-8) manufactured by Hexion, is a mixture of carboxylic acids with the common structural formula of $\mathrm{C}_{10} \mathrm{H}_{20} \mathrm{O}_{2}$, and a molecular weight of $172.26 \mathrm{~g} / \mathrm{mol}$. Components of this mixture are acids with three alkyl groups at carbon two, with at least one of the alkyl groups consisting of a methyl group (Figure 74). Research by Baba et. al. [85] suggests that Versatic 10 may also useful for extraction of rare earth elements from neutral $\mathrm{pH}$ solutions. 


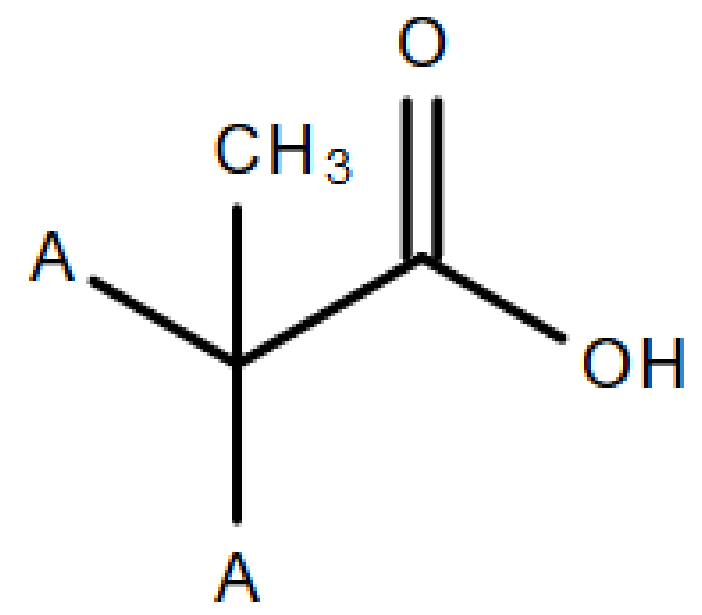

Figure 74 Versatic 10, Neodecanoic Acid

An experiment was performed to determine the lanthanide extraction efficiency of Versatic 10 by performing liquid-liquid extraction of lutetium-177 from a neutral $\mathrm{pH}$ aqueous stock solution. Seven milliliters of a $30 \mu \mathrm{Ci}{ }^{177} \mathrm{Lu}$ neutral $\mathrm{pH}$ solution was mixed in a scintillation vial with $7 \mathrm{~mL}$ of Versatic 10 , which was diluted with varying amounts of dodecane. The percentage of ${ }^{177} \mathrm{Lu}$ extracted as measured by HPGe gamma spectroscopy activity after $1 \mathrm{~h}$ and after $5 \mathrm{~h}$ of mixing are presented in (Table 18). 


\begin{tabular}{|c|c|c|c|c|}
\hline $\begin{array}{c}\text { Concentration } \\
\text { Neodecanoic acid } \\
\text { (Versatic 10) }\end{array}$ & pH & $\begin{array}{c}\text { Mix } \\
\text { Time h }\end{array}$ & $\begin{array}{c}\text { \% } \\
\text { Extraction }\end{array}$ & $\begin{array}{c}\text { \% } \\
\text { Stripping } \\
\mathbf{0 . 7} \mathbf{~ M} \\
\mathbf{H}_{2} \mathbf{S O}_{4}\end{array}$ \\
\hline Neat & 6.5 & 1 & 77 & \\
\hline $5 \mathrm{M}$ in Dodecane & 6.5 & 1 & 73 & \\
\hline $1 \mathrm{M}$ in Dodecane & 6.5 & 1 & 24 & \\
\hline $0.6 \mathrm{M}$ in Dodecane & 6.5 & 1 & 16 & \\
\hline Neat & & & & \\
\hline $5 \mathrm{M}$ in Dodecane & 6.5 & 5 & 81 & 92 \\
\hline $1 \mathrm{M}$ in Dodecane & 6.5 & 5 & 31 & \\
\hline $0.6 \mathrm{M}$ in Dodecane & 6.5 & 5 & 19 & \\
\hline
\end{tabular}

\section{Table 18 Lutetium-177 Extraction with Varying Versatic 10 Concentration and Mixing Time $(n=1)$}

In a second experiment, the stripping of ${ }^{177} \mathrm{Lu}$ from the Versatic 10 into $0.7 \mathrm{M}$ $\mathrm{H}_{2} \mathrm{SO}_{4}$ was investigated. Seven milliliters of a $22 \mu \mathrm{Ci}{ }^{177} \mathrm{Lu}$ in Versatic 10 was mixed with 7 milliliters of $0.7 \mathrm{M} \mathrm{H}_{2} \mathrm{SO}_{4}$ in a scintillation vial. The percentage of ${ }^{177} \mathrm{Lu}$ stripped from the Versatic 10 as measured by HPGe gamma spectroscopy activity after $1 \mathrm{~h}$ of mixing is listed in (Table 18).

The results of the initial liquid-liquid extraction showed $77 \%$ of the ${ }^{177}$ Lu activity removed from the aqueous feed in $60 \mathrm{~min}$. by the neat Versatic 10. The results of the stripping experiment showed the $0.7 \mathrm{M} \mathrm{H}_{2} \mathrm{SO}_{4}$ solution stripped $92 \%$ of the ${ }^{177} \mathrm{Lu}$ activity from the Versatic 10 solution in $60 \mathrm{~min}$. Therefore the conditions for HFSLM extraction testing should use an aqueous feed solution at neutral $\mathrm{pH}$, neat Versatic 10 in the membrane pores, and $0.7 \mathrm{M} \mathrm{H}_{2} \mathrm{SO}_{4}$ stripping solution. 


\section{Chapter 6 FUTURE DIRECTION AND ONGOING WORK}

\subsection{Batch Collection Optimization, Single Element Separation}

The successful batch collection of lutetium from the Purolite NRW100x10 cation resin with Eichrom DGA resin will continue to be improved upon. In future work, experiments will take place to optimize the elution volume of the DGA cartridge, and/or to isolate individual lanthanide ions. Temperature effects upon the DGA resin have yet to be considered.

\subsection{HFSLM Extraction Conditions Optimization}

The HFSLM cartridge used for vanadium extraction experiments was a Liqui-Cel $2.5 \times 8$ operated at room temperature and maintained at $6 \mathrm{gph}(\sim 450 \mathrm{~mL} / \mathrm{min})$ by flowmeter throughout the experiments. The temperature dependence of the HFSLM extraction of vanadium was not investigated, and vanadium extraction rates at elevated temperatures warrant further investigation.

The large amounts of energy deposited in the beam dump will cause radiolysis of beam dump water into peroxides and other radiolytic products. These radiolytic products will not be scrubbed out before the HFLSM and should be considered in further investigations.

Another area for further investigation is the maximum flowrate of the HFSLM. The cartridge is rated for much higher flowrates (up to $3 \mathrm{gpm}$ ) but the point at which the liquid membrane is washed from the pores has not yet been established. 
There is a concention effect with HFSLM that also needs to be maximized. By significantly increasing the volume of the feed solution in comparison with the volume of the stripping solution, the final concentration of extracted metal in the strip solution could be greatly increased. With the $7000 \mathrm{~L}$ beam dump loop as the feed solution, a $1 \mathrm{~L}$ strip solution would offer a 7000x concentration factor.

\subsection{HFSLM Extraction of Other Isotopes}

The potential for seamless integration of HFSLM extraction into the FRIB primary beam dump loop makes it an exciting option for the recovery of many rare radionuclides that cannot be easily produced by other means. Two examples of isotopes

from FRIB that are in high demand include the lanthanides: ${ }^{147} \mathrm{Pm}$ and ${ }^{148} \mathrm{Gd}$, which will be the focus for future harvesting studies. In addition, many rare stable elements will be generated at FRIB and cost analysis/feasibility studies should be performed to evaluate harvesting of these elements.

Carboxylic acids still hold promise for use in HFSLM extraction of lanthanides from the neutral $\mathrm{pH}$ beam dump loop, especially those connected to crown ethers. Symdibenzo-16-crown-5-oxyacetic acid (Figure 75) has been listed in the literature as efficient and selective for extracting tervalent lanthanide ions from natural waters [86] [87]. Further investigation into its feasibility for lanthanide extraction with HFSLM should be performed. 


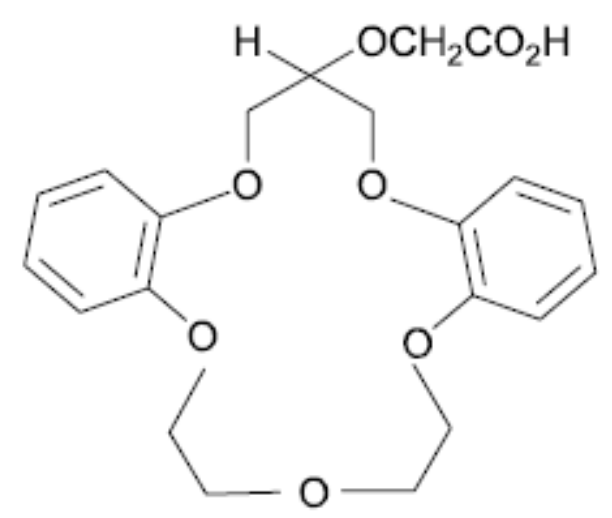

Figure 75 Structure of Sym-Dibenzo-16-Crown-5-Oxyacetic Acid

Reprinted from Tetrahedron, vol. 61, R.A. Bartsch et. al., Structures of Sym-®Dibenzo-16-Crown-5Oxyacetic Acids and Their Alkali Metal Cation Binding, pp. 8351-8357, Copyright 2005, with permission from Elsevier.

\subsection{HFSLM for Radioisotope Separation/Purification}

Hollow Fiber Supported Liquid membranes also have the potential for use in separation/purification of reactor produced radioisotopes. The no carrier added production of ${ }^{177} \mathrm{Lu}$ involves a difficult separation of ${ }^{177} \mathrm{Lu}$ from macroscopic levels of $\mathrm{Yb}$. Utilization of HFSLM extraction technology should make this separation possible from a $1 \mathrm{M} \mathrm{HCl}$ feed solution with $1 \%$ HDEHP in cyclohexane [88].

Cyclotron production of radioisotopes with HFSLM separation/purification should also be investigated, particularly for use with liquid targets. 


\section{BIBLIOGRAPHY}

[1] "National Nuclear Data Center," [Online]. Available: www.nndc.bnl.gov/. [Accessed 2016].

[2] B. Sherrill, "Presentation," in Ecole Joliot Curie, 2011.

[3] T. Mastren, A. Pen, G. Peaslee, N. Wozniak, S. Loveless, S. Essenmacher, L. Sobotka, D. Morrissey and S. Lapi, "Feasiliblity of Isotope Harvesting at a Projectile Fragmentation Facility: 67Cu," Scientific Reports, vol. 4, p. 6706, 2014.

[4] T. Mastren, A. Pen, S. Loveless, B. Marquez, E. Bollinger, B. Marois, N. Hubley, K. Brown, D. Morrissey, G. Peaslee and S. Lapi, "Harvesting 67Cu from the Collection of a Secondary Beam Cocktail at the National Superconducting Cyclotron Laboratory," Analytical Chemistry, vol. 87, pp. 10323-10329, 2015.

[5] A. Pen, T. Mastren, G. Peaslee, K. Petrasky, P. DeYoung, D. Morrissey and S. Lapi, "Design and Construction of a Water Target System for Harvesting Radioisotopes at the National Superconducting Cyclotron Laboratory," Nucl. Instrum. Meth. A, vol. 747, pp. 62-68, 2014.

[6] C. Shaun Loveless, private communication..

[7] J. Neuhausen and D. Schumann, "Accelerator Waste as a Source for Exotic Radionuclides," J. Phys. G: Nucl. Part. Phys., vol. 35, p. 014046, 2007.

[8] D. Schumann, M. Ayranov, T. Stowasser, L. Gialanella, A. d. Leva, M. Romano and D. Schuermann, "Radiochemical Separation of 7Be from the Cooling Water of the Neutron Spallation Source SINQ at PSI," Radiochim. Acta, vol. 101, pp. 509-514, 2013.

[9] R. Dressler, M. Ayranov, D. Bemmerer, M. Bunka, Y. Dai, C. Lederer, J. Fallis, A. S. Murphy, M. Pignatari, D. Schumann, T. Stora, T. Stowasser, F.-K. Thielemann and P. Woods, "44Ti, 26Al, and 53Mn Samples for Nuclear Astrophysics: The Needs, the Possibilities and the Sources," J. Phys. G: Nucl. Part. Phys., vol. 39, p. 105201, 2012.

[10] A. Visser and N. Scielzo, "Feasibility of Harvesting Radon from FRIB Beam Dump," LLNL-TR-709438, 2016.

[11] G. Severin, "Isotope Harvesting at FRIB: Additional Opportunities for Scientific Discovery," Michigan State University, 2017.

[12] G. Machicoane, H. Felice, J. Fogfeman, R. Hafalia, G. Morgan, H. Pan, S. Prestemon, E. Pozdeyev, X. Rao, H. Ren and L. Tobos, "Status of ECR Ion Sources for the Facility for Rare Isotope Beams (FRIB)," Review of Scientific Instruments, vol. 87, p. 02A743, 2016.

[13] C. Wrede, "The Facility for Rare Isotope Beams," EPJ Web of Conferences, vol. 93, p. 07001, 2015.

[14] "Facility for Rare Isotope Beams," [Online]. Available: www.frib.msu.edu/about. [Accessed 2016]. 
[15] D. Morrissey, B. Sherrill, M. Steiner, A. Stolz and I. Wiedenhoever, "Commissioning the A1900 Projectile Fragment Separator," Nucl. Instr. And Meth. In Phys. Res. B, vol. 204, pp. 90-96, 2003.

[16] D. Morrissey and B. Sherrill, Philos. Trans. R. Soc. Lond. Ser. A. Math. Phys. Eng. Sci., vol. 356, p. 1985, 1998.

[17] B. Sherril, "Fundamental Symmetry Tests with Rare Isotopes," Presentation, 2014.

[18] "Facility for Rare Isotope Beams," [Online]. Available: https://frib.msu.edu/news/2016/beam-dump.html. [Accessed 2016].

[19] R. Ronningen, Presentation, 2010.

[20] M. Hausmann, A. Aaron, A. Amthor, M. Avilov, L. Bandura, R. Bennett, G. Bollen, T. Borden, T. Burgess, S. Chouhan, V. Graves, W. Mittig, D. Morrissey, F. Pellemoine, M. Portillo, R. Ronningen, M. Schein and B. Sherrill, "Design of the Advanced Rare Isotope Separator ARIS at FRIB," Nuclear Instruments and Methods in Physics Research B, vol. 317, pp. 349-353, 2013.

[21] R. Flores-Espinosa, H. Ortiz-Oliveros, M. Olguin, M. Perusquia-Cueto and R. Gallardo-San-Vicente, "Separation and Treatment of Ion-Exchange Resins Used in Cleaning Systems of a Research Nuclear Reactor," Chem. Eng. J., vol. 188, pp. 71-76, 2012.

[22] K. Funabashi, T. Fukasawa, F. Kawamura and H. Yusa, "Reuse System for Powdered Ion-Exchange Resins," Nuc. Tech., vol. 73, pp. 220-227, 1986.

[23] A. Reents and F. Kahler, "Mixed-Bed Deionization," Indust. and Eng. Chem., vol. 43, no. 3, pp. 730-734, 1950.

[24] S. Marsch, J. Alarid, C. Hammond, M. McLeod, F. Roensch and J. Rein, "Cation Exchange of 53 Elements in Nitric Acid," Los Alamos Report LA-7083, 1978.

[25] F. Strelow, R. Rethemeyer and C. Bothma, "Ion Exchange Selectivity Scales for Cations in Nitric Acid and Sulfuric Acid Media With a Sulfonated Polystyrene Resin," Anal. Chem., vol. 37, pp. 106-111, 1965.

[26] M. Rucandio, "Cation-Exchange Isolation and ICP-AES Determination of Rare Earth Elements in Geological Silicate Materials," J. Anal. Chem., vol. 357, pp. 661-669, 1997.

[27] H. Smith and D. Hoffman, "Ion-Exchange Separations of Lanthanides and Actinides by Elution with Ammonium Alpha-Hydroxy-Isobutyrate," J. Inorg. Nucl. Chem., vol. 3, pp. 243-247, 1956.

[28] H. Deelstra and F. Verbeek, "The Separation of the Lanthanides and Yttrium by

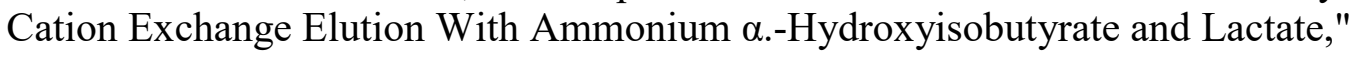
J. Chromatog., vol. 17, pp. 558-566, 1965.

[29] Nuryono, C. Huber and K. Kleboth, "Ion-Exchange Chromatography With an Oxalic Acid- $\alpha$.-Hydroxy-Isobutyric Acid Eluent for the Separation and Quantitation of Rare-Earth Elements in Monazite and Xenotime," Chromatographia, vol. 48, no. 5/6, pp. 407-414, 1998.

[30] S. Mayer and E. Freiling, "Ion Exchange as a Separation Method. VI. Column Studies of the Relative Efficiencies of Various Complexing Agents for the 
Separation of Lighter Rare Earths," J. Am. Chem. Soc., vol. 75, no. 22, pp. 56475649, 1953.

[31] [Online]. Available: https://www.transtutors.com/Uploadfile/CMS_Images/22301_image121.jpg.

[32] [Online]. Available: https://www.kullabs.com/uploads/9470_image114.jpg.

[33] J. Faris and R. Buchanan, "Anion Exchange Characteristics of Elements in Nitric Acid Medium," Analytical Chemistry, vol. 36, no. 6, pp. 1157-1158, 1964.

[34] X. Chen, G. Goff, W. Ewing, B. Scott and W. Runde, "Solid-State and SolutionState Coordination Chemistry of Lanthanide (III) Complexes with $\alpha$ Hydroxyisobutyric Acid," Inorg. Chem., vol. 51, pp. 13254-13263, 2012.

[35] G. Saipriya et. al., "Studies on the Adsorption Behavior of Americium and Europium on Radiolytically Degraded Solvent Impregnated Resin Containing Neutral and Acidic Extractants," J. Radioanal. Nucl. Chem., vol. 314, pp. 25572568, 2017.

[36] S. A. Catalog. [Online]. Available:

https://www.sigmaaldrich.com/catalog/product/aldrich/240494?lang=en\&region =US. [Accessed 0706 2018].

[37] "Eichrom," [Online]. Available: http://www.eichrom.com/products/info/re_resin.aspx. [Accessed 2016].

[38] A. Pourmand and N. Dauphas, "Distribution coefficients of 60 elements on TODGA resin: Application to $\mathrm{Ca}, \mathrm{Lu}, \mathrm{Hf}, \mathrm{U}$ and Th isotope geochemistry," Talanta, vol. 81, pp. 741-753, 2010.

[39] O. Tarasov and D. Bazin, "LISE ++ software," Michigan State University, [Online]. Available: http://lise.nscl.msu.edu/lise.html. [Accessed 2018].

[40] D. Lide, CRC Handbook of Chemistry and Physis, 73rd edition, Boca Raton: CRC Press, 1992.

[41] K. S.A., P. G.N. and L. Puzyrnaya, "Uranium (VI) in Natural Waters: Study of Occurrence Forms," Journal of Water Chemistry and Technology, vol. 34, no. 6, pp. 277-283, 2012.

[42] "Membrana," [Online]. Available: http://www.power-technology.com/wpcontent/uploads/sites/7/2017/09/3fca13b3-c25e-4cef-b33c-1e8386a01163.pdf. [Accessed 2018].

[43] N. Kocherginsky, Q. Yang and L. Seelam, "Recent Advances in Supported Liquid Membrane Technology," Separation and Purification Technology, vol. 53, pp. 171-177, 2007.

[44] D. Kim, L. Powell, L. Delmau, E. Peterson and J. Herchenroeder, "Selective Extraction of Rare Earth Elements From Permanent Magnet Scraps With Membrane Solvent Extraction," Environ. Sci. Technol., pp. A-H, 2015.

[45] S. Ansari, P. Mohapatra and V. Manchanda, "Recovery of Actinides and Lanthanides from High Level Waste Using Hollow Fiber Supported Liquid Membrane with TODGA as the Carrier," Ind. Eng. Chem. Res., vol. 48, pp. 8605-8612, 2009. 
[46] P. Danesi, "Permeation of Metal Ions Through Hollow-Fiber Supported Liquid Membranes: Concentration Equations for Once-Through and Recycling Module Arrangements," Solvent Extraction and Ion Exchange, vol. 2, no. 1, pp. 115-120, 1984.

[47] P. Rout and K. Sarangi, "Comparison of Hollow Fiber Membrane and Solvent Extraction Techniques for Extraction of Cerium and Preparation of Ceria by Stripping Precipitation," Chem. Technol. Biotechnol., vol. 90, pp. 1270-1280, 2015.

[48] T. Wannachod, V. Mohdee, S. Suren, P. Ramakul and U. Pancharoen, "The Separation of Nd(III) from Mixed Rare Earth via Hollow Fiber Supported Liquid Membrane and Mass Transfer Analysis," J. Ind. Eng. Chem., p. in press, 2014.

[49] A. Bhattacharyya, P. Mohapatra, S. Ansari, D. Raut and V. Manchanda, "Separation of Trivalent Actinides from Lanthanides using Hollow FIber Supported LIquid Membrane Containing Cyanex-301 as the Carrier," J. Mem. Sci., vol. 312, pp. 1-5, 2008.

[50] S. Ansari, P. Mohapatra, D. Raut, M. Kumar and B. Rajeswari, "Performance of Some Extractants Used for Actinide Partitioning in a Comparative Hollow Fiber Supported Liquid Membrane Transport Study Using Simulated High Level Nuclear Waste," J. Mem. Sci., vol. 337, pp. 304-309, 2009.

[51] V. Adya, A. Sengupta and S. Ansari, "Application of Hollow Fiber Supported Liquid Membrane for the Separation of Americium from the Analytical Waste," J. Radioannal. Nucl. Chem., vol. 295, pp. 1023-1028, 2013.

[52] "FRIB: Opening New Frontiers in Nuclear Science," [Online]. Available: https://www.frib.msu.edu/_files/pdfs/frib_opening_new_frontiers_in_nuclear_sci ence.pdf. [Accessed 2012].

[53] T. Wichard, "Identification of Metallophores and Organic Ligands in the Chemosphere of the Marine Macroalga Ulva (Chlorophyta) and at Land-Sea Interfaces," Front. Mar. Sci., vol. 3, pp. 1-10, 2016.

[54] A. Kraipial, J. Bellenger, T. Wichard and F. Morel, "Multiple Roles of Siderophores in Free-Living Nitrogen-Fixing Bacteria," Biometals, vol. 22, pp. 573-581, 2009.

[55] A. Rosell, C. Palet and M. and Valiente, "Selective Separation and Concentration of Vanadium(V) by a Chemical Pumping Hollow-Fiber Supported Liquid Membrane," Analytica Chimica Acta, pp. 171-178, 1997.

[56] C. Palet et. al., "Transport of Vanadium (V) Through a Tricaprylylmethylammonium Solid Supported Liquid Membrane from Aqueous Acetic Acid/Acetate Solutions," J. Mem. Sci., vol. 98, pp. 241-248, 1995.

[57] J. Huheey, E. Keiter and R. Keiter, Inorganic Chemistry: Principles of Structure and Reactivity, New York: Harper Collins, 1993.

[58] M. Pope, Heteropoly and Isopoly Oxometalates, New York: Springer-Verlag, 1983.

[59] D. Brooks, in Eh-pH Diagrams for Geochemistry, New York, Springer-Verlag, 1988. 
[60] E. Baum, H. Knox and T. Miller, Chart of the Nuclides, 16th edition, Knolls Atomic Power Laboratory, Lockheed Martin, 2002.

[61] "Lund/LBNL Nuclear Data Search," [Online]. Available: http://nucleardata.nuclear.lu.se/toi/nuclide.asp?iZA=230048. [Accessed 2018].

[62] S. Zeisler and T. Ruth, "Preparation of [48V]-VO2+ for Biomedical Studies," J. Radioanal. Nucl. Chem. Letters, vol. 200, pp. 283-290, 1995.

[63] N. Greenwood and A. Earnshaw, Chemistry of the Elements, Boston: Butterworth-Heinmann, 1997.

[64] R. Pearson, J. Am. Chem. Soc., vol. 85, pp. 3533-3539, 1963.

[65] M. Ferrier, B. Stein, E. Batista, J. Berg, E. Birnbaum, J. Engle, K. John, S. Kozimor, J. Pacheco and L. Redman, "Synthesis and Characterization of the Actinium Aquo Ion," ACS Cent. Sci., vol. 3, pp. 176-185, 2017.

[66] H. Aspinall, Chemistry of the f-Block Elements, Australia: Gordon and Breach Science Publishers, 2001.

[67] "Lund/LBNL Nuclear Data Search," [Online]. Available: http://nucleardata.nuclear.lu.se/toi/nuclide.asp?iZA=710177. [Accessed 2018].

[68] S. Fry and N. Pienta, J. Am. Chem. Soc., vol. 107, pp. 6399-6400, 1986.

[69] J. Boon, J. Levisky, J. Pflug and J. Wilkes, J. Org. Chem., vol. 51, pp. 480-483, 1986.

[70] K. Marsh, J. Boxall and R. Lichtenthaler, "Room Temperature Ionic Liquids and Their Mixtures - A Review," Fluid Phase Equilibria, vol. 219, pp. 93-98, 2004.

[71] J. Huddleston, A. Visser, W. Reichert, H. Willauer, G. Broker and R. Rogers, Green Chem, vol. 3, p. 156, 2001.

[72] A. Visser, R. Swatloski, W. Reichert, S. Griffin and R. Rogers, "Traditional Extractants in Nontraditional Solvents: Groups 1 and 2 Extraction by Crown Ethers in Room-Temperature Ionic Liquids," Ind. Eng. Chem. Res., vol. 39, p. 3956, 2000.

[73] J. Law, K. Brewer, R. Herbst and T. Todd, "Demonstration of the TRUEX Process for Partitioning of Actinides from Actual ICPP Tank Waste Using Centrifugal Contactors in a Shielded Cell Facility," Idaho National Engineering Laboratory, INEL-96/0353, 1996.

[74] E. Horwitz, "Solvent Extraction and Recovery of the Transuranic Elements from Waste Solutions using the TRUEX Process," [Online]. Available: http://www.iaea.org/inis/collection/NCLCollectionStore/_Public/19/089/1908980 5.pdf. [Accessed 2018].

[75] K. Nakashima, F. Kubota, T. Maruyama and M. Goto, "Ionic Liquids as a Novel Solvent for Lanthanide Extraction," Analytical Sciences, vol. 19, p. 1097, 2003.

[76] D. Archer, J. Widegren, D. Kirklin and J. Magee, J. Chem. Eng. Data, vol. 50, pp. 1484-1491, 2005.

[77] R. Swatloski, J. Holbrey and R. Rogers, Green Chem, vol. 5, pp. 361-363, 2003. 
[78] M. Freire, L. Santos, A. Fernandes, J. Coutinho and I. Marrucho, "An Overview of the Mutual Solubilities of Water-Imidazolium-Based Ionic Liquids Systems," Fluid Phase Equilibria, vol. 261, pp. 449-454, 2007.

[79] X. Song et. al., "Hydrolysis of Polycarbonate Catalyzed by Ionic Liquid [Bmim][Ac]," Journal of Hazardous Materials, Vols. 244-245, pp. 204-208, 2013.

[80] P. Kubisa, "Application of Ionic Liquids as Solvents for Polymerization Processes," Prog. Polym. Sci., vol. 29, pp. 3-12, 2004.

[81] E. Jean, D. Villemin, M. Hlaibi and L. Lebrun, "Heavy Metal Ions Extraction Using New Supported Liquid Membranes Containing Ionic Liquid as Carrier," Separation and Purification Technology, vol. 201, pp. 1-9, 2018.

[82] D. Bauer and R. Linstrom, "Naphthenic acid solvent extraction of rare earth sulfates, Report RI 6396," Bureau of Mines, U.S. Deptarment of the Interior, Washington, 1966.

[83] A. V. Korpusov et. al., "Investigation of rare earth elements extraction with different carboxylic acids," in Proceedings of International Solvent Extraction Conference (ISEC 74), Lyon, 1974.

[84] I. McGill, "Rare Earth Elements," in Ullmann's Encyclopedia of Industrial Chemistry, Weinheim, Wiley-VCH, 2003, p. 37.

[85] Y. Baba, A. Fukami, F. Kubota, N. Kamiya and M. Goto, "Selective Extraction of Scandium from Yttrium and Lanthanides with Amic Acid-Type Extractant Containing Alkylamide and Glycine Moieties," RSC Adv., vol. 4, pp. 5072650730, 2014.

[86] J. Tang and C. Wai, "Preconcentration of Lanthanides from Natural Waters with a Lipophilic Crown Ether Carboxylic Acid," Talanta, vol. 36, no. 11, pp. 11291133, 1989.

[87] J. Tang and C. Wai, "Solvent Extraction of Lanthanides with a Crown Ether Carboxylic Acid," Anal. Chem., vol. 58, pp. 3233-3235, 1986.

[88] S. Lahiri et. al., "Separation of Carrier Free Lutetium Produced in Proton Activated Ytterbium with HDEHP," Appl. Radiat. Isot., vol. 49, no. 8, pp. 911913, 1998.

[89] "Liqui-Cel Membrane Contactors," [Online]. Available: www.liquicel.com/product-information/gas-transfer.cfm. [Accessed 2015].

[90] "Membrane contactor search," [Online]. Available: http://g01.s.alicdn.com/kf/HTB1A3P.GFXXXXcCaXXXq6xXFXXX3/2022539 18/HTB1A3P.GFXXXXcCaXXXq6xXFXXX3.jpg. [Accessed 2018].

[91] M. Pourbaix, Atlas of Electrochemical Equilibria in Aqueous Solutions, Oxford: Pergamon Press, 1966.

[92] "GE Healthcare," [Online]. Available: www3.gehealthcare.com. [Accessed 2018]. 


\section{VITA}

Matthew Douglas Scott was born November 12, 1974 to Patrick D. and Judith M. (Engelbrecht) Scott. He grew up in Jefferson City, MO and graduated from Jefferson City High School. Following graduation, he attended Missouri State University in Springfield, MO, graduating Magna Cum Laude with a bachelor's degree in chemistry. After nearly fifteen years of analytical chemistry work in an industry setting, Matt began working at the MU Research Reactor and fell in love with radiochemistry. He entered graduate school at the University of Missouri, where he earned a Nuclear Engineering Certificate (2016) and his Radiochemistry Ph.D. (2018) while continuing to work full time at MURR.

Matt married the love of his life, Jennifer Joyce Swanigan, August 9, 1997. Together they are raising three wonderful children, Stephanie Renae, Alexander Matthew, and Elizabeth Josephine Scott. 